\title{
Zweymüller cementless total hip arthroplasty with two designs of titanium rectangular stem and a titanium threaded cup : a clinical, radiological and DEXA study
}

Citation for published version (APA):

Vervest, A. M. J. S. (2005). Zweymüller cementless total hip arthroplasty with two designs of titanium rectangular stem and a titanium threaded cup : a clinical, radiological and DEXA study. [Doctoral Thesis, Maastricht University]. Thela Thesis. https://doi.org/10.26481/dis.20050126av

Document status and date:

Published: 01/01/2005

DOI:

10.26481/dis.20050126av

Document Version:

Publisher's PDF, also known as Version of record

Please check the document version of this publication:

- A submitted manuscript is the version of the article upon submission and before peer-review. There can be important differences between the submitted version and the official published version of record.

People interested in the research are advised to contact the author for the final version of the publication, or visit the DOI to the publisher's website.

- The final author version and the galley proof are versions of the publication after peer review.

- The final published version features the final layout of the paper including the volume, issue and page numbers.

Link to publication

\footnotetext{
General rights rights.

- You may freely distribute the URL identifying the publication in the public portal. please follow below link for the End User Agreement:

www.umlib.nl/taverne-license

Take down policy

If you believe that this document breaches copyright please contact us at:

repository@maastrichtuniversity.nl

providing details and we will investigate your claim.
}

Copyright and moral rights for the publications made accessible in the public portal are retained by the authors and/or other copyright owners and it is a condition of accessing publications that users recognise and abide by the legal requirements associated with these

- Users may download and print one copy of any publication from the public portal for the purpose of private study or research.

- You may not further distribute the material or use it for any profit-making activity or commercial gain

If the publication is distributed under the terms of Article 25fa of the Dutch Copyright Act, indicated by the "Taverne" license above, 
Zweymüller cementless total hip arthroplasty with two designs of titanium rectangular stem and a titanium threaded cup

A clinical, radiological and DEXA study

\author{
PROEFSCHRIFT \\ ter verkrijging van de graad van doctor aan \\ de Universiteit Maastricht, \\ op gezag van de Rector Magnificus, \\ Prof. mr. G.P.M.F. Mols \\ volgens het besluit van het College van Decanen, \\ in het openbaar te verdedigen \\ op woensdag 26 januari 2005 om 14.00 uur \\ door
}

Antonius Maria Johannes Simon Vervest 
Promotor:

Beoordelingscommissie:
Prof. dr. R.G.T. Geesink

Prof. dr. J.M.A. van Engelshoven (voorzitter)

Prof. dr. S.K. Bulstra

Prof. dr. H. van Mameren

Prof. dr. R.G. Pöll

(Vrije Universiteit, Amsterdam)

Prof, dr. K. Zweymüller

(Vienna, Austria) 
Dit proefschrift is mede tot stand gekomen door onvoorwaardelijke financiële bijdragen van de Nederlandse Orthopaedische Vereniging. Stichting tot Bevordering van Wetenschappelijk Onderzoek in Ziekenhuis Rijnstate en Zimmer Netherlands bv.

ISBN 90-9018918-1

Copyright (C) A.M.J.S. Vervest, Amsterdam, the Netherlands, 2005

Niets uit deze uitgave mag worden verveelvoudigd, opgeslagen in een geautomatiseerd gegevensbestand of openbaar gemaakt worden in enige vorm of op enige wijze, hetzij elektronisch, mechanisch of door fotokopieèn, opname, of op enige andere manier, zonder voorafgaande schriftelijke toestemming van de auteur.

Illustraties en cover.

Fotografie:

Engelse taalcorrecties:

Methodologische ondersteuning:

Druk:

\section{R.P. Slagter, Voorschoten}

A. Daemen, Slotervaart Ziekenhuis Amsterdam

J. Abma-Hill

Trialbureau Orthopaedie AZM Maastricht

Ortho Research Sint Maartenskliniek Nijmegen

Thela Thesis Publishers Amsterdam 
Zweymüller cementless total hip arthroplasty

with two designs of titanium rectangular stem and a titanium threaded cup 
To those suffering from endstage osteoarthritis of the hip 



\section{Contents}

$\begin{array}{llr}\text { chapter 1 } & \text { General introduction } & 9 \\ \text { chapter 2 } & \text { The Zweymüller Hip System } & 23 \\ \text { chapter 3 } & \text { A Historic Cohort Study on 754 Zweymüller } & \\ & \text { Total Hip Arthroplasties } & \\ \text { chapter 4 } & \text { Bone Mineral Density 10 Years after Receiving the } & \\ & \text { Zweymüller Cementless Stem Prosthesis } & 57 \\ \text { chapter 5 } & \text { Long-term Results of the Zweymüller Cementless } & \\ & \text { Titanium Threaded Cup } & 71 \\ \text { chapter 6 } & \text { Two Designs of the Zweymüller Cementless Stem } & \\ & \text { Prosthesis } & 89 \\ \text { chapter 7 } & \text { The Zweymüller Prosthesis in Patients Aged 50 Years } & \\ & \text { and Younger } & 105 \\ \text { chapter 8 } & \text { The Oxford Hip Score Applied to the Cohort Study } & 123 \\ \text { chapter 9 } & \text { General Discussion } & 133 \\ \text { chapter 10 } & \text { Summary/Samenvatting } & 139 \\ \text { chapter 11 } & \text { References } & 151 \\ & \text { Appendices } & 167 \\ & \text { Publications } & 187 \\ & \text { Acknowledgements/Dankwoord } & \end{array}$





\section{General Introduction}

\subsection{HISTORICAL BACKGROUND}

The natural articular cartilage provides the lubrication and low-wear conditions necessary for normal joint function. During life, primary or secondary degenerative changes in the articular cartilage lead to osteoarthritis. Endstage osteoarthritis requires total joint replacement [191].

For many decades, surgeons and engineers have been searching for methods to restore normal physiological pain-free joint function. Early in the twentieth century, fascia lata grafts were used for arthroplasty, in 1912 Sir Robert Jones applied gold foil as an interpositional layer. Judet and Judet developed an acrylic femoral head prosthesis, but arthroplasty failed, because fragmentation of the acrylic caused bone destruction. Moore and Thompson introduced a prosthesis for femoral hemiarthroplasty. It had press-fit fixation with a long intramedullary stem to enable weight-bearing. The problem of this prosthesis was pelvic bone erosion. As a solution, a prosthesis was developed by G. Kennedy McKee and J. Watson-Farrar that consisted of a metal cup and metal stem with a $40 \mathrm{~mm}$ head. Metal wear and high friction led to pain and loosening, and to (temporary) dissolution of the McKee-Farrar concept [111].

Around 1960, sir John Charnley, orthopaedic surgeon at Wrightington Hospital United Kingdom, developed the concept of the low-friction arthroplasty in answer to these experiences. To reduce torque friction, Charnley used a $22 \mathrm{~mm}$ head. Later, the prosthesis was secured with polymethylmethacrylate (PMMA) cement. Charnley succeeded in performing arthroplasties with a stainless steel stem prosthesis and a teflon cup. However, after catastrophic osteolysis, teflon was exchanged for polyethylene and this modification accelerated the success of the total hip arthroplasty. Nowadays, total hip arthroplasty can be regarded as the most successful orthopaedic invention of the twentieth century, an increasing number of interventions are being performed each year. In 1998, a total of 144,133 primary total hip arthroplasties were performed in the United States of America and that number is increasing annually [280]. In the year 2000, at Swedish hospitals, 11,000 primary total hip arthroplasties were done [183]. In the period 1986-1997 in the Netherlands, the number of total hip arthroplasties increased by $68 \%$ to 17,400 operations in 1997 and it is expected that this number will increase further in the coming decennia [223]. 
After the initial success of the Charnley low-friction arthroplasty, a new problem appeared. Increasing numbers of failed arthroplasties were encountered. The cement-bone interface seemed to be the cause of devastating osteolysis and subsequent aseptic loosening. In 1976, Harris published the first four cases of periprosthetic osteolysis [115]. Jones and Hungerford called the new entity "cement-disease" and recommended that the cement be abandoned in order to prevent this man-made illness [143]. Nowadays, it is well-understood that the polyethylene wear particles cause a biological response with resorption of the bone surrounding the implant, and that this process of periprosthetic osteolysis does not occur solely in cemented total hip arthroplasties.

Later, cemented prostheses revealed limited stability and durability as a result of the so-called ageing processes. Also, thermal damage during PMMA polymerisation and the toxic effects of free monomers discouraged the use of cement fixation $[273,276]$.

The disadvantages encountered with cemented total hip arthroplasties led to the era of cementless total hip arthroplasties [185, 200, 206, 263]. During the development of the cementless total hip prosthesis, various issues were addressed, such as the stability of the implant, biocompatibility and the biomechanical properties of the implant.

Stability of an implant is achieved during surgery (primary stability) and will increase afterwards (secondary stability). Press-fit ensures primary stability of cementless components. Press-fit means that the acetabulum or the femoral canal are prepared to match the same shape of the implant [82]. The geometry of the femoral stem also determines the degree of stability. Rectangular femoral stems have better primary stability than cylindrical shaped stems $[19,20,74$, 186]. Tapering of the stem by diminishing its size from proximal to distal, further enhances primary stability. Some stems are tapered in the frontal plane, such as the Zweymüller stem prosthesis that was used in this study, or in both the frontal and sagittal planes (Omnifit). Primary stability has also been enhanced by the addition of ribs or flutes, such as in the Spotorno stem prosthesis [4]. Other prosthesis achieved primary stability by posterior bowing of the stem to match the normal femoral antecurvation. These anatomical stems needed a right and left version of the stem [32].

Primary stability of the cementless acetabular cup is achieved by press-fitting or screwing in the cup. Primary stability of press-fit acetabular shells can be enhanced by screws or pegs. A threaded cup can be screwed into the pelvic bone and the primary stability depends on the large surface contact with the acetabular bone stock [178]. The (Spotorno) expansion shell cup can be regarded as combining the press-fit and screw thread principles to achieve primary stability [21]. This cup system has semiflexible pegs which are retracted with a special 
device while the threaded cup is being screwed in. After the cup has been screwed in, the pegs are released so that the Spotorno cup expands and fixates.

Secondary stability of cementless prostheses is achieved by biological boneingrowth. This could be improved by changing the texture of the implant surface by giving it a porous coating or a calcium phosphate coating $[66,124]$. Porous coatings are obtained by sintering cobalt-chrome powder or beads, or bonding titanium wire mesh to the metal [206]. Pore sizes differ markedly (150-1200 $\mu \mathrm{m})$ and bone ingrowth occurs if the pores are at least $40 \mu \mathrm{m}$. A porous coating enlarges the bonding surface to three to seven times that of smooth metal and thus enhances bone ingrowth.

Calcium phosphate coatings consist of hydroxyapatite $\left(\mathrm{Ca}\left(\mathrm{PO}_{4}\right)_{2}\right)$ that possesses osteoconductive properties to stimulate osseointegration [35, 52, 98, 202, 209]. Hydroxyapatite coatings are manufactured by the plasma-spray method, which means that under high-speed and high temperature conditions, the molten hydroxyapatite granules are sprayed on to the metal. The thickness of the coating seems to be essential. Usually the coatings are 50 to $110 \mu \mathrm{m}$ thick. Thicker coatings become brittle, whereas thinner coatings may be resorbed [99]. The adhesive strength of the hydroxyapatite coating to the metal is also crucial, because granule separation can potentially induce severe (third body) wear in the event of early coating degradation [210].

\subsection{BIOCOMPATIBILITY AND BIOMECHANICS}

The biocompatibility and biomechanical properties of an implant are determined by the material used and the manufacturing process.

To make cementless total hip prostheses, two materials are mainly used: titanium and cobalt-chromium alloys. Titanium has excellent strength and is resistant to corrosion. Cobalt-chromium alloys are highly corrosion-resistant, but their fatigue resistance is lower than that of titanium. Stainless steel has lower fatigue strength than the other two materials and is no longer in use for cementless hip prostheses $[231,266]$.

Sufficient strength to prevent fracture depends on the grain size, which is determined by the manufacturing process. Larger grains are weaker. Heating to melting point increases the grain size; forging decreases the grain size. Strength also increases by using pressure to consolidate the powder into a solid form, thus reducing porosity. Also, the strength of the material can be enhanced by adding various elements (aluminum, vanadium, molybdenum, nickel) to the raw material [266]. During manufacture, the materials have to be formed into the geometry of a prosthesis. Isothermal forging is a manufacturing process in which the raw material is heated and kept at the same temperature as the die that has the form of the prosthesis. By applying pressure, the material obtains the geometry of the prosthesis. Isothermal forging preserves the mechanical properties of the material and facilitates the manufacturing of complex components that are difficult to manufacture mechanically. The Zweymüller stem prosthesis 
evaluated in this study is manufactured by the process of hot-forging. Special grinding processes give the desired microstructure.

The biomechanical behaviour of a material inserted into bone is another important feature that depends on the modulus of elasticity, defined as the ratio of the load (stress) to the amount of deflection (strain). The modulus of elasticity of titanium alloys is about $50 \%$ of that of the cobalt-chromium alloys [126]. A stiffer material (high modulus of elasticity) will cause less loading of the surrounding bone and subsequent disuse osteoporosis, called stress shielding. This might cause aseptic loosening of an implant. Titanium alloys cause less stress shielding than cobaltchromium alloys.

The prosthetic material should also be biocompatible, i.e. it must not cause inflammatory or allergic reactions, or induce malignancies. Cobalt-chromium and titanium alloys have the required properties.

In conclusion, primary stability of an implant depends on the geometry, secondary stability depends on the surface texture and coating; biocompatibility and biomechanical properties merely depend on the material. There are several solutions for each feature with various pros and cons. Any implantable prosthesis is therefore a compromise between geometry, surface texture, coating and material.

\subsection{WEAR}

To enable mobile arthroplasty, the acetabular cup and the femoral head have to articulate. After the teflon catastrophe, Charnley used high-density polyethylene as the acetabular component. This material is formed by the polymerisation of ethylene. Nowadays, ultra-high molecular weight polyethylene (UHMWPE) is used as the visco-elastic component in acetabular inserts. In cemented arthroplasties, a fully polyethylene acetabular cup is frequently used. Polyethylene is bio-active, which leads to bone resorption. Therefore, a fully polyethylene cup is not suitable as a cementless prosthesis [75]. Most cementless acetabular cups have a metal outer shell and a polyethylene insert.

During the lifespan of the arthroplasty, the femoral head articulates millions of times with the polyethylene acetabular insert. The polyethylene gradually breaks up and produces billions of small (less than one micrometer in size) particles [65]. This wear debris leads to the activation of macrophages and osteoclasts. Ultimately, the osteoclastic activity leads to periprosthetic bone resorption and aseptic loosening of the component(s) $[114,138]$. The amount of wear does not only depends on the time that the prosthesis is in situ, but also on the intensity of use [245, 247].

The other component to enable mobile articulation is the femoral head. Ceramic materials, such as aluminium oxide and zirconium oxide, are primarily used to manufacture femoral heads. The material has a hard surface, but the material is 
brittle and can break under non-uniform loading. A ceramic head is frequently used in combination with a polyethylene insert, but this design is under debate, because the polyethylene suffers from wear. Although ceramic cannot articulate with metal, a ceramic head can be placed on a metal femoral stem when a precise Morse taper is used [111].

To solve the problem of polyethylene wear, other bearings have been introduced. During the seventies, ceramic $\left(\mathrm{Al}_{2} \mathrm{O}_{3}\right)$ material became popular. The ceramic - on - ceramic prosthesis according to Mittelmeier consisted of a ceramic femoral head and a fully ceramic cementless acetabular component. Garcia-Cimbrelo et al reported $53 \%$ radiographic loosening of the socket after 16 years and found no osseointegration of either the cup or the metal stem [93]. Huo et al found $87.9 \%$ survival of the ceramic Mittelmeier prosthesis at 10 years follow-up, with 21.5\% overall mechanical failure of the cup [133]. The ceramic Mittelmeier prosthesis is no longer being used in the United States of America.

The metal - on - metal bearing drew new interest. Titanium-on- titanium gave unacceptable wear, but cobalt-chromium alloys were considered to be feasible. The former McKee-Farrar had a large head diameter and a high coefficient of friction. This led to frictional torque with aseptic loosening of the component. Walker et al discovered that a prosthesis with equatorial contact, such as the McKee-Farrar prosthesis, had higher frictional torque than prostheses with polar contact [270]. Thus, a smaller ball diameter and polar contact would decrease the friction torque and wear [249]. The annual wear debris of metal-on-metal articulation is lower than that of polyethylene [276]. Opponents of the metalon-metal bearing emphasized the possible carcinogenic effects of the release of metal ions, but these suggestions have never been proved [36, 267]. Jacobs et al found elevated chromium and cobalt levels in the serum and urine of patients after long-term (> 20 years) implantation of a McKee-Farrar metal-on-metal prosthesis [139]. No clinical consequences were established.

\section{5}

\section{FAILURE SCENARIOS}

Many patients enjoy the benefit the successful total hip arthroplasty, but some only for a limited time. Failure should not be seen as a single event, but as a progressive process. Thus, early detection is mandatory. Huiskes described six failure scenarios [128].

The accumulated-damage scenario is based on mechanical damage to the material from repetitive loading; it depends on the stress and strength of the material. Although this failure scenario is more relevant to cemented arthroplasties, cementless prostheses can also fail due to mechanical debonding of the implant-bone interface. The destructive-wear scenario refers to mechanical wear of the articulating components. In young patients and patients with high activity levels, the prosthesis will suffer increased wear and then fail. The important particulate-reaction scenario is closely linked to the former scenario and depends on loosening of the implant due to polyethylene wear. Use of the arthroplasty by the patient (cemented and cementless) will cause wear of the 
articulating polyethylene. During this process of polyethylene wear, polyethylene particles accumulate that have an approximate size of less than $1 \mu \mathrm{m}$; these particles are only visible under the polarized light microscope. After these small particles have been released, they are phagocytosed by macrophages. Although the cellular mechanism has not yet been clearly defined, the activated macrophages probably release cytokines (interleukins and prostaglandins) and these stimulate osteoclastic bone resorption. Capsular tissue is able to transport certain amounts of fluid with particle debris to the lymphatic system. When fluid production exceedes that capacity, debris accumulates in the periarticular space. Macrophage activation thickens the pseudocapsule of the total hip arthroplasty and the accumulated debris follows the path of least resistance to the area of resorbed bone around the implant. Consequently, the effective joint space expands. As the particle debris formation progresses and continues to produce fluid, the effective joint space expands further, with subsequent loosening of the implant [116, 138, 246].

A fourth failure scenario is the failed-bonding scenario, solely applicable to cementless arthroplasties and based on the surgical press-fit technique. It is impossible to rasp a non-fixed bone manually to the same shape as the implant [127]. During rasping, little gaps are always left and these gaps undermine the rigidity of the press-fit. Osteoinductive coating helps to fill the gaps and encourage fixation.

The stress-shielding scenario only involves the stem and this process of loadsharing depends on the relative stiffness of the stem, which is a biomechanical feature of the implant material. After implantation of the cementless stem, the normal forces of the hip will act on the prosthesis and the femoral bone. When there is a difference in the elasticity modulus, the forces will either have more influence on the bone or on the prosthesis. If the prosthesis is stiffer than the bone, the forces will be guided to the prosthesis, with consequential sparing of the bone. This so-called shielding of the bone leads to bone loss [153]. On the other hand, if the bone is stiffer than the implant, failure of proximal osseointegration might occur [85].

The stress-bypass scenario is related solely to the shape of the femoral stem. Cementless stem prostheses achieve their primary stability by press-fit. In the proximal zones, the press-fit is limited due to the dissimilar elasticity modulus, so there is a less tight relationship between the bone and the implant. This diminishes proximal stress transfer through the bone and causes bone loss. The prosthesis will subside and find a new position of stability. This form of enhanced stable fixation of the implant can only be expected with a tapered femoral stem [186]. Radiologically, the progressive stability can be seen as calcar remodelling. A disadvantage of this fixation enhancement is raised circumferential (hoop) stress. Clinically, this hoop stress manifests itself as thigh pain. To prevent this thigh pain, various authors have advocated applying proximal circumferential porous coating to the metaphyseal region $[206,226,233]$.

Arthroplasty failure is a complex process and none of the scenario's can be considered as the sole cause of failure. Frequently, clinical and radiological 
investigations are needed for the early detection of arthroplasty patients with a failure scenario. To assist early detection and to score questionable stability, Engh et al described the radiological assessment of stability of a porous coated stem prosthesis [82]. However, for certain stable or unstable stems the rating was unsuitable. Furthermore, stability needed to be assessed on a single X-ray, although some signs of the rating scale required two or more X-rays. To make the assessment, Engh et al defined implant fixation and stability. Implant fixation was the histological term for osseointegration and could solely be ascertained by removing the implant. Stability of the implant referred to the absence of any visible motion between the loaded bone and the implant. This mechanical quality can be tested surgically, without removing the implant. To prevent the removal of a well-fixed implant, Engh et al defined several signs of fixation and stability and incorporated these signs into a score (Appendix 1). Reactive lines and radiolucent lines around the implant were considered to be mayor signs of poor fixation and instability of the implant when they were present in more than $50 \%$ of the Gruen zone. New bone that bridges the gap between the bone and implant is called an endosteal spotweld. It was considered to be a minor sign of adequate fixation. New bone that forms at the tip of the stem prosthesis is known as a pedestal and it was considered to be relevant if the stem was unstable. Calcar modelling was defined as changes in calcar bone density compared to the direct postoperative $\mathrm{X}$-rays. Progression of reactive lines and radiolucent lines on consecutive X-rays was defined as interface deterioration. Migration was defined as more than $2 \mathrm{~mm}$ of change in the vertical distance between the lateral shoulder of the stem and the superior tip of the trochanter major on the consecutive X-rays. Particle shedding refers to loosening of metal particles in the surface coating; it was considered to be relevant when the latest X-ray showed metal particles surrounding the implant that had not been visible on earlier X-rays. Each of these signs was given a score and by adding the fixation and stability scores, a total score was obtained. Engh et al defined several categories of stability (Appendix 1).

\subsection{DUAL ENERGY X-RAY ABSORPTIOMETRY}

It is difficult to detect stress shielding in clinical situations solely on the basis of predicted failure scenarios. Conventional X-rays are too insensitive to monitor the process of stress shielding (and bone remodelling) [86, 159, 205, 239, 242]. Dual energy X-ray absorptiometry (DEXA) is an accurate technique to assess bone stock $[8,147,165,198,273]$ and to quantify the process of bone remodelling around a femoral prosthesis $[79,84,205,275]$. Dual energy X-ray absorptiometry equipment consists of an X-ray source that provides alternating pulses of $70 \mathrm{kvp}$ and $140 \mathrm{kvp}$. The two radiation energies generate two collimated beams (Figure 1.1). Bone and soft tissues have different absorption values and this information can be analysed by a computer into the bone mineral content (in grams) and after division by the measured area into the areal bone mineral density $\left(\mathrm{gram} / \mathrm{cm}^{2}\right)[49,86]$. DEXA results are linearly related to the mineral-equivalent solution $\left(\mathrm{K}_{2} \mathrm{HPO}_{4}\right)[196,243]$. 


\section{Figure 1.1}

DEXA equipment: Two alternating collimated radiation beams ( $70 \mathrm{kvp}$ and $140 \mathrm{kvp}$ ) have different absorption values in bone and soft tissue. From these data a computer can analyse the bone mineral content, and after division by the areal measurement, the bone mineral density. Patients are scanned in the supine position. It is not necessary to undress

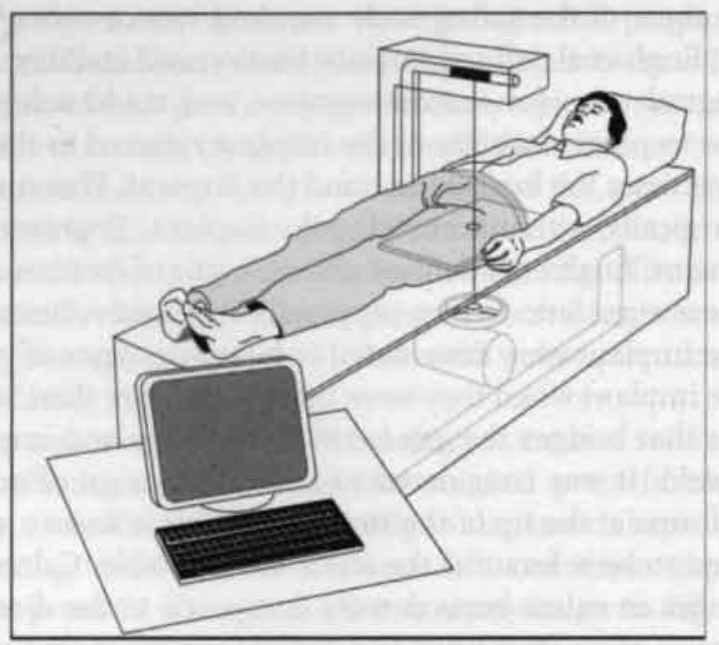

The radiation dose of DEXA scanning is very low, about $2-5 \mathrm{mRem}(0.02-0.05$ $\mathrm{mSv}$ ). This is comparable with $1 / 50$ of the exposure from a chest radiograph and is 2400 times lower than the natural background radiation per year $[44,86,147,238]$.

DEXA has some limitations. There is variation in absolute bone mineral densities measured by different systems and there is a lack of uniformity in the reference data provided by the manufacturers $[43,169]$. Femoral rotation affects the measurements, so a foot jig is applied that fixes the rotation angle of the femur (Figure 1.2) [192]. Osteophytes overrate DEXA measurements, but metal implants do not influence BMD measurements [37, 238]. Furthermore, the average lifespan of the X-ray tube is only about 7 years [243].

Figure 1.2

Foot jig used during DEXA scanning to ensure the same bilateral endorotation of the femur

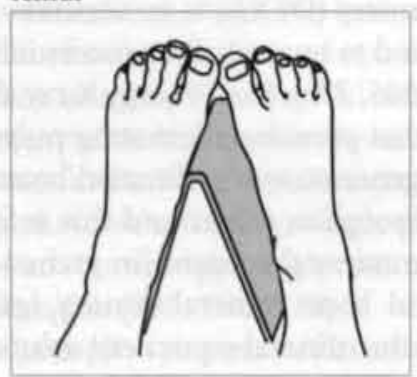




\subsection{HIP SCORES}

The technical advances in hip prostheses led to the development of rating systems to assess the clinical results. In 1952, Robert and Jean Judet reported on the acrylic femoral head prosthesis [144] and in 1954, R. Merle D'Aubigné and M. Postel (Paris, France) reported their results on a cervico-capital prosthesis that had a long intramedullary stem, but no acetabular component [204]. The results of these arthroplasties were evaluated with a newly devised grading system, which consisted of the items: pain, ability to walk and mobility (PWM score). Each item had a seven-point scoring scale and by combining the results of all the items, the arthroplasty could receive a grade from very good to very poor (Appendix 2). Subtracting the postoperative score from the preoperative score was called the amelioration rate and it gave an idea about the level of improvement. A few months after the report by Merle D'Aubigné had appeared in the American Journal of Bone and Joint Surgery, Margaret Shepherd published the assessment score of the British Orthopaedic Association Research Group in British Journal of Bone and Joint Surgery [253]. The British system added the mobility index according to Gade, an assessment of the functional score and the patient's own assessment [89]. The mobility index was based on the weighted value of each (part of the) hip movement. For example, the first 45 degrees of flexion of the hip were much more important than the last 20 degrees. Gade developed a mathematical system to weight the value of each range of motion [89]. In the hip flexion example, the first 45 degrees of flexion were multiplied by 0.6 , while the last 20 degrees were multiplied by 0.1 . A factor was ascribed to each movement of the hip and the scores from all the movements were calculated into the mobility index. Shepherd also added a functional assessment with the items: walking distance, use of crutches, ability to put on shoes and socks, stair climbing, toilet and bathing, employment status and daily activities. The Trendelenburg test and limp assessment were also included as indications of stability. In the original article, Shepherd mentioned several remarks made by patients to express their satisfaction. Shepherd combined the assessment of pain, mobility index, functional score and patient satisfaction into an assessment table.

Owing to the complexity and lack of a single over-all rating value in the Shepherd assessment table, Harris proposed a new rating system to assess the results of arthroplasty in 1969 [112]. This rating system was also based on the items pain, function, range of motion and absence of deformity, but it led to one single rating value of between 0 (very poor result) and 100 points (excellent result) (Appendix 2). The items pain and functional score were comparable to the Shepherd system and, based on the Gade mobility index, Harris introduced an index for the range of hip motion. Harris found the weighting of patients' assessments in the Shepherd system a too heavy task and consequently deleted "patient's opinion". Trendelenburg test should be regarded as a static test, this test was recorded, but not rated in the score. Despite the complexity of the Harris Hip Score, this score is the most widely used $[95,181,256]$. 
J. Charnley used the Merle D'Aubigné rating score to evaluate the long-term results of low-friction arthroplasty and added three alphabetical prefixes to the Merle D'Aubigné rating score [38]. In this Charnley classification, "A" denoted patients with unilateral arthroplasty without any conditions that interfered with walking, " $\mathrm{B}$ " denoted patients with bilateral hip arthroplasty or osteoarthritis without any other defects that affected the ability to walk, while " $\mathrm{C}$ " denoted patients with unilateral or bilateral arthroplasty or osteoarthritis with some failure of normal locomotion. Charnley mentioned conditions such as polyarthritis, rheumatoid arthritis, senility, hemiplegia and cardiovascular or respiratory disabilities in association with failure of normal locomotion [38].

Many other rating systems have been developed. However, no rating system has demonstrated superiority. Bryant et al compared thirteen rating systems and found inconsistencies in the results [28]. They therefore advised only to score pain, walking distance and range of hip flexion, and not to combine these items into a single score. Furthermore, the outcome of an assessment score was found to be influenced by the patient's age, general physical condition and the Charnley classification $[22,33,95,96,137]$. Therefore, a rating system should always be combined with the Charnley classification $[33,96]$.

A disadvantage of many rating systems is that they are more so-called ordinal than numerical without any definable magnitude [95]. Most patients receive a higher rating and better scores. Thus these systems differentiate poorly between good and bad. Furthermore, the result of arthroplasty is mostly assessed by comparing the preoperative and postoperative scores (amelioration rate). It has been suggested that the amelioration rate expresses the reason for arthroplasty and does not differentiate between a good or bad result.

Another disadvantage of these rating systems is their lack of radiological assessment. Kavanagh et al developed the Mayo Hip Score [150]. This score ranges from 0 (very poor result) to 100 points (excellent result). The clinical evaluation is similar to that in the Harris Hip Score, but without the range of motion, and accounts for 80 points. The other 20 points are assigned according to the radiological evaluation: 10 points each for the evaluation of the femur and acetabulum. The radiological assessment consisted of assigning scores for radiolucent lines, acetabular migration and stem subsidence.

Thus, many scoring systems have been developed and it is impossible to compare the results obtained with the different systems. J. Galante recommended a uniform method to evaluate and report the results of hip-replacement surgery and advised the use of uniform nomenclature [90]. Galante's concerns led to the formation of a committee by the Hip Society, SICOT and AAOS to develop a standard system of terminology to report results. This system was reported by Johnston et al and consisted of standard clinical and radiological evaluations to rate cemented and cementless prostheses [142]. On the basis of the information from this standard system, other rating scores such as the Harris Hip Score, can be computed. The essential feature in this recently developed system is the standardized nomenclature to evaluate hip arthroplasties that is necessary to compare different studies. 
Most scoring systems are based on judgement of the clinical and radiological data by the (treating) surgeon and lack any subjective contribution by the most important participant: the patient [97]. It is assumed that a surgeon's judgement will agree with the opinion of a satisfied patient, but a surgeon might also have a favourable perception of the outcome in a dissatisfied patient [25]. McGee et al studied the agreement in answers between the doctor and patient on the sixteen item total hip arthroplasty clinical evaluation questionnaire [197]. There was agreement on 12 questions. For the items capacity to work, degree of pain and decreased need for medication, the doctor gave a better score than the patient, while patients gave better scores for the ability to go up and downstairs. McGee et al concluded that usually the doctor's and patient's perceptions of the outcome agreed. In the patients with other joint problems or health problems, and in those with persistent pain, the opinions disagreed, which emphasized the importance of the patient's opinion. On the other hand, a self-report questionnaire cannot replace the surgeon's judgement, but it would provide additional subjective information about the result of arthroplasty.

To assess patient satisfaction, general health questionnaires have been developed such as the Medical Outcomes Study 36-item Short-Form Health Survey (SF-36) or the Nottingham Health Profile, and disease-specific questionnaires such as the Western Ontario and McMaster Universities Osteoarthritis index (WOMAC). These questionnaires have proved to be reliable (reproducible over time) and valid (measuring what they are intended to measure) to assess patient satisfaction with the result of total hip arthroplasty $[255,274]$. However, they are time-consuming to complete and contain items that are not relevant to specific problems. Dawson et al therefore developed a self-report disease-specific 12-item questionnaire to evaluate patient satisfaction with total hip arthroplasty. the Oxford Hip Score (Appendix 2) [53). It has proved to be reliable and valid and better able to distinguish between symptoms related to arthroplasty than other questionnaires [53-55, 87].

To use such a questionnaire in the Netherlands, either a new questionnaire must be developed or an existing one must be translated into the Dutch language and validated [108]. Hoefnagels et al produced a Dutch language version of the Oxford Hip Score and added seven questions as well as a Visual Analogue Scale to score pain complaints (Appendix 2) [123]. This Dutch Oxford Hip Score has been published in the professional journal of the Dutch Orthopaedic Society and was used in the studies presented in this thesis. Total hip arthroplasty outcome rating systems and satisfaction scales assess patient functioning, but do not assess the level of functioning. Moreover, wear has become a major issue in implant failure and the amount of wear depends on the level of use of the implant, instead of the time that it has been in situ [247, 247]. In the standard system of terminology of the Hip Society, SICOT and AAOS to report arthroplasty results, the level of activity is recorded as a specific item (Appendix 2 Hip Society Work/Activity Level) [142]. Amstutz et al introduced the University of California at Los Angeles 10-point rating system (Appendix 2) [7]. This score only assesses sporting activities. Zahira et al compared the UGLA score to the results obtained 
with a pedometer and found that the UGLA score was a valid method to assess routine activities, but it was not suitable for extreme levels of activity or inactivity [285]. In this thesis, we assessed a wide range of activity levels.

\subsection{IMPLANT SURVIVAL}

Scoring systems assess individual patient functioning, but do not predict the final outcome in the total group. The survival rate of an implant depends on the results of all the arthroplasties. To assess survival, it is obligatory to register every implant.

In 1979, the Swedish Orthopaedic Association opened the Swedish Hip Register and collected prospective data on all reoperations after total hip arthroplasty. Malchau et al reported the results of an analysis on 4,828 first-time revisions in a cohort of 92,675 primary interventions performed in the period $1978-1990$ [182]. Although cementless prostheses only had a small market share, Malchau et al concluded that the reproducibility of cementless fixation was not on par with that of cemented fixation. Revision rates derived from the Swedish Hip Register of cementless implants did not show any significant improvement in 2000. Moreover, some implants had even deteriorated compared to earlier reports [122].

Havelin et al analysed the results recorded in the Norwegian Arthroplasty Register and concluded that cementless coated femoral stems had better results than cemented stems, but that cemented cups had better results than cementless cups [117]. In 2002, Malchau et al concluded that intermediate-term survival rates for cementless implants were promising [183].

Cemented or cementless fixation of a prosthesis is a continuing debate. The low-friction arthroplasty according to Charnley has good long-term results and should be regarded as the golden standard. However, manufacturers are constantly changing their designs and materials. Therefore, many long-term results are based on prostheses that are no longer available [281].

\subsection{AIM OF THE STUDY}

The Zweymüller cementless total hip prosthesis has been available in the Netherlands since 1983 [260]. This prosthesis has been frequent used at several Dutch hospitals and around 1995, a multicentre cohort study was conducted to investigate the results of the Zweymüller cementless total hip prosthesis. Patients who had undergone arthroplasty in the period 1 January 1987 to 31 December 1994 were evaluated after receiving the titanium C.S.F. threaded cup and either the Hochgezogen or Stepless stem prosthesis (Chapter 2). The patients had been operated on at the Rijnstate Hospital Arnhem, Pasteur Hospital Oosterhout (Amphia Hospital), Diaconessenhuis Eindhoven, St. Joseph Hospital Veldhoven, or Elkerliek Hospital Helmond. 
The study was approved by the Medical Ethics Committee at St. Joseph Hospital, Veldhoven, the Netherlands and by the "Stichting tot bevordering van Wetenschappelijk Onderzoek in Ziekenhuis Rijnstate" (S.W.O.R.). Participants signed an informed consent form.

The aims of this thesis were formulated in the following questions:

1. What are the medium-term and long-term results of the Zweymüller total hip prosthesis?

2. Can signs of stress shielding be detected on the femoral side of the Zweymüller stem prosthesis?

3. How much polyethylene wear occurs in the C.S.F. acetabular cup?

4. Are there any clinical and radiological differences between the Hochgezogen stem prosthesis and the Stepless stem prosthesis?

5. Is the Zweymüller total hip prosthesis suitable for young patients?

6. How satisfied are the patients in the long-term?

In Chapter 2 a literature study was conducted on the development and results of the Zweymüller total hip prosthesis. Chapter 3 presents the results of our cohort study on 754 Zweymüller total hip arthroplasties. This cohort study led to the DEXA study on 32 patients, described in Chapter 4. The long-term results of the C.S.F. threaded acetabular cup and the polyethylene wear are reported in Chapter 5 . Chapter 6 deals with the long-term results of the Hochgezogen stem prosthesis and the Stepless stem prosthesis. The results of this cementless prosthesis in young patients are described in Chapter 7, based on the cohort study. Patient satisfaction is addressed in Chapter 8. 



\section{The Zweymüller Hip System, a review of the literature}

\subsection{INTRODUCTION}

Since 1972, Prof. dr. K. Zweymüller and co-workers at the Orthopaedic Clinic of the University of Vienna have been working to develop a cementless prosthesis made from a biocompatible material.

At that time, ceramic materials $\left(\mathrm{Al}_{2} \mathrm{O}_{3}\right)$ had just been introduced for the manufacture of prosthetic components. Experimental studies on dogs revealed newly formed connective tissue between the bone and a ceramic implant [240]. This favourable biocompatibility led to the use of this prosthesis in man. The first implanted prostheses were applied to bridge bone defects and to replace joints after tumour resection $[240,271,287]$. Femoral replacements were done according to the conical sleeve principle, which means that the prosthesis was positioned extracortically on the femoral stump [229].

The ceramic femoral stem proved to be unsuitable for the treatment of degenerative diseases [240]. However, the acetabular component (a cementless ceramic cup) seemed to be promising [39]. It consisted of a dome with three pegs for anchoring. Later, Wanivenhaus and Zweymüller reported loosening of these cups and radiolucent lines in sixty per cent of the cases 89 months after the index operation [271]. They concluded that this cementless ceramic cup prosthesis showed poor osseointegration, perhaps due to the different elasticity modulus of the prosthesis and the pelvic bone. Consequently, the use of this ceramic cup prosthesis was discouraged in patients with degenerative diseases.

To match the elasticity of bone, a conical threaded cup fully made of ultra-high molecular weight polyethylene, was developed [75]. After good initial results, the polyethylene caused tremendous osteolysis, with subsequent loosening. The use of this type of cup prosthesis was then abandoned $[109,166,174,175,209,252$, $277,287,288]$.

Besides the special cup, the Vienna group developed the articulating stem prosthesis. First, in cooperation with the Institutio Rizolloi in Bologna, they succeeded in constructing a ceramic head that was fixed to a femoral component. Together with the already avialable ceramic acetabular cup, they devised a mobile combination of cup, head and stem [39]. Furthermore, they developed a round femoral component. However, this stem prosthesis did not match the normal 
anatomy and it almost completely obliterated the medullary cavity. Therefore, the Vienna group designed a wedge shaped stem with rectangular cross-section [289].

Albrektsson et al described the osseointegrative properties of titanium [3]. Osseointegration was defined as direct contact between the living bone and implant on a light microscopic level. The retrieved specimens showed collagenous filaments that were firmly anchoring the titanium implant. On an electron microscopic level, the researchers confirmed osseointegration. Furthermore, the titanium implant was covered by a $\mathrm{Ti}$ - oxide layer, which mechanically prevented the infiltration of micro-organisms. They also found normal cells surrounding the titanium implant, which provided evidence of the less toxic properties of titanium.

In Vienna, wrought titanium-aluminum-vanadium alloy (Ti-6Al-4V) had been used to manufacture stem prostheses since the start of the cementless hip system [286]. The unsuitability of polyethylene as the basic material for the cup prosthesis that led to the failure of the Endler cup and favourable reports by Albrektsson et al about titanium alloys convinced the Vienna group to use titanium as the basic material for the stem as well as for the acetabular cup prosthesis [290].

\subsection{ACETABULAR CUP}

In 1985, the titanium conical threaded cup became available for clinical use (Figure 2.1). It was made of forged wrought grade 4 Protasul titanium with a microstructure of 3-5 $\mu \mathrm{m}$ and a $1 \mathrm{~mm}$ thickness (Sulzer, Winterthur, Switzerland) (Table 2.1). The first generation of this self-cutting cup had a truncated shape with a closed dome. The ultra-high molecular weight polyethylene insert was $1.5 \mathrm{~mm}$ thick (Chirulen ${ }^{\circledR}$, Ruhrchemie AG, Oberhausen, Germany). Later, the dome of the cup was furnished with two openings. During implantation, the surgeon could see the implant touching the bottom of the prepared acetabulum and this facilitated bone grafting. The outside of the polyethylene insert of this Conical Self-taping cement-Free cup (C.S.F., AlloproAG, Baar, Switzerland) was covered with titanium so that the polyethylene would not come into contact with the bone $[167,250]$.

First generation cups had a deep broad double-pitched thread, which was changed to single pitch in the second generation [58]. The single-pitched cup led to a smaller torque moment during implantation [290].

The polyethylene cup insert articulated with the ceramic $\left(\mathrm{Al}_{2} \mathrm{O}_{3}\right)$ biolox head that had three different neck lengths (Biolox ${ }^{\oplus}$, CeramTec,

Figure 2.1

C.S.F. titanium cup and polyethylene insert

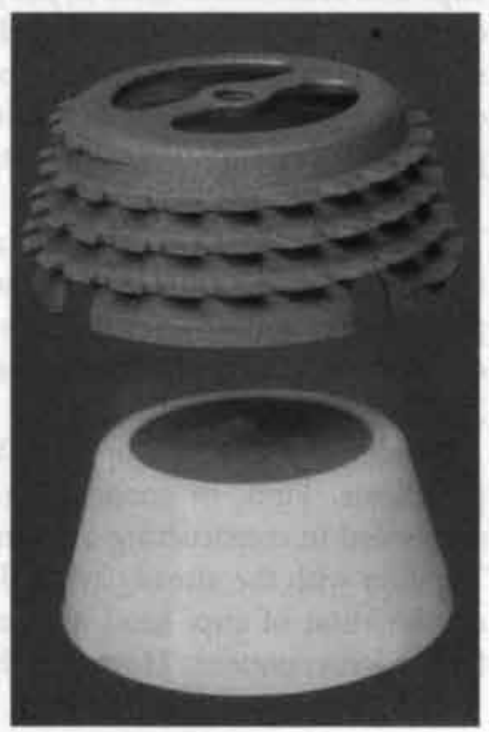


Table 2.1

Chemical structure of the titanium alloy in the Zweymulller total hip prosthesis [250]

\begin{tabular}{|c|c|c|c|c|}
\hline \multirow{2}{*}{$\begin{array}{l}\text { Elements } \\
\text { in weight } \%\end{array}$} & \multicolumn{2}{|c|}{ Pure titanium/ASTM F67 } & \multirow{2}{*}{$\begin{array}{l}\text { TI-6AI-AV/ELI } \\
\text { ASTM F } 136\end{array}$} & \multirow{2}{*}{$\begin{array}{l}\text { Ti-6Al-7Nb } \\
\text { Protasul-100 }\end{array}$} \\
\hline & Grade 1 & Grade 4 & & \\
\hline Carbon (C) & Max. 0.10 & Max. 0.10 & Max. 0.08 & Max. 0.08 \\
\hline Hydrogen $(\mathrm{H})$ & 0.015 & 0.015 & 0.012 & 0.009 \\
\hline Nitrogen $(\mathrm{N})$ & 0.03 & 0.05 & 0.05 & 0.05 \\
\hline Oxygen $(0)$ & 0.18 & 0.50 & 0.13 & 0.20 \\
\hline Iron $(\mathrm{Fe})$ & 0.20 & 0.50 & 0.25 & 0.25 \\
\hline Aluminium (AI) & & & $5.50-6.50$ & $5.50-6.50$ \\
\hline Vanadium (V) & & & $3.50-4.50$ & \\
\hline Niobium $(\mathrm{Nb})$ & & & & $6.50-7.50$ \\
\hline Tantal (Ta) & & & 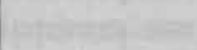 & 0.50 \\
\hline Titanium (Ti) & basis & basis & basis & basis \\
\hline
\end{tabular}

Qualification of the implant materials of the Zweymüller total hip prosthesis

\begin{tabular}{|c|c|c|c|c|c|}
\hline \multirow{2}{*}{ Component } & \multirow{2}{*}{ Implant material } & \multicolumn{4}{|c|}{ Norm } \\
\hline & & $\mathrm{SN}$ & DIN & ASTM & ISO \\
\hline $\begin{array}{l}\text { Acetabular cup } \\
\text { Insert bottom }\end{array}$ & $\begin{array}{l}\text { Pure titanium } \\
\text { forged } \\
\text { Protasul-Ti }\end{array}$ & & & F 67 & $5832-2$ \\
\hline Insert & $\begin{array}{l}\text { Polyethylene UHMW } \\
\text { sintered } \\
\text { Chirulen }\end{array}$ & & 58834 & F 648 & $5834-1$ \\
\hline Head & $\begin{array}{l}\text { Ceramic }\left(\mathrm{Al}_{2} \mathrm{O}_{3}\right) \\
\text { sintered } \\
\text { Biolox }\end{array}$ & & 58835 & F 603 & 6474 \\
\hline \multirow[b]{2}{*}{ Femoral stem } & $\begin{array}{l}\text { Ti-6Al-4VIELI } \\
\text { forged } \\
\text { Protasul-64 WF }\end{array}$ & & & F 136 & $5832-3$ \\
\hline & $\begin{array}{l}\text { Ti-6Al-7Nb } \\
\text { forged } \\
\text { Protasul-100 }\end{array}$ & 056512 & & & $5832-11$ \\
\hline
\end{tabular}


Plochingen, Germany). The diameter of this head was 32 millimetres with a 14/16 $\mathrm{mm}$ taper. Since 1985 , a $28 \mathrm{~mm}$ head with a $12 / 14 \mathrm{~mm}$ taper has been available. Two years later, Prof. Zweymüller implanted a $28 \mathrm{~mm}$ head in acetabular cups with a diameter of 52 to $58 \mathrm{~mm}$, while the larger cups $(61-72 \mathrm{~mm})$ had a $32 \mathrm{~mm}$ head and a $12 / 14 \mathrm{~mm}$ conus [250].

\subsection{FEMORAL STEM}

\subsubsection{Hochgezogen stem prosthesis}

In the autumn of 1979, clinical application of the first generation of cementless femoral stem prostheses began in Vienna (Figure 2.2). The wedge shape of the stem prosthesis, broad in the frontal plane and narrow in the sagittal plane, suited the normal anteversion-anteflexion of the femur and the same stem could be used for the left femur and right femur. As the stem prosthesis did not completely fill the medullary cavity, the endosteal blood supply was preserved. Other advantages were the enhanced rotational stability of the wedge shape and the press-fit insertion of this stem prosthesis $[74,102,289]$.

Besides the wedge shape and rectangular cross-section, this stem prosthesis was proximally thinner in the sagittal plane and was therefore called the "Hochgezogen" stem prosthesis. This proximal narrowing was intended to prevent splitting of the bone during implantation. On the ventral and dorsal sides, this collarless prosthesis had longitudinal grooves to enlarge the bone-implant surface. In cross-section the stem showed four points to enhance the anchoring of the stem. The distal portion of the stem tapered and was round at the end.

The Hochgezogen stem prosthesis was designed with nine holes in the proximal narrowed section. The most cranial hole can be used for stem extraction. The lateral caudal and the central holes are positioned in line with the neck axis. The angle between the neck axis and the line through the longitudinal axis of the stem should measure 49 degrees. According to Prof. Dr. K. Zweymuller the other holes can be used to monitor the bone ingrowth [287].

The Hochgezogen stem prostheses were available in ten different sizes, ranging from 145 to $185 \mathrm{~mm}$ in length.

Figure 2.2: The Hochgezogen stem prosthesis

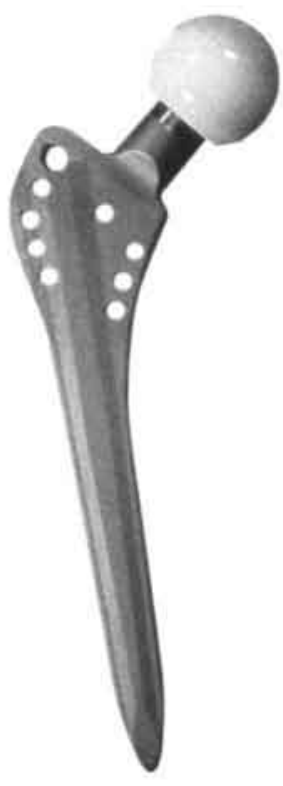

The stem was made of wrought hot-forged titanium alloy (Ti-6Al-4V, Protasul-64 WF) with a microsurface roughness of $1 \mu \mathrm{m}(\mathrm{Ra} 1.23 \pm 0.3 \mu \mathrm{m})$ [16]. In the gritblasted surface condition, this material has a fatigue strength of $600-660 \mathrm{~N} / \mathrm{mm}^{2}$, while the tensile strength values are about $30 \%$ higher than the ISO standard $5832-3$ [287]. The elasticity modulus of the titanium alloy is $100,000-110,000 \mathrm{~N} /$ $\mathrm{mm}^{2}$. Compared to iron-base and cobalt-base alloys, titanium is about half as stiff. Zweymüller and Semlitsch performed static and dynamic strength studies [287]. 
Under maximum static loads $(8,000$ and $11,000 \mathrm{~N})$ the smallest stem prostheses showed elastic deflection and no permanent deformation. After dynamic loading to about 5-10 million load cycles (at a frequency of 5-10 cycles per second) the smallest stem prosthesis could still be loaded to $6,000 \mathrm{~N}$ without fracturing. These studies revealed the safe mechanical properties of the Hochgezogen stem prosthesis.

Prof. F. Lintner and colleagues from the Vienna group performed several autopsy studies on the ingrowth of the bone into the metal implant $[16,17,175-177]$. On the distal segments of the retrieved specimens, the cortical bone was firmly connected to the implant. This bone showed increased thickness, compression of the osteons and retrenchment of the medullary cavities [175]. These signs of osseointegration progressed as the duration of implantation increased. Furthermore, no evidence was seen of inflammation, giant cell formation or corrosion of the metal stem $[176,177]$.

On the proximal segments, there was lamellar bone ingrowth. In the most proximal zone (e.g. the region of narrowing) bone ingrowth was pronounced on the medial and lateral sides, with a border of connective tissue on the ventral and dorsal sides. Macrophages in the connective tissue in the proximal zone of specimens with an Endler polyethylene cup contained polyethylene partikels [175]. Böhm et al confirmed the decreased osseointegration in the proximal zone $[16,17]$. Several of the retrieved specimens showed lower bone-implant contact in the proximal zone than in the distal zones.

The longitudinal grooves were intended to enhance bone-implant contact. However, retrieval studies showed that the newly formed bone had skipped the grooves [289].

Figure 2.3

Stepless stem prosthesis with the CSF cup, polyethylene insert and ceramic head

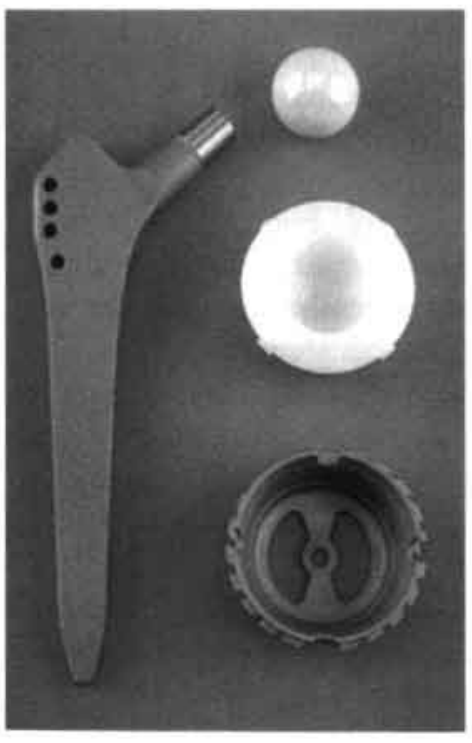

\subsubsection{Stepless stem prosthesis}

Clinical use of the Hochgezogen stem prosthesis disclosed that this stem had another disadvantage. The size of the jumps in the consecutive stems was too large to be able to make suitable matches to the normal human variations in size of the femur. Length differences between two consecutive sizes appeared to be about three to four centimetres, assuming that the femoral diameter and the primary press-fit were the same. This led to unacceptable leg length discrepancies [102]. The latter together with the above-mentioned disappointing proximal osseointegration, prompted the Vienna group to develop a second generation of Zweymüller stem prostheses (Figure 2.3).

The rectangular wedge shape was maintained, but the proximal narrowing in the sagittal plane and the longitudinal grooves were discontinued. Toxic vanadium was replaced by biocompatible niobium (Ti-6Al- 
$7 \mathrm{Nb}$, Protasul-100) and the non-sintered microstructure was changed to $3-5 \mu \mathrm{m}$, which was the same as the titanium cup prosthesis.

Successive sizes increased steplessly, based on so-called growth factors. This meant that increasing sizes became longer, wider and thicker. In addition, the area of the stem prosthesis increased and the difference between two consecutive large sizes was greater than that between the small sizes $[289,290]$.

The mechanical properties of this Stepless stem prosthesis were tested in dynamic-loading tests $[251,286]$. After five million cycles with a pulsing load, even the smallest stem prosthesis was strong enough to resist a load of $7,000 \mathrm{~N}$. The critical limit for fracturing was $2,500 \mathrm{~N}$, so the smallest stem had a safety factor of 2.5. Obviously, larger stem prostheses had even higher safety margins.

Retrieval studies revealed direct contact between the pre-existing bone and almost the whole metal surface [286]. Some parts had no direct contact shortly after the operation, but newly formed trabeculae were seen close to the metal surface. The researchers observed the formation of elephant-like feet of osteoid tissue that matured into bony incorporation of the implant. This process could take two to three years, but most of the surface of the implant had become osseointegrated in a short time. Thus, a well-implanted stem prosthesis could be difficult to remove after only $2-3$ months [289].

Böhm et al reported a retrieval study in which they made morphometrical and histological comparisons of the Hochgezogen and Stepless stem prostheses [16]. To obtain morphometric data on bone-implant contact, the extent of bone-cover was determined on ten sectioned segments of a retrieved implant. This area was divided by the total surface area on that segment and multiplied by 100 . The Stepless stem prosthesis was found to have more uniform bone-implant contact from the proximal to the distal segments, whereas the Hochgezogen stem prosthesis was found to have less contact in the proximal zones than in the distal zones. Histologically, the above-mentioned elephant-like feet of bone were seen on both stems. Implants were fixed at the edges within a frame of cortical bone. The altered micro-roughness $(1 \mu \mathrm{m}$ to $4 \mu \mathrm{m})$ had not caused any differences in histological patterns between the two stems. Böhm et al concluded that the shape of the Stepless stem prosthesis had led to equally distributed bone coverage that reflected uniform load transfer. Radiologically, this could be seen as more sclerosis in Gruen zones 3 and 5 on the Stepless stem prosthesis. They did not find any histological differences between the two stems. Furthermore, no differences were seen in terms of duration in situ, patient age at arthroplasty and age at retrieval. 
In this section, some remarks are made concerning implantation of the Zweymüller total hip prosthesis (Figures 2.4 and 2.5). To determine the size of prosthesis a patient needs, femoral templating should be done on the preoperative standardized radiographs. The usual anterolateral, transtrochanteric or posterolateral access routes are suitable for implantation of the Zweymüller hip prosthesis. Resection of the femoral head should be done about 1 centimetre proximal to the lesser trochanter at an angle of 45 degrees to the long axis of the femur. After careful placement of the retractors around the acetabulum, the removal of osteophytes (if present) and clearing of the (interposing parts of the) capsule, motorized reamers are used to remove the remnants of cartilage. The reamers have the same shape and diameter as the ultimate cup prosthesis. Acetabular reaming, with correct inclination and anteversion angle, is done to the level of bleeding of the subchondral bone. Reaming is complete when the rasps jam in the subchondral bone and the size corresponds with the cup. The entrance to the prepared acetabulum needs to be one size overreamed to enhance cup implantation. Trial components are not necessary. To facilitate implantation, the self-tapping cup prosthesis is mounted on a socket insertion guide. The first few rotations to screw in the cup are counter-clockwise; then the cup prosthesis is screwed clockwise into the floor of the reamed acetabulum. Sometimes the threaded cup jams during implantation. By alternately turning the prosthesis clockwise and anticlockwise the cup prosthesis can be implanted more easily. The cup is in the correct position when the bottom reaches the floor of the acetabulum, or when the edge of the cup is flush with the rim of the acetabulum. After removal of the socket insertion guide, the polyethylene cup can be inserted (Figure 2.4).

To enter the femoral canal, a square-tipped chisel is used in right anteversion position to remove the cancellous bone on the lateral side of the trochanter major, at the side of the piriform fossa. Care must be taken to place the chisel on the lateral side of the femur to prevent varus positioning of the stem prosthesis (Figure 2.5). Femoral rasps with adequate conical-rectangular cross-section and consecutively increasing sizes are used to prepare the canal for press-fitting of the stem prosthesis. Rasping can be done with a manual gliding hammer or a motorized hammer. Rotary drills are not needed, which also avoids thermal damage to the bony bed. During rasping, the surgeon should frequently check the inner surface of the femoral canal with a bone curette to ensure that no fracture has occurred. Rasping is complete when the rasp makes tight contact with the cortex of the femoral canal; the surgeon is sometimes alerted to this by an audible change in pitch. The femoral rasp is used as a trial stem with a trial head and varying neck lengths. It is important to ensure that the centre of rotation has been restored and that the height of the centre of the head is correct in relation with the trochanter tip. Then limb length and the stability of the prosthesis must be assessed. When everything is ready, the rasp can be removed and an adequate size stem prosthesis can be implanted. Care should be taken to punch the stem at the neck of the prosthesis and not at the precision taper. Once the stem has been implanted a trial reduction can be done with a trial head. The arthroplasty 
is completed by putting the head onto the stem prosthesis and repositioning the femoral head in the cup prosthesis. After wound closure, the usual rehabilitation programme can be started.

\section{Figure 2.4}

Acetabular side for the cup (see text)
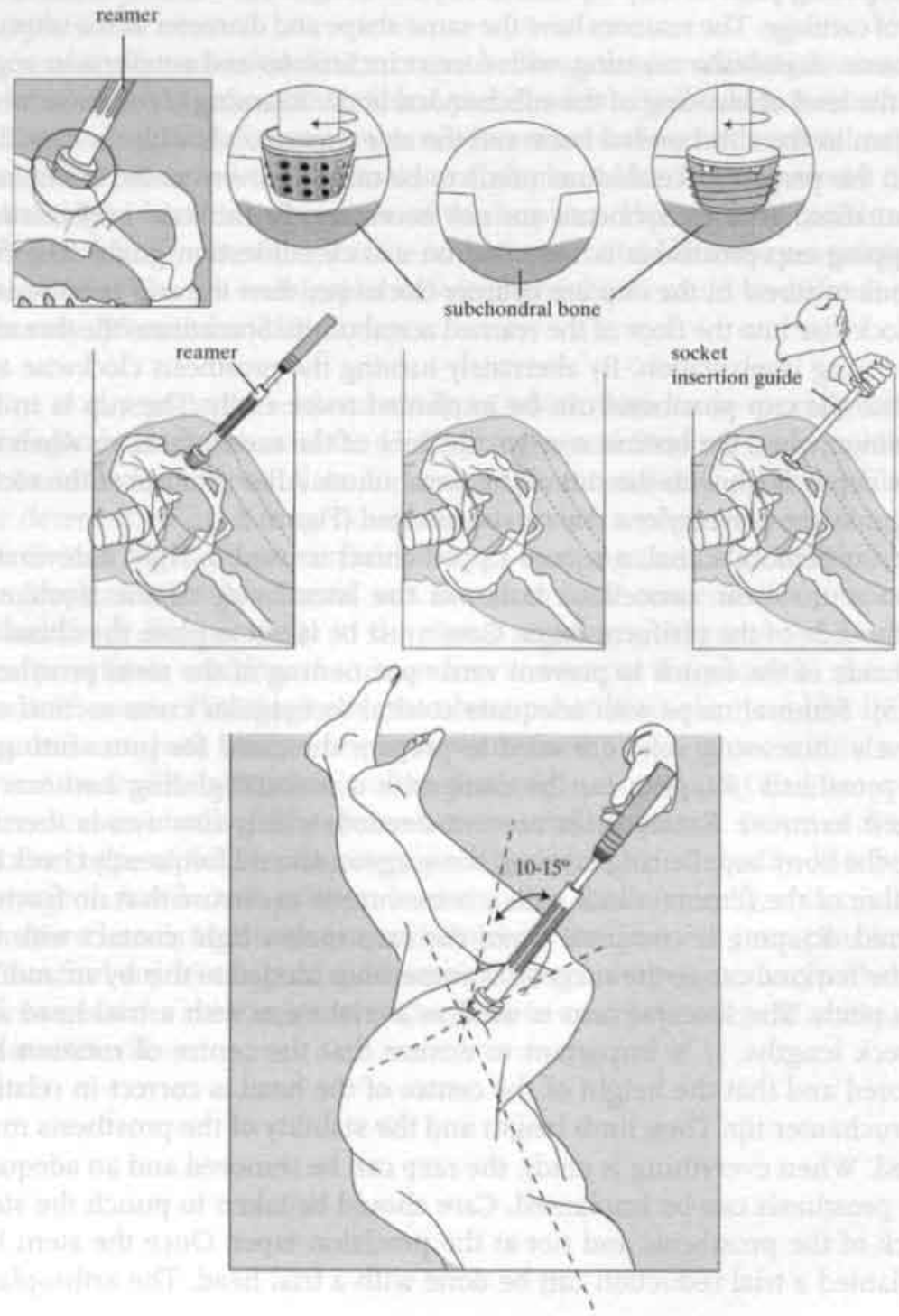


\section{Figure 2.5}

Preparing the femoral side for the stem (see text)

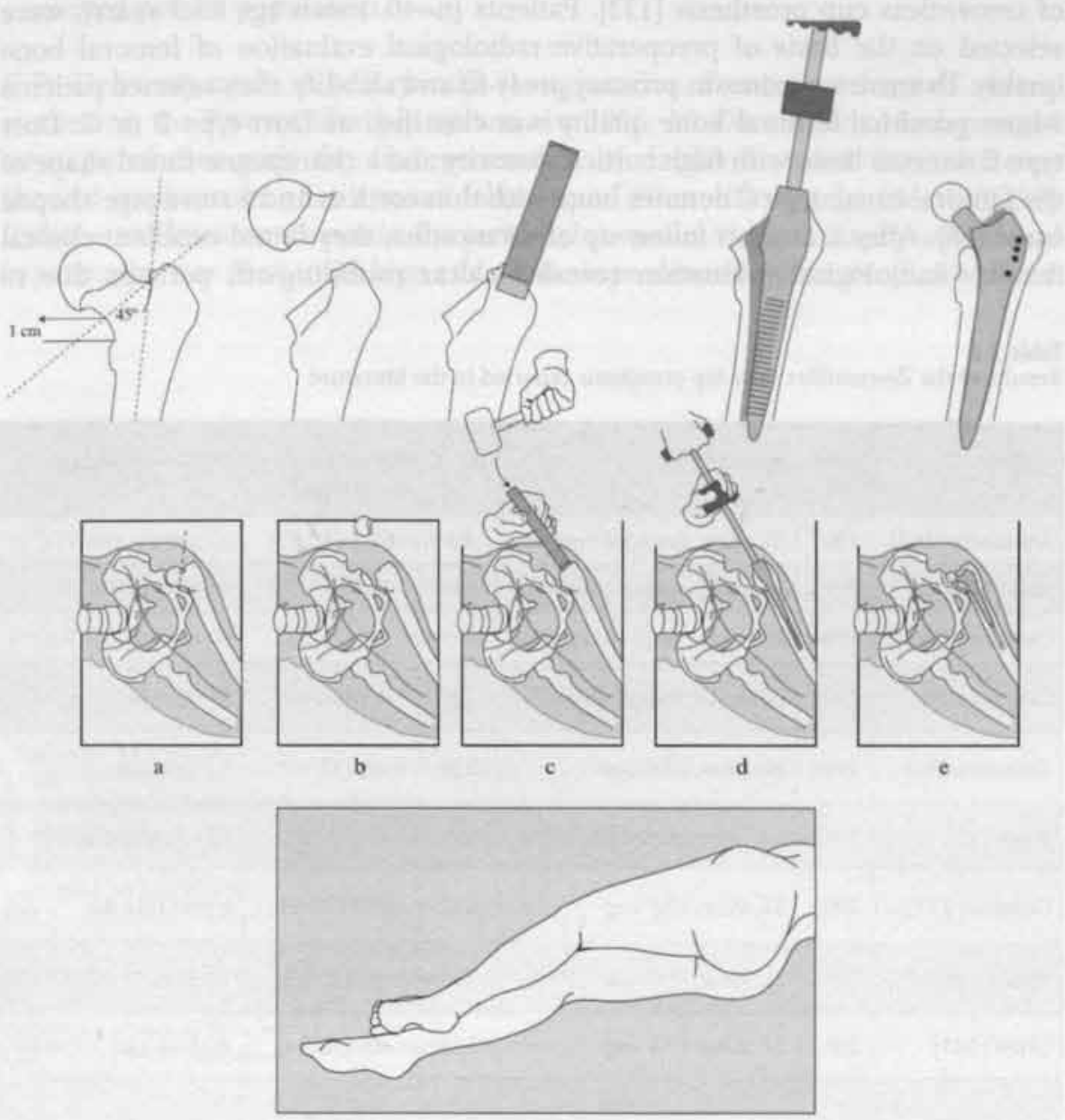

\subsection{RESULTS REPORTED IN THE LITERATURE}

In 1995, Murray et al published a study on the total hip prostheses that had been used in the United Kingdom [214]. The Zweymüller hip system had only been available in the United Kingdom since 1993 and had a market share of less then 5 per cent. Murray et al wrote that to their knowledge, no peer-reviewed clinical data had been published until then, but Kutschera et al had reported their results with the Zweymüller total hip prosthesis in 1993 (Table 2.2) [167]. 
Huo et al (Baltimore, Maryland, U.S.A.) reported the clinical results of a prospective study on 46 Zweymüller Stepless stem prostheses, with several types of cementless cup prosthesis [132]. Patients ( $n=40$, mean age 65.3 years), were selected on the basis of preoperative radiological evaluation of femoral bone quality. To ensure maximum primary press-fit and stability, they selected patients whose proximal femoral bone quality was classified as Dorr type B or C. Dorr type B denotes bone with high cortical porosity and a champagne fluted shape of the femoral canal; type $\mathrm{C}$ denotes bone with thin cortices and a stove pipe shaped canal [68]. After a median follow-up of 48 months, they found excellent clinical results. Radiological evaluation revealed calcar rounding-off, perhaps due to

Table 2.2

Results of the Zweymuller total hip prosthesis reported in the literature

\begin{tabular}{|c|c|c|c|c|c|}
\hline author & year & prosthesis & $\mathbf{N}$ & $\begin{array}{l}\text { age at surgery } \\
\text { yrs (range) }\end{array}$ & follow-up (range) \\
\hline Kutschera $[167]$ & 1993 & SL stem; threaded cup( $\left(^{\bullet}\right)$ & 85 & $67.3(41-87)$ & 63 months (60-71) \\
\hline Huo [132] & 1995 & SL stem; several cups & 40 & $65.3(36-77)$ & 48 months (36-73) \\
\hline Delaunay [59] & 1996 & HG stem; threaded $\operatorname{cup}\left({ }^{*}\right)$ & 60 & $62(26-87)$ & 80 months $(60-108)$ \\
\hline Delaunay [60] & 1997 & HG stem; threaded cup $\left(^{*}\right)$ & 126 & $63(26-84)$ & 84 months $(60-121)$ \\
\hline Delaunay [56] & 1998 & SL stem; CSF cup & 129 & $65(32-91)$ & 5.9 yrs $(4-8)$ \\
\hline Aigner $[1]$ & 1998 & HG stem; threaded $\operatorname{cup}\left({ }^{*}\right)$ & 50 & $81.1(\mathrm{nr})$ & 123 months (114-150) \\
\hline Delaunay [57] & 2001 & SL stem; CSF cup & 157 & $65.9(32-91)$ & 6 yrs $(1-11.4)$ \\
\hline Weissinger $[272]$ & 2001 & SL stem; CSF cup & 123 & $61(37-82)$ & 10.5 yrs $(9.5-12)$ \\
\hline Grubl [105] & 2002 & SL stem; CSF cup & 127 & $61(22-84)$ & median 120.7 months \\
\hline Von Allmen [5] & 2002 & $\begin{array}{l}\text { SL stem; CSF cup (metal- } \\
\text { on-metal vs polyethylene- } \\
\text { ceramic } 28 / 32 \mathrm{~mm} \text { ) }\end{array}$ & 440 & $\begin{array}{c}\mathrm{m}-0-\mathrm{m} 59.9 \\
\quad( \pm 8.7) \\
28 \mathrm{~mm} 64.9 \\
\quad( \pm 8.4) \\
32 \mathrm{~mm} 64.0 \\
\quad( \pm 6.9)\end{array}$ & $\begin{array}{l}\text { m-0-m } 60.2 \text { months } \\
28 \mathrm{~mm} 65.1 \text { months } \\
32 \mathrm{~mm} 66.3 \text { months }\end{array}$ \\
\hline $\begin{array}{l}\text { Garcia- } \\
\text { Cimbrelo [92] }\end{array}$ & 2003 & SL stem; CSF cup & 104 & $62.3(25-77)$ & 11.3 yrs $(10-130$ \\
\hline Grabl [106] & 2003 & SL stem; CSF cup & 848 & $\begin{array}{c}62.6 \\
(22.3-88.3)\end{array}$ & 81.3 months (nr) \\
\hline Pieringer [228] & 2003 & SL stem; CSF cup & 75 & $58.0(24-75)$ & 129 months $(121-136)$ \\
\hline Perka [225] & 2004 & SL stem; CSF cup & 121 & $52.6(26-73)$ & 112 months $(82-143)$ \\
\hline
\end{tabular}

( ) means first generation threaded cup $\mathrm{nr}=$ not reported 
remodelling, and no evidence of osteolysis. Despite these favourable results Huo et al advised that the Zweymüller Stepless stem prosthesis should only be used in a selected patient population.

C.P. Delaunay and A.I. Kapandji (Longiumeau, France) performed several studies on the Zweymüller hip system. In 1996, 60 Zweymüller Hochgezogen stem prostheses with the first generation of double-threaded titanium cups showed good results after a mean follow-up of 80 months (range $60-108$ ) [59]. Radiolucent lines were seen in the proximal zones in 45 hips; diaphyseal cortical hypertrophy was seen in 35 hips and all the hips showed calcar atrophy, while all

\begin{tabular}{|c|c|}
\hline $\begin{array}{l}\text { survival end-point aseptic } \\
\text { loosening }\left(\mathrm{Cl}_{9 s}\right)\end{array}$ & remarks \\
\hline nr & 1 cup aseptic loosening \\
\hline nr & stem prostheses in selected cases \\
\hline nr & 2 cups aseptic loosening; 6 intraoperative femoral fractures \\
\hline $\begin{array}{l}\text { cup } 10 \text { yrs } 98.7 \% \\
(80-99.9 \%)\end{array}$ & 2 cups aseptic loosening; no stem revisions \\
\hline $\begin{array}{l}\text { cuptstem } 8 \text { yrs } 98.4 \% \\
(83.4-99.8 \%)\end{array}$ & 1 aseptic loosening cup; 9 fractures troch.major; 5 femoral fractures \\
\hline cup $92.6 \%$ stem $90.6 \%$ & 4 cups and 3 stems aseptic loosening: \\
\hline $\begin{array}{l}\text { cup }+ \text { stem } 10 \text { yrs } 99.3 \% \\
(89.9-99.9 \%)\end{array}$ & 1 cup aseptic loosening \\
\hline $\mathrm{nr}$ & 2 cups aseptic loosening; polyethylene wear \\
\hline $\begin{array}{l}\text { cup }+ \text { stem } 10 \text { yrs } 92 \% \\
(88-97 \%) \text { (any reoperation) }\end{array}$ & 5 cups aseptic loosening \\
\hline $\mathrm{nr}$ & more wear and resorption polyethylene cups \\
\hline $\begin{array}{l}\text { cup } 12 \text { yrs } 94.2 \% \\
(91.9-96.5 \%)\end{array}$ & 3 cups aseptic loosening; 18 acetabular osteolysis \\
\hline $\begin{array}{l}\text { cuptstem } 6.7 \text { yrs } 98.6 \% \\
(97.8-99.5 \%)\end{array}$ & 6 cups aseptic loosening \\
\hline $\begin{array}{l}\text { cup +stem } 132 \text { months } 96.9 \% \\
(86.3-99.4 \%)\end{array}$ & 4 cups aseptic loosening cup; 8 acetabular osteolysis \\
\hline $\begin{array}{l}\text { cup } 112 \text { months } 97.5 \% \\
(95.1-99.9 \%)\end{array}$ & $\begin{array}{l}\text { hip dysplasia; at least one tread firmly anchored; } n=7 \text { femoral fractures } \\
\text { (cerclages) }\end{array}$ \\
\hline
\end{tabular}


the stems had spot welds. After initial vertical subsidence within the first year postsurgery, all the stems (except for one septic stem) were stable. Two acetabular cups had been revised. In two thirds of the cases, heterotopic ossification was noted; $23.3 \%$ had grades 3 or 4 according to Brooker.

In a subsequent paper, Delaunay and Kapandji confirmed these favourable results in a study on 126 Hochgezogen stem prostheses, with first generation threaded cups [60]. Pain in the groin was considered to be associated with the acetabular cup. Eight patients had pain in this region, four of whom improved spontaneously. In the other four patients, one cup prosthesis stabilized after initial subsidence in an obese patient; one cup prosthesis showed osseointegration so the pain remained largely unexplained; one polyethylene cup insert was replaced that proved to be macroscopically unimpaired; one cup prosthesis revealed insufficient stability, but was not revised due to the poor physical condition of the patient. One other cup prosthesis was revised. Delaunay and Kapandji wrote that with "definite loosening" as the end point, the cumulative survival of the cup was $98.7 \%$ after ten years, although the confidence interval was $80 \%$ to $99.9 \%$. No failures of the stem prosthesis were reported.

Another study on 129 Stepless stem prostheses and the second generation of C.S.F. cups with a $28 \mathrm{~mm}$ ceramic-on-polyethylene bearing surface, revealed an 8 year survival of $99.3 \%\left(\mathrm{CI}_{95} 85.2-99.9 \%\right)$ for the stem and $99.1 \%\left(\mathrm{CI}_{95} 85-99.9 \%\right)$ for the cup [56]. Delauney et al described nine fractures of the greater trochanter $(6.4 \%)$ and five fractures of the proximal femoral shaft $(3.4 \%)$. Thirty-nine stems $(30 \%)$ had a varus position without any clinical consequences. Within the first two years, 21 stem prostheses had subsided by more than $2 \mathrm{~mm}$. Later, one stem showed aseptic loosening that led to revision. Delaunay et al found proximal radiolucent lines and cortical thickening around Gruen zones 3, 4 and 5 .

In an analysis on 157 Zweymüller total hip arthroplasties, Delaunay and Kapandji reported 10-year survival rates of $99.3 \%\left(\mathrm{CI}_{95} 89.9-99.9 \%\right)$ for the end-point "revision due to aseptic loosening" and $91.5 \%\left(\mathrm{Cl}_{95} 77.5-97.1 \%\right)$ for any cause [57]. They concluded that the Zweymuller total hip system matched the best-performing second-generation cemented total hip arthroplasties reported in the Swedish Arthroplasty Registry.

The study by Weissinger et al (Zwettl, Austria) again showed good results with the Zweymüller total hip system [272]. In a cohort of 123 patients (133 total hip arthroplasties with the Stepless stem prosthesis and a C.S.F. cup) with an average age at surgery of 61 years $(37-82)$ and a mean follow-up of 10.5 years (range 9.5 - 12 years), there had been no revisions of the Stepless stem prosthesis. However, two threaded cup prostheses had been revised for aseptic loosening and two polyethylene inserts and the ceramic ball head had been replaced. After ten years all the arthroplasties were found to have an eccentric head. Polyethylene wear averaged $1 \mathrm{~mm}$, while 22 patients $(16.5 \%$ ) had $1.5 \mathrm{~mm}$ or more (range 1.5 $-8 \mathrm{~mm}$ ). Radiolucent lines were noted in Gruen zone 1 in $13.5 \%$ of the stem prostheses and in Gruen zone 7 in $9.0 \%$. The investigators could not find any correlation with the amount of polyethylene wear. They concluded that the 
Zweymüller hip system is suitable for all femoral shapes and for a wide range of age groups.

Grübl et al (Vienna, Austria) reported the long-term results of the Zweymüller total hip system in the American Journal of Bone and Joint Surgery [105]. The median follow-up of the 127 arthroplasties (Stepless stem prosthesis and a C.S.F. cup) was 120.7 months. Five cups had been revised due to aseptic loosening. The authors found an annual linear wear of $0.1 \mathrm{~mm}$. Radiolucent lines were seen on the femoral side in $23 \%$ in Gruen zone 1 and in $8 \%$ in Gruen zone 7 . At ten-years follow-up the cumulative survival with the end-point "revision for any reason" was $92.0 \%\left(\mathrm{CI}_{95} 88.0\right.$ - $\left.97.0 \%\right)$ for both components, $93 \%\left(\mathrm{CI}_{95} 89.0-97.0 \%\right)$ for the cup only and $99.0 \%\left(\mathrm{CI}_{95} 97.0-100 \%\right)$ for the stem only. Grübl et al concluded that fixation of the stem prosthesis was secure, but the threaded cup was prone to aseptic loosening.

Garcia-Cimbrelo et al (Madrid, Spain) reported their long-term results in the British Journal of Bone and Joint Surgery [92]. A total of 104 hips (Stepless stem prosthesis and a C.S.F. cup) had been investigated 11.3 years (range 10-13 years) after the index operation. Acetabular osteolysis without any clinical decline was seen in 18 cups; three cups had been revised due to aseptic loosening and an additional four had radiographic signs of loosening, but a good clinical result. The mean annual linear wear was $0.08 \mathrm{~mm}( \pm 0.08)$. Forty stem prostheses had a varus position, which was associated with a narrow canal and less canal filling in the distal third of the stem. Non-progressive subsidence with radiographic evidence of stable fixation was seen in 12 stem prostheses. In the best-case scenario, patients who were lost to follow-up patient were classified as unrevised, while in the worst-case scenario, they were classified as revised. The cumulative survival with the end-point "revision for any cause" at 12 years follow-up was $94.1 \%\left(\mathrm{CI}_{95} 91.9 \%-96.3 \%\right)$ for best-case scenario, versus $85.3 \%\left(\mathrm{CI}_{95} 82.1 \%\right.$ $-\mathbf{8 8 . 5} \%$ ) for the worst-case scenario.

Von Allmen compared the five-year clinical and radiological results of patients with a Stepless stem prosthesis and a C.S.F. cup with a metal insert / metal head $(n=132)$, or a polyethylene insert / $28 \mathrm{~mm}$ ceramic head $(n=177)$, or a polyethylene insert / $32 \mathrm{~mm}$ ceramic head $(\mathrm{n}=131)$ [5]. Radiological analysis revealed more linear wear and more resorption around the stem prostheses with the polyethylene insert cups. However, all the short-term clinical results were equally favourable.

Grübl et al (München, Vienna, Paris) performed a multicentre study on 848 patients who had received a Stepless stem prosthesis and a C.S.F. cup [105]. After 81.8 months, the survival rate of the stem and cup was $98.6 \%\left(\mathrm{CI}_{95} 97.8\right.$ $-99.5 \%)$. After ten years this rate was $93.6 \%\left(\mathrm{CI}_{95} 89.8-97.3 \%\right)$. Six acetabular cups had been revised for aseptic loosening. A disadvantage of the study was that the survival of 320 arthroplasties had been assessed by means of a telephone questionnaire.

Pieringer et al (Linz, Austria) investigated 75 patients who had received a Stepless stem and a C.S.F. cup [228]. Four acetabular cups were considered to show aseptic loosening (two revised, two unrevised) and one cup had been 
revised for massive polyethylene wear. They found eight cases of osteolysis behind the C.S.F. cup. All the stems were unrevised and radiological analysis revealed proximal radiolucent lines and distal bone hypertrophy, which indicated typical Stepless stem load transfer.

Perka et al (Berlin, Germany) reported good results with the Zweymüller system (SL stem prosthesis and a C.S.F. cup) for the treatment of developmental hip dysplasia [225]. They evaluated 121 arthroplasties in 93 patients, whose mean age at surgery was 52.6 years (range $26-73$ years); mean follow-up was 112 months (range $82-143$ months). Primary stability of the cup had been achieved by anchoring the cup to the bone with at least one thread. No bone grafts had been used to reconstruct the deficient anterolateral acetabular rim. In 78 hips $(66 \%)$ they had succeeded in restoring the centre of rotation by placing the acetabular cup in or near to the true acetabulum. Annual polyethylene wear was $<0.1 \mathrm{~mm}$ in 71 hips, between $0.1-0.2 \mathrm{~mm}$ in 37 hips and $>0.2 \mathrm{~mm}$ in nine hips. Survival of the cup with the end-point "aseptic loosening" after 9.3 years was $97.5 \%\left(\mathrm{Cl}_{95} 95.1-99.9 \%\right)$. None of the stem prostheses had been revised, but seven proximal femoral fractures had occurred intraoperatively due to increased anteversion of the femoral neck, the tight medullary canal, or altered anatomy following previous surgery. These seven fractures were treated with cerclage and did not alter the survival of the stem.

\subsection{SUMMARY}

After an experimental phase with ceramic and polyethylene materials, a titanium hip system was developed. The threaded cup and the wedge shaped stem matched the normal anatomy of the acetabulum and femur.

Two versions of the stem prosthesis had been used in man. The first generation stem ("Hochgezogen") was wedge shaped; in the sagittal plane, the stem grew thinner proximally. In the second generation of stems ("Stepless") the proximal thinning was discontinued and consecutive stem sizes increased proportionally. Autopsy studies revealed less osseointegration of the first generation of Hochgezogen stem prostheses, compared to more equally distributed osseointegration of the Stepless stem prostheses owing to the different geometry. No other differences were seen.

Clinical studies showed good long-term results with both stem prostheses. The titanium threaded cup prosthesis had less favourable results and involved the risk of aseptic loosening. 


\section{A Historic COHORT Study ON 754 Zweymüller Total Hip ARThroplasties}

\subsection{ABSTRACT}

From 1 January 1987 to 31 December 1994,820 primary Zweymüller cementless total hip arthroplasties were performed in 732 patients at five Dutch hospitals; all the prostheses had a ceramic head and a threaded titanium cup. A total of 670 patients (754 prostheses: 275 Hochgezogen and 479 Stepless stem prostheses) visited the clinic for evaluation by physicians who had not been involved in the treatment. Fifty-two patients could not be evaluated personally. Data on their histories were obtained by telephone, from family and general practitioners. Ten further patients had already undergone revision surgery. six threaded titanium cups had been revised after aseptic loosening; three total prostheses had been revised after septic loosening and one cup had been revised due to recurrent dislocation. No stems had been revised due to aseptic loosening.

After an average follow-up of six years, the mean Harris Hip Score was 92.5 (sd 9.6). This historic cohort analysis showed good middle to long-term follow-up results with primary cementless Zweymüller total hip arthroplasty. 
Since 1986, five Dutch hospitals with a general orthopaedic department have been using the Zweymüller cementless total hip prosthesis (Rijnstate Hospital Arnhem, Pasteur Hospital Oosterhout, Diaconessenhuis Eindhoven, St. Joseph Hospital Veldhoven, Elkerliek Hospital Helmond). Two of these institutes are orthopaedic training hospitals. The Zweymüller cementless hip prosthesis was the only one being used at one hospital. At the other hospitals, standard and cemented prostheses were also being used, and on indication (e.g. young age) the cementless Zweymüller total hip prosthesis.

Figure 3.1

the Zweymüller Hochgezogen prosthesis with nine holes

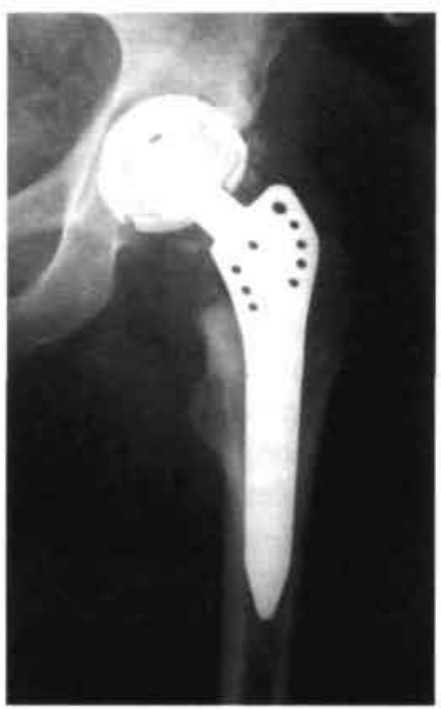

Up to 1989 , the surgeons had been using the titanium (Ti-6Al-4V) femoral stem with nine holes (Allopro, Switzerland) (Figure 3.1). This stem only had a wedged shape in the frontal plane. The cross-section of the stem was rectangular and in the sagittal plane, there was narrowing of the proximal part (Hochgezogen) (HG). This narrowing could reduce the fixation of the proximal part of the stem. As a solution, the four hole Stepless (SL) femoral stem was developed, which gradually became longer, wider and thicker. The stem also had a wedge shape and a rectangular cross-section. To support osteointegration, there was no narrowing of the stem in the sagittal plane (Figure 3.2). Furthermore, the toxic vanadium of the titanium alloy had been replaced by the biocompatible niobium [289].

Initially, a polyethylene cup (Endler type) was used. However, the results were disappointing, so in 1985, the cup was replaced by a self-tapping threaded titanium cup with a polyethylene insert [289]. Several authors have reported good results with the Zweymüller cementless total hip prosthesis $[58,105,289]$.

The literature shows good results of cementless total hip prostheses in general [77, 101, 133 , 179, 264]. Yahiro et al performed a metaanalysis on 95 publications [284]. Revision rates with various types of cementless threaded cup were higher than those with cementless
Figure 3.2 the Zweymüller Stepless prosthesis with four holes

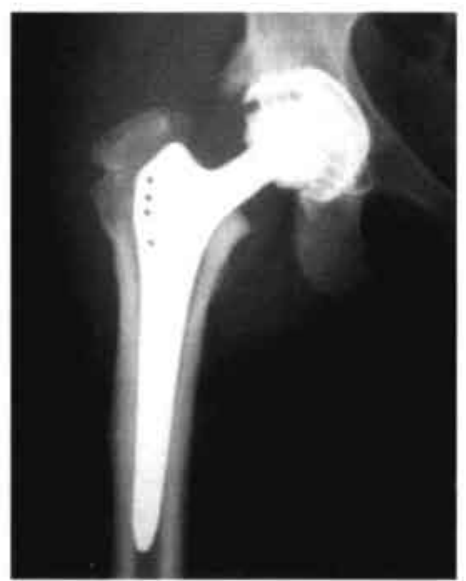


porous-coated and cemented acetabular cups $(3.58 \%, 1.44 \%$ and $1.61 \%$ after follow-up of 2.5, 3.6 and 6.8 years, respectively). Signs of aseptic loosening, such as pain, migration and increasing areas of radiolucency, were more common with threaded cups than with porous-coated and cemented acetabular cups. The conclusion drawn on the basis of this meta-analysis was that threaded cups should no longer be used. However, the Zweymüller threaded titanium cup was not included in the meta-analysis.

In the present historic cohort study, we analysed the results of the cementless Zweymüller total hip prosthesis. Our primary goal was to determine the fate of the prosthesis, especially revision due to aseptic loosening. In addition, we wanted to investigate differences in clinical outcome between the two versions of the stem.

\subsection{MATERIALS AND METHODS}

Hospital administration offices and theater records were consulted to identify all the patients who had undergone hip surgery during the period 1 January 1987 to 31 December 1994. A total of seventeen orthopaedic surgeons who were not specialists in hip surgery had performed the operations. The Hochgezogen (HG) and the Stepless (SL) stem prostheses were used, all with a $32 \mathrm{~mm}$ ceramic head and a threaded titanium C.S.F. cup. Thus, the Endler cup was excluded. All the prostheses had been implanted using the posterolateral approach.

The patients were contacted by several physicians who had not been involved in the treatment (A.M.J.S. Vervest, M. Kenters, I. Klomp). If a patient had died during follow-up, the fate of the prosthesis was determined via contact with the family or general practitioner. Patients who had moved away or refused to participate were evaluated by telephone; they were asked whether they had any complaints about the prosthesis or had undergone revision surgery. The remaining patients were invited to the clinic for an evaluation that included anamnesis, hip function tests and standard antero-posterior and axial X-rays. The researchers completed a standard form that contained questions about preoperative and postoperative functioning, pre-operative Charnley class [38] and indication for hip surgery. Thirteen patients who could not visit the clinic were examined at home; no X-rays could be taken in these cases. One patient took part in the evaluation, but refused to have the X-rays. A total of $740 \mathrm{X}$-rays were taken.

We judged true revisions of the prostheses to be failures. Surgery for fracture, leg length difference, recurrent dislocation or removal of periarticular ossification were classified as re-intervention.

The standard X-rays were compared to those taken shortly after surgery. On the femoral side, the zones of Gruen were used to evaluate bonestock (Figure 3.3) [107]. Line formation, bone apposition, cortical reactions and osteolysis were recorded (Figures 3.4 and 3.5). Line formation was defined as increased linear bone density along the prosthesis; only the presence of line formation was 
Figure 3.3

Gruen zones and radiological analysis of 740 stem prostheses (266

Hochgezogen and 474 Stepless stem prostheses). More Hochgezogen stem prostheses showed radiolucent lines in the proximal Gruen zones than the Stepless prostheses $(\mathrm{p}=0.002)$

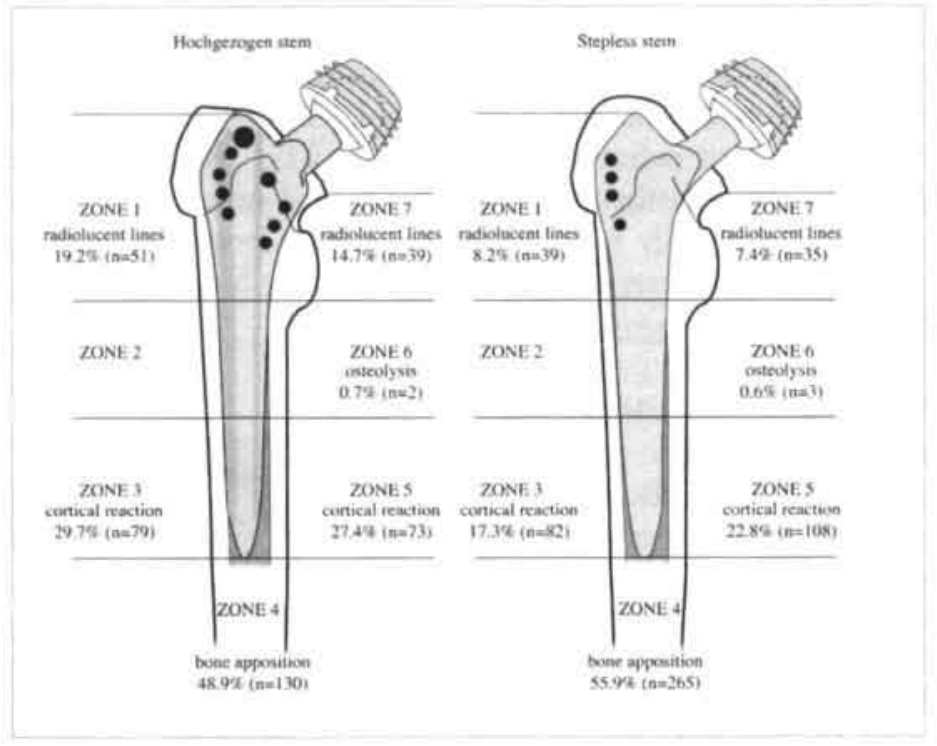

Figure 3.4

Radiographs demonstrating the development of radiolucent lines in Gruen zones I and 7

postoperative

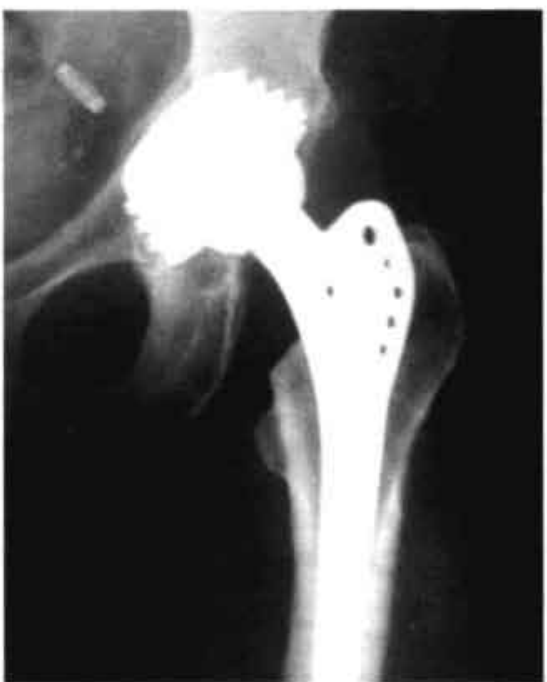

follow-up 84.3 months

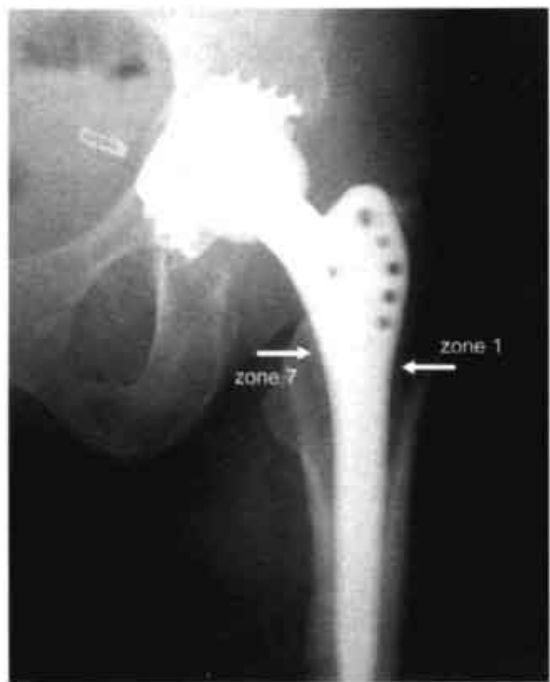


Figure 3.5

Development of bone apposition in Gruen zone 4 (tip of the prosthesis)

postoperative

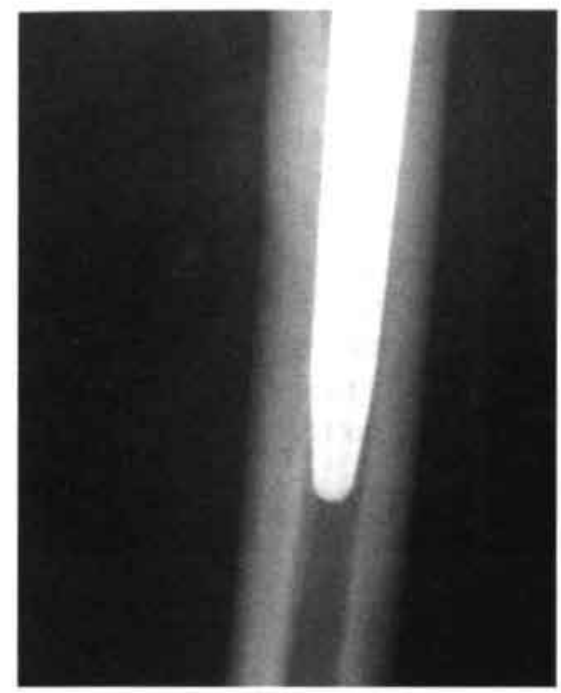

Osteolysis in Gruen zone 1

postoperative
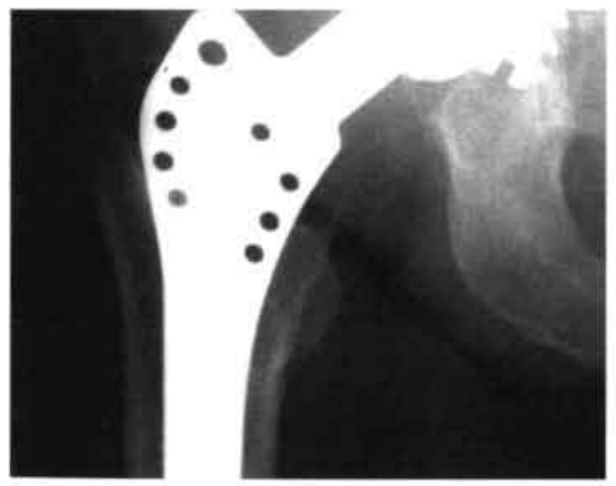

follow-up 143 months

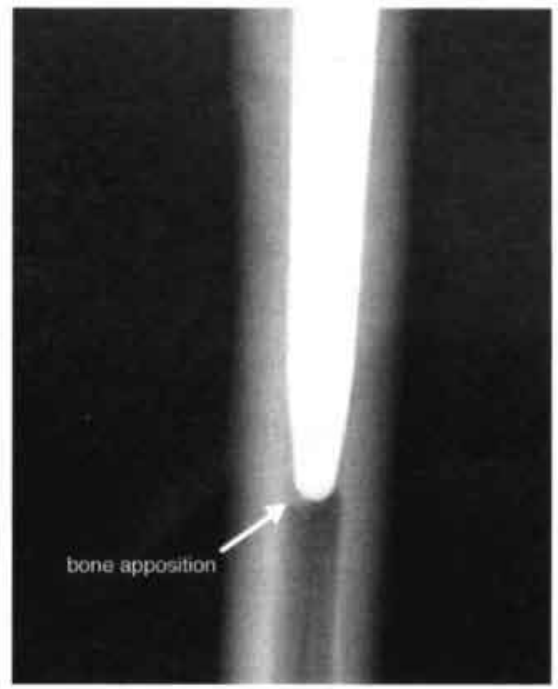

follow-up 132 months

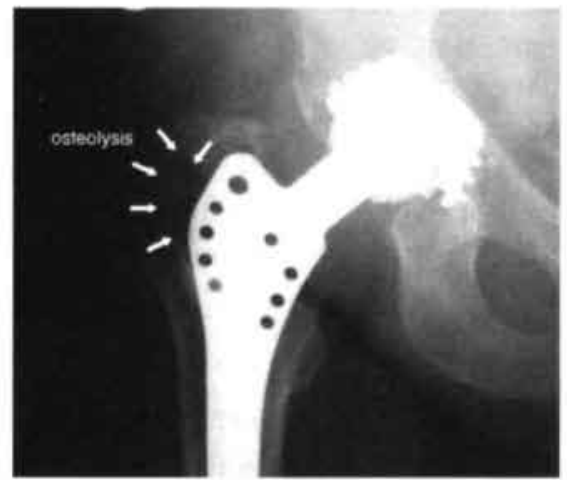

recorded. Bone apposition was defined as the formation of new bone around the prosthesis. Cortical reactions were defined as increased density of all the bone around the prosthesis. Decreased bone density was judged as osteolysis.

The position of the femoral component was measured by comparing the long axis of the prosthesis to the long axis of the femur, position was classified as varus, neutral, or valgus. Subsidence of the femoral component was measured from the tip of the stem to the centre of the trochanter minor. Only gross component migration was recorded. Heterotopic ossification was classified according to 
Brooker et al [26]. The degree of remodelling of the calcar femoris was described as atrophy, hypertrophy, or unchanged. An inclination of more than $60^{\circ}$ of the cup was considered to be abnormal. A cup was judged to have migrated only when there was a visible difference in position relative to the teardrop.

During the study period, the seventeen orthopaedic surgeons had performed 820 primary cementless Zweymüller total hip arthroplasties in 732 patients.

Fifty-two patients ( 56 prostheses) could not be evaluated according to our protocol. Nine of them (12 prostheses) had moved away and were approached by telephone. Two patients ( 2 prostheses) could not be evaluated due to other diseases. One patient (1 prosthesis) refused to participate in the study. All these patients were satisfied about the functioning of their prostheses and their primary prosthesis was still in situ. Forty patients ( 41 prostheses) had died of causes unrelated to total hip arthroplasty. Their general practitioners or family reported that none of these patients had hip complaints and no revision procedures had been conducted.

A further ten prostheses had already been revised. Six of them had required cup revision due to aseptic loosening $(0.79 \%)$. In one of these patients, cup loosening was detected during this follow-up study. Three total hip prostheses had been revised due to septic loosening and one had been revised due to recurrent dislocation. This historic cohort study was therefore performed on 754 prostheses in 670 patients.

Data from the anamnesis and physical examination were used to determine the Harris Hip Score [112]. Student's T-test (significance $\mathrm{p}<0.05$ ) and linear regression were used to analyse the outcomes. Kaplan-Meier curves and a lifetable were calculated for revision of the acetabular cup [148, 212, 213]. Worst case scenario of the survival curve and the lifetable according to Poss et al were applied to arthroplasties with revision of the acetabular cup, septic loosening, component breakage, osteolysis around the cup and stem, and migration of the components [230]. These figures were calculated.

\subsection{RESULTS}

A total of 670 patients (754 prostheses) took part in this historic cohort follow-up study. Table 3.1 shows the distributions and numbers of prostheses, the Harris Hip Scores, the Charnley classes at the time of surgery and the diagnoses. The Harris Hip Scores of the patients with a SL stem prosthesis were higher than those of the patients with an HG stem prosthesis ( $\mathrm{p}=0.001$ ). Linear regression analysis showed that the Harris Hip Score was not influenced by the factors age and follow-up duration $\left(R^{2}=0.006\right)$ (Figures 3.6-3.9). The higher scores of patients with an SL stem prosthesis were related to fewer pain complaints, higher scores 
for gait (distance walking and limp) and daily activities (stairs, sitting) (Table 3.2) $(\mathrm{p}<0.007)$. There were no differences in the range of motion ( $\mathrm{p}=0.107)$.

Only the Charnley class C patients had a Harris Hip Score that was statistically significantly lower than that of the class A patients or the class B patients $(\mathrm{p}<0.016)$. The number of patients operated on because of rheumatoid arthritis or a fracture was too low to compare their Harris Hip Scores to those of the patients with idiopathic osteoarthritis.

Table 3.1

Descriptive data on 754 cementless Zweymuller total hip prostheses (670 patients)

\begin{tabular}{|c|c|c|c|}
\hline & $\begin{array}{l}\text { Hochgezogen prosthesis } \\
\qquad(\mathrm{n}=275)\end{array}$ & $\begin{array}{l}\text { Stepless prosthesis } \\
(\mathbf{n}=479)\end{array}$ & $\underset{(n=754)}{\text { Total }}$ \\
\hline Age at surgery (years) & $62.9(\mathrm{sd} \mathrm{11.0)}$ & $63.9(\operatorname{sd} 9.8)$ & $63.6(10.2)$ \\
\hline Age at follow-up (years) & $69.7(\mathrm{sd} \mathrm{11.1})$ & $69.5($ sd 9.7$)$ & $69.6(\mathrm{sd} \mathrm{10.3)}$ \\
\hline Follow-up duration (months) & $81.7(\operatorname{sd} 14.8)$ & $67.0(\mathrm{sd} 14.6)$ & $72.4(\mathrm{sd} \mathrm{16.3)}$ \\
\hline Harris Hip Score & 90.1 (sd II.3) & $93.9(\mathrm{sd} 8.2)$ & 92.5 (sd 9.6) \\
\hline $\begin{array}{l}\text { Charnley class } \\
\text { A } \\
\text { B } \\
\text { C }\end{array}$ & $\begin{array}{l}106(38.5 \%) \\
84(30.5 \%) \\
85(30.9 \%)\end{array}$ & $\begin{array}{c}193(40.3 \%) \\
205(42.8 \%) \\
81(16.9 \%)\end{array}$ & $\begin{array}{l}299(39.7 \%) \\
289(38.3 \%) \\
166(22.0 \%)\end{array}$ \\
\hline $\begin{array}{l}\text { Diagnosis } \\
\text { Idiopathic osteoarthritis } \\
\text { Avasc. Necrosis } \\
\text { Rheumatoid arthritis } \\
\text { Fracture }\end{array}$ & $\begin{array}{c}220(80.0 \%) \\
11(4.0 \%) \\
22(8.0 \%) \\
22(8.0 \%)\end{array}$ & $\begin{array}{c}412(86.0 \%) \\
6(1.3 \%) \\
20(4.2 \%) \\
41(8.6 \%)\end{array}$ & $\begin{array}{c}632(83.8 \%) \\
17(2.3 \%) \\
42(5.6 \%) \\
63(8.4 \%)\end{array}$ \\
\hline
\end{tabular}

Charnley class:

$\mathrm{A}=$ patient with unilateral osteoarthritis in whom no other condition interferes with walking

$\mathrm{B}=$ patient with bilateral osteoarthritis in whom no other condition interferes with walking

$\mathrm{C}=$ patient with unilateral or bilateral osteoarthritis with some factor that contributes to failure to achieve normal locomotion (polyarthritis, rheumatoid arthritis, senility, hemiplegia and cardiovascular or respiratory disability) [38] 


\section{Figure 3.6}

Relationship between Harris Hip Score and age of the patients with a Hochgezogen prosthesis. The difference between the age groups was not statistically significant

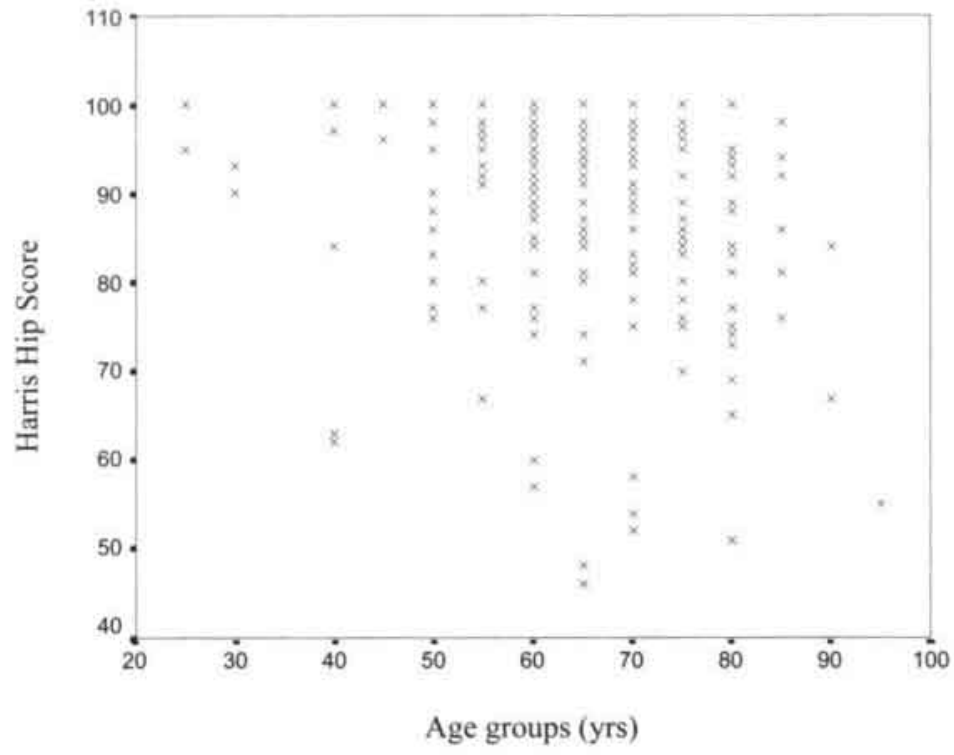

\section{Figure 3.7}

Relation between Harris Hip Score and age of the patients with a Stepless prosthesis.

The difference between the age groups was not statistically significant

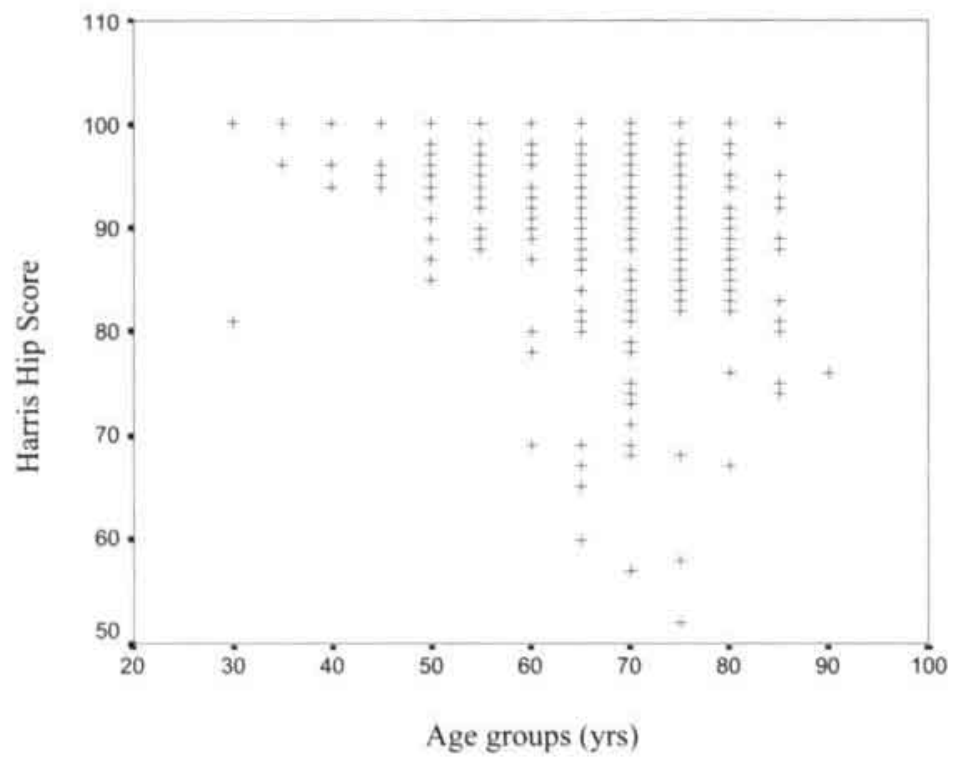


Figure 3.8

Relation between Harris Hip Score and follow-up duration in the patients with a Hochgezogen prosthesis.

The difference between the follow-up duration groups was not statistically significant

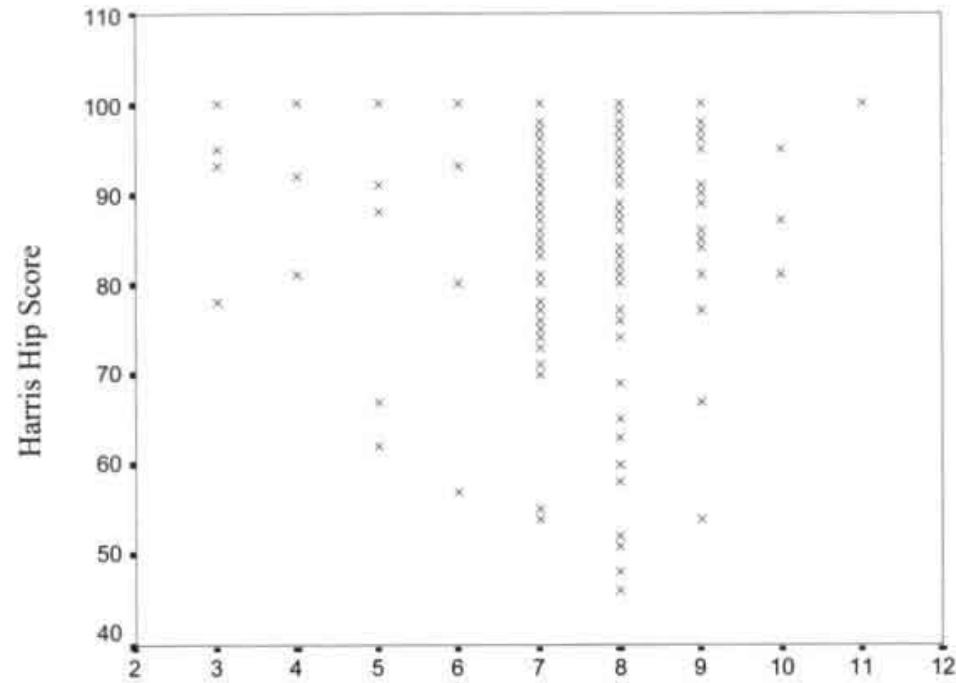

Follow-up period (yrs)

\section{Figure 3.9}

Relation between Harris Hip Score and follow-up duration in patients with a Stepless prosthesis. The difference between the follow-up duration groups was not statistically significant

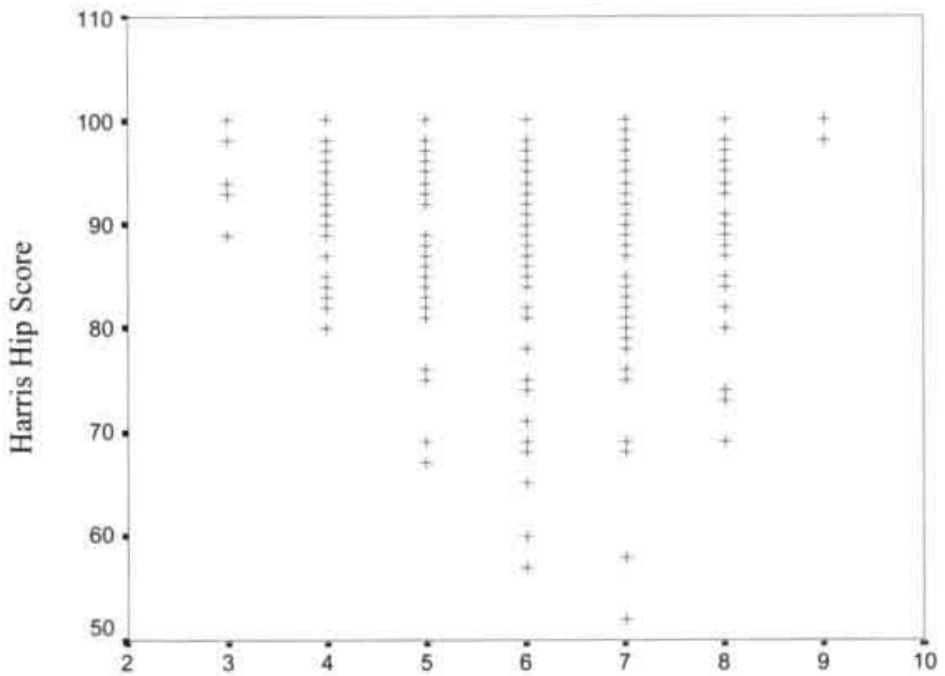

Follow-up period (yrs) 
Table 3.2

Clinical results of 670 patients with 754 prostheses

"**" means that for that function the difference between the two groups of stem prostheses was statistically different

\begin{tabular}{|c|c|c|c|c|}
\hline & & $\begin{array}{l}\text { Hochgezogen } \\
\text { prosthesis } \\
\text { Number }(\%) \\
(n=275)\end{array}$ & $\begin{array}{c}\text { Stepless prosthesis } \\
\text { Number }(\%) \\
(n=479)\end{array}$ & $\underset{(\mathrm{n}=754)}{\text { Total }}$ \\
\hline \multirow[t]{5}{*}{$\begin{array}{l}\text { Pain } \\
\mathrm{P}=0.007 \text { * }\end{array}$} & None or ignores & $218(79.0)$ & $424(88.7)$ & $642(85.2)$ \\
\hline & Slight & $40(14.5)$ & $44(9.1)$ & $84(11.2)$ \\
\hline & Mild & $10(4.0)$ & $7(1.4)$ & $17(2.2)$ \\
\hline & Marked & $6(2.0)$ & $4(0.8)$ & $10(1.3)$ \\
\hline & Totally disabled & $1(0.5)$ & 0 & $1(0.1)$ \\
\hline \multirow[t]{5}{*}{$\begin{array}{l}\text { Distance walking } \\
\mathrm{P}=0.001\end{array}$} & Unlimited & $149(54.2)$ & $347(72.4)$ & $496(65.8)$ \\
\hline & $800-1500 \mathrm{~m}$ & $57(20.7)$ & $79(16.5)$ & $136(18.0)$ \\
\hline & $150-800 \mathrm{~m}$ & $42(15.3)$ & $38(7.9)$ & $80(10.6)$ \\
\hline & Indoors only & $25(9.1)$ & $12(2.5)$ & $37(4.9)$ \\
\hline & Bed and chair & $2(0.8)$ & $3(0.6)$ & $5(0.7)$ \\
\hline \multirow[t]{6}{*}{$\begin{array}{l}\text { Walking support } \\
\mathrm{P}=0.175\end{array}$} & None & $199(72.4)$ & $368(76.8)$ & $56775.2)$ \\
\hline & $\begin{array}{l}\text { Cane for long } \\
\text { walk }\end{array}$ & $22(8.0)$ & $46(9.6)$ & $68(9.0)$ \\
\hline & $\begin{array}{l}\text { Cane most of the } \\
\text { time }\end{array}$ & $24(8.7)$ & $24(5.0)$ & $48(6.4)$ \\
\hline & One crutch & $6(2.2)$ & $4(0.8)$ & $10(1.3)$ \\
\hline & Two crutches & $21(7.6)$ & $34(7.1)$ & $55(7.3)$ \\
\hline & Not able to walk & $3(1.1)$ & $3(0.6)$ & $6(0.8)$ \\
\hline \multirow[t]{4}{*}{$\operatorname{Limp}_{\mathrm{P}=0.001}$ * } & None & $211(77.0)$ & $418(87)$ & $629(83.4)$ \\
\hline & Slight & $41(14.9)$ & $47(9.8)$ & $88(11.7)$ \\
\hline & Moderate & $13(4.7)$ & $13(2.7)$ & $26(3.4)$ \\
\hline & Severe & $10(3.6)$ & $\mathrm{I}(0.2)$ & $11(1.5)$ \\
\hline \multirow[t]{4}{*}{$\begin{array}{l}\text { Stairs } \\
\mathrm{P}=0.001 \text { * }\end{array}$} & Normally & $108(39.3)$ & $243(50.7)$ & $351(46.6)$ \\
\hline & Using a railing & $116(42.2)$ & $190(39.7)$ & $306(40.6)$ \\
\hline & In any manner & $18(6.5)$ & $2(0.4)$ & $20(2.7)$ \\
\hline & Unable & $33(12.0)$ & $44(9.2)$ & $77(10.2)$ \\
\hline \multirow[t]{3}{*}{$\begin{array}{l}\text { Shoes and socks } \\
P=0.72\end{array}$} & With ease & $189(68.7)$ & $341(71.2)$ & $530(70.3)$ \\
\hline & With difficulty & $68(24.7)$ & $112(23.4)$ & $180(23.9)$ \\
\hline & Unable & $18(6.5)$ & $26(5.4)$ & $44(5.8)$ \\
\hline \multirow[t]{3}{*}{$\begin{array}{l}\text { Sitting } \\
\mathrm{P}=0.001\end{array}$} & $\begin{array}{l}\text { Comfortably any } \\
\text { chair one hour }\end{array}$ & $234(85.1)$ & $451(94.2)$ & $685(90.8)$ \\
\hline & $\begin{array}{l}\text { High chair half } \\
\text { an hour }\end{array}$ & $41(14.9)$ & $28(5.8)$ & $69(9.2)$ \\
\hline & $\begin{array}{l}\text { Unable to sit } \\
\text { comfortably }\end{array}$ & 0 & 0 & 0 \\
\hline $\begin{array}{l}\text { Public Transportation } \\
\mathrm{P}=0.124\end{array}$ & Able & $270(98.2)$ & $476(99.4)$ & $746(98.9)$ \\
\hline & Unable & $5(1.8)$ & $3(0.6)$ & $8(1.1)$ \\
\hline
\end{tabular}


Re-intervention had been performed in twenty patients (Table 3.3). A total of 83 complications had occurred in the 670 patients (754 prostheses). The most common complication was dislocation $(n=40)$ (Table 3.4). These dislocated hips had been treated by closed manipulation. In the postoperative period, seven patients had developed deep vein thrombosis. There were no cases of lung embolism or death during the postoperative period.

Table 3.3

Number of re-interventions in the cohort of 754 cementless Zweymuller total hip prostheses (670 patients)

\begin{tabular}{|c|c|c|}
\hline $\begin{array}{l}\text { Indication } \\
\text { Re-intervention }(n=20)\end{array}$ & $\begin{array}{l}\text { Number of } \\
\text { prostheses }\end{array}$ & Re-intervention surgery \\
\hline $\begin{array}{l}\text { Fracture of ceramic head } 6 \text { years } \\
\text { after primary surgery }\end{array}$ & 1 & Ceramic head and insert replacement \\
\hline Leg length difference & 2 & $\begin{array}{l}\text { Stem revision directly and } 3 \text { days } \\
\text { postoperatively }\end{array}$ \\
\hline Dislocation & 8 & Antiluxation insert replacement \\
\hline Brooker IV P.A.O. & 7 & P.A.O. removal \\
\hline $\begin{array}{l}\text { Traumatic acetabular fracture } 14 \\
\text { days after primary surgery }\end{array}$ & 1 & Cup revision \\
\hline $\begin{array}{l}\text { Traumatic femoral fracture } 3 \\
\text { weeks after primary surgery }\end{array}$ & 1 & Cerclage \\
\hline
\end{tabular}

Table 3.4

Complications after 754 cementless Zweymüller total hip prostheses (670 patients)

\begin{tabular}{|l|c|c|}
\hline $\begin{array}{l}\text { Complication } \\
\text { ( } \mathrm{n}=\mathbf{8 3} \text { in } 71 \text { operations) }\end{array}$ & $\begin{array}{l}\text { Number of } \\
\text { prostheses }\end{array}$ & Percentage of prostheses $(\mathbf{n}=\mathbf{7 5 4})$ \\
\hline Dislocation $<6$ weeks & 28 & 3.7 \\
\hline Dislocation $>6$ weeks & 12 & 1.6 \\
\hline Haematoma & 27 & 3.6 \\
\hline Superficial wound infection & 6 & 0.79 \\
\hline Deep wound infection (all revised) & 3 & 0.39 \\
\hline Trombosis & 7 & 0.93 \\
\hline
\end{tabular}


At follow-up, eighty-five per cent of the prostheses $(n=642)$ were pain-free. The remaining $14.9 \%(n=112)$ had slight to moderate pain in the groin, upper leg or lateral hip region. In one patient $(0.13 \%)$ with severe pain, subsidence of $4 \mathrm{~mm}$ was visible on the X-ray. Radiologically, the HG stem appeared to be loosened, but the patient refused revision. Eight patients $(1.06 \%)$ had 'mid-thigh' pain. These complaints were transient and had a mean duration of six months. No prostheses had been revised because of mid-thigh pain.

The X-rays from the whole cohort showed line formation in zone 1 in $12 \%(n=90)$ and in zone 7 in $10 \%(n=74)$. Bone apposition was judged to be present in zone 4 on $53 \%(n=395)$ of the X-rays. Cortical reactions were visible in zone 3 in $21 \%$ $(n=161)$ and in zone 5 in $24 \%(n=181)$ (Table 3.5). When we compared the Harris Hip Scores of the patients without these radiological abnormalities who had the same duration of follow-up, no differences were observed ( $p>0.05$ ). Radiological analyses of the HG and the SL stem prostheses are compared in Table 3.5 and Figure 3.3. More radiolucent lines were present in the proximal zones in patients with the HG stem prosthesis.

Table 3.5

Radiolucent lines in zones 1 and 7 , cortical reactions in zones 3 and 5 and bone apposition in zone 4

\begin{tabular}{|c|c|c|c|}
\hline & $\begin{array}{c}\text { Hochgezogen prosthesis } \\
(n=266)(\%) \\
\text { FU duration } 81.7 \\
\text { months }\end{array}$ & $\begin{array}{c}\text { Stepless prosthesis } \\
(n=474)(\%) \\
\text { FU duration } 67.0 \text { months }\end{array}$ & $\begin{array}{c}\text { total group } \\
(n=740)(\%) \\
\text { FU duration } 72.4 \text { inonths }\end{array}$ \\
\hline $\begin{array}{l}\text { radiolucent line in } \\
\text { zone I }\end{array}$ & SI $(19.2 \%)$ & $39(8.2 \%)$ & $90(12.2 \%)$ \\
\hline $\begin{array}{l}\text { radiolucent line in } \\
\text { zone } 7\end{array}$ & $39(14.7 \%)$ & $35(7.4 \%)$ & $74(10 \%)$ \\
\hline $\begin{array}{l}\text { cortical reaction in } \\
\text { zone } 3\end{array}$ & $79(29.7 \%)$ & $82(17.3 \%)$ & $161(21.8 \%)$ \\
\hline $\begin{array}{l}\text { cortical reaction in } \\
\text { zone } 5\end{array}$ & $73(27.4 \%)$ & $108(22.8 \%)$ & $181(24.5 \%)$ \\
\hline $\begin{array}{l}\text { bone apposition in } \\
\text { zone } 4\end{array}$ & $130(48.9 \%)$ & $265(55.9 \%)$ & $395(53.4 \%)$ \\
\hline
\end{tabular}

Osteolysis was visible in zone 6 (medial cortex distally from the trochanter minor) on the X-rays of five patients (two with an HG stem prosthesis and three with an SL stem prosthesis). Their mean Harris Hip Score (83.2) was lower than that of the other patients $(\mathrm{p}=0.028)$. Only one patient complained of slight pain in the upper leg. We saw no signs of stem migration in these five patients. 
In 226 patients, the femoral stem was in the varus position (Table 3.6). The patients with an SL stem prosthesis in the varus position had a higher Harris Hip Score than the patients whose femoral stem was in the neutral position $(\mathrm{p}=0.001)$. The eight patients with an HG prosthesis in the valgus position had a lower Harris Hip Score than the patients with a neutral or varus position $(\mathrm{p}<0.024)$. In the whole group, the differences in Harris Hip Score between the stem prostheses in varus, neutral and valgus position were significantly different $(\mathrm{p}<0.047)$.

Table 3.6

Position of the femoral stem in 740 cementless Zweymuller total hip prostheses

\begin{tabular}{|l|c|c|c|}
\hline Position of the prosthesis & $\begin{array}{c}\text { Hochgezogen prosthesis } \\
(\mathrm{n}=266)(\%)\end{array}$ & $\begin{array}{c}\text { Stepless prosthesis } \\
(\mathbf{n}=474)(\%)\end{array}$ & $\begin{array}{c}\text { Total } \\
(\mathrm{n}=740)(\%)\end{array}$ \\
\hline $\begin{array}{l}\text { varus } \\
\text { Harris Hip Score (sd) }\end{array}$ & $\begin{array}{c}\mathrm{n}=65(24.5) \\
89.4(10.0)\end{array}$ & $\begin{array}{c}\mathrm{n}=161(34.0) \\
95.6(6.5)\end{array}$ & $\begin{array}{c}\mathrm{n}=226(30.6) \\
93.8(8.1)\end{array}$ \\
\hline $\begin{array}{l}\text { neutral } \\
\text { Harris Hip Score (sd) }\end{array}$ & $\begin{array}{c}\mathrm{n}=193(72.5) \\
91.2(10.9)\end{array}$ & $\begin{array}{c}\mathrm{n}=309(65.2) \\
93.1(8.9)\end{array}$ & $\begin{array}{c}\mathrm{n}=502(67.8) \\
92.3(9.8)\end{array}$ \\
\hline $\begin{array}{l}\text { valgus } \\
\text { Harris Hip Score (sd) }\end{array}$ & $\begin{array}{c}\mathrm{n}=8(3.0) \\
79.9(17.6)\end{array}$ & $\begin{array}{c}\mathrm{n}=4(0.8) \\
93.2(4.4)\end{array}$ & $\begin{array}{c}\mathrm{n}=12(1.6) \\
84.3(15.6)\end{array}$ \\
\hline
\end{tabular}

There was no heterotopic ossification in $57 \%$ of the prostheses $(n=424)$. Brooker grade 4 ossification had been removed from seven patients and there had been no recurrence. The other patients with Brooker grade 3 or 4 had a lower Harris Hip Score than the patients with Brooker grade 1 or $2(\mathrm{p}<0.036)$ (Table 3.7$)$.

In $10 \%$ of the prostheses $(n=75)$, there was moderate resorption of the calcar (Table 3.8). Only the Harris Hip Scores of the patients with an HG prosthesis with moderate resorption were higher than those of patients without resorption $(\mathrm{p}=0.001)$. An inclination of more than 60 degrees was measured in forty-three acetabular cups $(5.8 \%)$. Nine cups $(1.2 \%)$ had migrated. Three of these cups have been revised since this study.

Table 3.7

Degree of heterotopic ossification in 740 cementless Zweymüller total hip prostheses [26]

\begin{tabular}{|l|c|c|c|c|c|}
\hline Brooker & 0 & 1 & 2 & 3 & 4 \\
\hline Number prostheses (\%) & $424(57.3)$ & $153(20.7)$ & $82(11.1)$ & $75(10.1)$ & $6(0.8)$ \\
\hline Harris Hip Score (sd) & $92.7(9.7)$ & $93.1(8.9)$ & $94.1(7.3)$ & $90.1(11.1)$ & $83.8(15.9)$ \\
\hline
\end{tabular}


Table 3.8

Calcar remodelling in 740 cementless Zweymúller total hip prostheses

\begin{tabular}{|l|c|c|c|}
\hline $\begin{array}{l}\text { Caicar remodelling } \\
\text { Hochgezogen prosthesis } \\
(\mathrm{n}=266)(\%)\end{array}$ & $\begin{array}{c}\text { Stepless prosthesis } \\
(\mathrm{n}=474)(\%)\end{array}$ & $\begin{array}{c}\text { Total } \\
(\mathbf{n}=740)(\%)\end{array}$ \\
\hline $\begin{array}{l}\text { atrophy } \\
\text { Harris Hip Score (sd) }\end{array}$ & $\begin{array}{c}\mathrm{n}=43(16.2 \%) \\
95.5(5.8)\end{array}$ & $\begin{array}{c}\mathrm{n}=32(6.8 \%) \\
92.8(8.9)\end{array}$ & $\begin{array}{c}\mathrm{n}=75(10 \%) \\
94.4(7.4)\end{array}$ \\
\hline $\begin{array}{l}\text { unchanged } \\
\text { Harris Hip Score (sd) }\end{array}$ & $\mathrm{n}=222(83.4 \%)$ & $\mathrm{n}=436(91.9 \%)$ & $\mathrm{n}=658(88.9 \%)$ \\
$99.2(11.8)$ & $94.0(8.9)$ & $92.4(9.8)$ \\
\hline $\begin{array}{l}\text { hypertrophy } \\
\text { Harris Hip Score (sd) }\end{array}$ & $\mathrm{n}=1(0.4 \%)$ & $\mathrm{n}=6(1.3 \%)$ & $\mathrm{n}=7(0.9 \%)$ \\
$93(-)$ & $94.8(3.6)$ & $93.1(5.6)$ \\
\hline
\end{tabular}

Kaplan-Meier analysis showed a survival of $98.5 \%\left(\mathrm{CI}_{95} 99.9-97.1 \%\right)$ for aseptic loosening of the threaded titanium cup after 85.5 months (Figure 3.10). The lifetable showed that the probability of cup revision because of aseptic loosening was $0.9 \%\left(\mathrm{CI}_{95} 0-1.3 \%\right)$ after 84 months (Table 3.9). Calculated worst scenario rates for survival were $95.2 \%\left(\mathrm{CI}_{95} 97.7-92.6 \%\right)$ after 85.5 months and in the lifetable $3.88 \%\left(\mathrm{CI}_{95} 1.82-5.94 \%\right)$ after 84 months (Figure 3.11, Table 3.10).

\section{Figure 3.10:}

Survival curve of the acetabular cup [148].

Cumulative survival of the prosthesis after 85.5 months for aseptic loosening of the cup was $98.5 \%\left(\mathrm{CI}_{95}\right.$ $99.9-97.1 \%$ ). At the time 37 months, twice at time 64 months, 58 months, 72 and 85 months there was a revision of the cup due to aseptic loosening. 40 patients died of causes not related to the prosthesis

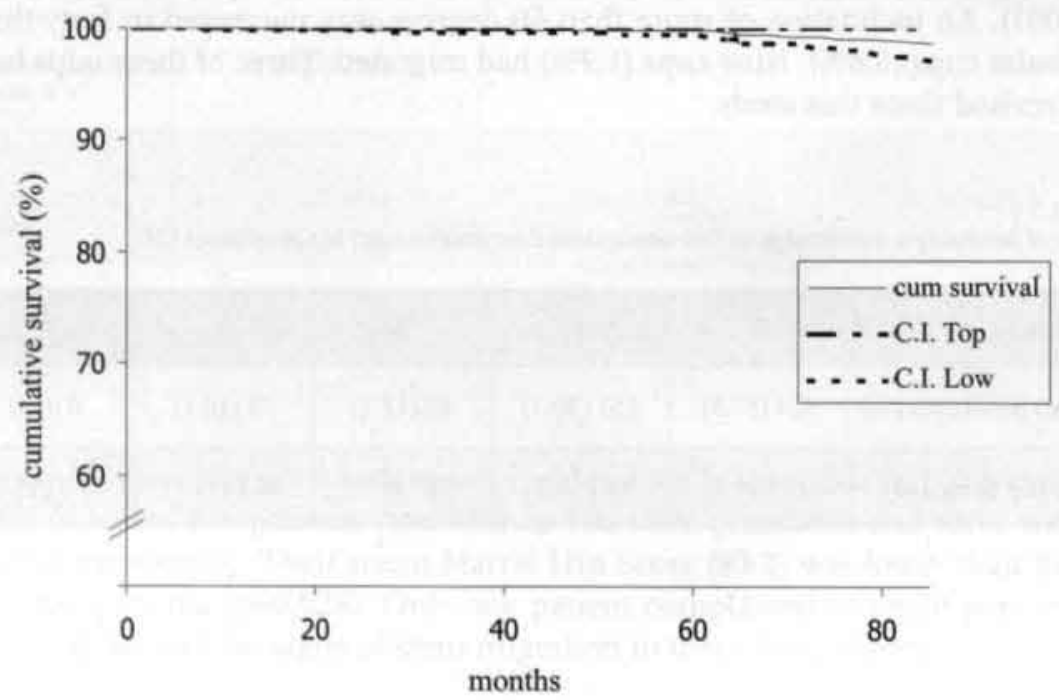


Table 3.9

Lifetable: 84.0 months after the operation the probability of having aseptic loosening of the cup was $0.9 \%\left(\mathrm{Cl}_{\mathrm{*}} \mathrm{0}-1.3 \%\right)$. After that time, the number of patients at risk was too small to make any reasonable predictions

\begin{tabular}{|c|c|c|c|c|c|c|}
\hline $\begin{array}{l}\text { Months since } \\
\text { operation }\end{array}$ & $\begin{array}{c}\text { Number at } \\
\text { start }\end{array}$ & Withdrawn & $\begin{array}{l}\text { Number at } \\
\text { risk }\end{array}$ & Failure & $\begin{array}{c}\text { Survival rate } \\
(\%)\end{array}$ & $\begin{array}{l}\text { SE survival } \\
\text { rate }(\%)\end{array}$ \\
\hline 0 to 6 & 820 & 3 & 818.5 & 0 & 100 & 0 \\
\hline 6 to 12 & 817 & 3 & 815.5 & 0 & 100 & 0 \\
\hline 12 to 18 & 814 & 2 & 813 & 0 & 100 & 0 \\
\hline 18 to 24 & 812 & 2 & 811 & 0 & 100 & 0 \\
\hline 24 to 30 & 810 & 5 & 807.5 & 0 & 100 & 0 \\
\hline 30 to 36 & 805 & 10 & 800 & 0 & 100 & 0 \\
\hline 36 to 42 & 795 & 25 & 782.5 & 1 & 99.87 & 0.13 \\
\hline 42 to 48 & 769 & 57 & 740.5 & 0 & 99.87 & 0.13 \\
\hline 48 to 54 & 712 & 51 & 686.5 & 0 & 99.87 & 0.13 \\
\hline 54 to 60 & 661 & 51 & 635.5 & 1 & 99.72 & 0.2 \\
\hline 60 to 66 & 609 & 73 & 572.5 & 2 & 99.37 & 0.32 \\
\hline 66 to 72 & 534 & 76 & 496 & 0 & 99.37 & 0.32 \\
\hline 72 to 78 & 458 & 117 & 399.5 & 1 & 99.12 & 0.4 \\
\hline 78 to 84 & 340 & 147 & 266.5 & 0 & 99.12 & 0.4 \\
\hline 84 to 90 & 193 & 109 & 138.5 & 1 & 98.4 & 0.82 \\
\hline
\end{tabular}

\section{Figure 3.11}

Worst case scenario survival curve [230]

Cumulative worst case survival (see text for the inclusion criteria) was $95.2 \%\left(\mathrm{Cl}_{95} 97.7-92.6 \%\right)$ after 85.5 months

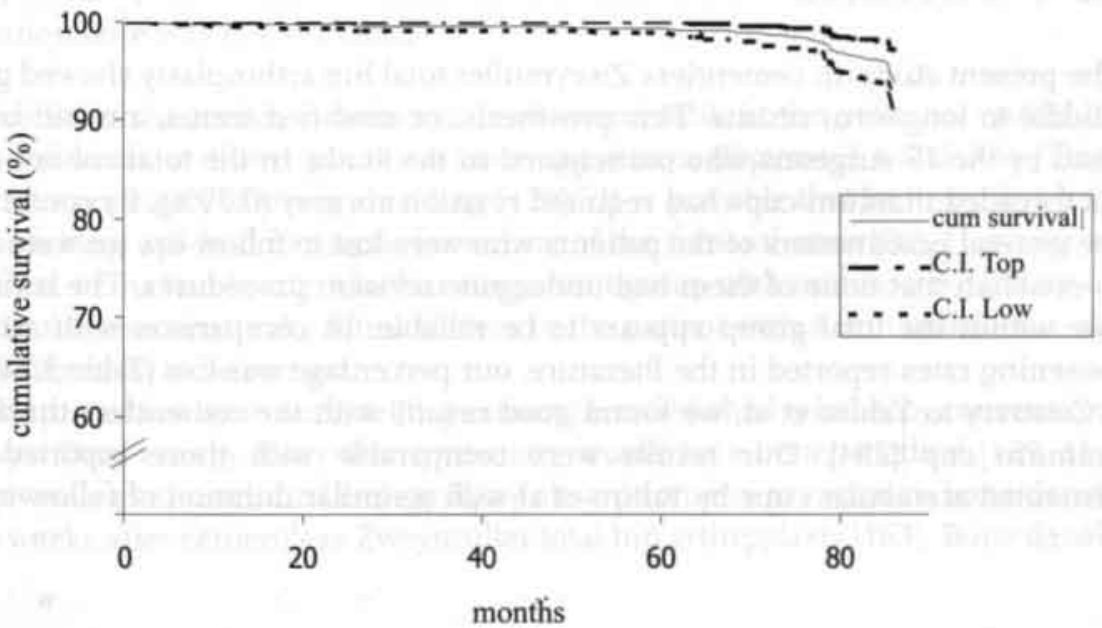


Table 3.10

Worst case scenario lifetable [230]: probability for revision of the prosthesis (see text for inclusion criteria) was $3.88 \%\left(\mathrm{Cl}_{95} 1.82-5.94 \%\right)$ after 84 months

\begin{tabular}{|c|c|c|c|c|c|c|}
\hline $\begin{array}{c}\text { Months since } \\
\text { operation }\end{array}$ & $\begin{array}{c}\text { Number at } \\
\text { start }\end{array}$ & Withdrawn & $\begin{array}{c}\text { Number at } \\
\text { risk }\end{array}$ & Failure & $\begin{array}{c}\text { Survival } \\
\text { rate (\%) }\end{array}$ & $\begin{array}{c}\text { SE survival } \\
\text { rate (\%) }\end{array}$ \\
\hline 0 to 6 & 820 & 3 & 818.5 & 0 & 100.00 & 0 \\
\hline 6 to 12 & 817 & 3 & 815.5 & 0 & 100.00 & 0 \\
\hline 12 to 18 & 814 & 1 & 813.5 & 1 & 99.88 & 0.12 \\
\hline 18 to 24 & 812 & 1 & 811.5 & 1 & 99.75 & 0.17 \\
\hline 24 to 30 & 810 & 4 & 808 & 1 & 99.63 & 0.21 \\
\hline 30 to 36 & 805 & 10 & 800 & 0 & 99.63 & 0.21 \\
\hline 36 to 42 & 795 & 25 & 782.5 & 1 & 99.50 & 0.25 \\
\hline 42 to 48 & 769 & 57 & 740.5 & 0 & 99.50 & 0.25 \\
\hline 48 to 54 & 712 & 51 & 686.5 & 0 & 99.50 & 0.25 \\
\hline 54 to 60 & 661 & 51 & 635.5 & 1 & 99.35 & 0.29 \\
\hline 60 to 66 & 609 & 73 & 572.5 & 2 & 99.00 & 0.38 \\
\hline 66 to 72 & 534 & 75 & 496.5 & 1 & 98.80 & 0.43 \\
\hline 72 to 78 & 458 & 116 & 400 & 2 & 98.31 & 0.55 \\
\hline 78 to 84 & 340 & 141 & 269.5 & 6 & 96.12 & 1.03 \\
\hline 84 to 90 & 193 & 106 & 140 & 4 & 93.37 & 1.69 \\
\hline 90 to 96 & 83 & 46 & 60 & 4 & 87.15 & 3.39 \\
\hline
\end{tabular}

\subsection{DISCUSSION}

The present study on cementless Zweymüller total hip arthroplasty showed good middle to long-term results. This prosthesis, or modified forms, are still being used by the 17 surgeons who participated in the study. In the total cohort, only six threaded titanium cups had required revision surgery $(0.79 \%)$. By contacting the general practitioners of the patients who were lost to follow-up, we were able to establish that none of them had undergone revision procedures. The revision rate within the total group appears to be reliable. In comparison with aseptic loosening rates reported in the literature, our percentage was low (Table 3.11).

Contrary to Yahiro et al, we found good results with the cementless threaded titanium cup [284]. Our results were comparable with those reported for cemented acetabular cups by Yahiro et al with a similar duration of follow-up ( 6 
versus 6.8 years). However, in our study, the revision rate for cups was lower than that reported by Yahiro et al $(0.79 \%$ versus $1.61 \%)$.

Table 3.11

Literature data on various cementless total hip prostheses

\begin{tabular}{|c|c|c|c|c|c|c|}
\hline Author & $\begin{array}{l}\text { No. of } \\
\text { patients/ } \\
\text { prostheses }\end{array}$ & $\begin{array}{l}\text { Type of } \\
\text { prosthesis }\end{array}$ & $\begin{array}{l}\text { Average } \\
\text { age (years) }\end{array}$ & $\begin{array}{l}\text { Average } \\
\text { follow-up } \\
\text { (years) }\end{array}$ & $\begin{array}{l}\text { Harris } \\
\text { Hip Score }\end{array}$ & $\begin{array}{l}\text { Aseptic } \\
\text { loosening } \\
\text { cup/stem/ } \\
\text { Both }\end{array}$ \\
\hline Kutschera [167] & $85 / 96$ & Zweymüller SL & $67(41-87)$ & $\begin{array}{c}5.3 \\
(5.0-5.9)\end{array}$ & $\begin{array}{c}87 \\
(37-100)\end{array}$ & $1 / 0 / 0$ \\
\hline Engh [77] & $167 / 174$ & AML & $54(16-79)$ & $11(10-13)$ & - & $4 / 3 / *$ \\
\hline Geesink [101] & $99 / 118$ & Omnifit HAP & $53(21-65)$ & $\begin{array}{c}6.2 \\
(5.6-7.6) \\
\end{array}$ & 98 & $0 / 0 / 0$ \\
\hline Huo [133] & $86 / 99$ & $\begin{array}{l}\text { Keramische } \\
\text { Mittelmeier }\end{array}$ & $56(18-73)$ & $8.9(5-11)$ & $\begin{array}{c}89 \\
(42-100) \\
\end{array}$ & $1 / 0 / 4$ \\
\hline Loupasis [179] & $71 / 77$ & Furlong HAP & $55(37-67)$ & $\begin{array}{c}5.5 \\
(4.0-7.0)\end{array}$ & $\begin{array}{c}89 \\
(47-100)\end{array}$ & $2 / 0 / 0$ \\
\hline Tompkins [264] & $157 / 173$ & $\begin{array}{c}\text { Harris Gallante } \\
\text { PCA }\end{array}$ & $52(20-84)$ & $\begin{array}{c}8.6 \\
(6.5-12.5) \\
\end{array}$ & $\begin{array}{c}90 \\
(44-100) \\
\end{array}$ & $0 / 18 / 2$ \\
\hline $\begin{array}{l}\text { Vervest } \\
\text { present study }\end{array}$ & $670 / 754$ & $\underset{\& \text { SL }}{\text { Zweymüller HG }}$ & $64(23-93)$ & $\begin{array}{c}6 \\
(2.4-10.3)\end{array}$ & $\begin{array}{c}92.5 \\
\text { (sd 9.6) }\end{array}$ & $6 / 0 / 0$ \\
\hline
\end{tabular}

".*" means "not mentioned"

We used the Harris Hip Score to evaluate the results of total hip arthroplasty, because this scoring system can be considered as the golden standard [112, 212]. Furthermore, the questions to establish a Harris Hip Score have been translated into the Dutch language [18]. 'Quality of life' was not measured, because at the time of this cohort study, a validated translated Dutch version of a hip-specific questionnaire was not available.

On some of the X-rays, radiolucent lines were visible at the proximal end of the femoral stem, or there was distal bone apposition (Figures 3.4 and 3.5). These features are signs of stress shielding [129]. It is possible that in time, this bone remodelling will lead to aseptic loosening of the femoral stem [29]. However, no femoral stems had been revised in our patient group with middle-term follow-up, but in the near future the femoral stem in the patient with $4 \mathrm{~mm}$ subsidence will probably need to be revised.

The process of bone remodelling cannot be established reliably by conventional X-rays. Dual energy X-ray absorptiometry would be a better method [129, 162]. Korovessis et al used dual energy X-ray absorptiometry to measure bone density two weeks after cementless Zweymüller total hip arthroplasty [163]. Bone density 
was significantly lower than the preoperative value, but at 1 and 4-years followup, the value had remain stable. The removal of bone during the operation was believed to be responsible for the postoperative decrease in bone density. Although we did not measure bone density in our patients using dual energy $\mathrm{X}$-ray absorptiometry, it can be assumed on the basis of our study results that cementless Zweymüller total hip arthroplasty does not cause any clinically relevant bone remodelling.

In this study, no relationship was found between the radiological findings and the Harris Hip Score which confirms reports in the literature that radiological findings do not always agree with the clinical results [234]. Evaluation of radiological parameters provides an accurate estimate of the success and fixation of a prosthesis. Similarly, clinical evaluation gives information about patient satisfaction, function, pain complaints, etc. A major disadvantage of the Harris Hip Score (and many other rating scores) is that it has an ordinal character. Many patients have a score in the good or excellent classes, but the Harris Hip Score does not always differentiate adequately between good and poor cases. For instance, in this study, aseptic loosening of the cup was detected on the radiograph of a patient who had a Harris Hip Score of 80 points. Therefore, both radiological and clinical evaluations should be made $[142,150]$.

The majority of patients did not have any heterotopic ossification. Grade 4 heterotopic ossifications had been removed from seven patients. At some point (the exact date is unknown), NSAIDs were introduced to prevent such ossification. The value of NSAIDs was confirmed by our observation that the number of patients with grade 0 heterotopic ossification increased in the patients who had been operated on towards the end of the study [160, 282].

In a micrographic and histological study, Lintner et al found that the SL stem prosthesis had better osteointegration than the HG stem due to different morphology and metallurgy [175]. We also observed more HG stems than SL stems with atrophy in the calcar region. The patients with calcar atrophy had higher Harris Hip Scores, probably due to fewer pain complaints. Engh et al developed the fixation and stability score, with the item "calcar atrophy" as a sign of implant stability (Appendix 1) [82]. Calcar atrophy can be explained as stress shielding bypass with proximal bone loss as a result of progressive distal fixation (Chapter 1.5). Thus, our results could indicate progressive fixation of the HG stem prosthesis with diminishing pain complaints. Additionally, more proximal radiolucent lines were seen in the HG stem prosthesis group. Proximal radiolucent lines can also be seen as stress shielding bypass; they reflect distal fixation of the HG stem prosthesis. However, when we compared the group of patients with an HG stem prosthesis to those with an SL stem prosthesis, we found higher Harris Hip Scores in the SL stem prosthesis group. Statistical analysis revealed that the 
differences were related to fewer pain complaints and higher scores for gait and daily activities in the group with an SL stem prosthesis.

As unbiased researchers, we assessed the outcome of the prosthesis implanted by surgeons who had not been aware of this study at the time of surgery. We believe that our results have been determined accurately. According to Justice et al this study showed independent validation [145]. Further follow-up study of this cohort will establish whether the good results are maintained in the long-term.

\subsection{CONCLUSION}

This historic cohort study on 670 patients with 754 Zweymüller cementless total hip prostheses (275 HG and 479 SL stem prostheses, all with a ceramic head and a threaded titanium cup) showed favourable clinical results with the HG and SL stem prostheses. Only six threaded titanium cups were revised due to aseptic loosening. The stem prosthesis did not cause any clinically relevant bone remodelling. Further studies are required to establish whether the good results of this prosthesis are maintained in the long-term. 



\section{Bone Mineral Density 10 Years after Recieving the Zweymüller Cementless Stem Prosthesis}

\subsection{ABSTRACT}

Dual-energy X-ray absorptiometry was used to examine long-term femoral bone remodelling in patients who had received a Zweymüller cementless stem prosthesis. Thirty-two patients ( 11 men, 21 women) with a unilateral prosthesis (18 Hochgezogen and 14 Stepless) were scanned an average of 129.8 months after the index operation. The average Harris Hip Score was 93.7; ten patients were classified as Charnley class A, two patients as class B and 20 patients as class $\mathrm{C}$. The patient group had a moderate activity level and most of the patients were satisfied with the result of the operation. All the stem prostheses showed osseointegration.

BMD measurements on the non-operated contralateral femur were used to detect changes in the femur around the prosthesis. Bone mineral density was decreased in the region of the calcar on the side with the prosthesis. There were no signs of clinical decline or radiographic abnormalities. 
Wolff's law states that bone reacts to the stress applied [128, 278]. Therefore, an endoprosthesis can be expected to cause changes in the surrounding bone stock. The extent of bone remodelling depends on several factors, such as the preoperative bone mineral density, biological status, interface bonding and the biomechanical behaviour of the prosthesic material [189, 231]. A stiff prosthesis induces more stress shielding and more bone resorption than a flexible stem [15, $85,131]$. Bone resorption has been reported in the proximal femur $[129,155,162$, 194]. On the other hand, Engh et al found spot welds, i.e. new bone formation that bridged the endosteal surface of the bone, around the whole prosthesis as a result of stress [82]. These spot welds could be a sign of progressive fixation of the stem. It is still unclear whether stress shielding induces implant failure [29].

In the historical cohort study, we confirmed good mid-term results with the Zweymüller prosthesis. On $53 \%$ of the X-rays, bone apposition was seen around the distal tip of the stem. Cortical reactions, defined as increased density of the whole bone around the prosthesis, were found in Gruen zone $3(21 \%)$ and in Gruen zone $5(24 \%)$. Radiolucent line formation was visible at the proximal end of the stem prosthesis in Gruen zone $1(12 \%)$ and in Gruen zone $7(10 \%)$. This indicated that the prosthesis had caused proximal bone loss and a distal increase in cortical bone (Figure 4.1). There were no cases of aseptic loosening of the femoral stem.

Bone mass cannot be established reliably on conventional X-rays $[86,159,205,239]$. Dualenergy X-ray absorptiometry (DEXA) is a sensitive technique to assess bone stock and to quantify the process of bone remodelling produced by a femoral prosthesis $[8,42,147,205,273,275]$. In

Figure 4.1

Radiolucent lines in Gruen zones 1 and 7 ; bone apposition in zone 4

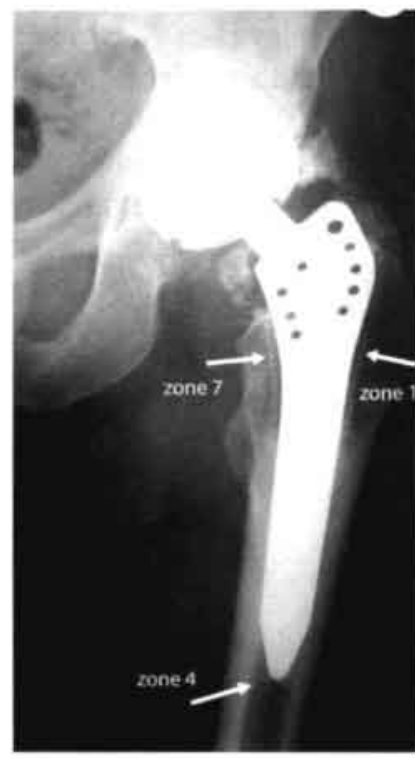
a prospective study, Korovessis et al found that shortly after implantation of the Zweymüller femoral stem, the bone mineral density (BMD) decreased, but that this reduction was not progressive four years after implantation [163]. They concluded that the Zweymuller stem prosthesis did not induce any significant bone loss or bone thickening.

The aim of this study was to investigate bone mineral density in a subset of patients in the historical cohort, ten years after implantation of the cementless Zweymüller stem prosthesis. 
Only patients with a unilateral hip prosthesis were included in this study. Implantation had taken place between 1 January 1987 and 31 December 1990. To minimize confounding by bone mineralization, participants were selected on the basis of idiopathic osteoarthritis and an age of between 50 and 70 years at the time of surgery. Thus, any differences in bone mineralization could be attributed to the presence of a prosthesis in one of the femora. A total of 52 patients met these criteria. None of them had undergone revision procedures. The Hochgezogen (HG) prosthesis and Stepless (SL) stem prosthesis were evaluated. They all had a ceramic head and a CSF threaded cup.

Densitometry was done with one DEXA device, thus all the patients had to travel to the same hospital. Twenty patients could not be scanned: seven patients had died of causes unrelated to the index operation, two patients could not be reached by telephone at the time of the investigation, seven patients refused because of the travelling distance (although we offered financial compensation for the travelling expenses), one patient could not travel due to poor physical health, one patient had left the country and one patient refused to participate. One patient who agreed to participate in the study, collapsed due to a febrile illness (erysipelas) at the time of scanning.

Dual-energy X-ray absorptiometry was performed with Hologic QDR 4500 Elite equipment (Amphia Hospital, Oosterhout). Line spacing was $1 \mathrm{~mm}$, while the point resolution was $0.5 \mathrm{~mm}$. The patient's leg was positioned in a foot jig to ensure constant hip endorotation (Figure 1.2). The quality of the DEXA scanner was inspected using a phantom model with standard fixed density. The patients were scanned over a period of three days; the equipment was checked each day. To compare the DEXA measurements to the results of conventional X-rays, seven regions of interest were defined around the stem prosthesis, according to Gruen et al [107].

The contralateral femoral head, without any previous surgery, was used to standardize the interpatient variation in bone stock quality. We determined the bone mineralisation status of the patients by measuring the BMD in Ward's Triangle and the total femoral head. Ward's Triangle is the area in the femoral neck that is most sensitive to loss of trabecular bone $[154,268]$. On the other hand, total femoral head measurements are more commonly used in the assessment of bone mineralization status [268]. We decided to assess bone mineralization in both areas and compare the results (Figure 4.2).

Figure 4.2: Bone mineral density measurements in Ward's Triangle (small square) and the total femoral head (upper. on DEXA scan; lower illustration)
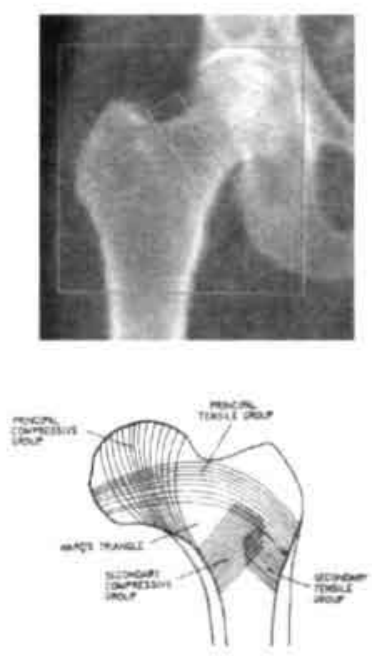
In the guidelines of the World Health Organisation, a BMD value with a T-score of less than -2.5 times the standard deviation is classified as osteoporotic; between -1 and - 2.5 it is classified as osteopenic and above -1 it is classified as normal [279]. To compare BMDs on the prosthesis side to BMDs on the contralateral side, the prosthesis was transposed digitally as described by Martini et al [194]. BMD and BMC values were calculated in seven regions of interest in each femur (Figure 4.3).

The scans were performed by two radiographers. To assess the inter and intra-observer variability in the definition of the seven regions of interest, two patients were analysed on five different occasions by each radiographer, and the radiographer repeated their analyses on an additional four patients. The intraclass correlation coefficient (ICC) was calculated to measure the consistency of the DEXA values obtained by the two radiographers. The ICC was $0.97\left(\mathrm{C}_{95} 0.95-0.98\right)$, which indicates that the inter-observer and intra-observer reproducibility of BMD measurements within a ROI was extremely good.

Harris Hip Scores and the Charnley classifications were recorded at the time of DEXA scanning $[38,112]$. To judge patients satisfaction and activities, we used the Oxford Hip Score, the U.C.L.A. Activity-level rating score and the Hip Society level of activity [7, 53, 142]. The Oxford Hip Score has been translated into Dutch and validated [123]. The Dutch version of the Oxford Hip Score comprises fourteen questions on general daily activities to determine a patient's activity level. Each question has five answer categories; the best score can be 14 points, the lowest score 70 points. A visual analogue score for pain $(0-100 \mathrm{~mm} ; 0 \mathrm{~mm}$ means no pain) and several satisfaction questions (true-false) complete the score.

To obtain additional data, the standard radiographs of all the patients were evaluated. The position of the femoral component was classified as varus, neutral or valgus and the angle between the long axis of the prosthesis and the femur was measured. Degree of heterotopic ossification was classified according to Brooker et al [26]. Calcar remodelling was classified as atrophic, hypertrophic or unchanged. Length and width of radiolucent line formation and cortical reactions were measured using a computerized device (X-caliper ${ }^{\star}$, Eisenlohr Technologies, California, U.S.A.). Osteolysis and bone apposition were recorded. Stem prosthesis fixation and stability scores were classified according to Engh et al [82]. 
A repeated-measures multivariate analysis of variance (MANOVA) with alpha set at 0.05 was used to evaluate BMD in the Gruen zones on the prosthesis side and on the non-prosthesis side.

Wide variation in bone stock quality could lead to spurious results in the analysis of variance. To reduce variance, the values in each zone were standardized using the BMD in the head of the normal femur as a reference. BMD in each zone was expressed as a standardized effect score (see end note). Two sets of standardized effect scores were produced. Each set of scores comprised the seven zones on the prosthesis side and the seven corresponding zones of the normal side. In one set, BMD from Ward's triangle was used as the reference value; in the other set, BMD in the total femoral head was used as the reference value.

A difference in standardized effect scores of greater than 1.00 between the Gruen zone on the prosthesis side and the non-prosthesis side indicates that the difference cannot be explained by the wide variation in bone stock quality.

Associations between interval variables (age, Harris Hip Score, etc.) were calculated with Pearson's correlation coefficient, while associations between ordinal variables (Brooker score, Charnley classification etc.) were calculated with Spearman's correlation coefficient. Both coefficients were two-tailed with alpha set at 0.05 .

The patients and radiographs were evaluated by an orthopaedic surgeon (A.M.J.S. Vervest) who had not been involved in the primary arthroplasty. All the patients gave informed consent.

\subsection{RESULTS}

DEXA scanning was performed on 32 patients (11 men, 21 women), who had received 20 right-sided and 12 left-sided unilateral prostheses (18 HG stem prostheses and $14 \mathrm{SL}$ stem prostheses). The average age at surgery was 60.3 years (sd 4.1); average age at DEXA scanning was 71.1 years (sd 4.1); mean follow-up duration was 129.8 months (sd 7.2). At follow-up, the mean Harris Hip Score was 93.7 (sd 7.1) (median 96.5). Pain was absent in 26 patients $(81.3 \%)$, while 5 patients $(15.6 \%)$ had slight pain in the lateral hip region after a long walk. One patient (66-year-old man) complained of mild pain and the $\mathrm{X}$-rays revealed aseptic loosening of the titanium threaded cup. The femur and stem prosthesis showed no abnormalities. Seven patients $(21.9 \%)$ had a slight Trendelenburg lurch. Only one of these patients was using a cane full-time.

Ten patients $(31.3 \%)$ were classified as Charnley class A, two patients $(6.2 \%)$ had contralateral hip complaints (class B) and twenty patients $(62.5 \%)$ were classified as class $\mathrm{C}$. There were no comorbid diseases that might have influenced bone mineralization. The Oxford Hip Score averaged 20.6 (sd 8.9); thirty patients $(93.8 \%)$ were satisfied with the result of arthroplasty. The average pain score on the visual analogue scale was $11.6 \mathrm{~mm}$ (sd 10.9). The U.C.L.A. and the Hip Society level of activity showed that $80 \%$ of the patients were moderately active (Tables 4.1 and 4.2). 
Table 4.1

University of California at Los Angeles activity-level rating. Levels above 4 were classified as moderate

\begin{tabular}{|c|c|c|}
\hline Level & Aetivity & Number $(\%)$ \\
\hline 1 & Wholly inactive: dependent on others: cannot leave residence & $0(0)$ \\
\hline 2 & Mostly inactive: restricted to minimum activities of daily living & $2(6.3)$ \\
\hline 3 & $\begin{array}{l}\text { Sometimes participates in mild activities such as walking, } \\
\text { limited housework, and limited shopping }\end{array}$ & $3(9.4)$ \\
\hline 4 & Regularly participates in mild activities & $1(3.1)$ \\
\hline 5 & $\begin{array}{l}\text { Sometimes participates in moderate activities, such as } \\
\text { swimming and can do unlimited housework or shopping }\end{array}$ & $1(3.1)$ \\
\hline 6 & Regularly participates in moderate activities & $4(12.5)$ \\
\hline 7 & Regularly participates in active events, such as cycling & $14(43.8)$ \\
\hline 8 & $\begin{array}{l}\text { Regularly participates in very active events, such as bowling } \\
\text { or golf }\end{array}$ & $1(3,1)$ \\
\hline 9 & $\begin{array}{l}\text { Sometimes participates in impact sports, such as jogging, } \\
\text { tennis, skiing, acrobatics, ballet, heavy labor, or backpacking }\end{array}$ & $0(0)$ \\
\hline 10 & Regularly participates in impact sports & $6(18.8)$ \\
\hline & Total & $32(100)$ \\
\hline
\end{tabular}

Table 4.2

Hip Society Activity level. Levels A, B and C were classified as moderate

\begin{tabular}{|c|c|c|}
\hline Level & Aetivity & Number $(\%)$ \\
\hline A & $\begin{array}{l}\text { Heavy manual labour - frequently lifts } 23-45 \mathrm{~kg} \text {,vigorous sports } \\
\text { (e.g. singles tennis or recquetbali) }\end{array}$ & $11(34.4)$ \\
\hline B & $\begin{array}{l}\text { Moderate manual labour - lifts } \leq 23 \mathrm{~kg} \text {, moderate sports (e.g. } \\
\text { walking or bicyeling }>5 \mathrm{~km} \text { ) }\end{array}$ & $8(25.0)$ \\
\hline C & $\begin{array}{c}\text { Light labour - heavy house-cleaning, yard work, assembly line, } \\
\text { light sports (e.g. walking } \leq 5 \mathrm{~km} \text { ) }\end{array}$ & $7(21.9)$ \\
\hline D & $\begin{array}{c}\begin{array}{c}\text { Semi-sedentary - white collar job, bench worker, light } \\
\text { housekeeping }\end{array} \\
\text { hous }\end{array}$ & $4(12.5)$ \\
\hline $\mathrm{E}$ & Sedentary - minimum capacity for walking or other activity & $2(6.3)$ \\
\hline $\mathbf{F}$ & Bedridden or confined to wheelchair & $0(0)$ \\
\hline & Total & $32(100)$ \\
\hline
\end{tabular}


Table 4.3

Radiological analysis of the $32 \mathrm{X}$-rays taken at the most recent follow-up visit

\begin{tabular}{|c|c|c|}
\hline & $\begin{array}{c}\text { Radiographic } \\
\text { appearance }\end{array}$ & $\begin{array}{c}\text { Number of } \\
\text { patients }(\%)\end{array}$ \\
\hline \multirow{3}{*}{$\begin{array}{l}\text { Calcar } \\
\text { remodelling }\end{array}$} & atrophy & $23(71.9)$ \\
\hline & unchanged & $6(18.8)$ \\
\hline & hypertrophy & $3(9.3)$ \\
\hline \multirow{5}{*}{$\begin{array}{l}\text { Heterotopic } \\
\text { ossification } \\
\text { according to } \\
\text { Brooker }\end{array}$} & 0 & $11(34.3)$ \\
\hline & I & $9(28.1)$ \\
\hline & II & $8(25.0)$ \\
\hline & III & $4(12.5)$ \\
\hline & IV & $0(0)$ \\
\hline \multirow{3}{*}{$\begin{array}{l}\text { Position } \\
\text { femoral } \\
\text { component }\end{array}$} & $\begin{array}{c}\text { varus } \\
\text { (mean } 3^{\circ} \text {, range } 2^{\circ} \\
-6^{\circ} \text { ) }\end{array}$ & $12(37.5)$ \\
\hline & neutral & $20(62.5)$ \\
\hline & valgus & $0(0)$ \\
\hline
\end{tabular}

Radiological analysis showed that most of the stem prostheses were in the neutral position. Calcar remodelling was atrophic in 23 patients (71.9\%) (Table 4.3). Proximal radiolucent lines were present in zone 1 in fourteen patients $(43.8 \%)$ (average length 30 $\mathrm{mm}$ (sd 17.6), average width $2.6 \mathrm{~mm}(\mathrm{sd} 1.3))$ and in zone 7 in ten patients (31.3\%) (average length $32 \mathrm{~mm}$ (sd 10.9), average width $1.5 \mathrm{~mm}$ (sd 0.4)). There were no signs of cortical reactions in the majority of the patients $(\mathrm{n}=24) \quad(75.0 \%)$. Only one stem prosthesis had produced a cortical reaction in zone 2 (length $43 \mathrm{~mm}$, width 1.6 $\mathrm{mm})$, while in seven patients $(21.9 \%)$, a cortical reaction was seen in zone 5 (average length

$35 \mathrm{~mm}$ (sd 15.2), average width $2.5 \mathrm{~mm}$ (sd2.5)). Twenty-three stem prostheses $(71.9 \%)$ were classified as having bone apposition in zone 4 . No osteolysis was seen and the fixation and stability score according to Engh et al was 100\% [78]. No signs of aseptic loosening were visible around the stem prostheses.

The two methods to determine bone stock quality (BMD in Ward's triangle and the total femoral head) resulted in different classifications of the patients (Table 4.4).

The results of DEXA scanning on the prosthesis side and non-prosthesis side in the seven Gruen zones are given in Table 4.5 and visualized in block graphs in Figure 4.4. BMD in the distal femur (zone 4) was greater than in the proximal femur (zones 1 and 7). On the prosthesis side, BMD was lower than on the nonprosthesis side.

\section{Table 4.4}

Distribution of bone stock quality in the 32 patients based on BMD in Ward's Triangle and in the total femoral head

\begin{tabular}{|l|c|c|c|}
\hline $\begin{array}{l}\text { Classification } \\
\text { method }\end{array}$ & $\begin{array}{c}\text { Normal } \\
\text { range }\end{array}$ & Osteopenic & Osteoporotic \\
\hline Ward's Triangle & 5 & 14 & 13 \\
\hline $\begin{array}{l}\text { Total femoral } \\
\text { head }\end{array}$ & 14 & 16 & 2 \\
\hline
\end{tabular}


Table 4.5

Bone mineral density measurements $\left(\mathrm{gram} / \mathrm{cm}^{2}\right)$ in seven Gruen zones on the prosthesis side and non-prosthesis side

\begin{tabular}{|c|c|c|c|c|}
\hline Gruen zone & Side & Mean & SD & $\begin{array}{c}\text { percentage } \\
\text { prosthesis/ } \\
\text { non-prosthesis }\end{array}$ \\
\hline \multirow{2}{*}{1} & Prosthesis & 0.66781 & 0.18691 & $89.8 \%$ \\
\hline & Non-prosthesis & 0.74375 & 0.13648 & \\
\hline \multirow{2}{*}{2} & Prosthesis & 1.11791 & 0.26578 & $82.2 \%$ \\
\hline & Non-prosthesis & 1.36066 & 0.23232 & \\
\hline \multirow{2}{*}{3} & Prosthesis & 1.34009 & 0.18369 & $92.8 \%$ \\
\hline & Non-prosthesis & 1.44338 & 0.22646 & \\
\hline \multirow{2}{*}{4} & Prosthesis & 1.56659 & 0.22487 & $96.7 \%$ \\
\hline & Non-prosthesis & 1.62063 & 0.21004 & \\
\hline \multirow{2}{*}{5} & Prosthesis & 1.37663 & 0.21913 & $101.8 \%$ \\
\hline & Non-prosthesis & 1.35194 & 0.29961 & \\
\hline \multirow{2}{*}{6} & Prosthesis & 0.93672 & 0.24000 & $76.1 \%$ \\
\hline & Non-prosthesis & 1.23012 & 0.22442 & \\
\hline \multirow{2}{*}{7} & Prosthesis & 0.72812 & 0.21297 & $66.1 \%$ \\
\hline & Non-prosthesis & $1.1024 \mathrm{I}$ & 0.21529 & \\
\hline
\end{tabular}

The magnitude of the differences between the prosthesis side and non-prosthesis side varied per Gruen zone and this interaction between the factor prosthesis and the factor Gruen zone was significant (Manova $F(31,6)=26.738 ; p=0.000$ ). Differences between the prosthesis side and non-prosthesis side were most notable in medial zones 6 and 7, and in lateral zone 2, as shown in Figure 4.5.

Inter-patient variation, reflected by the large standard deviation per zone, indicated that the mineralization varied considerably between subjects. This wide variation in bone stock quality could produce spurious results. However, the standardized effect scores, whether based on BMD in the total femoral head or in Ward's triangle that corrected for differences in bone stock quality, confirmed the pattern of mineralization distribution found in the MANOVA: the highest scores distally and lower scores on the prosthesis side than on the non-prosthesis side. 


\section{Figure 4.4}

Bone mineral density $\left(\mathrm{gram} / \mathrm{cm}^{2}\right)$ in seven Gruen zones. BMDs in the proximal zones were lower than in the distal zones

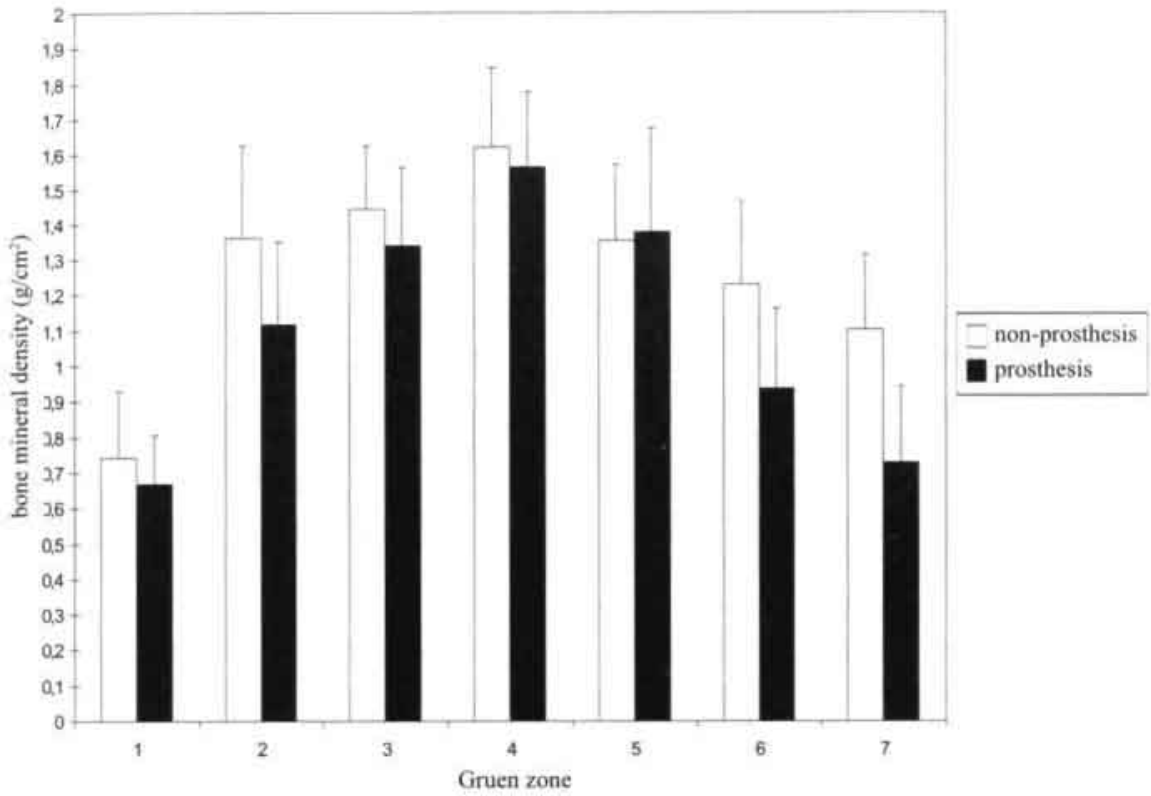

\section{Figure 4.5}

Differences between BMD measurements on the non-prosthesis side and prosthesis side. In zones 6 and $7 \mathrm{BMD}$ on the prosthesis side was lower than on the non-prosthesis side

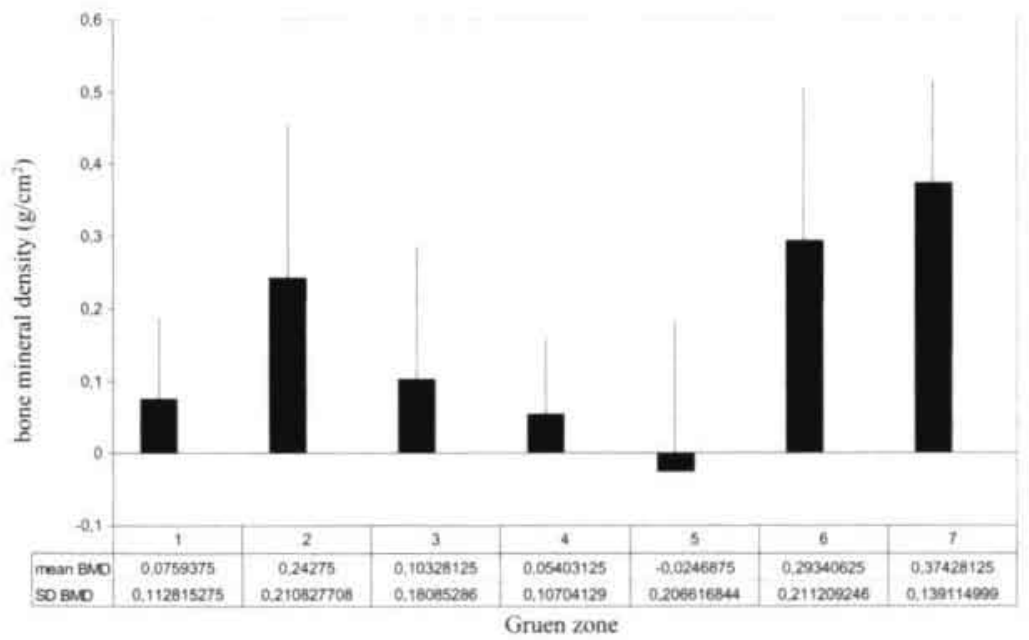


Table 4.6 shows the differences in standardized effect scores between the prosthesis and the non-prosthesis side in each of the Gruen zones. The absolute differences in standardized effect score of greater than 1.00 (zone 7 in both sets; zones 2, 5 and 6 in Ward's Triangle set) indicated that the presence of a prosthesis had resulted in significantly lower BMD in these regions. Thus, the results of the Manova did not appear to be an artefact. There was so little agreement between the two classification methods that no meaningful analysis could be carried out to compare the differences between patients with normal mineralization to patients with osteopenia or osteoporosis.

Table 4.6

Difference in standardized effect score between the prosthesis and non-prosthesis Gruen zones per bone stock quality classification (see text)

\begin{tabular}{|l|c|c|c|c|c|c|c|}
\hline Classification method & zone 1 & $\mathbf{2}$ & $\mathbf{3}$ & $\mathbf{4}$ & $\mathbf{5}$ & $\mathbf{6}$ & $\mathbf{7}$ \\
\hline Ward's Triangle & 0.81 & 1.63 & -0.21 & 0.63 & -1.21 & 1.73 & 2.1 \\
\hline Total femoral head & 0.18 & 0.72 & 0.07 & 0.25 & -0.37 & 0.8 & 1.05 \\
\hline
\end{tabular}

No correlations were found between BMD values and the interval between the index operation and the time of DEXA scanning, the age of the patients, the Harris Hip Score, the Charnley class, activity levels and patients satisfaction. Also, there were no correlations between the DEXA outcome and the X-ray analysis results (calcar remodelling, femoral stem position, radiolucent line formation, heterotopic ossification, cortical reactions and bone apposition).

\subsection{DISCUSSION}

This study investigated bone mineral density in the femur ten years after implantation of a Zweymüller cementless hip prosthesis. Decreased BMD was found in the region of the calcar compared to the same region on the non-prosthesis side. The only factor that was significantly related to the difference in BMD between the two femora was the presence of a prosthesis. All other factors, whether clinical or radiological, were unrelated to the lower values on the prosthesis side.

DEXA scanning was performed at one hospital with one set of equipment, because bone mass measurements can differ between DEXA systems $[44,169]$. To optimize measurement precision, the equipment was checked every day. DEXA measurements can be affected by variations in rotation of the hip $[8,42,159]$. Therefore, we used a foot jig to ensure that all the measurements were taken with the same hip rotation. Although DEXA measurements can be influenced by the amount of ectopic bone and osteophytes, we found no relation between BMD and the Brooker classification, or the radiological appearance of osteoarthritis on the non-prosthesis side [44]. We therefore conclude that our study design was valid and that the results were not influenced by the above-mentioned confounders. Brodner et al conducted a prospective DEXA study on 89 patients over a period 
of five years [24]. They measured BMD on the affected side using the automatic metal removal software. Three possible errors were found in that programme: the recognition of soft tissue as bone; the recognition of bone as metal and the recognition of metal as bone. In our study, determination of the region of interest was done manually, with high reproducibility.

Both femora were scanned and the area containing the prosthesis was copied onto the non-operated side [194]. In the literature, there is controversy as to whether BMD is the same in both femora. Hall et al found variation in interfemoral density of up to $20 \%$ [110]. For this reason, Kröger et al rejected the left - right comparison [165]. On the other hand, Korovessis et al and Kearns McCarthy et al did not demonstrate any difference in densities between the two femora in normal subjects $[153,162]$. Furthermore, Engh et al used the healthy contralateral femur as a control in postmortem densitometric analyses on five AML prostheses [83]. Visual inspection of the preoperative X-rays of both femora did not reveal any differences. In addition, they digitized these X-rays and calculated the periosteal diameter and the endosteal thickness. The average difference between the nonprosthesis side and prosthesis side was less than 1.0 millimetre.

In another study, Martini et al determined the reproducibility of bone densitometric measurements [193]. DEXA scans were performed preoperatively and ten days after implantation of the prosthesis. They measured preoperative BMD in the seven Gruen zones in both femurs. For the postoperative measurements, the prosthesis was copied onto the non-operated side. A slight (3.8\%) non-significant difference in BMD in Gruen zone 1 was found on the non-prosthesis side between the preoperative measurements and the measurements taken ten days postoperatively (with the prosthesis copied onto the non-operated side). There were no statistically significant differences between the other Gruen zones.

Kearns McCarthy et al used two circumscribed regions of $21 \times 6 \mathrm{~mm}$ on both femurs to compare BMD differences between the prosthesis side and nonprosthesis side [153]. Similarly, we compared BMD in all seven Gruen zones on the total femur on the prosthesis side and non-prosthesis side. Favourable interobserver and intraobserver variability revealed that our manual comparison was highly reproducible. Thus, we suggest that our methods of assessing BMD differences between the prosthesis side and normal femur were trustworthy.

The metal in a prosthesis will obscure the bone on the anterior and posterior sides. Cohen et al performed a study in which three different prostheses were positioned on a hydroxyapatite phantom that contained $10 \%$ to $15 \%$ cellulose acetate [42]. Bone mineral density adjacent to the prosthesis did not differ from that in the phantom without the prosthesis. Similarly, Cattermole et al and Kiratli et al did not find any influence of the metal implant on bone mineral density in the adjacent bone $[37,159]$. Thus, any difference between bone mineral density in the femur with the implant and the contralateral non-operated side would not be caused by the metal of the implant. 
In our study, the prosthesis side (left or right) did not affect the amount of change in BMD. The presence of a prosthesis was the only factor that affected the difference in BMD between the femora.

Owing to the small patient population in this DEXA study, it was not possible to assess whether patients with poor mineralization had a greater decrease in BMD in zone 7, or whether they had different BMD distribution across the seven Gruen zones. Irrespective of whether a more stringent definition was used to control for the wide variation in BMD between patients (the total femoral head), or a definition that was sensitive to small changes in mineralization (Ward's Triangle), the results found in the multivariate analysis of variance were confirmed. The decreased BMD in the proximal medial portion of the femur could be attributed to the presence of the prosthesis. This was predicted by stress-shielding bypass, as seen in the finite element analysis (Chapter 1.5).

Our study design was cross-sectional, but a prospective study on the operated hip with the follow-up duration in our study would have encountered technical difficulties of longitudinal drift [49]. Furthermore, the lifespane of an X-ray tube (DEXA) is approximately seven years and comparison of the preoperative BMD with the postoperative densities might have been less accurate because of the stiffness of the affected hip [239, 243].

The finite-element model and the postmortem study by Kim et al demonstrated the normal stress and strain distribution in a femur with a prosthesis [131, 157]. Stress in the distal part of the femur was higher than that in the proximal part. This study (Figure 4.4), as well as other DEXA studies confirmed these stress patterns $[42,194]$.

The prosthesis resulted in decreased BMD in the calcar region and on the proximal medial femoral side. A prosthesis will carry load, which subsequently leads to stress shielding and bone remodelling. This normal adaptive process should be visible on the side with the highest stress. According to Walker et al this would be the calcar region [269].

Engh et al performed a densitometric and quantitative radiographic analysis on retrieved femora and found decreased BMD in the calcar region on the prosthesis side [83]. Finite-element analysis provided theoretical support for these findings [128]. Also, several DEXA studies confirmed that the calcar region is sensitive to bone remodelling $[126,153,155,165,194,259]$. Lester et al found lower BMD in the calcar region on retrieved femora with a Zweymüller stem [171]. Brodner et al found a significant decrease in BMD in the Gruen zones 1, 6 and 7 and a significant increase in zones 2, 4 and 5 over a five-year follow-up period [24]. In Gruen zone 3 BMD did not change. BMD in the whole femur did not change either and the researchers concluded that these changes in BMD signified a shift in BMD from the proximal to the distal zones. Their results contradicted those from studies that revealed BMD changes in the calcar region alone, thus not in the 
region of the greater trochanter (Gruen zone 1). Stress shielding in Gruen zone 1 also disagreed with the finite-element analysis that predicted stress shielding in the proximal medial regions [131].

Six to eight weeks after surgery, stress-induced bone remodelling replaces the process of normal postoperative bone regeneration [231]. It is still unknown how long the processes of stress shielding and bone remodelling continue $[84,155$, $239,262]$. Engh et al observed that this process was pronounced in the first two years, but progressed at a slower rate thereafter [84]. Reigstad et al found that the process stabilized after three to four years [234]. Kearns McCarthy et al documented progressive bone loss 14 years after patients had received cemented stem prostheses [153]. In our study, ten years after inserting Zweymüller cementless stems, BMD in the calcar region (Gruen zone 7) was lower, without any clinical consequences for the patient and whitout any radiographic abnormalities.

\subsection{CONCLUSION}

Ten years after the implantation of a Zweymüller cementless stem prosthesis, a decrease in bone mineral density was documented by DEXA scanning in the region of the calcar. No clinical sequelae (or radiographic abnormalities) were found to be related to loss of BMD.

END NOTE: A standardized effect score is the ratio obtained by dividing the difference between the means in two groups by the pooled standard deviation (a weighted combined standard deviation):

Mean of non-reference group - Mean of reference group

Pooled standard deviation

A standardized effect score of 0.80 indicates that there is $79 \%$ probability of a higher score in the non-reference group [41]. 
and 


\title{
5 LONG-TERM RESULTS OF THE ZWEYMÜLLER
}

\author{
CEMENTLESS TITANIUM THREADED CUP
}

A cohort study on patients with at least ten years of follow-up

\subsection{ABSTRACT}

Between January 1987 and December 1990, 221 Zweymüller cementless, threaded titanium cups were implanted in 211 patients with idiopathic osteoarthritis. Seven acetabular cups had been revised due to aseptic loosening. A total of 136 patients (142 prostheses) were evaluated at a mean follow-up of 134 months (sd 9.5).

Radiolucent lines, osteolysis or migration were seen in 17 cups. Migration and radiolucent lines might indicate the development of osteolysis.

Mean linear polyethylene wear was $0.46 \mathrm{~mm}$ (sd 0.27 ) in 105 cups (74\%); annual wear was $0.04 \mathrm{~mm}$ (sd 0.02 ). Wear did not correlate with pain, body mass index, cup migration, radiolucent lines, or osteolysis.

Cumulative survival was $96 \%$; worst-case survival was $91 \%$ after 128 months.

Good long-term results were found with the Zweymüller cementless titanium threaded acetabular cup. 


\subsection{INTRODUCTION}

The threaded cup was one of the first cementless prostheses to be widely used on the acetabular side $[88,178]$. Unfortunately, several studies reported poor shortterm results with the threaded cup in the $1990 \mathrm{~s}[63,88,119,120]$. Yahiro et al performed a meta-analysis to evaluate the clinical performance of cementless, threaded cups [284]. In view of the high incidence of early failure, it was recommended to abandon threaded acetabular cups.

In this study, the Zweymüller cementless acetabular cup was investigated. This self-cutting, truncated conical cup (C.S.F.) was made of pure titanium with a microstructure of $3.5 \mu \mathrm{m}$, i.e. the same microstructure as the Stepless stem (Sulzer, Winterthur, Switzerland). The flat bottom was furnished with two openings and the lining had a titanium cover to prevent bone-polyethylene contact. An ultra-high density polyethylene insert (Chirulen; Ruhrchemie AG, Oberhausen, Germany) of at least $5.5 \mathrm{~mm}$ thickness was placed into the $1.5 \mathrm{~mm}$ thick metal shell. All the cups were used in combination with a $32 \mathrm{~mm}$ alumina ceramic head (Biolox; CeramTec, Plochingen, Germany) impacted onto the Morse taper [56].

In 1997, Delaunay et al reported on the first generation of Zweymüller threaded cups in 126 hips [60]. Survival after ten years with the endpoint aseptic loosening was $98.7 \%\left(\mathrm{CI}_{95} 80-99.9 \%\right)$. There were two failed cups due to inappropriate initial stability, but no osteolysis or radiolucent lines. Annual linear wear was $0.2 \mathrm{~mm}$. In 1998, Delaunay et al reported good results in a study that had also included the C.S.F. cup [58].

The aim of our study was to evaluate the clinical and radiological results of the Zweymüller titanium threaded acetabular cup prosthesis and to measure the amount of polyethylene wear in patients with at least ten years of follow-up. Patient satisfaction and functioning were also assessed. In 1996, Dawson et al developed the 12-item questionnaire to evaluate patient functioning after total hip arthroplasty (appendix 2) [53]. This questionnaire has been translated into the Dutch language and validated [123]. Hoefnagels et al added two items, a pain score and four questions to evaluate patient satisfaction to produce a Dutch Oxford Hip Score (appendix 2). This study was the first one to use this Dutch version of the questionnaire.

\subsection{MATERIALS AND METHODS}

Between 1 January 1987 and 31 December 1990, 221 hip arthroplasties had been carried out at five Dutch hospitals. Patients were selected if idiopathic osteoarthritis had formed the indication for the primary operation. Unilateral arthroplasty had been performed in 201 patients, while 10 patients had bilateral arthroplasty, 106 prostheses had been placed on the left side and 115 on the right. Mean age at primary surgery was 64.7 years (sd 8.4). At the time of surgery, 97 
arthroplasties (43.9\%) had been carried out in patients classified as Charnley class A, $69(31.2 \%)$ in class B patients and $55(24.9 \%)$ in class C patients.

Two clinical and radiological follow-up studies were performed on the cohort. Patients visited the out-patient clinic for the first follow-up study (FU one) in 1996, which was performed 86.8 months (sd 9.1) after primary surgery. The second follow-up study (FU two) took place in 2000, after a mean follow-up of 134 months (sd 9.5). Evaluations were conducted by physicians who had not been involved in the primary surgery (A.M.J.S. Vervest, F. van Hout, FH. Wapstra, R.T. Louwerse).

At FU one, all the patients could be traced. At FU two, 44 prostheses could not be evaluated, because the patient had died of causes unrelated to the index operation. Nine acetabular prostheses had been revised: seven for aseptic loosening, one for recurrent dislocations due to malpositioning and one due to septic loosening of both prosthetic components. It was not possible to evaluate six prostheses, because the patients were unable to attend due to dementia (2) or the patients refused to participate ( 2 patients, 4 prostheses). To obtain information on a further seven prostheses, the patients filled in a questionnaire, but did not undergo physical examination. These patients ( 13 prostheses) had no complaints and no revisions had taken place. Nine additional patients were willing to be examined at home by the investigator, but obviously, no radiographs could be taken.

At FU two, four prostheses were lost to follow-up, because it was not possible to trace these patients. In this study, a total of 142 prostheses underwent clinical and radiological evaluation. Survival data could be obtained on all 221 prostheses.

Clinical evaluation was conducted with the Harris Hip Score and the Merle d'Aubigné P.W.M. scores [112, 204]. Harris Hip Scores of between 100-90 points were classified as excellent, $89-80$ good, $79-70$ fair and 69 or below as poor [70]. The Charnley classification was also assessed [38]. At FU two, all the patients also completed the Oxford Hip Score, the U.C.L.A. activity level rating score and the Hip Society level of activity [7, 53, 142]. The Oxford Hip Score has been translated into the Dutch language [123]. The Dutch Oxford Hip Score can range from 14 points (excellent) to 70 points (lowest). In addition, the patients were asked to score their pain on a Visual Analogue Scale, with a range from zero $\mathrm{mm}$ (no pain) to $100 \mathrm{~mm}$ (intolerable pain).

We measured the height and weight of the patients. The Body Mass Index was calculated as the ratio of body weight in kilograms to height in metres ${ }^{2}$ [222].

Standard radiographs were taken of the pelvis (anteroposterior view) and the affected hip (anteroposterior and lateral views). During FU two, a true lateral radiograph of the acetabular cup was obtained. With the patient lying on the table, the contralateral hip was elevated; when, under fluorescence, the affected acetabulum was seen in the true lateral plane, the radiograph was taken. 
Figure 5.1

Radiological measurements were taken with a computerized device (X-caliper" Technologies, California, U.S.A.)

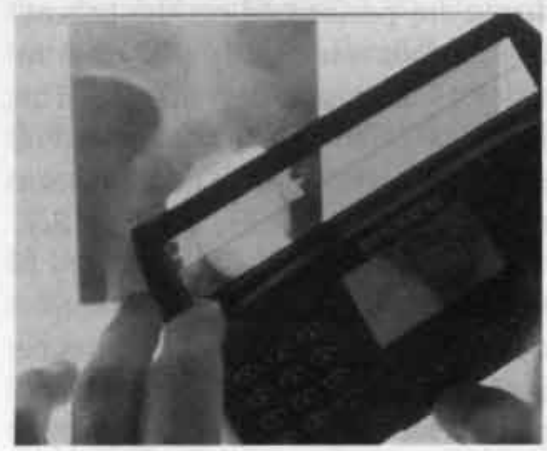

All the measurements were obtained with a computerized device (X-caliper ${ }^{\circledR}$, Eisenlohr Technologies, California, U.S.A.) (Figure 5.1). As the diameter of the head was known (all $32 \mathrm{~mm}$ ), magnification could be corrected to produce normalized measurements.

Radiolographs were evaluated according to the cementless prostheses classification described by Johnston et al. [142]. The acetabular component was assessed on the basis of DeLee zones (Figure 5.2) [61].

Radiolucent line formation and osteolysis were recorded and the length and width of radiolucent lines were measured. Radiolucent line formation was defined as increased linear bone density along the circumference of the prosthesis. Decreased density was classified as osteolysis.

Inclination of the cup was determined by measuring the angle between the inter-teardrop line and the line according through the plane of the cup (Figure 5.3) [121]. Linear wear was measured on the true lateral radio-

Figure 5.2 DeLee zones

\section{Figure 5.3:}

Cup angle was measured between the interteardrop line and the line through the plane of the cup

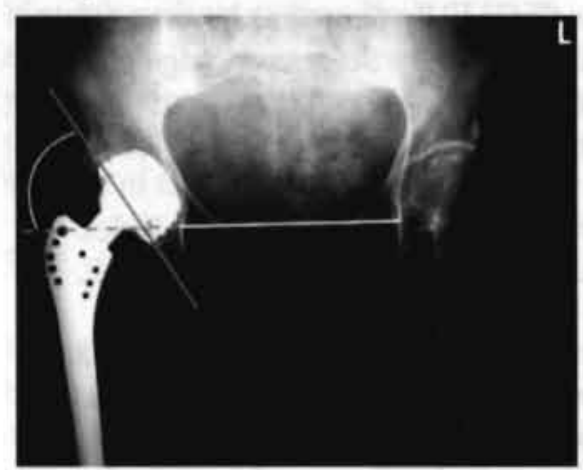

graph of the cup to the method of Dorr (Figure 5.4) [70]. By comparing the position of the acetabular cup on consecutive radiographs, we were able to determine whether migration of the acetabular component had taken place.

Radiological evaluation was conducted by two investigators (A.M.J.S. Vervest, J.W.A. Koetsier). Intraclass Correlation Coefficients of cup measurements varied. The I.C.C. of the inclination measurements was $0.97\left(\mathrm{CI}_{95} 0.87-0.99\right)$ while that of the wear measurements $0.27\left(\mathrm{CI}_{95}-0.32-0.76\right)$. 
Statistical analysis was performed with the Pearsor's correlation coefficient, Student's t-test and the Chi-square test. Significance was defined as a pvalue of less than 0.05 .

The Kaplan Meier curves and survival tables were calculated using data on all 221 prostheses $[148,212]$. The curves for the acetabular cup were drawn on the basis of the endpoint: true revision due to aseptic loosening. Worst-case scenarios included true revision due to aseptic loosening, probable revision for visible migration, radiolucent lines, osteolysis and the patients lost to follow-up. After the evaluation study, one additional acetabular cup prosthesis was revised due to aseptic loosening and this prosthesis was included in the worst-case scenario. The Kaplan Meier curve and survival tables were truncated when the confidence intervals exceeded $5 \%$ of the accumulated survival.

\subsection{RESULTS}

The study group comprised 41 men and 95 women, with 66 unilateral leftsided prostheses, 64 unilateral right-sided prostheses and 6 bilateral prostheses. Average age at the time of surgery was 61.1 years (sd 8.1), at FU one 68.2 years (sd 8.0) and at FU two 72.2 years (sd 7.9). Mean follow-up at FU one was 86 months (sd 9.1) and at FU two 134 months (sd 9.5). Average body mass index at FU one was 27.5 (sd 4.2) and at FU two 27.8 (sd 4.4). Harris Hip Scores, P.W.M., Charnley classifications and pain scores at FU one and FU two are summarized in Table 5.1. Statistical analysis revealed more Charnley class $C$ patients at FU two and lower P.W.M. scores $(\mathrm{p}=0.000)$. On the other hand, the pain scores did not differ $(p=0.09)$. The clinical results of the patients who were visited at home were no different from those of the study group.

Mean Oxford Hip Score in the study group was 24.1 (sd 11.8). The Visual Analogue Scale for pain showed an average score of $18.7 \mathrm{~mm}$ (sd 23.1). The results of the U.C.L.A. questionnaire are summarized in Table 5.2. In 129 prostheses $(90.8 \%)$, the patients reported that their daily functioning was better than before the operation; $93,7 \%$ of the patients (133 prostheses) were satisfied with the arthroplasty result.

The Hip Society level of activity is shown in Table 5.3. It correlated only weakly with the pain score (Spearman's rho 0.323; $\mathrm{p}=0.000$ ). There was no difference in patient satisfaction between the patients who returned their questionnaires by mail and those who were visited at home. 
Table 5.1

Harris Hip Scores, P.W.M. class, Charnley class and pain scores at FU one and FU two

\begin{tabular}{|c|c|c|}
\hline & $\begin{array}{c}\text { FU one } \\
N=142(\%)\end{array}$ & $\begin{array}{c}\text { FU two } \\
N=142(\%)\end{array}$ \\
\hline Harris Hip Score & $91.3(\mathrm{sd} 10.5)$ & $89.7(\mathrm{sd} 12.8)$ \\
\hline Excellent (score 100-90) & $97 .(68.3 \%)$ & $91(64.1 \%)$ \\
\hline Good (score 89-80) & $28(19.7 \%)$ & $26(18.3 \%)$ \\
\hline Fair (score 79-70) & $11(7.7 \%)$ & $16(11.3 \%)$ \\
\hline Poor $($ score $<70)$ & $6(4.3 \%)$ & $9(6.3 \%)$ \\
\hline \multicolumn{3}{|l|}{ PWM Class * } \\
\hline Class 1 & $93(65.5 \%)$ & $70(49.3 \%)$ \\
\hline Class 2 & $15(10.6 \%)$ & $13(9.2 \%)$ \\
\hline Class 3 & $18(12.7 \%)$ & $26(18.3 \%)$ \\
\hline Class 4 & $8(5.6 \%)$ & $11(7.7 \%)$ \\
\hline Class 5 & $8(5.6 \%)$ & $22(15.5 \%)$ \\
\hline \multicolumn{3}{|l|}{ Charnley Class * } \\
\hline Class A & $56(39.4 \%)$ & $26(18.3 \%)$ \\
\hline Class B & $50(35.2 \%)$ & $39(27.5 \%)$ \\
\hline Class C & $36(25.4 \%)$ & $77(54.2 \%)$ \\
\hline \multicolumn{3}{|l|}{ Pain score } \\
\hline No pain & $108(77.1 \%)$ & $104(73.2 \%)$ \\
\hline Slight pain & $25(17.6 \%)$ & $23(16.2 \%)$ \\
\hline Mild pain & $4(2.8 \%)$ & $8(5.6 \%)$ \\
\hline Moderate pain & $4(2.8 \%)$ & $4(2.8 \%)$ \\
\hline Severe pain & $1(0.7 \%)$ & $3(2.1 \%)$ \\
\hline Disabled, pain at rest & 0 & 0 \\
\hline
\end{tabular}


Table 5.2

University of California at Los Angeles activity-level rating [7]

\begin{tabular}{|c|c|c|c|}
\hline Level & \multicolumn{2}{|l|}{ Activity } & Number $(\%)$ \\
\hline 1 & \multicolumn{2}{|c|}{ Wholly inactive: dependent on others: cannot leave residence } & $1(0.7)$ \\
\hline 2 & \multicolumn{2}{|c|}{ Mostly inactive: restricted to minimum activities of daily living } & $8(6.6)$ \\
\hline 3 & \multicolumn{2}{|c|}{$\begin{array}{l}\text { Sometimes participates in mild activities such as walking, limited } \\
\text { housework and limited shopping }\end{array}$} & $24(16,9)$ \\
\hline 4 & \multicolumn{2}{|l|}{ Regularly participates in mild activities } & $12(8.5)$ \\
\hline 5 & \multicolumn{2}{|c|}{$\begin{array}{l}\text { Sometimes participates in moderate activities such as swimming and } \\
\text { can do unlimited housework or shopping }\end{array}$} & $17(12.0)$ \\
\hline 6 & \multicolumn{2}{|c|}{ Regularly participates in moderate activities } & $24(16.9)$ \\
\hline 7 & \multicolumn{2}{|c|}{ Regularly participates in active events such as cycling } & $35(24.6)$ \\
\hline 8 & \multicolumn{2}{|c|}{ Regularly participates in very active events such as bowling or golf } & $7(4.9)$ \\
\hline 9 & \multicolumn{2}{|c|}{$\begin{array}{l}\text { Sometimes participates in impact sports such as jogging, tennis, } \\
\text { skiing, acrobatics, ballet, heavy labour, or backpacking }\end{array}$} & $1(0.7)$ \\
\hline 10 & \multicolumn{2}{|l|}{ Regularly participates in impact sports } & $13(9.2)$ \\
\hline 8. Fet & ity: $58.3 \mathrm{~mm}$ (sd 25.2) & Total & $142(100)$ \\
\hline
\end{tabular}

Table 5.3

Hip Society Activity level [142]

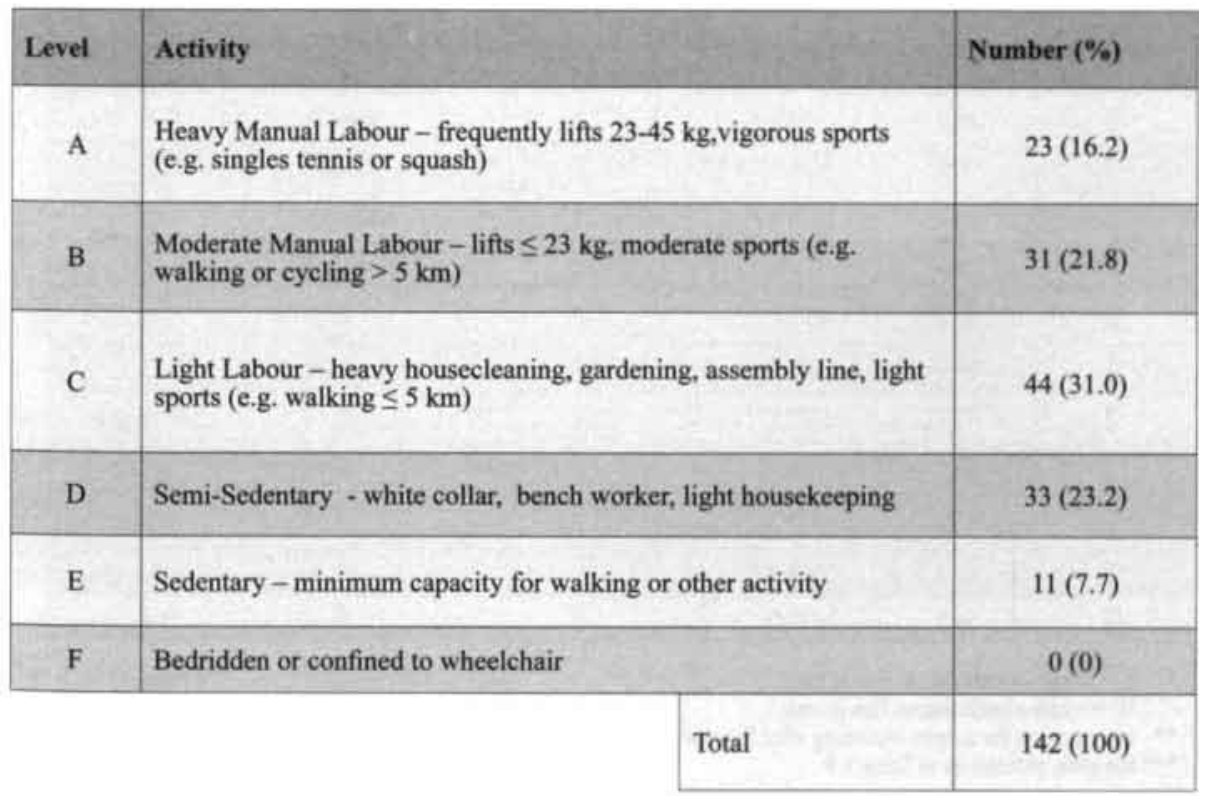


Non-progressive radiolucent lines were seen around three cups at FU one. An additional two cups showed only one radiolucent line at FU two; maximum length was $40 \mathrm{~mm}$, while maximum width was $7.1 \mathrm{~mm}$ at FU two. These patients had no pain complaints. Another cup showed migration, osteolysis and radiolucent lines in all three DeLee zones; the patient had severe pain and the cup was revised after the study.

At FU two, eight cups showed osteolysis: in zone $1(n=1)$, in zone $2(n=3)$, in zone $3(n=1)$, and in zones 1,2 and $3(n=3)$. Only one of these cups showed osteolysis in DeLee zone 3 at both follow-up evaluations.

The angle of the acetabular cup was an average of 48.4 degrees (sd 9.4) and had not changed since the first postoperative X-ray. However, signs of migration were noted on the consecutive X-rays of ten cups.

Summarized: seventeen cups showed radiolucent lines, osteolysis or migration; four cups showed radiolucent lines, osteolysis and migration; one cup showed radiolucent lines and osteolysis; one cup showed only radiolucent lines; four cups showed only osteolysis; seven cups showed only migration (Table 5.4).

\section{Table 5.4}

Seventeen cups showed radiolucent lines, osteolysis or migration

\begin{tabular}{|c|c|c|c|c|c|}
\hline Sex & $\begin{array}{c}\text { Age at } \\
\text { surgery (yrs) }\end{array}$ & FU (months) & Radiolncent lines * & Osteolysis & Migration \\
\hline$\vec{\theta} *$ & 54.8 & 136.6 & zones $1-2-3$; W 2 & zones $1-2-3$ & $\mathrm{~T}$ \\
\hline o*e. & 49.9 & 143.3 & zone 2; L 22.7 W 1.1 & zone 2 & $\mathrm{~T}$ \\
\hline$\sigma^{7 * \infty}$ & 54.3 & 160.2 & zone 3; L 24.1 W 3.9 & zone 3 & $\mathrm{~T}$ \\
\hline Q*** & 49.1 & 144.9 & $\begin{array}{l}\text { zone } 2 ; \text { L. } 27.6 \text { W } 1.7 \\
\text { zone } 3 ; \text { L } 26.6 \text { W } 7.1\end{array}$ & zones $1-2-3$ & $T$ \\
\hline$\sigma^{*}+\infty$ & 49.8 & 132.6 & $\begin{array}{c}\text { zone } 1 ; \text { L } 24.7 \text { W } 2 \\
\text { zone } 2 ; \text { L } 40.7 \text { W } 3.1\end{array}$ & zone 2 & $\mathrm{~F}$ \\
\hline q & 71.5 & 122.4 & zone 1; L15.7 W 4.2 & $\mathrm{~F}$ & F \\
\hline q & 68.2 & 150.8 & $\mathbf{F}$ & zone 2 & $\mathrm{~F}$ \\
\hline o & 739 & 128.8 & $\mathrm{~F}$ & zone 1 & $\mathrm{~F}$ \\
\hline 운 & 53.8 & 130.7 & $\mathrm{~F}$ & zones $1-2-3$ & F \\
\hline$\sigma^{*}$ & 48.9 & 145.3 & $\mathrm{~F}$ & zones $1-2-3$ & $\mathrm{~F}$ \\
\hline q & 76.2 & 128.4 & $\mathrm{~F}$ & $\mathbf{F}$ & $T$ \\
\hline q & 60.9 & 145.2 & $\mathrm{~F}$ & $\mathrm{~F}$ & $T$ \\
\hline q & 72.7 & 127.5 & F & F & $T$ \\
\hline$q$ & 55.6 & 128.6 & $\mathrm{~F}$. & F & $\mathrm{T}$ \\
\hline 우 & 63.2 & 132.2 & F & F & $T$ \\
\hline q & 60.8 & 121.8 & F & F & $T$ \\
\hline Q & 54.5 & 125.6 & F & F & $\mathrm{T}$ \\
\hline
\end{tabular}

* $\mathrm{L}=$ length of radiolucent line in $\mathrm{mm}$

$\mathrm{W}=$ width of radiolucent line in $\mathrm{mm}$

$\mathrm{F}=$ false

cup revision for aseptic loosening after the study

$\mathrm{T}=$ true

$* *$ the same patients as in Table 5.5 
On the true lateral radiograph of 37 acetabular cups (26.1\%), linear wear was zero; in the other 105 cups (73.9\%), average linear wear was $0.46 \mathrm{~mm}$ (sd 0.27 ), with an annual wear of $0.04 \mathrm{~mm}$ (sd 0.02 ) after 11.17 years (sd 0.8 ). In seven of these cups, linear wear was greater than $1 \mathrm{~mm}$, while annual wear was 0.10 (sd 0.02). However, these values must be interpreted with caution, because the reproducibility of the wear measurements was very low.

Statistical analysis did not reveal any correlations between pain and wear, migration of the cup, the presence of radiolucent lines, or osteolysis around the cup. Also, there was no correlation between body mass index and wear.

Analysis showed that the migration seen on the X-rays at FU one correlated weakly with the development of osteolysis at FU two (Spearman's rho 0.37; $\mathrm{p}=0.000$ ), while the presence of radiolucent lines at FU one correlated weakly with osteolysis around the cup at FU two (Spearman's rho $0.39 ; \mathrm{p}=0.000$ ). Thus, there was only a slight correlation between migration, radiolucent lines and the development of osteolysis. Data on the patients with radiolucent lines, migration and osteolysis around the acetabular cup are summarized in Table 5.5.

\section{Table 5.5}

Data on the patients with radiolucent lines, migration and osteolysis around the acetabular cup. The presence of migration and radiolucent lines at FU one had a weak correlation with osteolysis at FU two (Spearman's tho 0.37 and 0.39 , respectively; $p=0.000$ ).

The cup of one patient (not mentioned in this table) showed severe osteolysis and migration at FU two and was revised after this study

\begin{tabular}{|c|c|c|c|c|c|c|}
\hline $\begin{array}{l}\text { Sex - age at } \\
\text { surgery - period } \\
\text { of FU two }\end{array}$ & $\begin{array}{l}\text { Radiolucent } \\
\text { lines * } \\
\text { FU one }\end{array}$ & $\begin{array}{l}\text { Radiolucent } \\
\text { lines * } \\
\text { FU two }\end{array}$ & $\begin{array}{c}\text { Migration } \\
\text { FU one }\end{array}$ & $\begin{array}{l}\text { Migration } \\
\text { FU two }\end{array}$ & $\begin{array}{c}\text { Osteolysis } \\
\text { FU one }\end{array}$ & $\begin{array}{c}\text { Osteolysis } \\
\text { FU two }\end{array}$ \\
\hline $\begin{array}{l}\text { of }-49.9 \text { yrs - } \\
143.3 \text { months }\end{array}$ & F & $\begin{array}{c}\text { Zone } 2 \\
\text { L } 22.7 \text { W } 1.1\end{array}$ & $\mathrm{~T}$ & $\mathrm{~T}$ & $\mathrm{~F}$ & Zone 2 \\
\hline $\begin{array}{l}\text { or }-54.3 \text { yrs - } \\
160.2 \text { months }\end{array}$ & $\begin{array}{c}\text { Zone } 3 \\
\text { L } 24.1 \text { W } 3.9\end{array}$ & $\begin{array}{c}\text { Zone } 3 \\
\text { L } 24.1 \text { W } 3.9\end{array}$ & $T$ & $\mathrm{~T}$ & Zone 3 & Zone 3 \\
\hline $\begin{array}{l}\text { O. - } 49.1 \text { yrs - } \\
144.9 \text { months }\end{array}$ & $\begin{array}{c}\text { Zone 2 } \\
\text { L } 27.6 \text { W } 1.7 \\
\text { Zone } 3 \\
\text { L } 26.6 \text { W } 5.8\end{array}$ & $\begin{array}{c}\text { Zone } 2 \\
\text { L } 27.6 \text { W } 1.7 \\
\text { Zone } 3 \\
\text { L } 26.6 \text { W } 7.1\end{array}$ & $\mathrm{~T}$ & $\mathrm{~T}$ & $\mathrm{~F}$ & $\begin{array}{c}\text { Zones } 1,2 \\
\text { and } 3\end{array}$ \\
\hline $\begin{array}{l}\text { o. } 49.8 \text { yrs - } \\
132.6 \text { months }\end{array}$ & F & $\begin{array}{c}\text { Zone } 1 \\
\text { L } 24.7 \mathrm{~W} 2 \\
\text { Zone } 2 \\
\text { L } 40.7 \text { W } 3.1\end{array}$ & F & F & F & Zone 2 \\
\hline
\end{tabular}

- $\mathrm{L}=$ length of the radiolucent line in $\mathrm{mm}$ $\mathrm{W}=$ width of the radiolucent line in $\mathrm{mm}$ 
Seven acetabular cups had been revised due to aseptic loosening. Figure 5.5 shows the Kaplan Meier curve, while Table 5.6 shows the survival table with the end-point: revision of the acetabular cup because of aseptic loosening. One threaded acetabular cup was revised after this study. The worst-case scenario

\section{Figure 5.5}

Kaplan Meier curve: cumulative survival of the acetabular cup was $95.96 \%$ $\left(\mathrm{Cl}_{95} 92.14-99.78\right)$ after 138 months

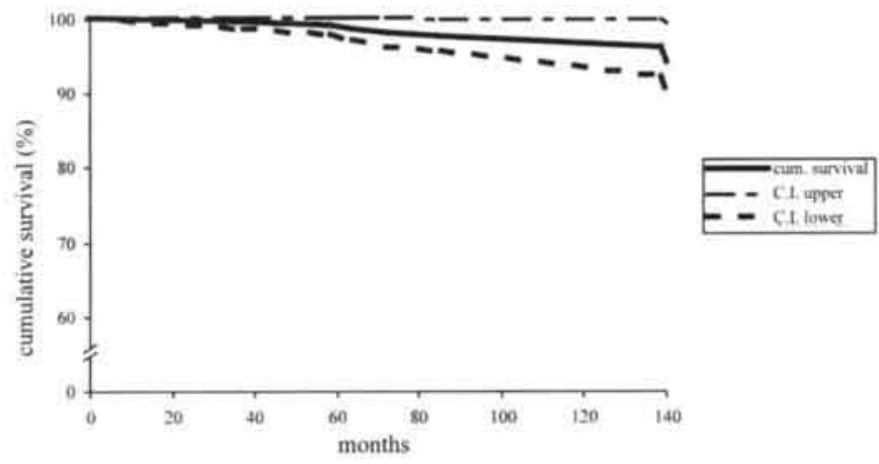

Table 5.6

Survival table with revision of the acetabular cup due to aseptic loosening as end-point. After 12 years, the chance that the patient will not have had revision was $94.64 \%\left(\mathrm{Cl}_{95} 90.08-99.2\right)$

\begin{tabular}{|c|c|c|c|c|c|c|}
\hline $\begin{array}{l}\text { Years since } \\
\text { operation }\end{array}$ & $\begin{array}{c}\text { Number at } \\
\text { start }\end{array}$ & Withdrawn & $\begin{array}{c}\text { Number at } \\
\text { risk }\end{array}$ & Failure & $\begin{array}{c}\text { Survival rate } \\
(\%)\end{array}$ & $\begin{array}{l}\text { SE survival } \\
\text { rate }\end{array}$ \\
\hline 0 to 1 & 221 & 4 & 219 & 0 & 100 & 0 \\
\hline 1 to 2 & 217 & 2 & 216 & 0 & 100 & 0 \\
\hline 2 to 3 & 215 & 0 & 215 & 0 & 100 & 0 \\
\hline 3 to 4 & 215 & 5 & 212.5 & 1 & 99.53 & 0.47 \\
\hline 4 to 5 & 209 & 4 & 207 & 1 & 99.05 & 0.67 \\
\hline 5 to 6 & 204 & 3 & 202.5 & 1 & 98.56 & 0.83 \\
\hline 6 to 7 & 200 & 6 & 197 & 1 & 98.06 & 0.96 \\
\hline 7 to 8 & 193 & 3 & 191.5 & 1 & 97.55 & 1.08 \\
\hline 8 to 9 & 189 & 6 & 186 & 0 & 97.55 & 1.08 \\
\hline 9 to 10 & 183 & 11 & 177.5 & 0 & 97.55 & 1.08 \\
\hline 10 to 11 & 172 & 79 & 132.5 & 0 & 97.55 & 1.08 \\
\hline 11 to 12 & 93 & 52 & 67 & 2 & 94.64 & 2.28 \\
\hline
\end{tabular}


included true revisions due to aseptic loosening (eight acetabular cups), probable revision due to signs of migration, radiolucent lines or osteolysis and the patients lost to follow-up (Figure 5.6 and Table 5.7).

Figure 5.6:

Worst-case scenario Kaplan Meier curve (inclusion parameters see Table 5.7).

Cumulative survival after 128 months was $91.05 \%\left(\mathrm{CI}_{95} 86.31-95.79\right)$

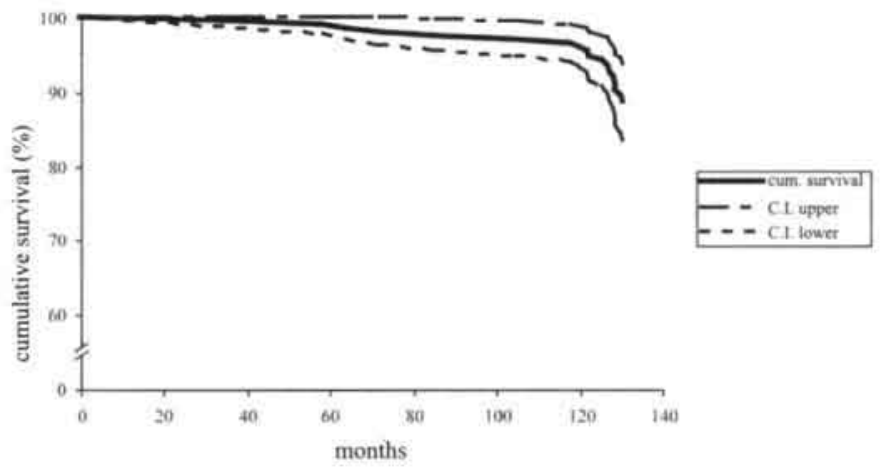

Table 5.7

Worst-case scenario life table: including the seven acetabular cups that had been revised due to aseptic loosening, the cup that had been revised after the study, all the cups with migration, radiolucent lines and osteolysis and the four patients lost to follow-up. After 11 years, the chance that a patient will not have had revision was $88.86 \%\left(\mathrm{Cl}_{v,} 83.84-93.88\right)$

\begin{tabular}{|c|c|c|c|c|c|c|}
\hline $\begin{array}{c}\text { years since } \\
\text { operation }\end{array}$ & $\begin{array}{c}\text { Number at } \\
\text { start }\end{array}$ & Withdrawn & $\begin{array}{c}\text { Number at } \\
\text { risk }\end{array}$ & Failure & $\begin{array}{c}\text { Survival rate } \\
(\%)\end{array}$ & $\begin{array}{c}\text { SE survival } \\
\text { rate }\end{array}$ \\
\hline 0 to 1 & 221 & 4 & 219 & 0 & 100 & 0 \\
\hline 1 to 2 & 217 & 2 & 216 & 0 & 100 & 0 \\
\hline 2 to 3 & 215 & 0 & 215 & 0 & 100 & 0 \\
\hline 3 to 4 & 215 & 5 & 212.5 & 1 & 99.53 & 0.47 \\
\hline 4 to 5 & 209 & 4 & 207 & 1 & 99.05 & 0.67 \\
\hline 5 to 6 & 204 & 3 & 202.5 & 1 & 98.56 & 0.83 \\
\hline 6 to 7 & 200 & 5 & 197.5 & 1 & 98.06 & 0.96 \\
\hline 7 to 8 & 194 & 2 & 193 & 1 & 97.55 & 1.08 \\
\hline 8 to 9 & 191 & 4 & 189 & 1 & 97.04 & 1.19 \\
\hline 9 to 10 & 186 & 11 & 180.5 & 1 & 96.5 & 1.3 \\
\hline 10 to 11 & 174 & 70 & 139 & 11 & 88.86 & 2.51 \\
\hline
\end{tabular}




\subsection{DISCUSSION}

This study confirmed the good results reported previously with the Zweymüller titanium cementless threaded cup $[1,57,167]$. As far as we know, our study with a follow-up of at least ten years (mean 134 months) has the longest follow-up period for this prosthesis. Furthermore, the study was designed so that the results were evaluated by researchers who had not been involved in the index operation. The arthroplasties had been performed by surgeons who were not specialized in hip surgery and at the time of the index operation, they did not know that a follow-up study would be conducted. Therefore, in our opinion, the results reflect the outcome of an unbiased long-term study in an aselect cohort of patients who had been operated on by general orthopaedic surgeons.

The Harris Hip Score, Oxford Hip Score, Merle D'Aubigné P.W.M. score, Hip Society level of activity and the U.C.L.A. activity level rating score were found to be excellent to good in the clinical study. The patients were satisfied with the result of arthroplasty. Seven cup prostheses had been revised due to aseptic loosening and the cup should be seen as the weak component of the prosthesis. Furthermore, seventeen cups showed radiolucent lines, osteolysis or migration. These cups could be at risk for aseptic loosening. Nevertheless, the survival for aseptic loosening was $95.96 \%\left(\mathrm{CI}_{95} 92.14-99.78\right)$ after 138 months and $91.05 \%$ $\left(\mathrm{Cl}_{95} 86.31-95.79\right)$ in the worst case scenario after 128 months.

In this study, radiological evaluation was conducted on the postoperative radiograph and two comparative standardized radiographs taken at FU. Although our approach had its drawbacks, a Roentgen Stereophotogrammetric analysis (RSA) study was impossible and an EBRA (Einzel-Bild-Röntgen-Analysis) would have required at least four comparative radiographs [135].

Measurement of the acetabular cup angle on consecutive radiographs did not reveal any change in cup position. We used the inter-teardrop line, which is considered to be reliable [184]. Another suitable method to evaluate acetabular migration would have been the Nunn method, in which the vertical and horizontal distance from the teardrop to the centre of the ball head is measured [220]. However, we decided not to use the Nunn method in view of the measurement error of $3 \mathrm{~mm}$ and because the study by Malchau indicated that only cup migration of more than $3-4 \mathrm{~mm}$ could be detected [184, 220]. Therefore, we made a qualitative assessment instead of giving a quantitative value for visible migration.

It was possible to take reliable measurements of the radiolucent lines around the acetabular component. The true lateral radiograph of the acetabulum provided a good view of three sides of the cup. Usually, only radiolucent lines of longer than two millimetres are considered [40, 133], but we recorded all the radiolucencies to better reflect the actual situation. Radiolucent lines were only noted around six cups. 
Visualization of the cups by means of true lateral radiographs also enabled the detection of osteolysis in nine cups. The presence of migration and radiolucent lines on the AP radiograph at FU one only showed slight correlation with osteolysis on the true lateral radiograph at FU two. Although this could be explained by the inability to detect osteolysis at FU one, we believe that migration and radiolucent lines may predict the development of osteolysis. As far as we know, this has not been reported previously.

On the true lateral radiograph of the acetabular cup, the amount of wear of the polyethylene insert was measured using the method described by Dorr et al [70]. Barrack et al performed a study to assess the correlation between the so-called shadowgraph technique and seven radiological methods to measure wear [11]. The shadowgraph method compares the diameter of a retrieved insert to the diameter of the original insert [146]. Barrack et al defined this technique as the golden standard and found that the Dorr method had the strongest correlation. Although the Livermore method has lower correlation, Ilchmann recommended it for clinical wear studies [136]. As the solid titanium shell obscures the periphery of the femoral head, the Livermore method is not suitable to evaluate wear in the Zweymüller cup prosthesis.

A possible disadvantage of the Dorr method is that wear is only measured in one direction (parallel to the acetabular cup), whereas polyethylene wear is multidirectional [2]. In fact, it had been reported that polyethylene wear is greatest on the dome of the cup [80]. Therefore, the Dorr method can be expected to underestimate the amount of wear in vivo. In our study, 105 cups (74\%) showed an average linear of $0.46 \mathrm{~mm}$, while annual wear was $0.04 \mathrm{~mm}$ (sd 0.02). Only seven cups had total linear wear of more than one millimetre. In a cohort of 127 Zweymüller acetabular cups, Grübl et al measured linear wear according to the method described by Charnley and Halley, which can be considered comparable with the Dorr method [105]. They found a mean linear wear of 1.1 $\mathrm{mm}$ after ten years, with an annual wear of $0.1 \mathrm{~mm}$. This is poorer than our result, but it should be noted that reproducibility of the wear measurements taken by the two investigators (the interclass correlation coefficient) was low in our study. Conversely, the low polyethylene wear might also explain the high interinvestigator variability. Nevertheless on the basis of our results, we conclude that the Zweymüller acetabular cup has low polyethylene wear.

One patient complained of pain at FU two and the radiographs showed cup migration with severe osteolysis. Linear wear of this cup was $0.79 \mathrm{~mm}$ (annual wear $0.06 \mathrm{~mm}$ ). Unfortunately, the true wear of the retrieved cup was not measured, which also applied to the seven other cups that had been revised due to aseptic loosening. According to the medical records, pain and osteolysis with cup migration were the reasons for revision in these seven cups. Our study on patients who had not undergone revision showed no correlation between the amount of wear and clinical deterioration of the prosthesis. It is generally accepted that polyethylene wear will lead to periprosthetic osteolysis $[11,116,146$, 
157]. Dowd et al pointed out that annual wear of less than $0.1 \mathrm{~mm}$ meant a lower risk of developing osteolysis, whereas annual wear of more than $0.3 \mathrm{~mm}$ could lead to osteolysis [71]. However, the amount of wear was not found to be correlated with the amount of periprosthetic osteolysis [116]. These discrepancies might be explained by an unknown cause of this man-made disease, but they may also be connected with the method used to measure the amount of wear in vivo, as mentioned above.

Initially, creeping of the femoral head causes penetration into the polyethylene insert $[151,172]$. Penetration progresses further by other wear mechanisms, such as adhesion, abrasion and fatigue. As we could only take one measurement, it was not possible to differentiate between creeping, wear or the resultant sum.

The aim of our study was to assess the results with the Zweymüller cementless titanium threaded cup. Long-term studies are necessary to determine the superiority of the cementless or cemented acetabular cup $[21,67]$. Our follow-up duration of 134 months was too short to match the studies on cemented types, but we found promising results with this cementless threaded cup. Laboratory studies showed favourable results with the threaded acetabular cup. Lord and colleagues performed a cadaver study in which conventional cemented cups were compared to cementless threaded cups [178]. They found that contrary to the cemented cup, the threaded cup had not changed the normal strain distribution in the pelvis. Huiskes reported that the first and last threads of a threaded cup transferred the load from the implant to the bone, as shown on a radiograph from the present study (Figure 5.7) [130]. Furthermore, Huiskes stated that the reaming of subchondral bone, as preparation for a cemented polyethylene cup, caused stress

Figure 5.7

True lateral view of the CSF cup. Bone density around the threads reflects load transfer (66-year-old woman; FU 139 months)

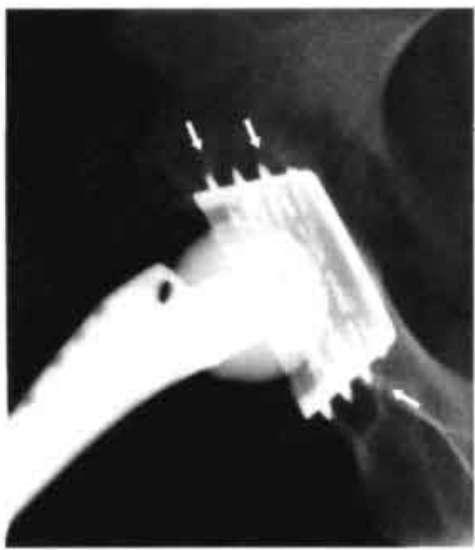
concentrations in the central and superior regions of the cement and the bone. However, the subchondral bone must be reamed to ensure adequate cement-bone fixation. A cementless threaded cup resolves this dilemma [130].

Various cementless acetabular systems are available and the best clinical results have been reported with the threaded cup and the press-fit component enhanced by screws and spikes, whether or not in combination with hydroxyapatite [211]. Several studies showed good short-term results, but less favourable long-term results with press-fit systems (Table 5.8) [13, 20, 76, 77, 152, 156, 168, 185, 203, 232, $235,283]$. Morscher et al reported that an additional cause of osteolysis could be hydroxyapatite particles, which stimulate osseointegration of press-fit cups that have come loose [210]. 
Table 5.8

Less favourable long-tem results reporied on several press-fit acelabular components

\begin{tabular}{|c|c|c|c|c|c|c|c|}
\hline guthor & year & prosthesis & $\mathbf{N}$ & $\begin{array}{l}\text { age (years) } \\
\text { at surgery }\end{array}$ & follow-up & $\begin{array}{l}\text { survival asepile } \\
\text { looseuling cup }\left(\mathrm{C}_{\%}\right)\end{array}$ & remarks \\
\hline Bettin [13] & 1995 & Judet & 83 & $46.3(29-68)$ & 10.8 yrs $(6-13)$ & 11 yrs $55.1 \%(\mathrm{nr})$ & $\begin{array}{l}61.5 \% \text { cup prosthesis radiological } \\
\text { loosening: } 14 \text { already revised. }\end{array}$ \\
\hline Bourne $[20]$ & 2001 & $\begin{array}{l}\text { Hex Loc Biomet } \\
\text { (Mallory Head stem } \\
\text { polyethylene-CoCr } \\
\text { head) }\end{array}$ & 307 & $64( \pm 10)$ & $10-13$ yrs & 10 yrs $90 \%(\pi r)$ & $\begin{array}{l}\text { I6 revisions for aseptic loosening cup } \\
\qquad \begin{array}{l}(5.2 \%) \\
14 \text { revisions for wear and osteolysis }(4.6 \%)\end{array}\end{array}$ \\
\hline Engh [77] & 1997 & AML Trispike & $174 *$ & $\$ 5(16-87)$ & 11 yrs $(10-13)$ & 12 yrs $92 \%( \pm 3 \%)$ & 4 revisions for aseptic loosening \\
\hline Engh [80] & 2001 & AML. Trispike & $204 *$ & $55(16-87)$ & 13.9 yrs $(2-18)$ & $\begin{array}{c}15 \text { yix } 95.3 \% \\
( \pm 3.4 \%)\end{array}$ & $\begin{array}{l}8 \text { revisions for aseptic loosening } \\
2 \text { unrevised aseptic loosening }\end{array}$ \\
\hline $\begin{array}{c}\text { Kawamura } \\
\text { [152] }\end{array}$ & 2001 & PCA & $187^{* \cdots *}$ & $61(20-81)$ & 12 yrs $(10-14)$ & $\begin{array}{c}14 \text { yrs } 92.7 \% \\
( \pm 5.1 \%)\end{array}$ & $\begin{array}{c}8 \text { revisions for aseptic loosening } \\
12 \text { radiological loosening }\end{array}$ \\
\hline $\operatorname{Kim}[156]$ & 1999 & PCA & 116 & $48.4(19-69)$ & $\begin{array}{l}11.2 \text { yrs } \\
(10-12)\end{array}$ & 12 yrs $89 \%$ (nr) & $\begin{array}{l}8 \text { revisions for aseptic loosening } \\
7 \text { revisions for wear of polyethylene insert } \\
65 \text { of } 116 \text { cups showed osteolysis }\end{array}$ \\
\hline Lai $[168]$ & 2002 & Landos Aloll HA coated & 85 & $50.2(29-71)$ & 10 yrs (nr) & nr & $\begin{array}{c}14 \text { revisions for aseptic loosening } \\
1 \text { revision for ostcolysis } \\
6 \text { loose and awaiting revision }\end{array}$ \\
\hline $\begin{array}{l}\text { Malchau } \\
\text { [185] }\end{array}$ & 1997 & PCA & 539 & $50.1(\mathrm{sd} 9.7)$ & $6.8 \mathrm{yrs}(\mathrm{nr})$ & 7 yrs $94.2 \%(\mathrm{nr})$ & $\begin{array}{l}18 \text { revisions for aseptic loosening } \\
88 \text { cups migrated at } 1 \text { yr and } 96 \text { cups at } 7 \\
\text { yIs }\end{array}$ \\
\hline Menon $[203]$ & 1999 & Freeman & 68 & $49.7(21-72)$ & $\begin{array}{c}66 \text { months } \\
(3-103)\end{array}$ & IIr & 9 revisions for aseptic loosening \\
\hline $\begin{array}{l}\text { Puolakki } \\
{[232]}\end{array}$ & 2001 & porous-coaled Biomel & 107 & $57(28-77)$ & $\begin{array}{l}74 \text { months } \\
(47-91)\end{array}$ & $\pi r$ & $\begin{array}{l}12 \text { cups migrated } \\
\text { high linear wear } 0.22 \mathrm{~mm} / \mathrm{yr}\end{array}$ \\
\hline $\begin{array}{l}\text { Reikeris } \\
{[236]}\end{array}$ & 2002 & $\begin{array}{l}\text { Landos Corail HA- } \\
\text { coated }\end{array}$ & 191 & $47(15-78)$ & $7-10 \mathrm{yrs}$ & nr & $\begin{array}{l}39 \text { revisions for aseptic toosening } \\
2 \text { unrevised osleolysis }\end{array}$ \\
\hline$X e n o s[283]$ & 1999 & PCA & 100 & $58(22-81)$ & $\begin{array}{l}11.6 \text { yrs } \\
\{10-13)\end{array}$ & $\mathrm{nr}$ & $\begin{array}{l}8 \text { revisions for aseptic loosening } \\
4 \text { unrevised aseptic loosening } \\
9 \text { acetabular osteolysis }\end{array}$ \\
\hline
\end{tabular}


The press-fit design of the Porous-Coated Anatomic cup is nonmodular with two superior lugs for additional fixation. Long-term studies on PCA total hip prostheses revealed unacceptably high incidences of thigh pain because of polyethylene wear, with subsequent high incidences of revision for aseptic loosening of both components $[152,156,185,224]$. Kawamura et al recommended abandoning the use of PCA total hip prostheses [152].

The Harris Galante cementless cup with screw fixation had low implant failure, but several studies showed high incidences of periacetabular osteolysis, which could lead to clinical problems [237, 258, 264]. Furthermore, supplemental screw fixation could lead to vascular damage and "fretting wear" between the shell and screws [248]. In the same study, Schmalzried et al did not observe any acetabular osteolysis after 56 months in 122 Harris Galante cementless socket arthrosplasties without screw fixation.

Success rates with cementless threaded cup devices vary. Engh et al reported disappointing short-term results with the cementless threaded Mecron cup and the comparable Anderson cup [78]. These threaded cups had an open metal dome so that the polyethylene insert was not covered. Bruijn pointed out that this direct contact between polyethylene and bone led to bone resorption and cup loosening [27]. Probably, the closed dome of the Zweymüller threaded cup, without direct contact between the polyethylene insert and the bone, avoided the Mecron cup disaster.

The Link Rippen System cementless threaded cup showed 89 per cent survival after seven years [244]. The PM threaded cup showed 88.8 per cent survival after six years [63]. The Omnifit cementless hydroxyapatite coated screw-cup showed 99 per cent survival after six years, although radiolucent line formation around the cup progressed with time; recently, $93 \%$ survival has been reported after 12 years [99-101]. Capello et al reported the United States Multicentre Study on hydroxyapatite-coated implants: out of the original 38 threaded cups, one cup had been revised due to aseptic loosening and one cup due to osteolysis. The average follow-up of the cohort was 8.1 years (range 5.6 - 9.9 years) [35].

Our study revealed 96 per cent survival of the cementless threaded cup after 134 months, with a worse-case scenario survival of 91 per cent. Other autors have reported similar results with the Zweymüller cup prosthesis. Aigner found 92.6 per cent survival of the same Zweymüller threaded cup after ten years, while Delaunay et al found a survival of 98.75 per cent after ten years [1, 60]. Grübl mentioned five revisions due to aseptic loosening in an original cohort of 208 arthroplasties; after 120 months, cumulative survival was $92 \%$ [105] . In a cohort of 104 Alloclassic Zweymüller total hip prostheses, Garcia-Cimbrelo et al found that three cups had been revised because of aseptic loosening and an additional four cups were loose without any clinical signs of decline after 11.3 years [92]. Although it is well-known that results can deteriorate with time, we conclude that this study revealed good long-term results with the Zweymüller cementless threaded cup. 


\subsection{CONCLUSION}

This study showed good results with the Zweymüller cementless threaded titanium cup after a follow-up of 134 months. Seven out of the 221 acetabular cups had been revised due to aseptic loosening. Wear of the polyethylene insert was low. Cumulative survival was $96 \%$, while survival in the worst case scenario was $91 \%$. 



\section{Two Designs of the ZweymülleR Cementless Stem Prosthesis}

A cohort study with at least ten years of follow-up

\subsection{ABSTRACT}

Unbiased physicians evaluated 78 Hochgezogen (HG) and 64 Stepless (SL) Zweymüller cementless, stem prostheses 134 months (sd 9.5) after implantation and found no differences between the clinical results of the two stem prostheses.

None of the stem prostheses had been revised due to aseptic loosening. Radiolucent lines were visible in Gruen zone 1 on more than one third of the Xrays and in Gruen zone 7 on about 30 per cent. Bone apposition was common at the tip of the stem prostheses.

Twenty-seven stem prostheses showed an average subsidence of $0.62 \mathrm{~mm}$ (sd 1.2). All the stem prostheses were stable.

Worst-case scenario survival after 138 months was $92.95 \%$ and the probability for revision was $4.72 \%$.

This study confirmed the excellent long-term results with the Zweymüller stem prostheses, with only slight differences between the two stem designs. 


\section{2}

In the historic cohort study (Chapter 3 ) we observed good middle and longterm results with the cementless Zweymüller total hip arthroplasty system. Two generations of stems (HG and SL) were used. Only slight differences were found between the two stem versions. Patients with an SL stem prosthesis had higher Harris Hip Scores and the statistical analysis showed that these patients had less pain and higher scores for gait and daily activities. Radiological analysis revealed more proximal radiolucent lines and calcar atrophy with the HG stem prosthesis, perhaps due to distal fixation of this stem prosthesis.

The primary aim of the historic cohort study was to assess the clinical outcome. This study assessed the long-term clinical and radiological results with the two versions of the cementless Zweymüller stem prostheses and determined whether there were any differences between the two stem prostheses.

\subsection{MATERIALS AND METHODS}

The first generation of Zweymüller cementless femoral stem prostheses (Allopro, Switzerland) had a wedged-shaped, rectangular, collarless stem made of wrought titanium (Ti-6Al-4V) with bead blasting and a mean surface roughness of $1 \mu \mathrm{m}$. In the sagittal plane, the stem narrowed proximally (HG) to prevent splitting the femur during implantation. There were two longitudinal grooves on the ventral and dorsal sides intended to stimulate osseointegration. Dissatisfaction with the steps in consecutive size that resulted in less favourable fit in the femur as well as poorer osseous fixation (due to the grooves and proximal thinning) led to the development of the SL stem prosthesis [102]. This second generation of Zweymüller stem prostheses is wedge-shaped in the frontal and sagittal planes. Consecutive stem sizes increase steplessly and proportionally. In addition, the toxic vanadium in the titanium alloy has been changed to niobium (Ti-6Al-7 Nb). A microstructure of $3-5 \mu \mathrm{m}$ can be obtained by corundum blasting [59, 289].

The primary stability of the two tapered stems is achieved by press-fit and is enhanced by the broad mediolateral width to ensure rotational stability [74]. After an initial stage with less bone-implant contact, the prosthesis becomes fixed along the edges within a frame of cortical bone. The titanium alloy is expected to stimulated osseointegration [16].

A total of 221 arthroplasties were performed in 211 patients at five Dutch hospitals between 1 January 1987 and 31 December 1990. In all the patients the pre-operative diagnosis was idiopathic osteoarthritis. There were 58 men and 153 women. Mean age at primary surgery was 64.7 years (sd 8.4). Ninety-seven patients were classified as Charnley class A, 69 patients as class B and 55 patients as class C. Patient selection is described in Chapter 5. 
In 1996, we performed clinical and radiological follow-up studies, which were repeated in 2000. Follow-up one (FU one) was performed at 86 months (sd 9.1) and follow-up two (FU two) at 134 months (sd 9.5) after surgery. Evaluations were made by physicians who had not been involved in the primary surgery (A.M.J.S. Vervest, F. van Hout, FH. Wapstra, R.T. Louwerse).

At follow-up two, 42 patients (44 prostheses) had died of causes unrelated to the index operation. Eight acetabular components had been revised, versus only one stem (and cup) prosthesis due to septic loosening. Nine patients were unable to come to the out-patient clinic, so they were visited at home by the investigators. Four patients ( 6 prostheses) did not participate, because of dementia or refusal. Seven patients completed a questionnaire sent to them by mail. These patients had no complaints and no revision procedures had been conducted. Four patients (4 prostheses) who attended FU one could not be traced at FU two and were lost to follow-up. To our knowledge, none of these stem prostheses had been revised due to aseptic loosening. A total of 136 patients (142 prostheses) were evaluated.

Clinical evaluation was performed with the Harris Hip Score and Merle d'Aubigné P.W.M. scores [112, 204]. Charnley classification was assessed [38]. At FU two, all the patients also completed the Oxford Hip Score, the U.C.L.A. activity level rating score and the Hip Society level of activity [7, 53, 142].

We measured the height and weight of all the patients. The Body Mass Index was calculated as the ratio of body weight (kilograms) to height (metres ${ }^{2}$ ) [222].

Standardized anteroposterior radiographs were taken of the pelvis, including anteroposterior and lateral views of the affected hip. At FU one and FU two true measurements were taken with a computerized device (X-calliper ${ }^{\circledR}$, Eisenlohr Technologies, California, U.S.A.).

The cementless prostheses were evaluated radiologically according to Johnston et al [142]. Gruen zones were used to evaluate the femoral side [107]. When preoperative radiographs were available, the canal flare index was measured according to Noble [218]. The canal flare index is defined as the ratio between the width of the medullary canal $20 \mathrm{~mm}$ proximal to the lesser trochanter and the width of the medullary canal at the isthmus (Figure 6.1). A canal flare index of greater than 4.7 was judged as a champagne

Figure 6.1

Preoperative radiograph demonstrating the canal flare index [217]: the ratio between the width $20 \mathrm{~mm}$ proximal to the lesser trochantor (arrow A) and the width of the medullary canal at the istmus (arrow B)

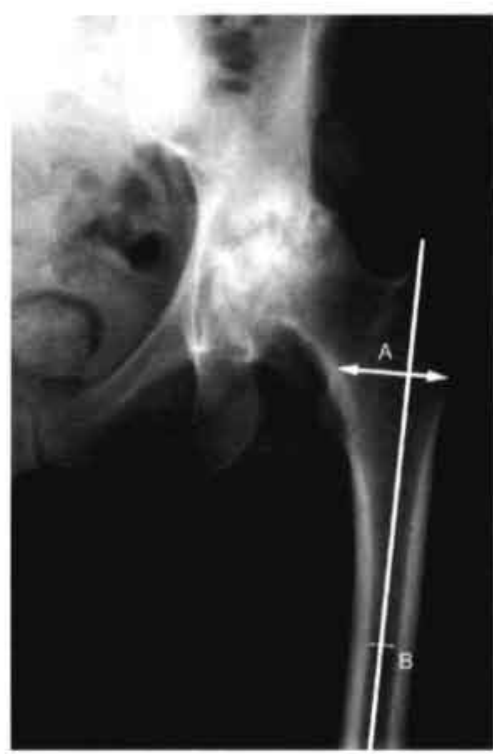


Figure 6.2

Preoperative radiograph showing a canal flare index of 4.71: champagne flute

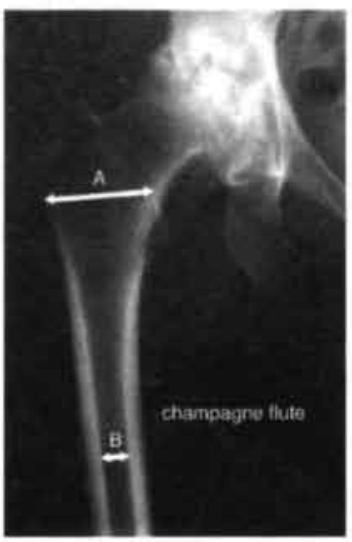

fluted canal shape (Figure 6.2); a canal flare index of less than 3.0 was classified as a stove pipe canal shape (Figure 6.3). A canal flare index of between 3.0 and 4.7 represented a normal shape femoral canal [217].

We also assessed the cortical index. This index was defined as the ratio between the width of the medullary canal at the tip of the stem prosthesis and the outer diameter of the femur at the same level (Figure 6.4) [121]. Cortical indices were obtained at FU one and FU two on the prosthesis side as well as on the non-prosthesis side (Figure 6.5).

Radiolucent line formation, cortical reactions, bone apposition and osteolysis were recorded. Radiolucent line formation was defined as increased linear bone density parallel to the prosthesis. Cortical reactions were defined as increased density of the femoral cortical bone around the prosthesis. The length and width of radiolucent lines

and cortical reactions were measured.

Figure 6.4

Radiological evaluation of a stem prosthesis. The cortical index was measured. The angle between the midline of the femur and the midline of the prosthesis was classified as varus, valgus or neutral. Subsidence and calcar width and height were also measured (see text)

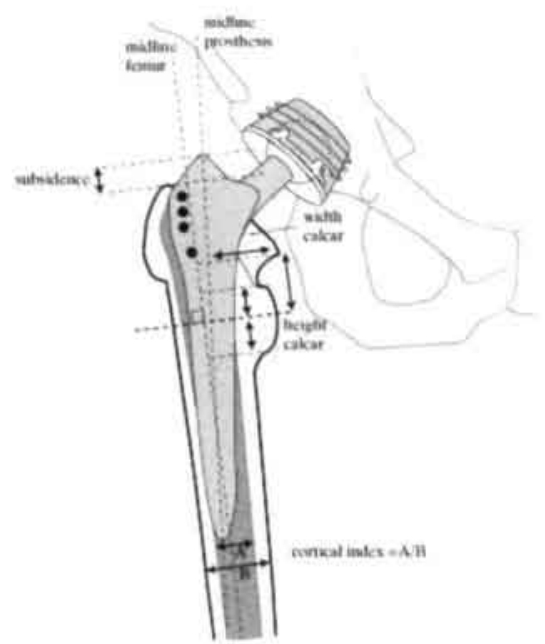

Figure 6.3

Preoperative radiograph demonstrating a stove pipe femoral canal (canal flare index 2.36)

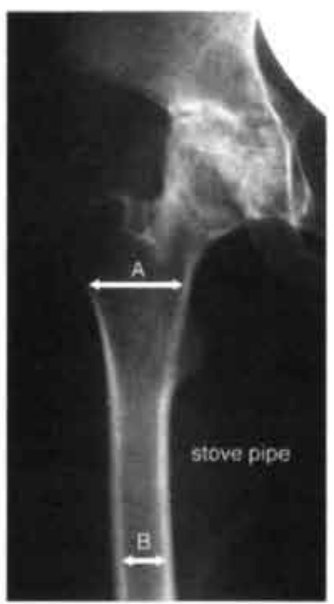
Bone apposition was defined as the formation of new bone around the tip of the stem prosthesis. Decreased femoral bone density was classified as osteolysis.

On the AP radiograph view of the femur, a line was drawn from the top of the prosthesis to the distal end and another line was drawn through the longitudinal centre of the femur. The angle between these lines formed the basis for the classification of varus, valgus or neutral position of the stem (Figure 6.4).

Femoral subsidence was classified as unchanged or increased. Subsidence was measured from the top of the trochantor major to the top of the prosthesis (Figure 6.4).

Fixation and stability scores were assessed according to Engh (Appendix 1; 
Figure 6.5

Radiographs showing widening of the femoral canal and an increase in cortical index
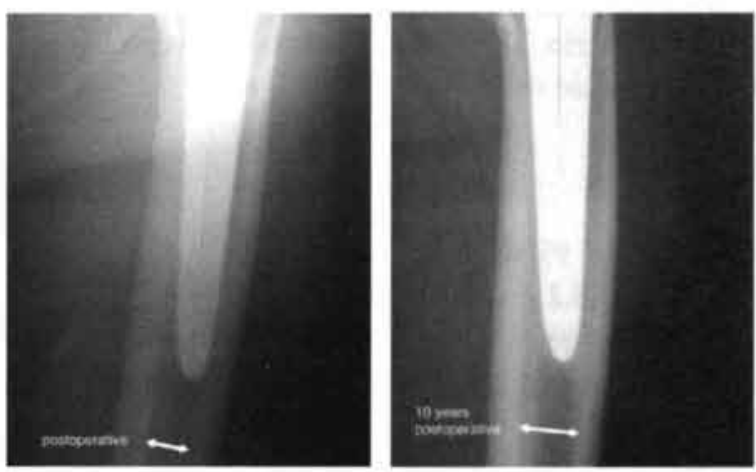

Figure 6.6) and the degree of heterotopic ossification was classified according to Brooker $[26,82]$.

Calcar remodelling was classified as unchanged, atrophic, or hypertrophic. Atrophy of the calcar was defined as flattening and diminishing of the calcar (Figure 6.7). Osseous outgrowth of the calcar was considered to indicate hypertrophy. We measured the width and height of the calcar. The distance from the calcar to the prosthesis line was taken as the width of the calcar (Figure 6.4). The distance from the middle of the calcar to the top was taken as the calcar height (Figure 6.4). These distances were compared at FU one and FU two.

Figure 6.6

A spot weld according to the Engh fixation and stability score

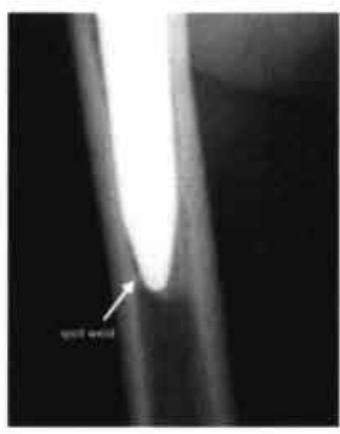

Figure 6.7 Radiographs demonstrating calcar remodelling (atrophy)

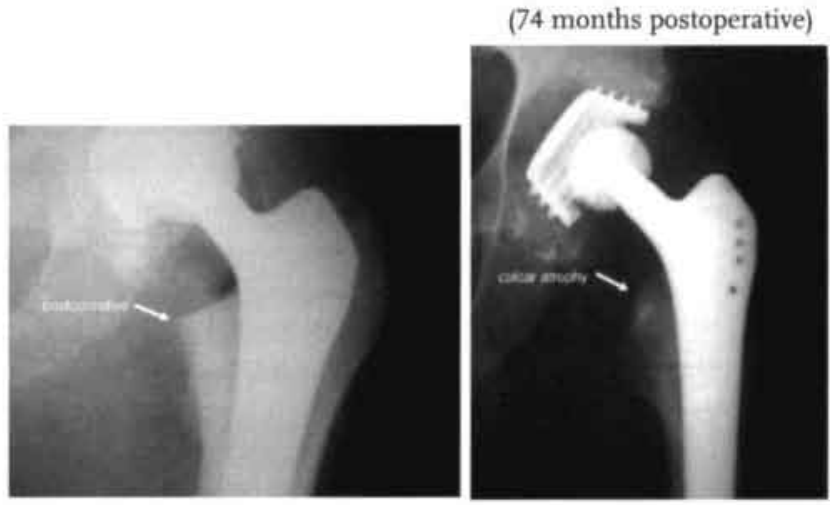

Radiological evaluation was performed by two investigators (A.M.J.S. Vervest, J.W.A. Koetsier) on 142 prostheses in 136 patients. Intraclass Correlation Coefficients varied: 0.94 to $0.98\left(\mathrm{CI}_{95}\right.$ lowest 0.80 - highest 0.99$)$ for measurements of the femoral stem, $0.60\left(\mathrm{CI}_{95}-0.03-0.88\right)$ for fixation and stability scores according to Engh and $0.99\left(\mathrm{CI}_{95} 0.96-0.99\right)$ for the Noble measurements.

Statistical analysis was performed with Pearson's and Spearman's correlation coefficients, the ANOVA test, Student's t-test and the Chi-square test. Significance was defined as a p-value of less than 0.05 .

Kaplan Meier curves and life tables were used [148, 213]. Survival curves and life tables were truncated when confidence intervals exceeded $5 \%$ of the cumulative 
survival. None of the stem prostheses had been revised for aseptic loosening. Worst-case scenarios with probable revision due to aseptic loosening were created on the basis of subsidence and osteolysis. Patients who were lost to follow-up were included as failures in the worst-case scenario. The median interval between FU one and FU two was taken as the time of possible revision.

\subsection{RESULTS}

The study group comprised 41 men and 95 women; average age at the time of surgery was 61.1 years (sd 8.1), at FU one 68.2 years (sd 8.0) and at FU two 72.2 years (sd 7.9). Harris Hip Scores at FU two averaged 89.7 (sd 12.8). Generally, the patients were satisfied with the result of the index operation. Details about the clinical results are presented in Chapter 5.

The study population had received 78 Hochgezogen (HG) and 64 Stepless (SL) stem prostheses. Table 6.1 and Figure 6.8 summarize the differences between the two femoral stem prostheses; the differences were not statistically significant (Chi-Square $\mathrm{p}=0.508$ pain score; $\mathrm{p}=0.865$ PWM class). Only the follow-up duration of the HG prostheses was longer $(\mathrm{p}=0.000)$, because the SL prosthesis was introduced later.

Table 6.1

Clinical results of the study group per type of stem prosthesis. The Hochgezogen stem prosthesis had longer follow-up, because this prosthesis had been longer in use. The other differences between the two stem prostheses were not statistically significant

\begin{tabular}{|l|c|c|}
\hline & $\begin{array}{c}\text { Hochgezogen prosthesis } \\
(\mathbf{N = 7 8 )}\end{array}$ & $\begin{array}{c}\text { Stepless prosthesis } \\
(\mathbf{N}=64)\end{array}$ \\
\hline Age at surgery & 61.5 years (sd 8.1) & 60.5 years (sd 8.2) \\
\hline Age at FU one & 68.9 years (sd 7.9) & 67.4 years (sd 8.2) \\
\hline Age at FU two & 72.9 years (sd 7.9) & 71.4 years (sd 7.9) \\
\hline Time FU one & 88.8 months (sd 9.6) & 82.7 months (sd 7.4) \\
\hline Time FU two & 136.3 months (sd 10.3) & 130.2 months (sd 7.3) \\
\hline Male/female & $19 / 59$ & $24 / 40$ \\
\hline Leftright & $42 / 36$ & $30 / 34$ \\
\hline BMI at FU one & $27.2($ sd 4.1) & 28.1 (sd 4.3) \\
\hline BMI at FU two & 27.9 (sd 4.2) & 27.6 (sd 4.6) \\
\hline HHS FU one & 91.9 (sd 9.2) & 90.6 (sd 11.9) \\
\hline HHS FU two & $90.0($ sd 11.0) & $89.4(14.7)$ \\
\hline
\end{tabular}




\section{Figure 6.8}

P.W.M. classifications and pain scores. Differences between the two stem prostheses were not statistically significant.
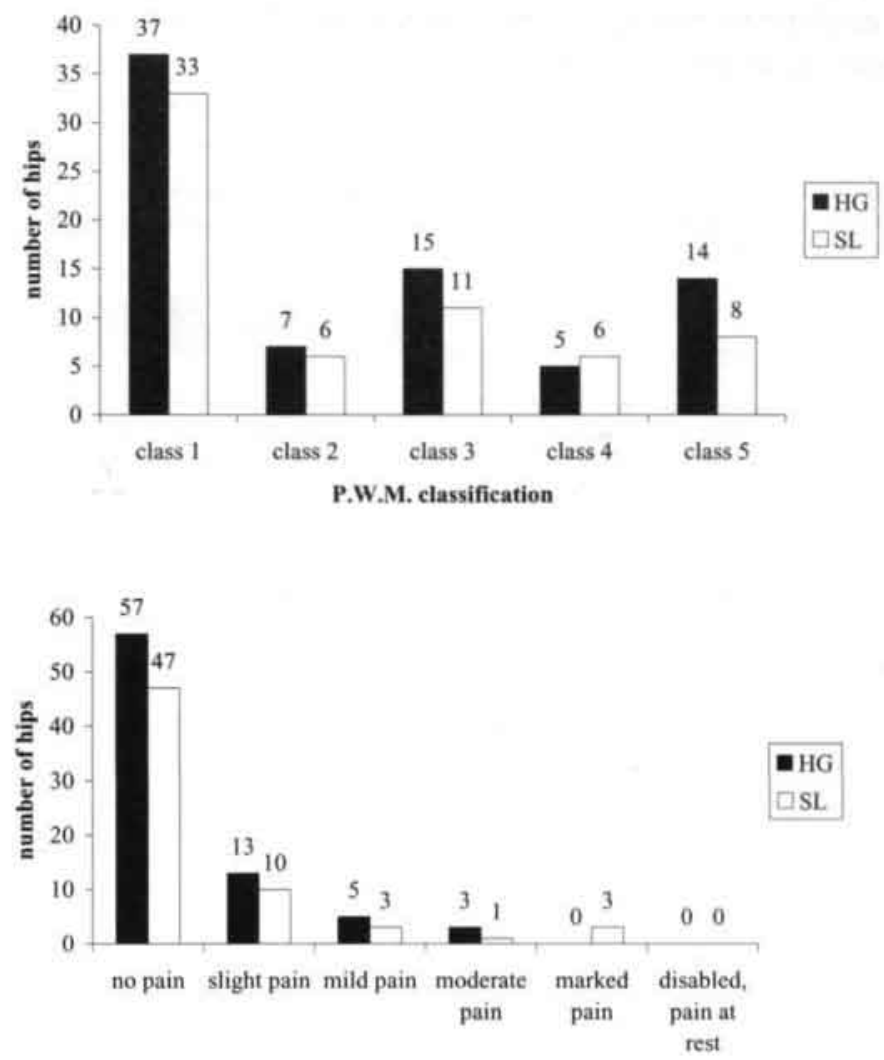

Pain score

The canal flare index could be assessed on 79 preoperative radiographs $(55.6 \%)$. Five femora ( 2 men, 3 women) were classified as champagne fluted, 38 femora $(7$ men, 31 women) as normal and 36 femora ( $12 \mathrm{men}, 24$ women) as stove pipe (Table 6.2). We found no differences in age at the time of the surgery or the shape of the femoral canal (Anova F $(2,75)=0.4, \mathrm{p}=0.6723$; Pearson's correlation coefficient $0.2 ; \mathrm{p}=0.06$ ).

The average cortical index on the preoperative radiographs was 0.436 (sd 0.066 ) on the prosthesis side and 0.434 (sd 0.063 ) on the non-prosthesis side. At FU two, the cortical index was 0.443 (sd 0.064) on the prosthesis side and 0.445 (sd 0.074 ) on the non-prosthesis side. The differences are within the measurement error.

All the radiographs taken shortly after the index operation could be evaluated. There were no signs of radiolucent lines, cortical reactions, bone apposition or osteolysis. On the radiographs obtained at $\mathrm{FU}$ one and $\mathrm{FU}$ two these signs were visible. 
Radiolucent lines were only seen in Gruen zones 1 and 7 (Table 6.3). Nine HG stem prostheses (11.5\%) and five SL prostheses $(7.8 \%)$ showed progression of these radiolucent lines in Gruen zone 1 between FU one and FU two, while three HG (3.8\%) and two SL prostheses (3.1\%) showed progression in Gruen zone 7. Radiolucent lines were seen in Gruen zones 1 and 7 around nineteen HG $(24.4 \%)$ and thirteen SL prostheses $(20.3 \%)$ at FU two.

Table 6.2

The canal flare index (C.F.I.) on the prosthesis side measured on preoperative $\mathrm{X}$-rays $(\mathrm{n}=79)$. Differences were not statistically significant. There was no correlation between age at the time of surgery and the shape of the femoral canal

\begin{tabular}{|c|c|c|c|}
\hline & & \\
\hline & & Male & Female \\
\hline \multirow[t]{3}{*}{ Champagne flute } & 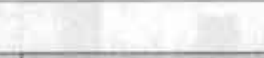 & 2 & 3 \\
\hline & Age at surgery (sd) & 60.3 years $(0.6)$ & 60.9 years $(10.5)$ \\
\hline & Average C.F.I. (sd) & $5.51(0)$ & $4.78(0.09)$ \\
\hline \multicolumn{2}{|l|}{ Normal } & 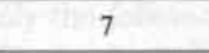 & 31 \\
\hline & Age at surgery (sd) & 55.9 years $(5.6)$ & 59.9 years $(9.24)$ \\
\hline & Average C.F.I. (sd) & $3.46(0.39)$ & $3.52(0.36)$ \\
\hline \multicolumn{2}{|l|}{ Stove pipe } & 12 & 24 \\
\hline & Age at surgery (sd) & 59.5 years $(7.1)$ & 61.6 years $(6.4)$ \\
\hline & Average C.F.I. (sd) & $2.51(0.36)$ & $2.64(0.28)$ \\
\hline
\end{tabular}

Table 6.3

Mean length and width radiolucent lines

\begin{tabular}{|c|c|c|c|c|c|}
\hline & & \multicolumn{2}{|c|}{$\begin{array}{l}\text { Hochgezogen prosthesis } \\
\qquad(N=78)\end{array}$} & \multicolumn{2}{|c|}{$\begin{array}{l}\text { Stepless prosthesis } \\
(N=64)\end{array}$} \\
\hline & & FU one & FU two & FU one & FU two \\
\hline \multirow{3}{*}{$\begin{array}{l}\text { Gruen } \\
\text { zone I }\end{array}$} & $\begin{array}{c}\text { Number of X-rays } \\
(\%)\end{array}$ & $31(39.7 \%)$ & $33(42.3 \%)$ & $24(37.5 \%)$ & $27(42.2 \%)$ \\
\hline & Length (mm) & 28.8 (sd 16.4) & $\begin{array}{c}29.3(\mathrm{sd} \\
16.9)\end{array}$ & $28.8(\mathrm{sd} \mathrm{14.1)}$ & 31.3 (sd 15.7) \\
\hline & Width (mm) & $1.7(\mathrm{sd} 0.6)$ & 2.1 (sd 1.0) & $2.0($ sd 0.8$)$ & $2.2(\mathrm{sd} 1.1)$ \\
\hline \multirow{3}{*}{$\begin{array}{l}\text { Gruen } \\
\text { zone } 7\end{array}$} & $\begin{array}{c}\text { Number of X-rays } \\
(\%)\end{array}$ & $23(29.5 \%)$ & $27(34.6 \%)$ & $13(20.3 \%)$ & $13(20.3 \%)$ \\
\hline & Length (mm) & $29.5(\mathrm{sd} \mathrm{11.5})$ & $\begin{array}{c}28.9(\mathrm{sd} \\
11.8)\end{array}$ & 31.1 (sd 11.8) & 34.9 (sd 12.5) \\
\hline & Width (mm) & $1.4(\mathrm{sd} 0.5)$ & $1.5(\mathrm{sd} 0.6)$ & $1.8(\mathrm{sd} \mathrm{0.7)}$ & $2.0(\mathrm{sd} 0.7)$ \\
\hline
\end{tabular}


Cortical reactions developed in Gruen zones 3 and 5; the lengths and widths are summarized in Table 6.4. The canal flare index did not correlate with the presence of a cortical reaction.

Bone apposition was often seen in Gruen zone 4 (at the tip of the prosthesis). At FU one, 46 HG stem prostheses $(59.0 \%)$ had bone apposition in zone 4 , which increased to 59 prostheses $(75.6 \%)$ at FU two. The SL prostheses showed bone apposition in 48 prostheses $(75.0 \%)$ at FU one and in 51 prostheses $(79.7 \%)$ at FU two. The difference between the HG and the SL stem prostheses was statistically significant at $\mathrm{FU}$ one (Chi-square $\mathrm{p}=0.045$ ), but at $\mathrm{FU}$ two, no difference was seen between the two stem prostheses (Chi-square $\mathrm{p}>0.05$ ).

Osteolysis was visible in the femur around two HG prostheses: once in Gruen zone 1 and once in Gruen zone 7.

Table 6.4

Mean length and width cortical reactions

\begin{tabular}{|c|c|c|c|c|c|}
\hline & & \multicolumn{2}{|c|}{$\begin{array}{l}\text { Hochgezogen prosthesis } \\
\qquad(\mathrm{N}=78)\end{array}$} & \multicolumn{2}{|c|}{$\begin{array}{l}\text { Stepless prosthesis } \\
\qquad(N=64)\end{array}$} \\
\hline & & FU one & FU two & FU one & FU two \\
\hline \multirow{3}{*}{$\begin{array}{l}\text { Gruen } \\
\text { zone } 3\end{array}$} & Number of X-rays $(\%)$ & $2(2.6 \%)$ & $3(3.8 \%)$ & $3(4.7 \%)$ & $3(4.7 \%)$ \\
\hline & Length (mm) & $23.5(\mathrm{sd} 8.9)$ & $21.7(\mathrm{sd} 7.1)$ & $30.9(\mathrm{sd} \mathrm{5.2)}$ & 30.9 (sd 5.2) \\
\hline & Width (mm) & $1.8(\mathrm{sd} 0.1)$ & $1.4(\mathrm{sd} 0.5)$ & 1.1 (sd 0.3) & 1.1 (sd 0.5) \\
\hline \multirow{3}{*}{$\begin{array}{l}\text { Gruen } \\
\text { zone } 5\end{array}$} & Number of X-rays (\%) & $12(15.4 \%)$ & $15(19.2 \%)$ & $8(12.5 \%)$ & $9(14.1 \%)$ \\
\hline & Length (mm) & 27.8 (sd 6.6) & $29.9(\mathrm{sd} 8.0)$ & $\begin{array}{l}40.7 \text { (sd } \\
13.4)\end{array}$ & $\begin{array}{c}45.1 \text { (sd } \\
13.3)\end{array}$ \\
\hline & Width (mm) & $2.9(\mathrm{sd} \mathrm{3.1})$ & $2.3(\mathrm{sd} 1.7)$ & $1.2(\mathrm{sd} 0.5)$ & $1.3(\mathrm{sd} 0.5)$ \\
\hline
\end{tabular}

Table 6.5 and Figure 6.9 show the radiological analysis of the two stem prostheses.

Remarkably, some prostheses showed radiolucent lines in Gruen zones 1 and 7, and bone apposition in zone 4. This combination was present in $17 \mathrm{HG}$ stem prostheses $(21.7 \%)$ and 12 SL prostheses $(18.8 \%)$. The difference between the two stem prostheses was not statistically significant. 
Table 6.6

Harris Hip Scores and the angle of the stem in the femoral canal. " 0 " degrees denotes that the midline of the prosthesis and the femur coincided. "1" to " 6 " degrees between the midline of the stem and the femur means varus positioning (see also Fig 6.4). Differences in Harris Hip Seores were not statistically significant

\begin{tabular}{|c|c|c|}
\hline $\begin{array}{c}\text { angle of the stem in } \\
\text { degrees }\end{array}$ & $\begin{array}{c}\text { number of prostheses } \\
(\mathrm{n}=142)\end{array}$ & Harris Hip Score (sd) \\
\hline 0 & 82 & $88.1(13.9)$ \\
\hline 1 & 3 & $85.24(17.3)$ \\
\hline 2 & 15 & $93.3(8.7)$ \\
\hline 3 & 13 & $93.6(7.5)$ \\
\hline 4 & 13 & $90.9(16.1)$ \\
\hline 5 & 10 & $95.4(6.9)$ \\
\hline 6 & 6 & $83.9(8.1)$ \\
\hline
\end{tabular}

Figure 6.10

Relation between the position of the femoral stem and the Harris Hip Score. A stem position of " 0 " degrees denotes neutral position, while a stem position of " 1 " means 1 degree of varus (see also legend Table 6.6)

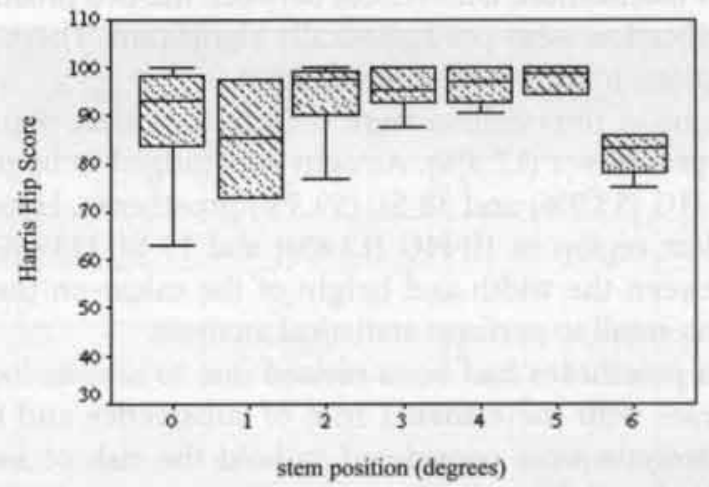

Migration of the stem prosthesis was seen on 27 radiographs between FU one and FU two. Seventeen HG (21.8\%) and ten SL prostheses (15.6\%) showed an average subsidence of $0.62 \mathrm{~mm}$ ( $\mathrm{sd}$ 1.2). More than $1 \mathrm{~mm}$ of subsidence was present in seven of these stems (all HG stems). All the stem prostheses were stable according to the Engh fixation and stability score (Table 6.7). 
Table 6.7

Engh Fixation and Stability score

Differences between the number of X-rays was caused by refusal of some patients. One patient with a Hochgezogen stem and two patients with a Stepless stem refused to have X-rays at FU one.

Differences between the two stem prostheses at FU one and FU two were not statistically significant (Chi-square $p>0.062$ )

\begin{tabular}{|c|c|c|c|c|c|}
\hline & \multicolumn{2}{|c|}{ Hochgezogen prosthesis } & \multicolumn{2}{|c|}{ Stepless prosthesis } \\
\hline & & FU one & FU two & FU one & FU two \\
\hline \multirow{4}{*}{$\begin{array}{l}\text { Total } \\
\text { Score }\end{array}$} & $\begin{array}{l}\text { Unstable } \\
\text { (score }<-10 \text { ) }\end{array}$ & 0 & 0 & 0 & 0 \\
\hline & $\begin{array}{l}\text { Suboptimum, but stable (score }-10 \\
\leftrightarrow 0 \text { ) }\end{array}$ & $3(3.8 \%)$ & $4(5.2 \%)$ & $2(3.2 \%)$ & $3(4.7 \%)$ \\
\hline & $\begin{array}{l}\text { Ingrowth probably } \\
\text { (score } 0 \leftrightarrow+10 \text { ) }\end{array}$ & $17(22.1 \%)$ & $20(25.6 \%)$ & $9(14.5 \%)$ & $8(12.5 \%)$ \\
\hline & $\begin{array}{l}\text { Bone ingrowth } \\
(\text { score }>+10)\end{array}$ & $\begin{array}{c}57 \\
(74.1 \%)\end{array}$ & $\begin{array}{c}54 \\
(69.2 \%)\end{array}$ & $\begin{array}{c}51 \\
(82.3 \%)\end{array}$ & $\begin{array}{c}53 \\
(82.8 \%)\end{array}$ \\
\hline & & $N=77$ & $\mathrm{~N}=78$ & $\mathrm{~N}=62$ & $N=64$ \\
\hline
\end{tabular}

Thirty HG stem prostheses $(38.5 \%)$ and 23 SL prostheses $(35.9 \%)$ did not show any heterotopic ossification, whereas two HG (2.6\%) and 1 SL (1.6\%) prosthesis had Brooker grade 4 ossification. Differences between the two prostheses regarding heterotopic ossification were not statistically significant. There had been no surgical re-interventions to remove this ossification.

At FU two, no signs of remodelling were seen in the calcar region in $26 \mathrm{HG}$ $(33.3 \%)$ and 11 SL prostheses $(17.3 \%)$. Atrophy was judged to be present in the calcar region in $42 \mathrm{HG}(53.9 \%)$ and $38 \mathrm{SL}(59.3 \%)$ prostheses. Hypertrophy was classified in the calcar region in $10 \mathrm{HG}(12.8 \%)$ and $15 \mathrm{SL}(23.4 \%)$ prostheses. The differences between the width and height of the calcar on the consecutive radiographs were too small to perform statistical analysis.

None of the stem prostheses had been revised due to aseptic loosening. The seven stem prostheses with more than $1 \mathrm{~mm}$ of subsidence and the two stem prostheses with osteolysis were considered to hold the risk of aseptic loosening and were included as failures in the worst-case scenario survival curve and life table (Figure 6.11 and Table 6.8). Also, the four prostheses lost to follow-up were included as failures. The cumulative worst-case scenario survival after 138 months was $92.95 \%\left(\mathrm{CI}_{95} 97.81-88.09 \%\right)$. The probability of revision was $4.72 \%$ $\left(\mathrm{CI}_{95} 1.2-8.24 \%\right)$ after 11 years. 


\section{Figure 6.11}

Worst-case scenario Kaplan Meier curve (inclusion criteria see table 6.8).

Cumulative worst-case survival after 138 months was $92.95 \%\left(\mathrm{Cl}_{6 \varsigma}, 97.81-88.09 \%\right)$.

The probability of revision was $4.72 \%\left(\mathrm{Cl}_{45} 1.2-8.24 \%\right)$

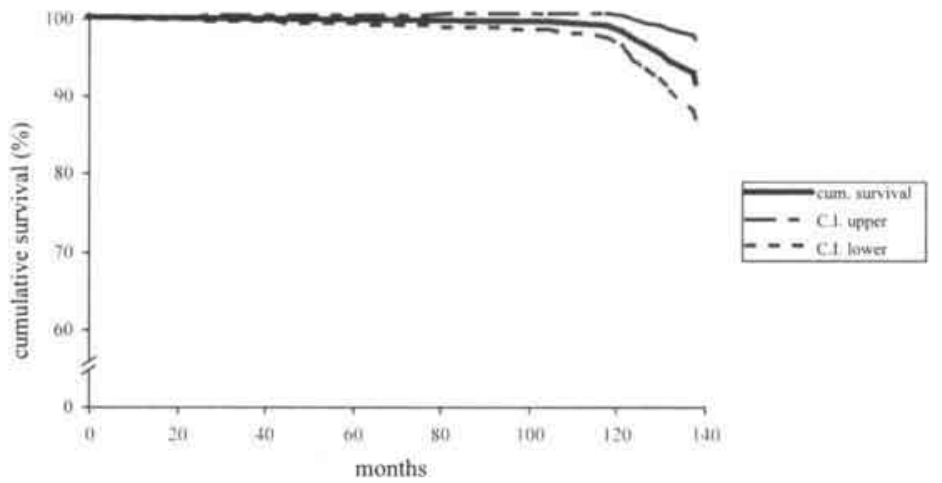

\section{Table 6.8}

Worst case scenario life table:

This life table was obtained by including the seven stem prostheses with more than I mm of subsidence at FU two and the two stem prostheses with osteolysis as failures. These stem prostheses could be at risk for revision due to aseptic loosening. Also, the four patients lost to follow-up at FU two were included as failures. The median interval between $\mathrm{FU}$ one and $\mathrm{FU}$ two was taken as the time that the prosthesis would have been in situ. The probability of revision was $4.72 \%\left(\mathrm{Cl}_{95} 1.2-8.24 \%\right)$.

The table contains 10 probable failures. Radiological evidence in three additional stem prostheses was truncated

\begin{tabular}{|c|c|c|c|c|c|c|}
\hline $\begin{array}{c}\text { Interval since } \\
\text { operation (yrs) }\end{array}$ & $\begin{array}{c}\text { Number at } \\
\text { start }\end{array}$ & Withdrawn & $\begin{array}{c}\text { Number at } \\
\text { risk }\end{array}$ & Failure & $\begin{array}{c}\text { Survival rate } \\
\text { (\%) }\end{array}$ & $\begin{array}{c}\text { SE } \\
\text { survival } \\
\text { rate }\end{array}$ \\
\hline 0 to 1 & 221 & 4 & 219 & 0 & 100 & 0 \\
\hline 1 to 2 & 217 & 2 & 216 & 0 & 100 & 0 \\
\hline 2 to 3 & 215 & 0 & 215 & 0 & 100 & 0 \\
\hline 3 to 4 & 215 & 6 & 212 & 0 & 100 & 0 \\
\hline 4 to 5 & 209 & 5 & 206.5 & 0 & 100 & 0 \\
\hline 5 to 6 & 204 & 4 & 202 & 0 & 100 & 0 \\
\hline 6 to 7 & 200 & 6 & 197 & 0 & 100 & 0 \\
\hline 7 to 8 & 194 & 3 & 192.5 & 0 & 100 & 0 \\
\hline 8 to 9 & 191 & 4 & 189 & 1 & 99.47 & 0.53 \\
\hline 9 to 10 & 186 & 11 & 180.5 & 1 & 98.92 & 0.76 \\
\hline 10 to 11 & 174 & 76 & 136 & 5 & 95.28 & 1.76 \\
\hline 11 to 12 & 93 & 51 & 67.5 & 3 & 91.05 & 2.92 \\
\hline
\end{tabular}




\subsection{DISCUSSION}

This study revealed only slight differences in good results between the two different Zweymüller stem prostheses. The patients with HG stem prostheses had longer follow-up, because this prosthesis had been in use longer. At FU one, the radiological study revealed that more SL stem prostheses had bone apposition at the tip of the prosthesis, but this difference from the HG stem prostheses had disappeared at FU two. Two HG stem prostheses showed osteolysis in the proximal zones, while seven HG stem prostheses (but none of the SL stem prostheses) had more than $1 \mathrm{~mm}$ of vertical subsidence. However, all the stem prostheses were stable according to the criteria of Engh et al [82].

Böhm et al performed a retrieval study on 19 HG and 15 SL stem prostheses [16]. They found that the HG stem prosthesis had progressively greater bone-implant contact from the proximal to the distal parts, whereas the SL stem prosthesis had uniform bone-implant contact. These different fixation patterns were expected to change the load transfer, e.g. uniform load transfer with the SL stem prosthesis. Any differences in load transfer should be visible on radiographs. However, in our study, we did not find any differences in radiolucent lines, cortical reactions and bone apposition between the two stem prostheses. Less bone apposition at Gruen zone 4 was only seen at FU one with the HG stem prosthesis. At FU two, we could not find any differences between the two stem prostheses. In addition, we did not find any differences in clinical (pain) scores between the patients with HG prostheses and those with SL. Thus, in our study group, there was no clinical evidence to suggest that the change in prosthesis stem design produced a different pattern of bone growth and there were no decisive radiological anomalies.

Noble et al found that elderly women of older than 60 years of age had higher cortical indices than younger women [218]. This difference manifested itself as an increase in diaphyseal diameter and a decrease in cortical bone at the isthmus. In our study, the cortical index did not change during the eleven years of follow-up. Furthermore, the cortical indices on the prosthesis side and on the non-prosthesis side did not differ.

During a patient's life, the shape of the femoral canal is expected to change from champagne flute to stove pipe. Therefore, one prosthesic design may not be suitable for all age groups. We did not find any differences in outcome between patients with champagne flute, normal or stove pipe shaped canals. It should be borne in mind that adequate implantation of the Zweymüller stem needs extensive rasping [59]. Thus a champagne flute canal shape could be converted into a stove pipe, which would avoid difficulties in implanting one stem design in all age groups.

Bone apposition was often seen at the distal tip of the stem prosthesis. The retrieval study by Böhm et al demonstrated the presence of newly formed progressive dense bony trabeculae [16]. This new bone corresponds with a good clinical result [252]. 
About 20 per cent of the prostheses in our study had proximal radiolucent lines and bone apposition at the tip of the stem. Other authors who investigated the Zweymüller prosthesis confirmed this pattern [64]. Dohle et al concluded that this remodelling was caused by the strength distribution of the prosthesis [64]. This would lead to stress shielding, i.e. proximal bone resorption and distal bone apposition. Unfortunately, conventional X-rays are unsuitable to monitor this process [128]. Thus, it is not yet clear whether the proximal radiolucent lines and the distal bone apposition indicate stress shielding.

In 100 total hip arthroplasties D'Lima et al compared the clinical and radiological results of between cemented and non-cemented femoral stems [51]. The results with the cemented stems were better than the results with the noncemented stems. The noncemented stems were associated with fewer excellent Harris Hip Scores, more thigh pain and greater subsidence. Harris had even advised that all the components should be cemented [113]. Cementless fixation was expected to cause devastating lysis around the femoral stem, but the idea was contradicted by several studies in which cementless stem prostheses led to progressive fixation $[81,125]$. Hozack et al wrote that loosening of a cementless prosthesis induced bone formation [125]. In our study, 27 stem prostheses had a mean subsidence of $0.62 \mathrm{~mm}$. Although our method of measuring subsidence could be disputed, we did not find any clinical deterioration in these femoral stems. We believe that the rectangular, tapered shape of the Zweymüller stem prosthesis leads to progressive fixation, perhaps after slight initial subsidence.

Mid-thigh pain was a frequent complaint after implantation of a cementless stem prostheses [30, 32, 132, 134, 156, 179, 188, 195, 216]. Possible causes for this disabling pain were believed to be suboptimal fixation, radial stress transfer from the stem prosthesis to the endocortex, and subsequent periosteal irritation $[132,215,226]$. Also, discrepancies in stiffness of the implant and the femur were offered as explanations and this led to the development of a low-modulus stem prosthesis (thar unfortunately resulted in other problems). Alternative proposals included tapering the stem prosthesis to diminish the incidence of thigh pain [124]. However, Jantsch et al implanted Zweymüller stem prostheses in cadaver femora and concluded that the final driving-in of this stem prosthesis might cause fissures in the shaft [140]. Such fissures would not be noticed during surgery and could be obscured by the implant on post-operative radiographs. Unexplained mid-thigh pain would be a likely result. Chapter 3 presents the results of the historic cohort study in which 754 Zweymüller total hip arthroplasties were implanted between January 1987 and December 1994. Only eight patients $(1.06 \%)$ suffered from transient mid-thigh pain. No stem prostheses were revised due to mid-thigh pain. In the present study, none of the patients complained of mid-thigh pain.

No stem prostheses had been revised due to aseptic loosening. In our worst-case scenario, cumulative survival was $92.95 \%\left(\mathrm{CI}_{95} 97.81\right.$ - 88.09) after 138 months 
and the risk of revision was $4.72 \%\left(\mathrm{CI}_{95} 1.2-8.24 \%\right)$ after eleven years. The stem prostheses at risk were all HG stem prostheses. In a cohort of 90 patients $(92$ arthroplasties), Aigner found aseptic loosening in one HG stem prosthesis after ten months and in three HG stem prostheses 5.5 to 8.5 years after primary surgery [1]. Delauney et al published favourable results with $60 \mathrm{HG}$ stem prostheses after a mean follow-up of 80 months. Only one stem prosthesis had been revised due to septic loosening [59].

In the study by Dohle et al on $120 \mathrm{SL}$ stem prostheses there had been no revisions up to 8.1 years [64]. In the 185 patients investigated by Delauney et al, no revisions had been conducted due to aseptic loosening of the SL stem prosthesis during a mean follow-up of 6 years [57]. After 100 months, Effenberger et al did not see any cases of aseptic loosening in 110 SL stem prostheses [74]. They concluded that this good result could be attributed to proximal broadening of the stem prosthesis. Furthermore, Grübl et al reported 100 per cent survival of 127 Zweymüller SL stem prostheses after a median follow-up of 120 months, but 12 patients (6\%) were lost to follow-up [105].

To our knowledge, no clinical studies have been published in which the HG stem was compared to the SL stem prosthesis. This study showed only slight differences between the HG stem and the SL stem. The clinical results with the HG stem prosthesis were so good that no improvement was achieved with the SL stem prosthesis. It can be concluded that the rectangular, titanium, cementless stem prosthesis has produced this excellent long-term results.

\subsection{CONCLUSION}

The cementless Zweymüller Hochgezogen stem and the Stepless stem both showed excellent long-term results at 134 months follow-up. Only slight radiological differences were observed between the two stem prostheses, while the clinical results were equal. 


\section{The Zweymüller Prosthesis in Patients Aged 50 Years and Younger}

\section{$7.1 \quad$ ABSTRACT}

Sixty-eight young patients (74 prostheses), mean age 43.1 years (sd 7.7) at the time of the index operation, with a Zweymüller cementless total hip prosthesis were evaluated at a mean follow-up of 75.3 months (sd 15.7).

Mean Harris Hip Score was 93.9 (sd 8.1). Six stem prostheses had vertical subsidence and nine cups showed signs of loosening. The Oxford Hip Score averaged 19.4 points (sd 8.7).

Revision surgery had been performed due to septic loosening ( $n=3$ stem and cup prostheses), aseptic loosening of the cup $(\mathrm{n}=2)$ and a trauma-induced periprosthetic fracture ( $\mathrm{n}=1$ stem).

Worst-case survival analysis for aseptic loosening of the cup showed a probability of $3.0 \%\left(\mathrm{CI}_{95} 0-7.2 \%\right)$ for revision and a cumulative survival of $95.9 \%\left(\mathrm{CI}_{95} 100\right.$ $-90.3 \%)$ after 84 months. The probability for revision of the stem prosthesis was $1.4 \%\left(\mathrm{CI}_{95} \mathrm{O}-4.3 \%\right)$ after 114 months, while the cumulative survival was $98.6 \%$ $\left(\mathrm{CI}_{95} 100-95.8 \%\right)$ after 72 months.

The results with the Zweymüller cementless hip prosthesis in younger patients were promising, but longer follow-up is necessary. 


\section{2}

Treating younger patients with end-stage osteoarthrosis is a considerable challenge for orthopaedic surgeons [14, 34, 161, 179, 261]. The good results generally reported for total hip arthroplasties pertain to older patients [12]. Young patients are liable to have a more active life-style and to make greater mechanical demands on the prosthesis. In addition, younger patients may also be suffering from other diseases, such as rheumatoid arthritis or osteonecrosis, which could interfere with the results of arthroplasty [31, 91, 94].

Historically, experience with arthroplasty in younger patients has been based on the cemented technique. Favourable long-term results in the literature may have little clinical relevance for present-day younger patients. Firstly, the specific prosthesis may no longer be available. Secondly, the cementing technique has evolved from hand-packing to pressurization and additional changes have been implemented to improve the prosthesis-cement bond. Therefore, any comparison between cemented and cementless total hip arthroplasties should be conducted with devices that are still available $[31,45,62]$.

Malchau et al reported arthroplasty results based on the Swedish National Hip Registry [182]. They concluded that in general, the results of cementless total hip arthroplasty were poorer than those of cemented total hip arthroplasty and that a young age was a risk factor. Although Havelin et al initially reported poorer results with cementless total hip arthroplasty in younger patients, in a subsequent publication they reported that the poor performance of the cementless prostheses must be attributed to inferior quality of these early prostheses $[117,118]$. The Zweymüller femoral stem prostheses formed an exception, because the survival was $99.1 \%$ after a follow-up of 4.5 years [119].

Cemented arthroplasties in younger patients generally show a high percentage of aseptic loosening of the acetabular component $[10,69,91,254,261]$. This aseptic loosening might be caused by polyethylene wear and pelvic osteolysis, because younger patients make greater demands on the prosthesis $[12,48]$. However, studies that reported on cementless total hip arthroplasty in younger patients are too scarce to provide sufficient evidence $[34,50,72,73,207,208]$.

In a subgroup of our cohort study (Chapter 3), we studied the patients who were 50 years or younger at the time of surgery, with the aim of assessing the clinical and radiological results of these arthroplasties as well as patient satisfaction.

\subsection{MATERIALS AND METHODS}

In the period 1 January 1987 to 31 December 1994, the orthopaedic surgeons at five Dutch hospitals performed 74 Zweymüller total hip arthroplasties on 68 patients aged younger than 50 years. Thirty-three Hochgezogen (HG) and 
41 Stepless (SL) stems were placed, all with the titanium threaded C.S.F. cup, polyethylene insert and a $32 \mathrm{~mm}$ ceramic head.

The patient group comprised 41 men and 27 women; 6 patients ( 4 men and 2 women) had a bilateral procedure. The mean age was 43.1 years (sd 7.5) at the time of the index operation. Clinical and radiological data were not collected in three patients, because revision surgery had already been performed: two total hip prostheses due to septic loosening ( 24 and 28 months after the index operation) and one acetabular cup due to aseptic loosening 85 months postsurgery. These patients were included in the survival curve and the life tables, but were excluded from the clinical study. At the first follow-up (FU one), all the patients were still alive and none had been lost to follow-up.

A clinical study on this cohort was performed by physicians who had not been involved in the original treatment. The investigators invited the patients to the outpatient clinic. Data were obtained from anamnesis and physical examination; the Harris Hip Score, the Merle d'Aubigné Pain Walk and Motion scores (P.W.M.) and the Charnley classification were assessed [38, 112, 204]. We specifically asked about mid-thigh pain after primary surgery and the duration of this pain.

Standardized radiographs of the pelvis and the affected hip were taken in anteroposterior and lateral views. These X-rays were compared to those taken directly after implantation. Unfortunately, in eight patients, the radiographs taken shortly after the index operation were not suitable for analysis. Thus, the analysis was conducted on 63 radiographs.

The computerized device X-caliper (Eisenlohr Technologies, California, U.S.A.) was used to measure radiological findings. On the preoperative radiographs, the canal flare index according Noble et al was measured [217]. The canal flare index was defined as the ratio between the width of the proximal femur $20 \mathrm{~mm}$ proximal to the lesser trochanter and the width of the femur at the isthmus. If the canal flare index was greater than 4.7 , the femoral canal was judged to have a champagne flute shape, whereas if the index was less than 3.0 , it was judged to have a stove pipe shape. An index of between 3.0 and 4.7 was classified as a normal shape femoral canal [217].

The cortical index was defined as the ratio between the medullary canal at the isthmus and the outer diameter of the femur at the same level (Figure 7.1) [121]. The cortical indices of the left and right femurs were compared, as well as the indices on the consecutive X-rays.

We inspected the Gruen zones for radiolucent line formation, bone apposition, cortical reactions and osteolysis [107]. Radiolucent line formation was defined as increased linear bone density along the prosthesis; bone apposition was defined as the formation of new bone at the distal tip of the stem prosthesis; cortical reaction was defined as an increase in femoral cortical bone; osteolysis was defined as a decrease in the bone density around the prosthesis. We measured the length and width of radiolucent lines and cortical reactions. 
Figure 7.1

Measurements of the femoral stem. Varus, neutral or valgus position of the stem was measured through the angle between midline prosthesis and midline femur. Vertical subsidence was measured by numbers 1 and 2 . Number " 1 " denotes the distance from the top of the trochanter major to the top of the stem of the prosthesis and the line through the middle of the trochanter minor

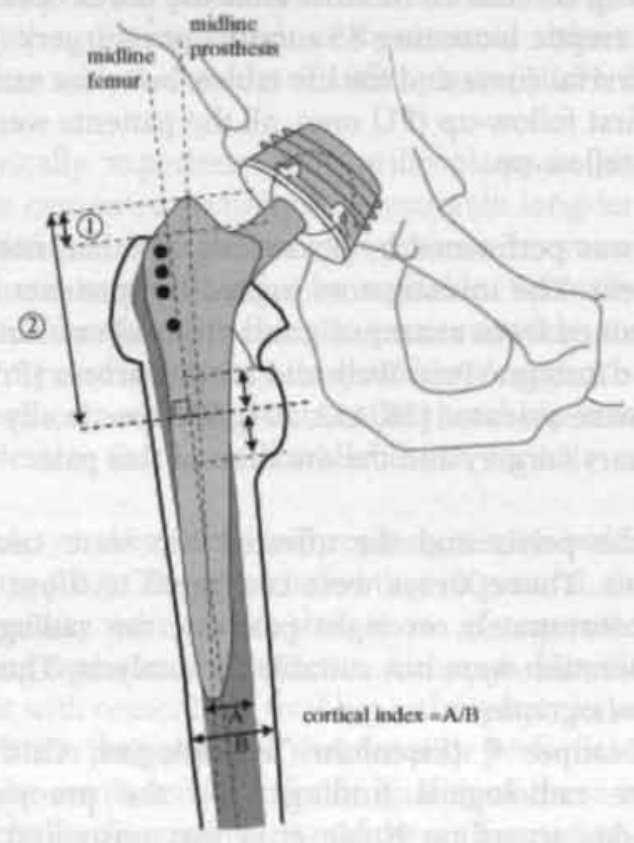
prosthesis. Number " 2 " measures the distance between the top

The position of the femoral component was evaluated as being in neutral, varus or valgus position. We measured the angle between the long axis of the femur and the long axis of the stem prosthesis to quantify the varus or valgus position (Figure 7.1).

If subsidence was suspected during radiological examination, we measured the distance from the top of the trochanter major to the top of the stem prosthesis, and the distance between the top of the prosthesis and the line through the middle of the trochanter minor. Differences between each of these distances on consecutive X-rays quantified the vertical subsidence of the femoral stem (Figure 7.1).

The stability and fixation score according to Engh et al was assessed [82].

The degree of remodelling of the femoral calcar was determined and classified as being atrophic, hypertrophic or unchanged. The degree of heterotopic ossification was classified according to Brooker et al [26].

Figure 7.2

The angle of the cup prosthesis according to Heekin (see text) [121]

Inclination of the cup was measured as the angle between the interteardrop line and the line through the rim of the cup (Figure 7.2) [121]. Migration of the cup on consecutive X-rays was classified as migrated or not migrated.

The zones of DeLee were used to evaluate the acetabular perimeter [61]. Osteolysis and radiolucent lines were noted.

Four years after FU one, we sent all the patients a questionnaire (second survey).

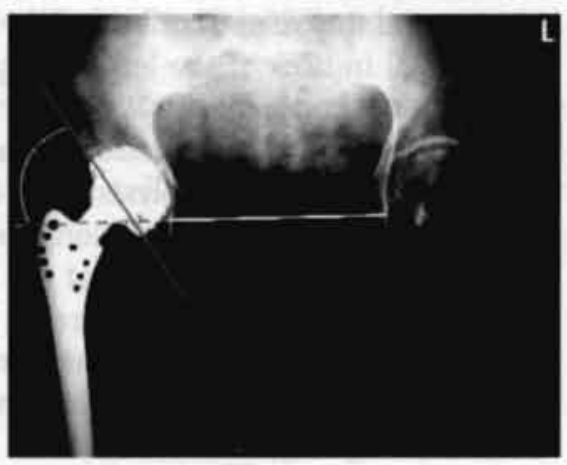


This questionnaire consisted of the Oxford Hip Score and the U.C.L.A. Activity level rating score [7, 53]. The Oxford Hip Score consists of fourteen questions on pain and functioning during activities of daily living. Each question has five answer alternatives. The sum of the 14 answers yields the total Oxford Hip Score. The best possible score is 14 points, while the poorest score is 70 points. The Oxford Hip Score has been translated into the Dutch language and validated [123]. The Charnley classification and patient satisfaction were assessed. Furthermore, the patients noted their level of pain on a 100 millimetre visual analogue scale $(0$ $\mathrm{mm}$ means no pain; $100 \mathrm{~mm}$ means severe pain).

Statistical analysis was conducted using Student's t-test. Statistical significance was set at $\mathrm{p}<0.05$.

A Kaplan Meier curve and life tables were calculated for cup revision due to aseptic loosening $[148,212]$. A worst-case scenario for cup prosthesis revision due to aseptic loosening was obtained by defining failures as true revision plus any cups that showed migration, radiolucent lines, or osteolysis. Worst-case scenario curves and tables for the stem prosthesis were calculated by defining subsidence of the femoral stem prostheses as failures. In addition, patients who were lost to follow-up at second survey were included as failures at a median time between the clinical examination and the time of the survey.

Poss et al proposed a uniform format to report long-term follow-up studies on total hip arthroplasties [230]. This survival analysis includes revision for any cause and these figures are given below.

\subsection{RESULTS}

A total of 71 prostheses ( $27 \mathrm{HG}$ and 44 SL stems) were evaluated in 65 patients ( 39 men and 26 women). In six cases, prostheses had been implanted in both hips. Mean age at the time of the index operation was 43.1 years (sd 7.7), while mean age at the time of the clinical follow-up evaluation was 49.4 years (sd 8.0). Mean follow-up was 75.3 months (sd 15.7).

Mean age at the time of surgery did not differ between the stem types: HG stem 43.7 years ( $(\mathrm{sd} 7.8)$ versus SL stem 42.7 years $(\mathrm{sd} 7.7)(\mathrm{p}=0.601)$. However, the mean duration of follow-up in the HG group was 85.6 months (sd 10.2) versus 69.0 months (sd 15.1) in the SL group; this difference was statistically significant $(p=0.000)$. Average Harris Hip Score was 93.9 (sd 8.1). There was no difference in the Harris Hip Score between the two stem types. Figure 7.3 shows the Merle d'Aubigné Pain Walk and Motion score and the Charnley classification. Remarkably, there were more Charnley class A patients with an SL stem prosthesis. Furthermore, most of the patients had no pain $(78.9 \%)$ or only slight to mild pain. 


\section{Figure 7.3}

Comparison of the percentages of hips with a Hochgezogen stem prosthesis (HG) and a Stepless stem prosthesis (SL) to the Merle d'Aubigné Pain Walk and Motion scores (P.W.M. classification) and the Charnley classification
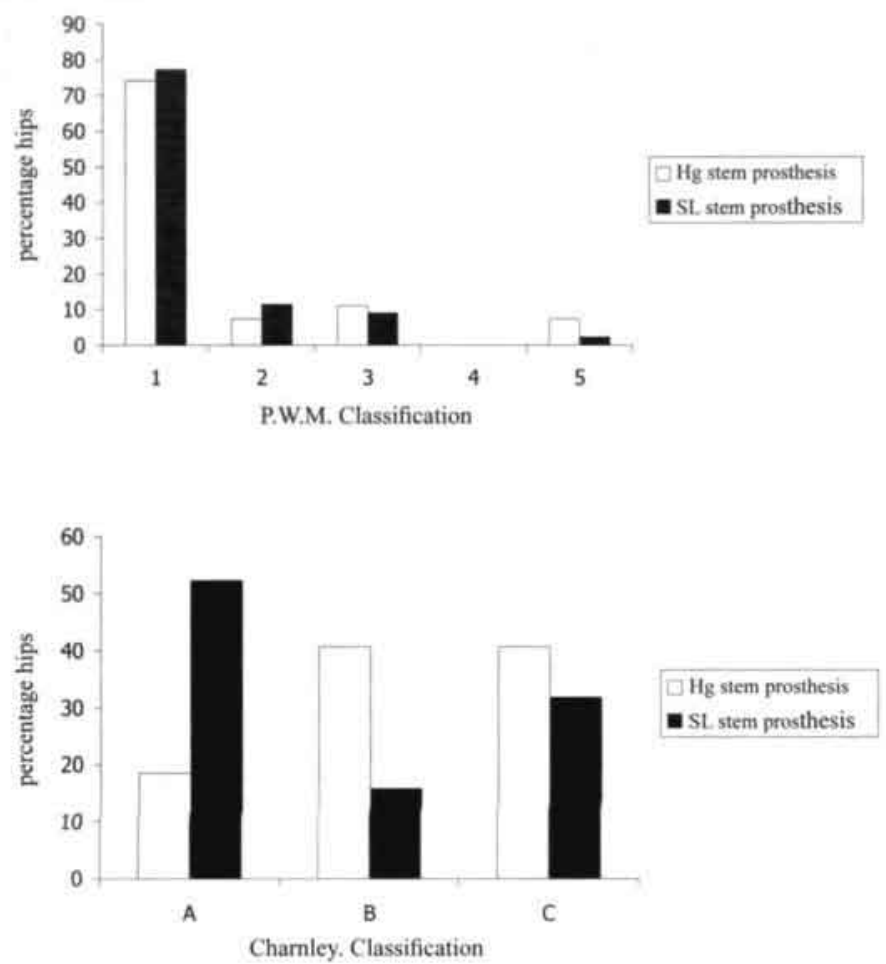

In this cohort, $43(60.6 \%)$ arthroplasties were performed for idiopathic osteoarthrosis. In 13 arthroplasties, the diagnosis was inflammatory osteoarthritis, caused by rheumatoid arthritis $(n=11)$ or ankylosing spondylitis $(n=2)$. Nine arthroplasties were performed for osteonecrosis (4 idiopathic, 3 corticosteroidinduced, 2 after failed surgery for femoral neck fracture). Six arthroplasties were performed after a high-impact accident in which the initial treatment failed (1 after femoral head dislocation with an associated fracture, 1 acetabular fracture and 4 femoral neck fractures).

In three patients, the primary operation was followed by re-intervention. One stem prosthesis was revised three days after the index operation because of leg length difference, one patient fractured the acetabulum 14 days after the operation (this cup prosthesis was revised) and one patient was operated on to remove grade IV heterotopic ossification five months after the arthroplasty. In view of the short period since the index operation and the non-prosthesis related cause of these operations, these cases were classified as re-interventions and not as prosthesis failures. 
Eight other complications were recorded in eight patients. Four patients $(5.4 \%)$ dislocated the prosthesis within six weeks and one other patient $(1.4 \%)$ dislocated the prosthesis 10 weeks after the index operation. All dislocated prostheses were restored by closed manipulation. In addition, three haematomas were noted. There were no cases of postoperative thrombosis, lung embolus or superficial wound infection.

One patient with an SL stem prosthesis complained of midthigh pain. This pain did not decrease during the follow-up period. At second survey, the patient was found to be suffering from multiple myositis.

Only 39 radiographs $(54.9 \%)$ were available for the preoperative analysis. The canal flare index showed 17 stove pipe femora, two champagne flute femora and 20 normal femora. The Harris Hip Scores in the patients with a stove pipe shape did not differ from those with a normal shape femoral canal.

There was no difference in the cortical index: average values preoperatively and at the clinical follow-up on the prosthesis side were 0.41 (sd 0.08) and 0.42 (sd 0.08 ) and on the non-prosthesis side 0.42 (sd 0.09 ) and 0.44 (sd 0.08 ). The mean duration of follow-up in these 39 patients was 73.5 months (sd 16.1).

Evaluation of the radiographs shortly after the index operation showed no signs of radiolucent lines, cortical reactions, bone apposition, or osteolysis. Table 7.1 shows the radiological follow-up results with signs of radiolucent lines, bone apposition and cortical reactions on the femoral component side.

The researchers found radiolucent lines only in the proximal zones. Bone apposition was seen in zone 4 at the tip of the prosthesis, while cortical reactions were only seen around the medial part of the femoral stem. The percentage of radiolucent lines in Gruen zone 7 was significantly higher in the HG stem prostheses than in the SL prostheses $(50 \%$ vs $22 \%$ ) ( $\mathrm{p}=0.023)$. No other differences were found between the two stem prostheses regarding radiolucent lines, bone apposition or cortical reactions.

Four HG (18.2\%) and five SL stem prostheses $(12.2 \%)$ had proximal radiolucent lines and distal bone apposition at the tip of the stem prosthesis. The Harris Hip Scores in these patients with a combination of proximal lines and distal bone apposition did not differ from those in the patients without these signs ( 94.5 (sd 4.4) versus 92.3 (sd 9.9) in the HG prostheses and 96.2 (sd 6.5) versus 94.6 (sd 7.8) in the SL stem prostheses). Radiological assessment did not reveal any osteolysis around the femoral stems.

The Harris Hip Score in the patients with a varus position of the HG stem was better than that in the patients with a neutral position of the HG stem ( $\mathrm{p}=0.006)$ (Table 7.2 and Figure 7.4). There were no differences in radiolucent lines, bone apposition or cortical reactions between the stem prostheses in varus or neutral position. 
Table 7.1

Number of X-rays on which the researchers found signs of radiolucent line formation, bone apposition and cortical reactions along the femoral stem. Zone classification according to Gruen et al [107].

When present, the length and width of the radiolucent lines and the cortical reaction were measured in millimetres. The Hochgezogen stem prosthesis had more radiolucent lines in Gruen zone $7(p=0.023)$

\begin{tabular}{|c|c|c|c|c|c|c|c|}
\hline & & \multicolumn{3}{|c|}{$\begin{array}{l}\text { Hochgezogen stem prosthesis } \\
\qquad(\mathrm{n}=22)\end{array}$} & \multicolumn{3}{|c|}{$\begin{array}{l}\text { Stepless stem prosthesis } \\
\qquad(\mathrm{n}=41)\end{array}$} \\
\hline & & $\begin{array}{c}\text { Number } \\
(\%)\end{array}$ & $\begin{array}{l}\text { Length (sd) } \\
\text { Width (sd) }\end{array}$ & $\begin{array}{l}\text { Harris Hip } \\
\text { Score (sd) }\end{array}$ & $\begin{array}{c}\text { Number } \\
(\%)\end{array}$ & $\begin{array}{l}\text { Length (sd) } \\
\text { Width (sd) }\end{array}$ & $\begin{array}{c}\text { Harris } \\
\text { Hip Score } \\
\text { (sd) }\end{array}$ \\
\hline \multirow{2}{*}{$\begin{array}{c}\begin{array}{c}\text { Radiolucent } \\
\text { lines }\end{array} \\
\text { zone } 1\end{array}$} & Present & $\begin{array}{c}6 \\
(27.3)\end{array}$ & $\begin{array}{c}36.5(\mathrm{sd} \\
15.1) \\
1.8(\mathrm{sd} 0.5)\end{array}$ & $\begin{array}{l}95.9(\mathrm{sd} \\
4.2)\end{array}$ & $\begin{array}{c}13 \\
(31.7)\end{array}$ & $\begin{array}{c}25.4(\text { sd } 11.7) \\
1.7 \text { (sd } 0.6)\end{array}$ & $\begin{array}{l}94.7(\mathrm{sd} \\
10.5)\end{array}$ \\
\hline & Absent & $\begin{array}{c}16 \\
(72.7)\end{array}$ & - & $\begin{array}{l}91.4(\mathrm{sd} \\
10.3)\end{array}$ & $\begin{array}{c}28 \\
(68.3)\end{array}$ & - & $\begin{array}{l}94.8(\mathrm{sd} \\
5.9)\end{array}$ \\
\hline \multirow[t]{2}{*}{$\begin{array}{l}\text { Radiolucent } \\
\text { lines } \\
\text { zone } 7\end{array}$} & Present & $\begin{array}{c}11 \\
(50)\end{array}$ & $\begin{array}{c}27.4(\text { sd } 10.5) \\
1.6(\text { sd } 0.7)\end{array}$ & $\begin{array}{l}94.1(\mathrm{sd} \\
4.4)\end{array}$ & $\stackrel{9}{(21.9)}$ & $\begin{array}{c}24.5(\mathrm{sd} \\
16.9) \\
1.7(\mathrm{sd} 0.9)\end{array}$ & $\begin{array}{l}96.4(\mathrm{sd} \\
5.3)\end{array}$ \\
\hline & Absent & $\begin{array}{l}11 \\
(50)\end{array}$ & - & $\begin{array}{c}91.2 \text { (sd } \\
12.4)\end{array}$ & $\begin{array}{c}32 \\
(78.1)\end{array}$ & - & $\begin{array}{c}94.3(\mathrm{sd} \\
8.1)\end{array}$ \\
\hline \multirow{2}{*}{$\begin{array}{c}\begin{array}{c}\text { Bone } \\
\text { apposition }\end{array} \\
\text { zone } 4\end{array}$} & Present & $\begin{array}{c}15 \\
(68.2)\end{array}$ & - & $\begin{array}{l}94.4(\mathrm{sd} \\
7.1)\end{array}$ & $\begin{array}{l}27 \\
(65.9)\end{array}$ & . & $\begin{array}{l}94.8(\mathrm{sd} \\
8.1)\end{array}$ \\
\hline & Absent & $\stackrel{7}{(31.8)}$ & - & $88.9(12.4)$ & $\begin{array}{c}14 \\
(34.1)\end{array}$ & . & $\begin{array}{l}94.8(\mathrm{sd} \\
6.6)\end{array}$ \\
\hline \multirow[t]{2}{*}{$\begin{array}{c}\begin{array}{c}\text { Cortical } \\
\text { reaction }\end{array} \\
\text { zone } 5\end{array}$} & Present & $\stackrel{4}{4}$ & $\begin{array}{c}33.8(\mathrm{sd} \\
15.2) \\
1.9 \text { (sd } 0.7)\end{array}$ & $\begin{array}{l}91.0(\mathrm{sd} \\
4.1)\end{array}$ & ${ }^{2}$ & $\begin{array}{l}47.9(\mathrm{sd} 5.3) \\
1.7(\mathrm{sd} 0.4)\end{array}$ & $\begin{array}{c}97.5(\mathrm{sd} \\
3.5)\end{array}$ \\
\hline & Absent & $\begin{array}{c}18 \\
(81.2)\end{array}$ & - & $\begin{array}{l}93.1(\mathrm{sd} \\
10.0)\end{array}$ & $\begin{array}{l}39 \\
(95.2)\end{array}$ & . & $\begin{array}{l}94.6(\mathrm{sd} \\
7.7)\end{array}$ \\
\hline
\end{tabular}

\section{Table 7.2}

The angle of the stem in the femoral canal and the Harris Hip Score. "0" degrees denotes that the midline of the prosthesis and the femur coincided. " 1 " to " 11 " degrees means a varus angle between the midline of the stem and the femur (see Figure 7.1). The differences in Harris Hip Scores were not statistically significant

\begin{tabular}{|c|c|c|}
\hline angle of stem in degrees & $\begin{array}{c}\text { number of prostheses }(\mathbf{n = 6 3 )} \\
(\mathbf{\%})\end{array}$ & Harris Hip Score (sd) \\
\hline 0 & $33(52.4)$ & $92.4(8.2)$ \\
\hline 1 & $2(3.2)$ & $81.4(26.4)$ \\
\hline 2 & $4(6.4)$ & $99.3(1.5)$ \\
\hline 3 & $6(9.6)$ & $97.9(2.5)$ \\
\hline 4 & $8(12.7)$ & $97.5(2.3)$ \\
\hline 5 & $3(4.8)$ & $98.6(2.4)$ \\
\hline 6 & $4(6.4)$ & $90.4(9.9)$ \\
\hline 7 & $1(1.5)$ & $96(-)$ \\
\hline 8 & $1(1.5)$ & $100(-)$ \\
\hline 11 & $1(1.5)$ & $94(-)$ \\
\hline
\end{tabular}


Figure 7.4

Harris Hip Scores and the stem position (see legend Table 7.2)

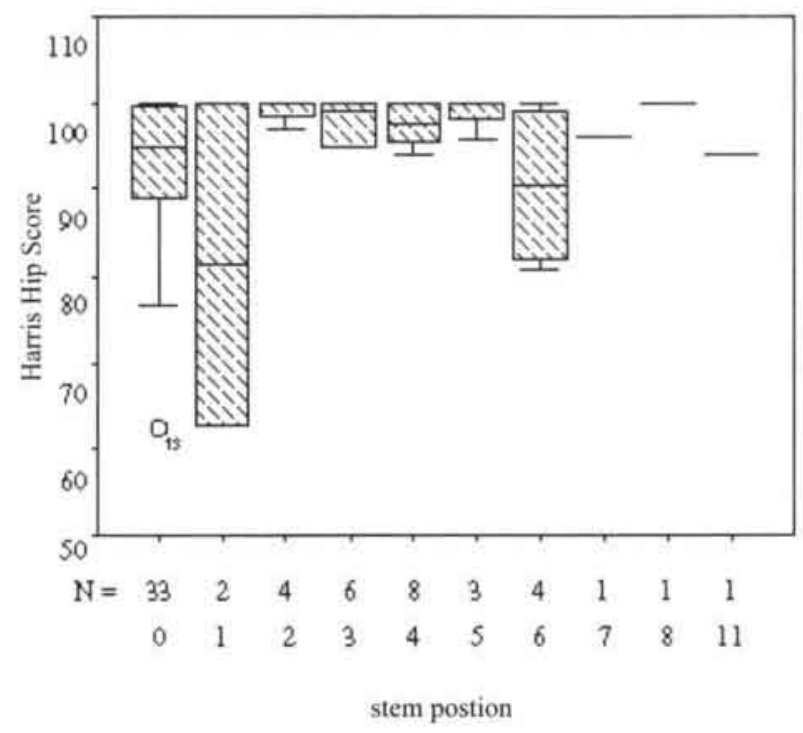

At the clinical followup, the researchers found that six stem prostheses (one HG and five SL) had sub. sided. A mean vertical subsidence of 1.9 millimetres (sd 0.9, range $1.0-2.9)$ was measured from the top of the trochanter major to the top of the stem prosthesis. The mean difference in distance from the top of the stem prosthesis to the mid-line through the trochanter minor was $1.8 \mathrm{~mm}$ (sd 0.4). Nevertheless, the fixation and stability scores according to Engh did not reflect any unstable stem prostheses.

More than fifty per cent of the calcar femoris were judged to show atrophic changes during follow-up. The Harris Hip Scores did not differ between the groups.

Despite various prevention measures, eight patients had heterotopic ossification grade III according to Brooker, whereas $36 \%$ of the patients did not have heterotopic ossification. Only one patient had grade IV ossification and underwent re-intervention five months after the index operation. Patient numbers were too small to be able to consider the impact of various grades of heterotopic ossification on the Harris Hip Score.

The acetabular cup angle averaged 51.1 degrees (sd 9.8). Five cups showed a change in inclination and were classified as migrated. An additional three cups had migrated and also had radiolucent lines around the cup. One cup only had radiolucent lines around the perimeter without any migration. One cup that showed severe migration with radiolucent lines and osteolysis in DeLee zone 1 was later revised.

In the period between FU one and second survey, two patients died of causes unrelated to the index operation. In one patient, the acetabular cup had been revised after 81 months due to aseptic loosening, another prosthesis had been 
revised after 66 months due to septic loosening of both components and one stem prosthesis had been revised after 107 months due to trauma-induced periprosthetic femoral fracture. One patient with two prostheses was lost to follow-up. Thus, second survey comprised 59 patients ( 36 men, 23 women) with 64 prostheses. Mean age was 53.1 years (sd 7.8) and the mean follow-up was 117.9 months (sd 21.8).

At second survey, the average Oxford Hip Score was 22.1 points (sd 9.5). Table 7.3 shows the results of the U.C.L.A. activity level rating score. At second survey, $31.3 \%$ of the patients were classified as Charnley class A, $20.3 \%$ as class B and $48.4 \%$ as class C (Figure 7.5). The visual analogue scale for pain was a mean of $16.5 \mathrm{~mm}$ (sd 23.5). Four patients reported that they had received no benefit from the surgical procedure, although all of them were satisfied.

\section{Table 7.3}

University of California at Los Angeles activity-level rating scale [7].

U.C.L.A. scores of the patients at second survey. Three patients did not answer this question (*)

\begin{tabular}{|c|l|c|}
\hline Level & Activity & Number (\%) \\
\hline 1 & Wholly inactive: dependent on others: cannot leave residence & $2(3.3)$ \\
\hline 2 & Mostly inactive: very restricted to minimum activities of daily living & $2(3.3)$ \\
\hline 3 & $\begin{array}{l}\text { Sometimes participates in mild activities, such as walking, limited } \\
\text { housework and limited shopping }\end{array}$ & $8(13.1)$ \\
\hline 4 & Regularly participates in mild activities & $2(3.3)$ \\
\hline 5 & $\begin{array}{l}\text { Sometimes participates in moderate activities, such as swimming } \\
\text { and can do unlimited housework or shopping }\end{array}$ & $6(9.9)$ \\
\hline 6 & Regularly participates in moderate activities & $7(11.5)$ \\
\hline 7 & Regularly participates in active events, such as cycling & $16(26.2)$ \\
\hline 8 & Regularly participates in very active events, such as bowling or golf & $7(11.5)$ \\
\hline
\end{tabular}


Figure 7.5

Charnley classifications of the patients who participated in the clinical follow-up study and the second survey.

Mean follow-up time of the first follow-up was 75.2 months (sd

15.9 ) and of the second survey 117.9 months (sd 21.8) after the index operation

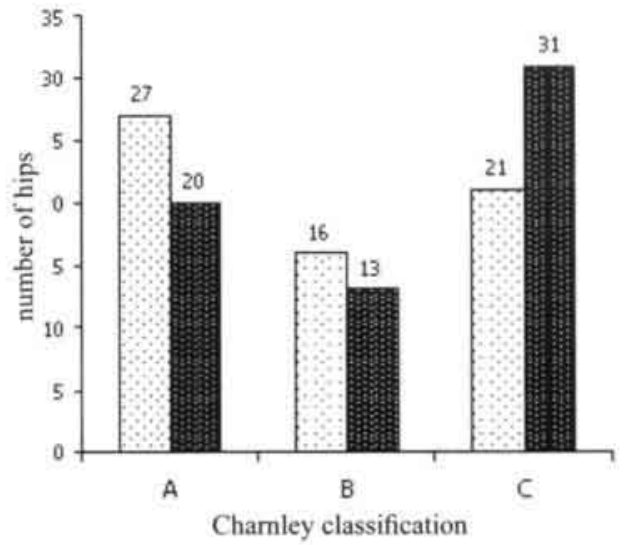

Two acetabular cup prostheses, in otherwise healthy patients, were revised due to aseptic loosening. An additional nine cups were judged to be at risk for aseptic loosening (Table 7.4). One patient (two arthroplasties) with rheumatoid arthritis was lost to follow-up. The survival curves for revision of the acetabular cup due to aseptic loosening

Table 7.4

Nine acetabular cups were at risk and two cups had been revised due to aseptic loosening. The diagnoses are given. "**" means one patient with two prostheses

\begin{tabular}{|c|c|c|c|c|}
\hline $\operatorname{sex}$ & $\begin{array}{l}\text { age at surgery } \\
\text { (years) }\end{array}$ & $\begin{array}{c}\text { follow-up } \\
\text { (months) }\end{array}$ & osteoarthritis & \\
\hline q & 43.4 & 85.5 & idiopathic & revised \\
\hline$q$ & 49.2 & 81.3 & idiopathic & revised \\
\hline 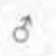 & 47.5 & 89.2 & theumatoid arthritis & unrevised \\
\hline$q$ & 23.6 & 111.6 & mucolipidosis & unrevised \\
\hline 우 & 35.8 & 145.4 & Behçet's syndrome * & unrevised \\
\hline 9 & 39.1 & 108.5 & Behçet's syndrome * & unrevised \\
\hline$\sigma$ & 45.9 & 125.7 & acetabulum fracture & unrevised \\
\hline$\delta$ & 49.9 & 143.3 & idiopathic & unrevised \\
\hline$q$ & 49.1 & 144.8 & idiopathic & unrevised \\
\hline$d$ & 44.8 & 110.8 & idiopathic & unrevised \\
\hline 8 & 31.9 & 116.1 & ankylosing spondylitis & unrevised \\
\hline
\end{tabular}


showed a cumulative survival of $96.9 \%\left(\mathrm{CI}_{95} 100-92.6 \%\right)$ after 84 months, while the life tables showed a probability of $3.1 \%$ for revision $\left(\mathrm{CI}_{95} 0-7.5 \%\right)$ after 90 months (Table 7.5 and Figure 7.6). The worst-case scenario for the acetabular cup produced a cumulative survival of $95.9 \%\left(\mathrm{Cl}_{95} 100-90.3 \%\right)$ and a (worst case) life table probability of revision of $3.0 \%\left(\mathrm{CI}_{95} 0-7.2 \%\right)$, both after 84 months. The worst-case scenario hardly differed from the cumulative survival with the endpoint aseptic loosening for the following reason: in the worst-case scenario, the nine cups that were at risk were considered to have been revised after 84 months. However, the confidence intervals exceeded $5 \%$, so the survival rate was not reliable. Furthermore, the nine cups at risk had yet not been revised at second survey four years later.

\section{Table 7.5}

Life table of survival with the end-point revision of the acetabular cup due to aseptic loosening. The probability of revision for aseptic loosening was $3.1 \%$ after 90 months $\left(\mathrm{Cl}_{9,} 0-7.5 \%\right)$

\begin{tabular}{|c|c|c|c|c|c|c|}
\hline $\begin{array}{c}\text { Interval since } \\
\text { operation (months) }\end{array}$ & $\begin{array}{c}\text { Number at } \\
\text { start }\end{array}$ & Withdrawn & $\begin{array}{l}\text { Number at } \\
\text { risk }\end{array}$ & Failure & $\begin{array}{c}\text { Survival rate } \\
(\%)\end{array}$ & $\begin{array}{l}\text { SE survival } \\
\text { Rate }\end{array}$ \\
\hline 0 to 6 & 74 & 0 & 74 & 0 & 100 & 0 \\
\hline 6 to 12 & 74 & 0 & 74 & 0 & 100 & 0 \\
\hline 12 to 18 & 74 & 0 & 74 & 0 & 100 & 0 \\
\hline 18 to 24 & 74 & 1 & 73.5 & 0 & 100 & 0 \\
\hline 24 to 30 & 73 & 1 & 72.5 & 0 & 100 & 0 \\
\hline 30 to 36 & 72 & 0 & 72 & 0 & 100 & 0 \\
\hline 36 to 42 & 72 & 0 & 72 & 0 & 100 & 0 \\
\hline 42 to 48 & 72 & 0 & 72 & 0 & 100 & 0 \\
\hline 48 to 54 & 72 & 0 & 72 & 0 & 100 & 0 \\
\hline 54 to 60 & 72 & 0 & 72 & 0 & 100 & 0 \\
\hline 60 to 66 & 72 & 0 & 72 & 0 & 100 & 0 \\
\hline 66 to 72 & 72 & 1 & 71.5 & 0 & 100 & 0 \\
\hline 72 to 78 & 71 & 3 & 69.5 & 0 & 100 & 0 \\
\hline 78 to 84 & 68 & 4 & 66 & 1 & 98.48 & 1.5 \\
\hline 84 to 90 & 63 & 4 & 61 & 1 & 96.87 & 2.18 \\
\hline 90 to 96 & 58 & 2 & 57 & 0 & 96.87 & 2.18 \\
\hline 96 to 102 & 56 & 6 & 53 & 0 & 96.87 & 2.18 \\
\hline 102 to 108 & 50 & 3 & 48.5 & 0 & 96.87 & 2.18 \\
\hline 108 to 114 & 47 & 8 & 43 & 0 & 96.87 & 2.18 \\
\hline
\end{tabular}


Figure 7.6

Kaplan Meier. The cumulative survival of the acetabular cup with revision due to aseptic loosening as end-point after 84 months was $96.9 \%\left(\mathrm{Cl}_{\text {es }} 100-92.6 \%\right)$

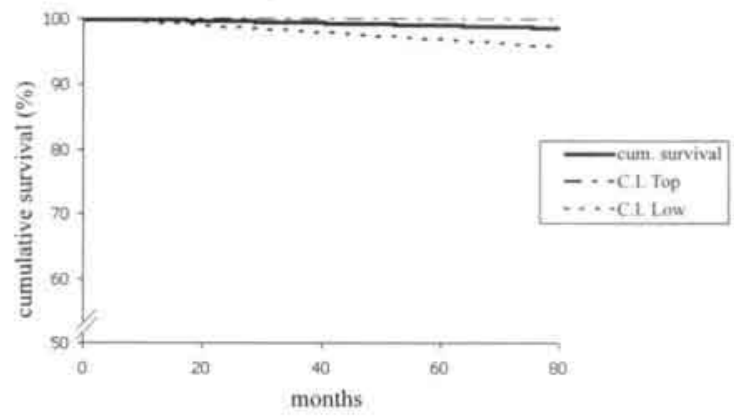

None of the stem prostheses were revised due to aseptic loosening. Worstcase scenario survival rates for the stem prostheses were obtained on the basis of six femoral stem prostheses that had subsided (Table 7.6, Figure 7.7). After a period of 114 months, the survival rate in the life table and the Kaplan Meier curve were unreliable, because the confidence intervals exceeded 5\%, although five stem prostheses were considered to be at risk after that period.

Table 7.6

Worst-case scenario for aseptic loosening of the femoral stem. The probability of revision was $1.4 \%$ after 114 months $\left(\mathrm{Cl}_{05} 0-4.3 \%\right)$

\begin{tabular}{|c|c|c|c|c|c|c|}
\hline $\begin{array}{c}\text { Interval since } \\
\text { operation (months) }\end{array}$ & $\begin{array}{c}\text { Number at } \\
\text { start }\end{array}$ & Withdrawn & $\begin{array}{l}\text { Number at } \\
\text { risk }\end{array}$ & Failure & $\begin{array}{c}\text { Survival rate } \\
(\%)\end{array}$ & $\begin{array}{l}\text { SE survival } \\
\text { rate }\end{array}$ \\
\hline 0 to 6 & 74 & 0 & 74 & 0 & 100 & 0 \\
\hline 6 to 12 & 74 & 0 & 74 & 0 & 100 & 0 \\
\hline 12 to 18 & 74 & 0 & 74 & 0 & 100 & 0 \\
\hline 18 to 24 & 74 & 1 & 73.5 & 0 & 100 & 0 \\
\hline 24 to 30 & 73 & 1 & 72.5 & 0 & 100 & 0 \\
\hline 30 to 36 & 72 & 0 & 72 & 0 & 100 & 0 \\
\hline 36 to 42 & 72 & 0 & 72 & 0 & 100 & 0 \\
\hline 42 to 48 & 72 & 0 & 72 & 0 & 100 & 0 \\
\hline 48 to 54 & 72 & 0 & 72 & 0 & 100 & 0 \\
\hline 54 to 60 & 72 & 0 & 72 & 0 & 100 & 0 \\
\hline 60 to 66 & 72 & 0 & 72 & 0 & 100 & 0 \\
\hline 66 to 72 & 72 & 1 & 71.5 & 0 & 100 & 0 \\
\hline 72 to 78 & 71 & 2 & 70 & 1 & 98.57 & 1.42 \\
\hline 78 to 84 & 68 & 5 & 65.5 & 0 & 98.57 & 1.42 \\
\hline 84 to 90 & 63 & 5 & 60.5 & 0 & 98.57 & 1.42 \\
\hline 90 to 96 & 58 & 2 & 57 & 0 & 98.57 & 1.42 \\
\hline 96 to 102 & 56 & 6 & 53 & 0 & 98.57 & 1.42 \\
\hline 102 to 108 & 50 & 3 & 48.5 & 0 & 98.57 & 1.42 \\
\hline 108 to 114 & 47 & 8 & 43 & 0 & 98.57 & 1.42 \\
\hline 114 to 120 & 39 & 2 & 38 & 1 & 95.98 & 2.91 \\
\hline
\end{tabular}


In addition, three prostheses (cup and stem) were terminated for septic loosening: one prosthesis in a 36-year-old man with rheumatoid arthritis, one in a patient with previous femoral osteotomy and one due to septic loosening after a septically-complicated arthroplasty procedure on the other side. The survival curve with revision of the prosthesis for any cause as the end-point (septic and aseptic loosening) as recommended by Poss et al revealed a survival rate of $94.5 \%\left(\mathrm{CI}_{95} 99.9-89.2 \%\right)$ after 81 months, while the probability of revision was $5.5 \%$ according to the life table $\left(\mathrm{CI}_{95} 0.2 \%-10.9 \%\right)$ after 78 months [230].

\subsection{DISCUSSION}

This evaluation on younger patients showed good results with the Zweymüller prosthesis. In this group of 68 patients (74 prostheses) two cup prostheses had been revised for aseptic loosening (2.7\%). In three other prostheses $(4.1 \%)$ revision surgery had been performed for septic loosening of the prosthesis. One stem was revised following trauma-induced periprosthetic femoral fracture.

Comparison with the cohort study performed on 754 Zweymüller total hip arthroplasties (Chapter 3) revealed that two out of the six revised cups were from the 74 arthroplasties in young patients $(2.7 \%)$, while only $0.6 \%$ of the cups ( 4 out of 680) had been revised in patients of older than fifty years at the time of surgery. The survival curve from the cohort study on arthroplasties in patients of older than fifty years at the time of the surgery showed a survival of $98.6 \%\left(\mathrm{CI}_{95} 100\right.$ - $96.8 \%$ ) after 86.4 months, while the life tables showed a probability for revision due to aseptic loosening of the cup of $1.4 \%\left(\mathrm{CI}_{95} \mathrm{O}-3.3 \%\right)$ after 90 months. Both these rates were slightly better than those in the young patients. Although aseptic loosening of the cup occurred more frequently in the younger patients, the difference in survival rates after more than seven years was small $(1.6 \%)$ and cannot be an argument to withhold arthroplasty from young patients.

One of the disadvantages of arthroplasty in young patients could be that comorbidity influences the results of arthroplasty. Kobayashi et al compared 
the results with the Charnley cemented total hip prosthesis in younger patients (younger than 50 years) to those in older patients [161]. After an average follow. up of 14 years, $20 \%$ of the acetabular cups had been revised in the younger patients versus $4 \%$ in the older patients. The high percentage of patients with rheumatoid arthritis (32\%) and the increased rate of wear of the polythene insert were considered to be responsible for this difference. In our study population, eleven patients had rheumatoid arthritis. One of them underwent revision of the acetabular cup after septic loosening. Three cup prostheses were classified as being at risk for aseptic loosening and were included in the worst-case scenario. Compared to the other cup prostheses in the worst-case scenario, we cannot confirm the conclusion drawn by Kobayashi et al that rheumatoid arthritis is a risk factor for aseptic loosening of the acetabular cup [161]. Devitt et al also found that rheumatoid arthritis was not a risk factor for aseptic loosening in an 18 . year long-term study on 110 Charnley cemented arthroplasties [62]. It has been proposed that the low demands made by rheumatoid arthritis patients on their hip prostheses perhaps prevent loosening of the cup [91].

In general, patients whose indication for arthroplasty was osteonecrosis have poorer results than patients with other indications or diseases [23, 46, 227]. Although our osteonecrosis numbers were too low to make valid comparisons, we did not see any differences between the various diagnoses and the results of the arthroplasty.

The most serious problem that can be expected in younger patients with total hip arthroplasty is polyethylene wear, which could lead to fixation problems in the cup and femoral stem. The amount of polyethylene wear, and subsequently osteolysis, was found to correlate inversely with the age of the patient [12, 48, 158]. Although it was not possible to take reliable measurements of the amount of polyethylene wear in our study, no gross polyethylene wear was seen. Furthermore, only one acetabular cup prosthesis had osteolysis in DeLee zone 1, which later led to revision and we saw no osteolysis along the femoral component.

Crowther et al reported good results with the Harris-Galante I acetabular cup prosthesis, which is made of porous-coated titanium alloy and has screw holes for additional fixation [48]. Fifty-six cup prostheses were evaluated 11 years (range 9 14) after implantation in 44 patients with an average age of 37 years (range 22-49) at the index operation. Although no acetabular revisions had been performed due to aseptic loosening, pelvic osteolysis was visible around thirteen cup prostheses (23\%). Furthermore, two asymptomatic stable cups were removed to prevent failure and the histological analysis of the tissue surrounding the osteolysis showed polyethylene particles. These authors attributed the good results with this Harris-Galante I cementless cup to its fixation with multiple screws.

Schmalzried et al discouraged the use of screws in the metal shell, because of the risk of vascular damage and fretting wear between the screws and the shell $[246,248]$. They stated that the presence of screw holes did not predict the development of osteolysis around the implant. On the other hand, screw holes could permit the passage of wear particles, with subsequent osteolysis [72]. 
In addition, Tonino et al found polyethylene debris in empty screw holes in a retrieval study of six hemispherical hydroxyapatite-coated cups [265]. Interpreting Crowther's pelvic osteolysis results in the light of these remarks, it is possible that the screw holes in the Harris-Galante I cup explain the high incidence of pelvic osteolysis. Thus, it is not advisable to use cup prostheses with screw holes [72].

The Zweymüller threaded titanium cup does not require screws and on the basis of this study, we suggest that the Zweymüller prosthesis does not involve the problems of polyethylene wear and subsequent osteolysis.

Noble et al measured the shape of the femoral canal and reported that younger women had a champagne flute shape, while women of older than sixty years had a stove pipe shape femoral canal [218]. Owing to this difference in the shape of the femoral canal, it can be expected that one stem prosthesis would not be suitable for the total age range of patients. However, in our study, we could not confirm the difference in femoral canal shape, as only two younger patients had a champagne flute shape. Furthermore, we did not find any differences in the clinical results (e.g. Harris Hip Score) between the patients with a stove pipe shape canal and patients who were classified as having a normal shape according to Noble.

The Zweymüller stem prosthesis has a straight stem and during implantation, the surgeon has to rasp the intramedullary canal close to the lateral side. If more rasping occurs centrally or medially in the canal, the prosthesis will have a varus position. Devitt et al found that cemented stems in varus position resulted in a high incidence of revision [62]. In our study, about fifty per cent of the stems had a varus position, but we did not find that this varus position led to poorer clinical or radiological results. In contrast, the patients with a varus stem position had higher Harris Hip Scores.

This study showed only slight differences between HG and SL stem prostheses. The follow-up of the HG stem prostheses was longer, because this prosthesis has been available for a longer period in the Netherlands. We found more Charnley class A patients in the SL stem group. Probably, this difference can be explained by the early implantation of the Hochgezogen stem prosthesis in the Charnley $\mathrm{B}$ or $\mathrm{C}$ patients. The radiological analysis revealed more HG stem prostheses with radiolucent lines in Gruen zone 7 (calcar region). However, the classification of calcar density did not differ. Furthermore, we saw no differences in Engh scores for fixation and stability between the two prostheses. The differences in radiolucent lines in Gruen zone 7, which had no clinical consequences, could be explained by the proximal narrowing of the HG stem prosthesis in the sagittal plane.

The SL prosthesis was developed to promote osseointegration [289]. Böhm et al performed a retrieval study on $19 \mathrm{HG}$ and $15 \mathrm{SL}$ stem prostheses and found more uniform bone-implant contact with the SL stems, which led to more sclerosis in Gruen zones 3 and 5 [16]. Our study could not confirm this difference. 
Furthermore, Böhm et al did not find any differences in bone-implant contact between the patients of older and younger than 65 years [16].

This study was conducted to assess the clinical and radiological results with the Zweymüller total hip arthroplasty system. Patient's satisfaction was not scored, because no validated and translated assessment tool was available in the Netherlands at that time. Since then the Dutch Oxford Hip Score has been developed [123]. Sending a questionnaire is considered to gather reliable assessment data on the outcome [53]. Thus, our results reflect long-term patient satisfaction with this prosthesis in younger patients.

Table 7.7

Literature data on various cemented total hip prostheses in patients of younger than 50 years

\begin{tabular}{|c|c|c|c|c|c|c|c|}
\hline \multirow[t]{2}{*}{ Author } & \multirow{2}{*}{$\begin{array}{l}\text { Type of } \\
\text { prosthesis }\end{array}$} & \multirow{2}{*}{$\begin{array}{l}\text { No. of } \\
\text { arthroplasties }\end{array}$} & \multirow{2}{*}{$\begin{array}{l}\text { Mean age } \\
\text { (range) }\end{array}$} & \multirow{2}{*}{$\begin{array}{l}\text { Mean } \\
\text { follow-up } \\
\text { (range) }\end{array}$} & \multicolumn{3}{|c|}{ Aseptic loosening } \\
\hline & & & & & Cup $(\%)$ & $\begin{array}{l}\text { Stem } \\
(\%)\end{array}$ & $\begin{array}{l}\text { Cup and } \\
\text { stem }(\%)\end{array}$ \\
\hline Ballard [10] & Various & 43 & $\begin{array}{l}41 \mathrm{yrs} \\
(18-49)\end{array}$ & $\begin{array}{l}11 \text { yrs } \\
(10-15)\end{array}$ & $\begin{array}{c}10 \\
(23.3 \%)\end{array}$ & $\frac{2}{(4.6 \%)}$ & $\begin{array}{c}0 \\
(0 \%)\end{array}$ \\
\hline Devitt [62] & Chamley & 110 & $\begin{array}{c}42 \text { yrs } \\
(16-49)\end{array}$ & $\begin{array}{c}18 \text { yrs } \\
(16-25)\end{array}$ & & & $\begin{array}{l}21(19 \%) \\
\text { aseptic } \\
\text { loosening } \\
\text { cup and } \\
\text { or stem }\end{array}$ \\
\hline Dorr [69] & Chamley & 49 & $\begin{array}{l}31 \mathrm{yrs} \\
(16-45)\end{array}$ & $\begin{array}{c}16 \text { yrs } \\
(13-20)\end{array}$ & $\begin{array}{c}9 \\
(18.4 \%)\end{array}$ & $\begin{array}{c}0 \\
(0 \%)\end{array}$ & $\begin{array}{c}24 \\
(48.9 \%)\end{array}$ \\
\hline $\begin{array}{l}\text { Garcia- } \\
\text { Cimbrelo } \\
\text { [91] }\end{array}$ & Charnley & 67 & $\begin{array}{l}32,4 \text { yrs } \\
(18-39)\end{array}$ & $\begin{array}{c}21.7 \mathrm{yrs} \\
(5-25)\end{array}$ & $\begin{array}{c}18 \\
(26.9 \%)\end{array}$ & $\begin{array}{c}12 \\
(17.9 \%)\end{array}$ & \\
\hline Smith [254] & Various & 47 & $\begin{array}{l}41 \text { yrs } \\
(21-50)\end{array}$ & $\begin{array}{l}15.9 \text { yrs } \\
(0.3-20)\end{array}$ & $\begin{array}{c}15 \\
(31.9 \%)\end{array}$ & $\begin{array}{l}3 \\
(6.4 \%)\end{array}$ & \\
\hline $\begin{array}{l}\text { Sullivan } \\
\text { [261] }\end{array}$ & Charnley & 84 & $\begin{array}{l}42 \text { yrs } \\
(18-49)\end{array}$ & $\begin{array}{l}18 \text { yrs } \\
(16-22)\end{array}$ & $11(13 \%)$ & $2(2 \%)$ & $0(0 \%)$ \\
\hline
\end{tabular}

Tables 7.7 and 7.8 summarize the results of various studies on total hip arthroplasty in younger patients. Cemented total hip prostheses had a high rate of aseptic loosening, particularly of the acetabular cup. However, the duration of follow-up was considerably longer than that for the cementless total hip prostheses. It is still too early to speak in terms of better results with the cementless prostheses than with cemented ones. Smith et al investigated the prevalence of revision during 20-years of follow-up in 47 cemented total hip arthroplasties and found a four-fold increase in cup loosening after 20 years compared to the first ten years [254]. In younger patients, a minimum follow-up of 15 years would be required 
to distinguish between good and poor prosthesic designs. Nevertheless, our results with the Zweymüller cementless prosthesis in younger patients were very promising.

table 7.8

Literature data on various cementless total hip prostheses in patients of younger than 50 years

\begin{tabular}{|c|c|c|c|c|c|c|c|}
\hline \multirow[t]{2}{*}{ Atuthor } & \multirow{2}{*}{$\begin{array}{l}\text { Type of } \\
\text { prosthesis }\end{array}$} & \multirow{2}{*}{$\begin{array}{l}\text { No, of } \\
\text { arthroplasties }\end{array}$} & \multirow{2}{*}{$\begin{array}{l}\text { Mean age } \\
\text { (range) }\end{array}$} & \multirow{2}{*}{$\begin{array}{c}\text { Mean } \\
\text { follow-up } \\
\text { (range) }\end{array}$} & \multicolumn{3}{|c|}{ Aseptic loosening } \\
\hline & & & & & Cup (\%) & Stem $(\%)$ & $\begin{array}{l}\text { Cup and } \\
\text { stem } \\
(\%)\end{array}$ \\
\hline Berger [12] & $\begin{array}{l}\text { Harris- } \\
\text { Galante I }\end{array}$ & 68 & $\begin{array}{c}37 \text { yrs } \\
(20-49)\end{array}$ & $\begin{array}{c}8.7 \text { yrs } \\
(6.5-10.5)\end{array}$ & 0 & (13.2\%) & $(2.9 \%)$ \\
\hline $\begin{array}{l}\text { Crowther } \\
\text { [48] }\end{array}$ & $\begin{array}{l}\text { Harris- } \\
\text { Galante I }\end{array}$ & 56 & $\begin{array}{c}37 \text { yrs } \\
(22-49)\end{array}$ & $\begin{array}{l}11 \text { yrs } \\
(9-14)\end{array}$ & 0 & 0 & 0 \\
\hline Dowdy [72] & $\begin{array}{l}\text { Mallory } \\
\text { Head }\end{array}$ & 41 & $\begin{array}{l}42 \text { yrs } \\
(19-50)\end{array}$ & $\begin{array}{c}5.3 \text { yrs } \\
(4-7)\end{array}$ & $\begin{array}{c}3 * \\
(7.3 \%)\end{array}$ & 0 & 0 \\
\hline Duffy [73] & $\begin{array}{c}\text { PCA } 39 \\
\text { Osteonic } 21 \\
\text { HG I } 22\end{array}$ & 82 & $\begin{array}{l}32 \text { yrs } \\
(17-39)\end{array}$ & $\begin{array}{l}10.3 \text { yrs } \\
(10-14)\end{array}$ & $\begin{array}{c}\text { PCA 10 } \\
(25.6) \\
\text { Osteonics } 4 \\
(19.1) \\
\text { HG I } 3 \\
(13.6)\end{array}$ & $\begin{array}{c}\text { PCA 9 } \\
(23.1) \\
\text { Osteonics } \\
0(0) \\
\text { HG 14 } \\
(18.2)\end{array}$ & \\
\hline $\operatorname{Kim}[158]$ & $\begin{array}{c}\text { Duraloc- } \\
\text { Elite ** }\end{array}$ & 64 & $\begin{array}{l}43.4 \text { yrs } \\
(21-50)\end{array}$ & $\begin{array}{l}9.4 \text { yrs } \\
(8-10)\end{array}$ & 0 & 0 & 0 \\
\hline $\begin{array}{l}\text { Loupassis } \\
{[180]}\end{array}$ & $\begin{array}{c}\text { Furlong } \\
\text { HAP }\end{array}$ & 45 & $\begin{array}{c}46 \text { yrs } \\
(31-50)\end{array}$ & $\begin{array}{c}5.9 \text { yrs } \\
(3.8-7.4)\end{array}$ & $0 *$ & 0 & 0 \\
\hline $\begin{array}{l}\text { Vervest } \\
\text { [this study] }\end{array}$ & $\begin{array}{c}\text { Zweymuller } \\
(\mathrm{HG} / \mathrm{SL})\end{array}$ & 74 & $\begin{array}{l}43.1 \mathrm{yrs} \\
(\mathrm{sd} 7.7)\end{array}$ & $\begin{array}{c}9.7 \mathrm{yrs} \\
(6.0-12.8)\end{array}$ & $(2.7 \%)$ & 0 & 0 \\
\hline
\end{tabular}

- Dowdy et al found a further 5 and Loupassis et al a further 2 patients with radiological signs of aseptic cup loosening.

** This prosthesis was a hybrid prosthesis: cementless Duraloc cup and cemented Elite stem

\subsection{CONCLUSION}

This multicentre study showed good results with the Zweymüller cementless prosthesis in younger patients after a follow-up of moderate duration. 


\section{THE OXFORD HIP SCORE APPLIED TO THE COHORT STUDY}

\subsection{ABSTRACT}

Patients with the Zweymüller cementless total hip prosthesis assessed their functioning with the replaced hip by means of the Dutch Oxford Hip Score (OHS). This validated Dutch translation of the disease-specific questionnaire consists of fourteen questions with five answer alternatives each. The best score is 14 points, while the poorest score is 70 points. The V.A.S. pain score and the Charnley classification were also assessed and three questions measured patient satisfaction.

The outcome of 582 (153 men and 367 women) returned and fully answered questionnaires were evaluated. Mean age at the time of this survey was 71.6 years (sd 9.7), while mean postoperative follow-up was 110.9 months (sd 21.1). The average OHS was 22.9 (sd 10.6). Analysis showed that the Charnley class C patients had poorer OHSs than the class A or B patients. The V.A.S. pain score averaged $16.9 \mathrm{~mm}(0 \mathrm{~mm}$ means no pain) and there was agreement with the answers to questions that assessed pain during A.D.L. Older patients reported more problems with A.D.L. About 91 per cent of the patients were satisfied with the result of the arthroplasty. Our analysis revealed that the satisfied patient had better OHSs.

It could be concluded that patients with a Zweymüller prosthesis were satisfied with their ability to function and very few patients were suffering from pain. Patients with comorbidity that interfered with walking (Charnley C) and older patients whose A.D.L. were restricted by age had poorer Oxford Hip Scores. 
Total hip arthroplasty for the treatment of osteoarthritis can be regarded as one of the greatest successes of orthopaedic surgery. Improvement in hip function, pain reduction and the number of prostheses with aseptic loosening determine the success of the intervention $[170,274]$.

Several questionnaires have been developed to assess the results of total hip arthroplasty $[95,112,137,204]$. W.H. Harris developed the well-known Harris Hip Score in 1969 [112]. This score ranges from 0 points (very poor result) to 100 points (excellent result). The item "pain" is the most important, because the alternative "no pain" yields 44 points. Limitations in the Activities of Daily Living (using stairs, managing shoes and socks, sitting, using public transport) account for a possible 14 points, while disorders during walking (limping, need for a support, limited walking distance) account for 33 points. Range of motion (max. 5 points) and deformities (contractures and limb-length discrepancies of less than 3.2 centimetres) (4 points) are relatively undervalued. The Harris Hip Score is determined by a medical professional. Patient satisfaction is not assessed. Harris rejected the importance attributed to the patient's judgement in the assessment of the result of total hip arthroplasties proposed by Shepherd in $1954[112,141,253]$. Nowadays, patients' opinions and patient satisfaction once more form essential factors in determining the result of total hip arthroplasty [87, $149,164,190]$.

Several reliable questionnaires have been developed to assess patient satisfaction $[55,149,199]$. The S.I.C.O.T., A.A.O.S. and the Hip Society agreed on a standard system of hip replacement research and standard terminology to report the results of arthroplasty studies [142]. This standard system advises measuring a patient's judgement of the result with the recommended validated questionnaire [149]. However, this validated questionnaire has not been translated into Dutch. A validated translation is essential for the reliability of a questionnaire [95].

In 1996, Dawson et al described a questionnaire with twelve questions to assess patient satisfaction [53]. This English Oxford Hip Score is a validated and reproducible questionnaire $[54,87,95,123]$. It was translated into the Dutch language by the Research Department Orthopaedic Surgery University of Maastricht, the Netherlands, in cooperation with the orthopaedic departments of the University of Utrecht and the Rijnland Hospital Leiderdorp. The translation was validated for the Dutch language and reported in the professional journal of the Dutch Orthopaedic Society [123]. Several additions have been made to the original questionnaire: question 13, question 14, the Charnley classification, a Visual Analogue Scale to evaluate pain and three questions to evaluate patient satisfaction. At the time of the first investigations on the cohort study, the translated questionnaire was not yet available. 
The aim of this study was to assess patient satisfaction with a Zweymüller cementless total hip prostheses in our cohort, using the Dutch Oxford Hip Score.

\subsection{PATIENTS AND METHODS}

The Dutch Oxford Hip Score comprises fourteen questions with five answer alternatives each. The best score possible is 14 points, while the poorest score is 70 points. Pain is measured with a Visual Analogue Scale. This score varies from $0 \mathrm{~mm}$ (no pain) to $100 \mathrm{~mm}$ (intolerable pain). Other information is also gathered, including the Charnley classification, i.e. unilateral osteoarthritis (Charnley class A), bilateral osteoarthritis (Charnley class B) without comorbidity, or uni- or bilateral osteoarthritis with comorbidity that interferes with walking (Charnley Class C) [38]. Three additional questions assess patient satisfaction with the result of arthroplasty.

All the patients (820 prostheses) operated on between 1 January 1987 to 31 December 1994 were traced using the hospital 's administrative records. Addresses or the date of death were verified. Information on revision procedures was also gathered from the clinical records.

At the time of this study, 97 patients (106 prostheses) had died of causes unrelated to the primary surgery. Eight prostheses had been revised due to aseptic loosening of the acetabular component. One acetabular prosthesis had been revised for recurrent dislocation. Four prostheses had been revised for septic loosening and one prosthesis because of trauma-induced periprosthetic femoral fracture. We could not trace four patients (4 prostheses). The Dutch Oxford Hip Score was sent to 617 patients (696 prostheses) with a stamped return envelope.

Seventy-five ( $10.8 \%$ ) out of the 696 mailed questionnaires were unanswered or not returned; 23 of these questionnaires contained a note that the patient had moved away. The latter 23 patients could not be traced in a subsequent investigation by telephone. It was not possible to trace 35 patients who had not returned the questionnaire. The remaining 17 questionnaires had not been answered because the patient had dementia ( 9 questionnaires), six patients refused to participate and two questionnaires had not been filled in. A telephone investigation revealed that these 17 patients had not undergone any revision of the primary arthroplasty and that they were satisfied with the result of arthroplasty.

The Dutch Oxford Hip Score could not be determined in 39 questionnaires, because not all the questions had been answered.

Fully answered questionnaires on 582 hip prostheses, $83.6 \%$ of the mailed questionnaires, were suitable for further analysis. Question number 15 (V.A.S. pain score) had not been answered on eight of these questionnaires and 
question number 16 (Charnley classification) had not been answered on two questionnaires. On three questionnaires, neither of these questions had been answered. Correlations between the answers to the Dutch Oxford Hip Score and the V.A.S. pain score were calculated from 571 questionnaires $(82.1 \%)$, while correlations between the Dutch Oxford Hip Score and the Charnley classification were calculated from the data on 577 questionnaires were used $(82.9 \%)$. The mean Dutch Oxford Hip Score was calculated per age category. Owing to the small numbers of patients in the age groups $20-30,30-40$ and $80-90$ years, these age groups were excluded from this part of the analysis. The Dutch Oxford Hip Score was divided into questions regarding pain (questions 1, 6, 8, 9, 10, 11 and 12) and questions regarding the Activities of Daily Living (questions 2, 3, 4, $5,7$ and 13$)$.

The data were analysed with SPSS software. ANOVA and Bonferroni Post Hoc test were used for the statistical analysis (significance $\mathrm{p}<0.05$ ).

\subsection{RESULTS}

The participants comprised 153 men and 367 women. Average age at the time of surgery and at the time of this study was 62.4 years (sd 9.8) and 71.6 years (sd 9.7), respectively. Mean follow-up was 110.9 months (sd 21.1).

Charnley classification at the time of this study was class A (unilateral prosthesis) in 149 prostheses $(25.6 \%)$, class B (bilateral prostheses and/or osteoarthritis) in 168 prostheses $(28.9 \%$ ) and class C (uni- or bilateral prostheses with comorbidity that interferes with walking) in 260 prostheses $(44.7 \%)$. This question had not been answered on five questionnaires $(0.9 \%)$.

Mean Dutch Oxford Hip Score $(\mathrm{n}=582$ ) was 22.9 (sd 10.6). In Charnley class A patients $(n=149)$ the mean Dutch Oxford Hip Score was 18.4 (sd 8.2), in class B patients $(n=168)$ it was 20.1 (sd 8.8) and in class C patients it was $(n=260)$ 27.4 (sd 11.3). The difference in scores between class $C$ and classes A and B was statistically significant (ANOVA $F(574,2)=49.814 ; \mathrm{p}=0.000$ ). Mean age of the patients in the three classes did not differ.

Differences in mean Dutch Oxford Hip Score were found between the age groups (ANOVA $\mathrm{F}(552,3)=8.58 ; \mathrm{p}=0.000$ ) (Table 8.1). Bonferroni Post-Hoc analysis revealed that patients in the age group 50 to 60 years at the time of surgery had better scores than those in the age groups 60 to 70 years $(p=0.000)$ and 70 to 80 years $(\mathrm{p}=0.000)$. The Dutch Oxford Hip Scores did not differ between the patients in the age groups 40 to 50 years and 50 to 60 years at the time of surgery. 
Table 8.1

Dutch Oxford Hip Score (OHS) per age group (see text)

\begin{tabular}{|c|c|c|c|}
\hline age group (yrs) & number of hips & mean OHS & Standard deviation \\
\hline $20-30$ & 6 & 18.5 & 8.3 \\
\hline $30-40$ & 12 & 26.1 & 14.9 \\
\hline $40-50$ & 44 & 21.4 & 7.7 \\
\hline $50-60$ & 147 & 19.5 & 7.0 \\
\hline $60-70$ & 251 & 23.8 & 11.7 \\
\hline $70-80$ & 114 & 25.4 & 10.7 \\
\hline $80-90$ & 8 & 35.1 & 11.8 \\
\hline
\end{tabular}

Table 8.2 shows the answers to the fourteen questions given by the study group $(\mathrm{n}=582)$. A low percentage patients of had pain complaints. The mean pain score $(\mathrm{n}=571$ ) on the V.A.S. was $16.9 \mathrm{~mm}$ (sd 20.2).

Table 8.3 shows the correlation between the V.A.S. pain score and the answers to question 1 of the Dutch Oxford Hip Score. The majority of patients did not have any pain. Analysis revealed the agreement between the answers to question 1 and the V.A.S. pain scores (ANOVA $F(566,4)=153.393 ; p=0.000$ ). Questions $6,8,9,10,11$ and 12 also concern pain. Again, the answers to these questions agreed with the V.A.S. pain scores. The answers to the first two answer catogories demonstrated this agreement, but there were not enough patients with answers in catogories in 3 to 5 to perform reliable analyses. The analysis also revealed that more patients who were classified as Charnley class $\mathrm{C}$ had pain than those classified as class A or B, and that the pain score was not related to the age of the patient at the time of surgery.

\section{Table 8.2}

Answers on 582 completed Dutch Oxford Hip Score questionnaires. The English Oxford Hip Score (12-item questionnaire) consists of questions 1 to 12 . Questions 13 and 14 were added by Hoefnagels et al [123]

\section{During the past four weeks}

Question 1: How would you describe the pain you usually had from your
hip?
\begin{tabular}{|l|l|c|c|}
\hline & $\begin{array}{c}\text { Number of } \\
\text { hips }\end{array}$ & Percentage \\
\hline 2 very mild & 397 & 68.2 \\
\hline 3 mild & 66 & 11.3 \\
\hline 4 moderate & 63 & 10.8 \\
\hline 5 severe & 44 & 7.6 \\
\hline
\end{tabular}




\begin{tabular}{|c|c|c|c|}
\hline \multicolumn{2}{|c|}{$\begin{array}{l}\text { Question 2: Have you bad any trouble with washing and drying yourself } \\
\text { (all over) because of your hip? }\end{array}$} & \multirow{2}{*}{$\begin{array}{c}\begin{array}{c}\text { Number of } \\
\text { hips }\end{array} \\
376 \\
\end{array}$} & \multirow{2}{*}{$\begin{array}{c}\text { Percentage } \\
64.6\end{array}$} \\
\hline & 1 no trouble at all & & \\
\hline & 2 very little trouble & 143 & 24.6 \\
\hline & 3 moderate trouble & 35 & 6.0 \\
\hline & 4 extreme difficulty & 19 & 3.3 \\
\hline & 5 impossible to do & 9 & 1.5 \\
\hline \multicolumn{2}{|c|}{$\begin{array}{l}\text { Question 3: Have you had any trouble getting in and out of a car or using } \\
\text { public transport because of your hip? (whichever you tend to use) }\end{array}$} & $\begin{array}{c}\text { Number of } \\
\text { hips }\end{array}$ & Percentage \\
\hline & I No trouble at all & 262 & 45.0 \\
\hline & 2 Very little trouble & 206 & 35.4 \\
\hline & 3 Moderate trouble & 72 & 12.4 \\
\hline & 4 Extreme difficulty & 36 & 6.2 \\
\hline & 5 Impossible to do & 6 & 1.0 \\
\hline \multicolumn{2}{|c|}{$\begin{array}{l}\text { Question 4: Have you been able to put on a pair of socks, stockings or } \\
\text { tights? }\end{array}$} & $\begin{array}{l}\text { Number of } \\
\text { hips }\end{array}$ & Percentage \\
\hline & 1 Yes, easily & 290 & 49.8 \\
\hline t & 2 With little difficulty & 185 & 31.8 \\
\hline thing on & 3 With moderate difficulty & 42 & 7.2 \\
\hline 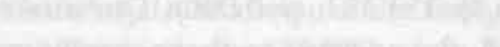 & 4 With extreme difficulty & 27. & 4.6 \\
\hline t. & $5 \mathrm{No}$, impossible & 38 & 6.5 \\
\hline \multicolumn{2}{|c|}{ Question 5: Could you do the household shopping on your own? } & $\begin{array}{c}\text { Number of } \\
\text { hips }\end{array}$ & Percentage \\
\hline \multirow{5}{*}{ 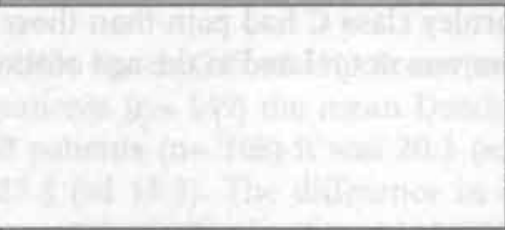 } & I Yes, easily & 377 & 64.8 \\
\hline & 2 With little difficulty & 101 & 17.4 \\
\hline & 3 With moderate difficulty & 28 & 4.8 \\
\hline & 4 With extreme difficulty & 30 & 5.2 \\
\hline & 5 No, impossible & 46 & 7.9 \\
\hline \multicolumn{2}{|c|}{$\begin{array}{l}\text { Question 6: For how long have you been able to walk before the pain } \\
\text { from your hip became severe? (with or without a stick) }\end{array}$} & $\begin{array}{l}\text { Number of } \\
\text { hips }\end{array}$ & Percentage \\
\hline & 1 No pain $/>30$ minutes & 374 & 64.3 \\
\hline & 216 to 30 minutes & 72 & 12.4 \\
\hline & 35 to 15 minutes & 59 & 10.1 \\
\hline & 4 Around the house only & 51 & 8.8 \\
\hline & 5 Not at all & 26 & 4.5 \\
\hline \multicolumn{2}{|c|}{ Question 7: Have you been able to climb a flight of stairs? } & $\begin{array}{c}\text { Number of } \\
\text { hips }\end{array}$ & Percentage \\
\hline & 1 Yes, easily & 306 & 52.6 \\
\hline & 2 With little difficulty & 158 & 27.1 \\
\hline & 3 With moderate difficulty & 37 & 6.4 \\
\hline & 4 With extreme difficulty & 39 & 6.7 \\
\hline & $5 \mathrm{No}$, impossible & 42 & 7.2 \\
\hline
\end{tabular}




\begin{tabular}{|c|c|c|c|}
\hline \multicolumn{2}{|c|}{$\begin{array}{l}\text { Question 8: After a meal (sat at a table), how painful has it been for you to } \\
\text { stand up from a chair because of your hip? }\end{array}$} & \multirow{2}{*}{$\begin{array}{c}\begin{array}{c}\text { Number of } \\
\text { hips }\end{array} \\
416\end{array}$} & \multirow{2}{*}{$\begin{array}{l}\text { Percentage } \\
71.5\end{array}$} \\
\hline 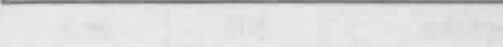 & 1 Not at all painful & & \\
\hline & 2 Slightly painful & 115 & 19.8 \\
\hline & 3 Moderately painful & 34 & 5.8 \\
\hline & 4 Very painful & 14 & 2.4 \\
\hline & 5 Unbearable & 3 & 0.5 \\
\hline \multicolumn{2}{|c|}{ Question 9: Have you been limping when walking, because of your hip? } & $\begin{array}{c}\text { Number of } \\
\text { hips }\end{array}$ & Percentage \\
\hline & 1 Rarely/never & 391 & 67.2 \\
\hline & 2 Sometimes or just at first & 104 & 17.9 \\
\hline & 3 Often, not just at first & 25 & 4.3 \\
\hline & 4 Most of the time & 26 & 4.5 \\
\hline & 5 All of the time & 36 & 6.2 \\
\hline \multicolumn{2}{|c|}{$\begin{array}{l}\text { Question 10: Have you had any sudden, severe pain -"shooting". } \\
\text { "stabbing or "spasms"- from the affected hip? }\end{array}$} & $\begin{array}{c}\text { Number of } \\
\text { hips }\end{array}$ & Pereentage \\
\hline & 1 No days & 433 & 74.4 \\
\hline & 2 Only 1 or 2 days & 68 & 11.7 \\
\hline & 3 Some days & 51 & 8.8 \\
\hline & 4 Most days & 17 & 2.9 \\
\hline & 5 Every day & 13 & 2.2 \\
\hline \multicolumn{2}{|c|}{$\begin{array}{l}\text { Question 11: How much has pain from your hip interfered with your usual } \\
\text { work (including housework)? }\end{array}$} & $\begin{array}{l}\text { Number of } \\
\text { hips }\end{array}$ & Percentage \\
\hline & I Not at all & 354 & 60.8 \\
\hline & 2A little bit & 139 & 23.9 \\
\hline & 3 Moderately & 49 & 8.4 \\
\hline & 4 Greatly & 27 & 4.6 \\
\hline & 5 Totally & 13 & 2.2 \\
\hline \multicolumn{2}{|c|}{$\begin{array}{l}\text { Question 12: Have you been troubled by pain from your hip in bed at } \\
\text { night? }\end{array}$} & $\begin{array}{c}\text { Number of } \\
\text { hips }\end{array}$ & Percentage \\
\hline 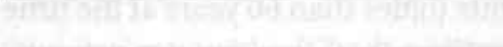 & 1 No nights & 432 & 74.2 \\
\hline & 2 Only 1 or 2 nights & 68 & 11.7 \\
\hline & 3 Some nights & 48 & 8.2 \\
\hline & 4 Most nights & 17 & 2.9 \\
\hline & 5 Every nights & 17 & 2.9 \\
\hline \multicolumn{2}{|c|}{$\begin{array}{l}\text { Question 13: Do you use walking aids (cane(s), crutch(es) or walking } \\
\text { frame) during walking? }\end{array}$} & $\begin{array}{c}\text { Number of } \\
\text { hips }\end{array}$ & Percentage \\
\hline \multirow{5}{*}{ 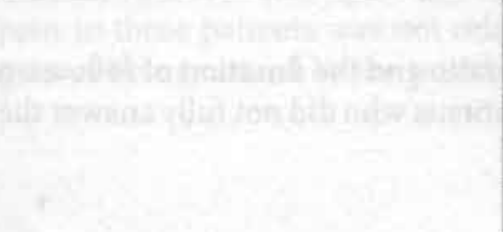 } & 1 Never & 403 & 69.2 \\
\hline & 2 Sometimes & 44 & 7.6 \\
\hline & 3 Often & 21 & 3.6 \\
\hline & 4 Most of the time & 33 & 5.7 \\
\hline & 5 All of the time & 81 & 13.9 \\
\hline
\end{tabular}


Question 14: Is your hip limiting your sexual activities? Number of Percentage hips

\begin{tabular}{|l|c|c|}
\hline 1 Neverinot appliable & 502 & 86.3 \\
\hline 2 Sometimes & 61 & 10.5 \\
\hline 3 Often & 8 & 1.4 \\
\hline 4 Most of the time & 4 & 0.7 \\
\hline 5 All of the time & 7 & 1.2 \\
\hline
\end{tabular}

Table 8.3

This table shows the relation between the V.A.S. pain score and the answers to question I of the Dutch Oxford Heup Score $(n=571)$

\begin{tabular}{|l|c|c|c|}
\hline \multicolumn{3}{|c|}{ Question 1: How would you describe the pain you usually had from your hip? } \\
\hline answer & Number of hips & Percentage & $\begin{array}{c}\text { V.A.S. pain score (mm) } \\
\text { (sd) }\end{array}$ \\
\hline 1 none & 391 & 68.5 & $\begin{array}{l}8.7 \mathrm{~mm} \\
\text { (sd 10.5) }\end{array}$ \\
\hline 2 very mild & 63 & 11.0 & $\begin{array}{l}21.3 \mathrm{~mm} \\
\text { (sd 15.6) }\end{array}$ \\
\hline 3 mild & 63 & 11.0 & $\begin{array}{l}34.4 \mathrm{~mm} \\
\text { (sd 19.7) }\end{array}$ \\
\hline 4 moderate & 42 & 7.4 & $\begin{array}{l}43.0 \mathrm{~mm} \\
\text { (sd 25.1) }\end{array}$ \\
\hline 5 severe & 12 & 2.1 & $\begin{array}{l}78.0 \mathrm{~mm} \\
\text { (sd 17.7) }\end{array}$ \\
\hline
\end{tabular}

In response to the questions on Activities of Daily Living, many of the patients indicated having problems with public transport (question 3), putting on a pair of socks, stockings or tights (question 4), household shopping (question 5) and climbing stairs (question 7). Eighty-one patients (13.9\%) were using crutches or a cane while walking. We found that older patients (older than 60 years at the time of surgery) had lower scores on the A.D.L. questions than the younger patients. We also found that the Charnley class $C$ patients had lower scores on the A.D.L. questions (questions 2, 3, 4, 5, 7 and 13) than the Charnley class A or B patients.

Table 8.4 shows the answers to the three general satisfaction questions. The patients who gave positive answers (satisfied with the prosthesis) had better Dutch Oxford Hip Scores than the patients who were not satisfied with the prosthesis.

There were no differences in age, male:female ratio and the duration of follow-up between the participants and the group of 39 patients who did not fully answer the 
questionnaires. Question 2 (washing and drying yourself) was most frequently $(n=23)$ left unanswered, followed by question 14 (sexuality) ( $n=21)$.

Table 8.4

Answers to the three general questions in the Dutch Oxford Hip Score (OHS).

\begin{tabular}{|c|c|c|c|}
\hline Question & Yes & No & Not answered \\
\hline $\begin{array}{c}\text { 17. Did the arthroplasty improve } \\
\text { your mobility or the function of } \\
\text { your hip? }\end{array}$ & $\begin{array}{c}\mathrm{n}=516(88.7 \%) \\
\text { OHS 21.7 (sd 9.2) }\end{array}$ & $\begin{array}{c}\mathrm{n}=45(7.7 \%) \\
\text { OHS 35.8 (sd 14.1) }\end{array}$ & $\begin{array}{c}\mathrm{n}=21(3.6 \%) \\
\text { OHS 27.9 (sd 15.4) }\end{array}$ \\
\hline $\begin{array}{c}\text { 18. Did you have less pain around } \\
\text { your hip after the arthroplasty? }\end{array}$ & $\begin{array}{c}\mathrm{n}=528(90.7 \%) \\
\text { OHS 22.0(sd 9.5) }\end{array}$ & $\begin{array}{c}\mathrm{n}=27(4.6 \%) \\
\mathrm{OHS} 41.3(\mathrm{sd} \mathrm{12.9)})\end{array}$ & $\begin{array}{c}\mathrm{n}=27(4.6 \%) \\
\text { OHS 23.0 (sd 13.0) }\end{array}$ \\
\hline $\begin{array}{c}\text { 19. Are you satisfied with the result } \\
\text { of the arthroplasty? }\end{array}$ & $\begin{array}{c}\mathrm{n}=531(91.2 \%) \\
\text { OHS 22.0 (sd 9.5) }\end{array}$ & $\begin{array}{c}\mathrm{n}=23(4.0 \%) \\
\text { OHS 41.1 (sd 14.1) }\end{array}$ & $\begin{array}{c}\mathrm{n}=28(4.8 \%) \\
\text { OHS 25.5 (sd 12.4) }\end{array}$ \\
\hline
\end{tabular}

\subsection{DISCUSSION}

This study showed that the patients in the Zweymüller cohort study were satisfied with their functional ability 110 months after the operation. We found that the Charnley class C patients had more pain and greater limitations in Activities of Daily Living.

The general health status of patients measured by the Charnley classification was found to affect the outcome of several disease-specific hip rating scales [33. $96,257]$. Elderly patients are liable to have more comorbid disorders that restrict their functional ability. Therefore, they will have lower A.D.L. scores despite a well-functioning hip prosthesis $[22,95,173]$. This study showed that the Charnley classification influenced the Dutch Oxford Hip Score and confirmed that the Charnley classification needs to be taken into account when interpreting the Dutch Oxford Hip Score.

Our patients with a Zweymüller cementless total hip prosthesis reported very little pain on the V.A.S. and ordinal scale. Dawson et al compared the English Oxford Hip Score to the general health questionnaire SF-36 and concluded that the English Oxford Hip Score was more appropriate to measure changes in pain than the general health questionnaire [54, 55]. Furthermore, the Oxford Hip Score discriminated hip pain from general sources of pain. In our study, the patients in Charnley class $\mathrm{C}$ had the most pain complaints. In contradiction with the conclusion drawn by Dawson et al $[54,55]$, a possible explanation is that the pain in these patients was not related to the prosthesis, but they interpreted the pain as being caused by the prosthesis. 
increasing age. Several other factors were also investigated, but they did not include the affect of comorbidity on the Harris Hip Score. Unfortunately they did not comment on or analyse their results, so their confounding factor "age" may have been influenced by the Charnley classification. The Harris Hip Score measures pain, limitations in Activities of Daily Living and motion [112]. The factor pain accounts for 44 out of the 100 HHS points. However, pain is multifactorial and extremely subjective. Other causes of pain (eg. lower back pain) could be regarded as pain that originates from the arthroplasty and consequently influence the Harris Hip Score. The Charnley classification discriminates between complaints by classifying comorbid interference with walking. The results of arthroplasty are much poorer in patients with comorbid problems that interfere with walking. Therefore, the Charnley classification should play an obligatory role in the evaluation of arthroplasty results $[33,95,123]$. Our study on the Dutch Oxford Hip Score (Chapter 8) confirmed the indispensability of the Charnley classification.

The historic cohort provided valuable insight into the fixation pattern of the cementless Zweymüller stem prosthesis. The radiological study showed proximal radiolucent lines and distal bone apposition at the tip of the prosthesis. This pattern indicates stress shielding. In a subset of the cohort study, we investigated bone mineral density (BMD) and found decreased BMD in the calcar region. No clinical or radiological sequelae were recorded. It remained uncertain whether stress shielding would have adverse effects in the long-term, such as aseptic loosening of the components, debris-induced osteolysis or mid-thigh pain.

Bugbee et al evaluated the X-rays of 48 hips two years after the implantation of cementless AML proximal porous coated prosthesis [29]. They found radiological stress shielding, but could not establish any clinically adverse effects. The proximal porous coating provided a barrier against distal migration of wear debris.

In our radiological studies on the Zweymüller stem prosthesis (Chapter 6) there was no evidence of aseptic loosening of the stems and only two HG stems showed clinically irrelevant osteolysis in the proximal regions. In the cohort study (Chapter 3) eight patients were found to be suffering from transient mid-thigh pain. Our study confirmed that stress shielding does not lead to deterioration of the arthroplasty. Moreover, such stress shielding could be the normal adaptive response of the bone to the implant and indicate progressive fixation.

Chapter 5 presents the long-term results of the cementless Zweymüller threaded titanium cup with a polyethylene insert. All the stem prostheses had a ceramic ball. The annual wear of $0.04 \mathrm{~mm}$ was low, 105 cups had a mean polyethylene wear of $0.46 \mathrm{~mm}$ (sd 0.27 ). Wear has been defined as the removal of material from the prosthesis, caused by adhesion, abrasion and fatigue [9]. Several wear mechanisms are known and the most important is when wear debris is generated by motion between two weight-bearing surfaces. Wear debris causes macrophage stimulation and subsequently the activation of cytokines and enzymes. Ultimately, 
increasing age. Several other factors were also investigated, but they did not include the affect of comorbidity on the Harris Hip Score. Unfortunately they did not comment on or analyse their results, so their confounding factor "age" may have been influenced by the Charnley classification. The Harris Hip Score measures pain, limitations in Activities of Daily Living and motion [112]. The factor pain accounts for 44 out of the 100 HHS points. However, pain is multifactorial and extremely subjective. Other causes of pain (eg. lower back pain) could be regarded as pain that originates from the arthroplasty and consequently influence the Harris Hip Score. The Charnley classification discriminates between complaints by classifying comorbid interference with walking. The results of arthroplasty are much poorer in patients with comorbid problems that interfere with walking. Therefore, the Charnley classification should play an obligatory role in the evaluation of arthroplasty results [33, 95, 123]. Our study on the Dutch Oxford Hip Score (Chapter 8) confirmed the indispensability of the Charnley classification.

The historic cohort provided valuable insight into the fixation pattern of the cementless Zweymüller stem prosthesis. The radiological study showed proximal radiolucent lines and distal bone apposition at the tip of the prosthesis. This pattern indicates stress shielding. In a subset of the cohort study, we investigated bone mineral density (BMD) and found decreased BMD in the calcar region. No clinical or radiological sequelae were recorded. It remained uncertain whether stress shielding would have adverse effects in the long-term, such as aseptic loosening of the components, debris-induced osteolysis or mid-thigh pain.

Bugbee et al evaluated the X-rays of 48 hips two years after the implantation of cementless AML proximal porous coated prosthesis [29]. They found radiological stress shielding, but could not establish any clinically adverse effects. The proximal porous coating provided a barrier against distal migration of wear debris.

In our radiological studies on the Zweymüller stem prosthesis (Chapter 6) there was no evidence of aseptic loosening of the stems and only two HG stems showed clinically irrelevant osteolysis in the proximal regions. In the cohort study (Chapter 3) eight patients were found to be suffering from transient mid-thigh pain. Our study confirmed that stress shielding does not lead to deterioration of the arthroplasty. Moreover, such stress shielding could be the normal adaptive response of the bone to the implant and indicate progressive fixation.

Chapter 5 presents the long-term results of the cementless Zweymüller threaded titanium cup with a polyethylene insert. All the stem prostheses had a ceramic ball. The annual wear of $0.04 \mathrm{~mm}$ was low, 105 cups had a mean polyethylene wear of $0.46 \mathrm{~mm}$ (sd 0.27 ). Wear has been defined as the removal of material from the prosthesis, caused by adhesion, abrasion and fatigue [9]. Several wear mechanisms are known and the most important is when wear debris is generated by motion between two weight-bearing surfaces. Wear debris causes macrophage stimulation and subsequently the activation of cytokines and enzymes. Ultimately, 
the macrophages are unable to destroy the debris, which leads to osteoclastic activation and bone resorption $[9,114]$. In our chort study, eight acetabular cups had been revised due to aseptic loosening. The loosening may have been caused by wear and subsequent bone resorption. However, we could not prove this. In addition, seventeen cups showed radiolucent lines, osteolysis or migration. Since the study, only one of these cups has been revised.

On the femoral side, osteolysis was detected in a few cases. In the cohort study on 754 cementless Zweymüller total hip arthroplasties, five stem prostheses had osteolysis in zone 6 (Chapter 3). In the study on the long-term results of the Zweymüller stems (Chapter 6) two (other) stem prostheses had osteolysis. In our final search, no stem revisions had been performed due to aseptic loosening. It was concluded that we cannot assess clinically relevant polyethylene wear.

The first question to be answered in the evaluation of arthroplasty results in young patients is: What is young? In several studies, "young" mostly referred to patients of younger than fifty years at the time of surgery $[10,12,31,34,62]$. In accordance with this literature, we defined young patients as those of younger than 50 years at the time of surgery. Typical problems associated with arthroplasties in young patients are the long-term fixation of the acetabular component, other diagnoses than idiopathic osteoarthritis (e.g. osteonecrosis of the hip joint) that interfere with the results and the higher demands made on the arthroplasty by young patients. The life-expectancy of young patients is fairly long and therefore other regimes must be kept in mind when treating hip osteoarthritis. Antiinflammatory analgesics, physiotherapy, modification of activities and osteotomydelaying arthroplasty tactics should be considered $[31,69]$. Chapter 7 spotlighted the results of the cementless Zweymüller total hip arthroplasty in young patients. The results looked promising. Survival of the cementless acetabular cup was only slightly shorter in the young patients than in those of older than 50 years. In the total cohort, two acetabular cups had been revised due to aseptic loosening. These two cups had been implanted in patients of older than fifty years. This finding endorses the statement that the results of the cementless Zweymüller total hip arthroplasty in young patients are promising.

Our cohort study evaluated the long-term results of two cementless stem prostheses. We found only slight differences between them. Zweymüller et al suggested better osseointegration when developing the second generation of Stepless stem prosthesis [286, 289]. The retrieval study by Böhm et al confirmed the equal distribution of bone-implant contact with the Stepless stem prosthesis [16]. Radiologically (Chapter 6), we found more bone apposition in Gruen zone 4 in the mid-term with the Stepless stem prosthesis, while in the long-term, there was no difference between the two stems. DEXA measurements did not establish any differences in bone mineral density between the two stem prostheses. In the cohort study (Chapter 3) and in the study on the young patients (Chapter 7) we found more proximal radiolucent lines with the Hochgezogen stem prosthesis than with the Stepless stems. The radiological study on patients with a follow- 
up of at least ten years (Chapter 6) did not confirm this difference between the two stem versions. Heterogenicity in the patients in the cohort explaines these differences. On the other hand, we did not find any clinical or radiological evidence that the proximal radiolucent lines would lead to loosening. Thus, no gross differences were encountered between the two stem prostheses (Chapters 3 and 4).

Manufacturers are continuously changing the concept of their product, sometimes to make necessary modifications, sometimes for financial profit [241]. However, new is not always better. Large prospective and randomized studies are necessary to prove any improvements in performance when a new product has been launched [103]. Furthermore, new products could have early failure [47, 187. 219]. This study confirmed the good results with cementless Zweymüller total hip arthroplasty. There were no gross differences between the two stem versions, but unforgivably, manufacturing of the Hochgezogen stem prosthesis has stopped. The titanium threaded acetabular component was found to have a survival that matched that of other cementless and cemented cups. High satisfaction of the patients is an important feature to convince orthopaedic surgeons to continue to implant the cementless total hip system according to Prof. Dr. K. Zweymüller. This unchanged concept is still being applied in the Netherlands.

This cohort of patients with the Zweymüller cementless total hip arthoplasty can be used to make further assessments of its clinical value. First, although this study revealed favourable results, it is well-known that preliminary results can deteriorate in the future. Continued monitoring of the cohort might encouter less favourable results and should be obligatory. Especially the younger patients need longer follow-up to prove the superiority of this prosthesis over the cemented devices that were first to appear on the market [31, 48, 120]. Furthermore, this study on young patients showed a survival of 75 months, which is short compared to other studies on hip arthroplasty in young patients $[69,91,161]$.

The DEXA study showed a decrease in BMD in the region of the calcar and it would be interesting to examine this group after longer follow-up to monitor the development of stress shielding and their possible run into clinical decline.

In this study, a validated Dutch translation of a disease-specific questionnaire was used to assess patient satisfaction and functioning. It is still unclear which scores reflect the good or poor results. Further research is needed to prove that in combination with the clinical and radiological investigations, a discriminative questionnaire has been developed.

It is obligatory to monitor any cohort that has received total hip prostheses. Regular scoring of patients with questionnaires, clinical and radiological investigations is necessary to detect patients at risk for deterioration of the prosthesis. Orthopaedic surgeons should be urged to monitor their patients. The Netherlands needs a national implant register that is comparable with the one in Sweden. Although there is a register in the Netherlands, it does not function well, because of lack of support and financial resources. 
This study found favourable results and evidence that the Zweymüller cementless total hip arthroplasty is a safe treatment for osteoarthritis of the hip. 



\section{Summary}

Total hip replacement for the treatment of arthrosis of the hip is one of the greatest successes of orthopaedic surgery. Initially, this success could be attributed to the cemented total hip prosthesis, developed by Sir John Charnley at the beginning of the nineteen sixties. However, this break-through was overshadowed when the prostheses showed symptoms of loosening several years later and had to be revised, often in relatively young patients. The use of cement to fix the prosthesis was considered to be the cause of loosening and a new disease was described: "cement disease".

Later it appeared that loosening was the result of macrophage reactions to polyethylene particles, with subsequent bone resorption. Consequently, the cement lost its grip on the bone. Before this mechanism became known, various techniques and prosthetic designs were developed to implant hip prostheses without cement. This thesis describes the long-term results of the uncemented total hip arthroplasty system developed by professor K. Zweymüller from Vienna in the nineteen seventies.

Chapter 1 describes the development of the uncemented total hip prosthesis. Stability of uncemented total hip prostheses is determined by primary and secondary stability. Primary stability means direct anchoring of the prosthesis. This can be achieved by adapting the medullary canal of the femur to the size and shape of the prosthesis, so that when the prosthesis is implanted, it is tightly wedged in the medullary canal. Secondary stability means fixation of the prosthesis by bone ingrowth through the metal openings. This secondary stability can be aided by applying e.g. a porous coating or hydroxyapatite coating to the implant surface.

The importance of biocompatibility and biomechanics became clear during the development of the uncemented total hip prosthesis. These properties depend on the raw materials and production process. Titanium and cobalt-chrome alloys proved to be extremely suitable metals for the manufacture of total hip prostheses. These metals were easy to forge in the production process and did not cause rejection or malignancies in human subjects. Titanium proved to have better bio-inert properties than cobalt-chrome and had less detrimental influence on the surrounding bone.

A total hip prosthesis comprises an acetabular cup and a femoral stem component. The Zweymüller total hip system is manufactured in titanium. Inside the titanium 
Clinical and radiological studies were performed on 136 patients with 142 prostheses. Mean age at implantation was 61.1 years (sd 8.1 years) and mean follow-up was 134 months (sd 9.5 months). Linear wear of the polyethylene was measured according to Dorr. In 37 cup prostheses, no wear was observed, whereas the remaining 105 cup prostheses had a mean wear of $0.46 \mathrm{~mm}$ (sd $0.27 \mathrm{~mm}$ ), with an annual wear of $0.04 \mathrm{~mm}$ (sd $0.02 \mathrm{~mm}$ ). In 17 cup prostheses, radiolucent lines, osteolysis or migration was found. Seven cups had been revised and the cumulative survival of the cup after 138 months was $95.9 \%\left(\mathrm{CI}_{95} 99.8-92.1 \%\right)$. It could be concluded that the titanium threaded cup showed very little polyethylene wear and good long-term results.

Chapter 6 presents the results of a study on $78 \mathrm{HG}$ and 64 SL stem prostheses that had been implanted in patients from the cohort described in Chapter 5 . None of the stems had been revised because of aseptic loosening. Radiolucent lines were found in Gruen zone 1 (trochanter major) and in Gruen zone 7 (trochanter minor) in 42\% and $28 \%$ of the patients, respectively. Bone apposition at the tip of the prosthesis was present in $78 \%$. In $20 \%$ of the stem prostheses, there were proximal radiolucent lines and bone apposition distally at the tip of the prosthesis. Varus position of the stem prosthesis did not have any unfavourable clinical consequences. In 27 stem prostheses, mean subsidence was $0.6 \mathrm{~mm}$ (sd $1.2 \mathrm{~mm}$ ) and according to the criteria of Engh et al, all the prostheses were stable.

This study showed excellent long-term results of the stem prostheses, without any notable differences between the two stem versions.

Chapter 7 presents the arthroplasty results of 68 young patients who formed part of the cohort described in Chapter 3. They had been younger than 50 years at the time of implantation and had various indications to receive an uncemented Zweymüller total hip prosthesis. Clinical and radiological data were analysed and the patients completed two questionnaires: the Oxford Hip Score and the U.C.L.A. activity level.

Mean age at the time of implantation was 43.1 years (sd 7.7 years) and mean duration until first follow-up was 75.3 months (sd 15.7 months). Mean Harris Hip Score was 93.9 (sd 8.1). There were no differences in Harris Hip Score between patients with an HG stem prosthesis and those with an SL stem prosthesis. We found radiolucent lines chiefly in the proximal Gruen zones and these were more common with the HG stem prosthesis. No other differences were found between the patients with an HG stem prosthesis and those with an SL stem prosthesis. According to the criteria of Engh et al, all the stems were stable and no revisions had been performed because of aseptic loosening.

Two cup prostheses had been revised due to aseptic loosening; survival of the cup was $96.6 \%\left(\mathrm{CI}_{95} 100-92.6 \%\right)$ after 84 months. Survival duration was slightly shorter than that in the patients of older than 50 years at implantation. We did not find any evidence that abnormalities other than idiopathic hip arthrosis had been responsible for the revisions. 
The second investigation (patient satisfaction) was performed 111.7 months (sd 9.5 months) after the primary operation. Patients completed a Dutch version of the Oxford Hip Score (OHS) and the translated UCLA activity level questionnaire. Mean OHS was 22.1 (sd 9.5) and the patients were satisfied with the result of the operation. Mean VAS pain score was $16.5 \mathrm{~mm}$ (sd $23.5 \mathrm{~mm}$ ) (N.B. a score of $0 \mathrm{~mm}$ means no pain). The majority of patients were active and taking part in sporting activities.

This study revealed favourable mid-term results with the uncemented Zweymüller total hip system in young patients. However, longer follow-up is necessary to confirm these good results.

Chapter 8 presents the results of the Dutch version of the Oxford Hip Score (OHS) that was filled in by 582 patients from the cohort study. Mean age at implantation was 62.4 years (sd 9.8 years) and mean follow-up was 110.9 months (sd 21.1 months). Mean VAS pain score was $16.9 \mathrm{~mm}$ ( $0 \mathrm{~mm}$ means no pain). Mean OHS was 22.9 (sd 10.6) (scale: best result 14 points, poorest result 70 points). The Charnley classification was found to influence the results. Patients with Charnley class $\mathrm{C}$ had poorer Oxford Hip Scores.

It could be concluded that the patients were satisfied with their functioning after implantation of an uncemented Zweymüller total hip prosthesis. Patients in Charnley class $\mathrm{C}$ and older patients with limited activities of daily living had poorer Oxford Hip Scores.

Conclusion: The studies described in this thesis showed good mid-term and long-term results with the uncemented Zweymüller total hip prosthesis. The two versions of the stem prosthesis had excellent survival, while survival of the titanium threaded cup was comparable with that of other types of threaded cup. DEXA scanning revealed decreased bone mineral density in the calcar region, without any clinical or radiological consequences. There was very little polyethylene wear of the cup in the long-term. A comparative study on the two versions of the stem prosthesis showed only slight differences between them. In young and active patients, the results with the uncemented Zweymüller total hip prosthesis were particularly good.

The patients from the cohort study were satisfied with the functioning of their prosthesis. Satisfaction was chiefly related to the Charnley classification and age of the patient.

The Zweymüller total hip prosthesis is a safe implant for the treatment of endstage osteoarthrosis of the hip. 
De totale heupprothese in de behandeling van coxarthrosis is een van de grootste successen van de orthopedie. Aanvankelijk werd dit succes bepaald door de gecementeerde totale heupprothese die in het begin van de zestiger jaren door wijlen sir John Charmley ontwikkeld was. Dit succes werd overschaduwd doordat de prothesen na enige jaren loslatingverschijnselen vertoonden en moesten worden gereviseerd, vaak bij relatief jonge patiënten. Het gebruik van cement voor de fixatie van de prothese werd geacht de oorzaak te zijn van de loslating en een nieuwe ziekte werd beschreven, "cement disease".

Later is gebleken dat de loslating het gevolg is van een macrofagen reactie op polyethyleen partikels met opeenvolgend botresorptie. Op deze wijze verliest het cement de fixatie aan het bot. Voordat dit mechanisme bekend was, zijn er mogelijkheden ontwikkeld om een heupprothese te plaatsen die niet door cement was gefixeerd. Dit proefschrift beschrijft de resultaten van een lange termijn onderzoek van de ongecementeerde totale heupprothese die in de zeventiger jaren door de Weense professor K. Zweymüller werd ontwikkeld.

In Hoofdstuk 1 wordt de ontwikkeling van de ongecementeerde totale heupprothese beschreven. De stabiliteit van ongecementeerde totale heupprothesen wordt bepaald door de primaire en secundaire stabiliteit. Onder primaire stabiliteit wordt verstaan dat de prothese direct verankerd kan worden. Dit wordt verkregen door de mergholte van het femur aan te passen aan de vorm van de prothese. Hierdoor past de prothese klemvast in de mergholte. Secundaire stabiliteit betekent dat door botingroei in metaalopeningen van de prothese de fixatie wordt versterkt. Deze secundaire stabiliteit wordt bevorderd door bijvoorbeeld een poreus oppervlak of door een hydroxy-apatiet coating.

In de ontwikkeling van de ongecementeerde totale heupprothese bleek het belang van biocompatibiliteit en biomechanica. Deze eigenschappen worden bepaald door het gebruikte materiaal en het productieproces. Titanium en kobaltchroom bleken uitermate geschikte metalen te zijn voor toepassing in een totale heupprothese. Deze metalen zijn goed bewerkbaar in het productieproces en veroorzaken in het menselijk lichaam geen afstotingsverschijnselen of maligniteiten. Voorts bleek titanium betere bioinerte eigenschappen te hebben dan kobaltchroom; titanium heeft minder nadelige invloed op het omringende bot. 
Een totale heupprothese bestaat uit een acetabulaire cup- en een femorale steelprothese. Deze componenten zijn bij de ongecementeerde totale heupprothese volgens Zweymüller vervaardigd van titanium. In het titanium deel van de cupprothese is een polyethyleen binnenwand geplaatst. Op de hals van de femurprothese is een kop geplaatst die veelal van keramiek vervaardigd is. Tijdens de levensduur van de prothese vinden vele miljoenen bewegingen plaats tussen het polyethyleen en het keramische deel van de prothese. Dit leidt tot slijtage van het polyethyleen. Deze slijtage geeft zeer kleine polyethyleen partikels (kleiner dan $1 \mu \mathrm{m}$ ). Deze partikels veroorzaken een ontstekingsreactie waardoor uiteindelijk het bot rondom de prothese vermindert. Dit leidt tot een aseptische loslating van de prothesecomponenten. De mate van slijtage is niet alleen afhankelijk van de tijdsduur, maar vooral van de intensiteit waarin de prothese gebruikt wordt.

Naast het faalscenario door de slijtage van het polyethyleen zijn nog vijf faalscenario's beschreven. De belangrijkste is de "stress shielding", waarbij door een verschil in elasticiteit van de prothese en het bot de belastingskrachten meer of minder door het bot dan wel door de prothese gaan. Indien de prothese meer krachten absorbeert, zal het bot minder belast worden en uiteindelijk atrofiëren (“disuse osteoporosis"). Dit proces van botremodellering kan worden vastgesteld door een DEXA scan. Dit röntgenapparaat bestaat uit twee röntgenbronnen met verschillende energieën en door een verschil in absorptie van de röntgenstralen door bot en weke delen, berekent de computer de botmineralencontent van een betreffende bot. Door deze waarde op het gemeten oppervlak te delen, wordt de botmineralendichtheid berekend.

Om het klinische resultaat van een totale heupprothese te evalueren zijn diverse scoringssystemen beschreven. De Harris Hip Score is de bekendste, maar heeft als nadeel dat de patiëntentevredenheid niet wordt gemeten. Daartoe zijn andere toetsen ontwikkeld zoals de Oxford Heup Score die in dit proefschrift beschreven staat.

Het doel van dit proefschrift betreft het evalueren van een patiëntengroep met een ongecementeerde totale heupprothese volgens Zweymüller op middellange en lange termijn, het vaststellen van stress shielding, de mate van slijtage van het polyethyleen, onderzoeken of er verschillen bestaan tussen twee versies van de femursteel, of de prothese geschikt is voor jonge patiënten en wat de tevredenheid is van de patiënten op lange termijn.

Hoofdstuk 2 beschrijft de ontwikkeling van de ongecementeerde totale heupprothese volgens Zweymüller. De cupprothese is een titanium schroefprothese met een polyethyleen insert. Aanvankelijk werd een steelprothese gebruikt die proximaal versmald was. Deze prothese werd de "Hochgezogen" steelprothese (HG) genoemd. Deze steelversie was te herkennen aan negen openingen in het proximale deel. Nadien is een prothese ontwikkeld waarbij de opeenvolgende steelmaten proportioneel groter, dikker en breder werden. Deze prothese werd de "Stepless"-prothese (SL) genoemd en is herkenbaar aan vier 
openingen. Deze steelprothese zou door het gelijkmatige oppervlak een meer gelijkmatige botingroei te zien geven.

De Zweymüller prothese is vanaf 1979 beschikbaar voor klinische toepassing en in Nederland vanaf 1983. In 1993 werden in de literatuur de eerste resultaten gemeld waarbij de prothese alleen onder bijzondere voorwaarden werd gebruikt. Nadien zijn meerdere publicaties verschenen waaruit geconcludeerd kan worden dat de steelprothese een goed resultaat heeft op lange termijn. Diverse publicaties tonen dat op lange termijn bij de cupprothese verschijnselen van aseptische loslating optreden. De cupprothese moet gezien worden als de zwakke schakel in deze ongecementeerde totale heupprothese.

Hoofdstuk 3 toont de resultaten van een cohort onderzoek van 754 ongecementeerde Zweymüller totale heupprothesen. Het betrof 275 HG en 479 SL steelprothesen met de titanium C.S.F. schroefcup en een $32 \mathrm{~mm}$ keramische kop. De gemiddelde leeftijd ten tijde van operatie bedroeg 63,6 jaar (sd 10,2) en de gemiddelde follow-up duur was 72,4 maanden (sd 16,3). De gemiddelde Harris Hip Score was 92,5 (sd 9,6) en de patiënten met een SL steelprothese hadden minder pijnklachten en scoorden beter op de items loopafstand, zitten en traplopen. De radiologische analyse toonde radiolucente lijnen in de proximale zones en de HG steelprothese hadden meer proximale radiolucente lijnen dan de SL steelprothese. Corticale reacties werden in Gruen zone 3 en 5 gezien en botappositie in ruim $50 \%$ bij de tip van de prothesen. Calcar atrofie werd vaker bij de HG steelprothese waargenomen dan bij de SL steelprothese. Een ongunstig gevolg van een varus positie van steelprothesen kon niet worden aangetoond.

We vonden verschillen tussen de twee steelversies. De HG steelprothese is vaker gebruikt bij patiënten die als Charnley $\mathrm{C}$ werden geclassificeerd. Dit betekent dat er comorbiteit bestaat, die de loopfunctie nadelig beïnvloedt. Hierdoor hebben deze patiënten een lagere Harris Hip Score. Voorts vonden we radiologische verschillen. De HG steelprothesen vertoonden vaker proximale radiolucente lijnen en calcar resorptie, waarschijnlijk door progressieve distale fixatie van de HG steelprothese. Evenwel vonden we geen aanwijzingen voor een slechter resultaat van een van de beide steelprothesen.

Zes cupprothesen werden gereviseerd en de survival bedroeg 98,5\% $\left(\mathrm{CI}_{95} 99,9\right.$ $-97,1)$ na 85 maanden. De worst-case scenario survival bedroeg $95,2 \%\left(\mathrm{CI}_{95} 97,7\right.$ $-92,6$ ) na eveneens 85 maanden.

Deze cohortstudie toonde een gunstig middellang termijn resultaat van de prothese hoewel een langere follow-up nodig was.

Om te onderzoeken of de gevonden proximale radiolucente lijnen en distale corticale reacties wijzen op vermindering van de botmineralendichtheid werd een DEXA studie uitgevoerd. Hoofdstuk 4 beschrijft deze studie van 32 patiënten met een unilaterale totale heupprothese. Alle patiënten waren geopereerd in verband met idiopathische coxarthrosis en hadden een minimale follow-up van tien jaar. De prothese werd digitaal op de gezonde, niet-geopereerde zijde gekopieerd en in de zeven Gruen zones van de linker en rechter heup werd de botmineralendichtheid 
gemeten. We vonden in Gruen zone 7, in de regio van de calcar femoris, een vermindering van de botmineralendichtheid. Daarin verschilden de twee steelversies niet. De vermindering van de botmineralendichtheid in de regio van de calcar femoris heeft geen klinische of radiologische consequenties.

De lange termijn resultaten van de titanium schroefcup (C.S.F.) zijn beschreven in Hoofdstuk 5. In de periode van 1 januari 1987 tot 31 december 1990 werden bij 221 patiënten met idiopathische coxarthrosis 211 ongecementeerde Zweymüller totale heupprothesen geplaatst. Een klinisch en radiologisch onderzoek werd verricht bij 136 patiënten met 142 prothesen. De gemiddelde leeftijd ten tijde van de operatie bedroeg 61,1 jaar (sd 8,1) en de gemiddelde follow-up duur was 134 maanden (sd 9,5). De lineaire slijtage van het polyethyleen werd gemeten volgens de methode van Dorr. $\mathrm{Bij} 37$ cupprothesen werd geen slijtage van het polyethyleen vastgesteld en de overige 105 cupprothesen hadden een gemiddelde slijtage van $0,46 \mathrm{~mm}$ (sd 0,27) met een jaarlijkse slijtage van 0,04 (sd 0.02).

$\mathrm{Bij}$ zeventien cupprothesen werden radiolucente lijnen, osteolysis of migratie gevonden.

Zeven cupprothesen waren gereviseerd en de cumulatieve survival na 138 maanden bedroeg $95,9 \%\left(\mathrm{CI}_{95} 92,1-99,8\right)$.

De conclusie van dit onderzoek is dat de titanium schroefcup weinig slijtage van het polyethyleen vertoonde en een goed resultaat heeft op lange termijn.

Hoofdstuk 6 beschrijft de resultaten van het onderzoek van 78 HG en 64 SL steelprothesen, die waren geplaatst bij de patiënten van de cohort beschreven in hoofdstuk 5. Geen steelprothese is gereviseerd in verband met een aseptische loslating. Bij $42 \%$ van de steelprothesen vonden we radiolucente lijnen in zone 1 (trochantor major) en $28 \%$ in zone 7 (trochantor minor). Botappositie bij de tip van de prothese werd bij $78 \%$ gezien. In $20 \%$ van de steelprothesen waren er proximaal radiolucente lijnen en distaal, bij de tip van de prothese, botappositie. Een varus positie van de steelprothese had geen nadelige klinische consequenties. Bij 27 steelprothesen werd een gemiddelde inzakking van 0,6 mm (sd 1,2) gemeten en volgens de criteria van Engh et al waren alle prothesen stabiel.

Dit onderzoek toonde de excellente resultaten van de steelprothesen op lange termijn zonder noemenswaardige verschillen tussen de twee steelversies.

In Hoofdstuk 7 wordt de studie van de jonge patiënten beschreven. In het cohortonderzoek dat in Hoofdstuk 3 is beschreven waren 68 patiënten die ten tijde van de operatie jonger waren dan 50 jaar en bij wie voor diverse aandoeningen een ongecementeerde Zweymüller totale heupprothese is geplaatst. De klinische gegevens en de röntgenfoto's van deze patiënten werden onderzocht en nadien werden aan deze patiënten twee enquêtes (Oxford Heup Score, UCLA activiteitenniveau) gezonden.

De gemiddelde leeftijd ten tijde van de operatie was 43,1 jaar (sd 7,7) en de gemiddelde duur tot de eerste follow-up was 75,3 maanden (sd 15,7). De gemiddelde Harris Hip Score was 93,9 (sd 8,1). De Harris Hip Scores van de 
patiënten met een $\mathrm{HG}$ en een SL steelprothese verschilden niet. We vonden radiolucente lijnen voornamelijk in de proximale Gruen zones en deze lijnen werden vaker bij de HG steelprothese gezien. We vonden geen andere verschillen tussen de patiënten met een HG of een SL steelprothese. Volgens de criteria van Engh et al waren alle stelen stabiel en er zijn geen revisies uitgevoerd voor aseptische loslatingen.

Twee cupprothesen zijn gereviseerd in verband met een aseptische loslating en de survival bedroeg $96,9 \%\left(\mathrm{CI}_{95}, 100-92,6\right)$ na 84 maanden. Deze survival is in geringe mate korter dan de survival van de patiënten ouder dan 50 jaar ten tijde van de operatie. We vonden geen aanwijzingen dat andere aandoeningen dan de idiopathische coxarthrosis verantwoordelijk zouden zijn voor de revisies.

Het tweede (tevredenheids)onderzoek werd 117,7 maanden (sd 9,5) na de primaire operatie uitgevoerd en bestond uit de toezending van de Nederlandstalige Oxford Heup Score (OHS) en de vertaalde UCLA activiteiten niveau score. De gemiddelde OHS bedroeg 22,1 (sd 9,5) en de patiënten waren tevreden met het resultaat van de operatie. De gemiddelde V.A.S. pijnscore bedroeg $16,5 \mathrm{~mm}$ (sd $23,5)$ (schaal $0 \mathrm{~mm}$ betekent geen pijn). Het merendeel van de patiënten was actief en beoefende sport.

Uit dit onderzoek volgde het gunstige middellange termijn resultaat van de ongecementeerde Zweymüller totale heupprothesen bij de jonge patiënt. Echter, een langere follow-up termijn is noodzakelijk om het goede resultaat te bevestigen.

De resultaten van de Nederlandstalige Oxford Heup Score (OHS) die verzonden is aan de patiënten van de cohortstudie, zijn beschreven in Hoofdstuk 8. De gegevens van 582 enquêtes werden geëvalueerd. De gemiddelde leeftijd ten tijde van de operatie bedroeg 62,4 jaar (sd 9,8) en de gemiddelde follow-up duur was 110,9 maanden (sd 21,1). De gemiddelde V.A.S. pijnscore bedroeg $16,9 \mathrm{~mm}(0$ mm betekent geen pijn). De gemiddelde OHS was 22,9 (sd 10,6) (schaal: beste resultaat 14 punten, slechtste resultaat 70 punten). We vonden dat de Charnley classificatie invloed had op de uitkomst. De patiënten in de Charnley C-klasse hadden een slechtere OHS.

De conclusie van dit onderzoek is dat de patiënten tevreden zijn met hun functioneren na een ongecementeerde Zweymüller totale heupprothese. Patiënten in de Charnley C klasse en oudere patiënten die beperkt zijn in hun algemene dagelijkse levensverrichtingen, hadden een slechtere OHS.

De conclusie van dit proefschrift is dat het onderzoek de goede resultaten heeft aangetoond van de ongecementeerde Zweymüller totale heupprothese op de middellange en lange termijn. De beide versies van de steelprothesen hebben een excellente survival en de titanium schroefcup een survival vergelijkbaar met die van andere typen schroefcups. Het DEXA onderzoek toonde een vermindering van de botmineralendichtheid ter hoogte van de calcar femoris zonder klinische of radiologische consequenties. Op lange termijn is weinig slijtage van het polyethyleen aantoonbaar. Het vergelijkende onderzoek van de 
twee steelprothesen liet slechts geringe verschillen zien tussen de beide versies. Juist ook bij jonge en actieve patiënten heeft de ongecementeerde Zweymüller totale heupprothese een goed resultaat.

De patiënten uit de cohortstudie zijn tevreden met het functioneren van de prothese. Het resultaat van deze tevredenheid wordt mede bepaald door de Charnley classificatie en de leeftijd van de patiënt.

De ongecementeerde Zweymüller totale heupprothese is een veilig implantaat voor de behandeling van het eindstadium van coxarthrosis. 



\section{REFERENCES}

1. Aigner C. 10-jahresergebnisse mit dem korundgestrahlten Reintitanschraubring nach Zweymüller. Z Orthop 1998; 136:110114

2. Akisue $T$, Bauer $T W$, Yamaguchi $M$, Matejczyk MB, Stulberg BN, Wilde AH. Multidirectional deformation in fully congruent acetabular components. J Arthroplasty 1999; 14:1011-1018

3. Albrektsson T, Brảnemark PI, Hansson HI, Lindström J. Osseointegrated titanium implants: requirements for ensuring a long-lasting, direct bone-to-implant anchorage in man. Acta Orthop Scand 1981; 52:155-170

4. Aldinger PR, Breusch SJ, Ludoschek $M$, Mau H, Ewerbeck V, Thomsen M. A tento 15-year follow-up of the cementless Spotorno stem. J Bone Joint Surg 2003; 85-B:209-214

5. Allmen von RS. Vergleich des klinischen Verlaufes und radiologischer Veränderungen fünf Jahre nach Implantation der zementlosen Alloclassic. Hüfttotalprothese mit Polyäthylen / Keramik/ und Metall / Metall Gleitpaarung., Thesis University of Basel. 2002

7. Amstutz HC, Thomas BJ, Jinnah R, Kim W, Grogan T, Yale C. Treatment of primary osteoarthritis of the hip: a comparison of total joint and surface replacement arthroplasty. J Bone Joint Surg 1984; 66-A: 228-241
8. Ang KC, Das dS, Goh JCH, Bose K. Periprosthetic bone mineral density after cementless total hip replacemant: a prospective comparison of two different implant designs. J Bone Joint Surg 1997; 79-B:675-679

9. Archibeck MJ, Jacobs JJ, Roebuck KA, Glant TT. The basic science of periprosthetic osteolysis. J Bone Joint Surg 2000; 82-A:1478-1489

10. Ballard WT, Callaghan JI, Sullivan PM, Johnston RC. The results of improved cementing techniques for total hip arthroplasty in patients less than fifty years old: a ten-year follow-up study. I Bone Joint Surg 1994; 76-A:959-964

11. Barrack RL, Lavernia C, Szuszczewicz ES, Sawhney J. Radiographic wear measurements in a cementless metal. backed modular cobalt-chromium acetabular component. J Arthroplasty 2001; $16: 820-828$

12. Berger RA, Jacobs J,, Quigley LR, Rosenberg AG, Galante JO. Primary cementless acetabular reconstruction in patients younger than 50 years old: 7-to

11-year results. Clin Orthop 1997; 344:216226

13. Bettin D, Greitemann B, Polster J, Schulte-Eistrup S. Long term results of uncemented Judet hip endoprostheses. Int Orthop 1995; 19:144-150

14. Bizot P, Banallec L, Sedel L, Nizard R. Alumina-on-alumina total hip prostheses 
53. Dawson I, Fitzpatrick R, Carr A, Murray D. Questionnaire on the perceptions of patients about total hip replacement. J Bone Joint Surg 1996; 78-B:185-190

54. Dawson J. Fitzpatrick R. Murray D. Carr

A. Comparison of measures to assess outcomes in total hip replacement surgery. Quality in Health Care 1996; 5:81-88

55. Dawson J, Fitzpatrick R, Murray D, Carr A. The problem of enoisen in monitoring patient-based outcomes: generic, diseasespecific and site-specific instruments for total hip replacement. J Health Serv Res Policy 1996; 1 (4):224-231

56. Delaunay C, Cazeau C, Kapandji AI. Cementless primary total hip replacement: four to eight year results with the Zweymulller-Alloclassic @ prosthesis. Int Orthop 1998; 22:1-5

57. Delaunay C, Kapandij Al. Survival analysis of cementless grit-blasted titanium total hip arthroplasties. I Bone Joint Surg 2001; 83-B:408-413

58. Delaunay CP, Kapandiji Al. Survivorship of rough-surfaced threaded acetabular cups: 382 consecutive primary Zweymüller cups followed for 0.2-12 years. Acta Orthop Scand 1998; 69:379-383

59. Delaunay CP. Kapandji AI. Primary total hip arthroplasty with the Karl Zweymüller first-generation cementless prosthesis: a 5- to 9-year retrospective analysis. I Arthroplasty 1996; 11:643-652

60. Delaunay CP, Kapandji AI. Acetabular screw rings and surface treatment. Clin Orthop 1997: 340:130-141

61. DeLee JG, Charnley J. Radiological demarcation of cemented sockets in total hip replacement. Clin Orthop 1976; 121: 20-32

62. Devitt A, O'Sullivan T, Quinlan W. 16- to 25. year follow-up study of cemented arthroplasty of the hip in patients aged 50 years or younger. I Arthroplasty 1997; 12: 479.489
63. Dickob M, Martini T. The cementless PM hip arthroplasty: four-to-seven-year results. I Bone Joint Surg 1996; 78-B:195-199

64. Dohle J, Becker W, Braun M. Radiologische Analyse der ossären Integration nach Implantation der Alloclassic-ZweymüllerHüft-TEP. Z Orthop 2001; 139:517-524

65. Doorn PF. Wear and biological aspects of metal on metal total hip replacements. Thesis University Medical Center Nijmegen. 2000

66. Dorr LD. Total hip replacement using APR system. Techn Orthop 1986; 1 (3):22-34

67. Dorr LD. Fixation of the acetabular component: the case for cementless bone ingrowth modular sockets. I Arthroplasty 1996: 11:3-6

68. Dorr LD, Faugere MC, Mackel AM, Gruen TA, Bognar B, Malluche HH. Structural and cellular assessment of bone quality of proximal femur. Bone 1993; 14:231-242

69. Dorr LD, Kane TJ. Conaty JP. Long-term results of cemented total hip arthroplasty in patients 45 years old or younger a 16 year follow-up study. J Arthroplasty 1994; 9: 453-456

70. Dorr LD, Wan Z. Comparative results of a distal modular sleeve, circumferential coating, and stiffness relief using the Anatomic Porous replacement II. I Arthroplasty $1996 ; 11: 419-428$

71. Dowd JE, Sychterz CI, Young AM, Engh CA. Characterization of long-term femoralhead-penetration rates: association with and prediction of osteolysis. I Bone Joint Surg 2000; 82-A:1102-1107

72. Dowdy PA, Rorabeck CH, Bourne RB. Uncemented total hip arthroplasty in patients 50 years of age or younger. I Arthroplasty 1997; 12:853-862

73. Duffy GP, Berry DJ, Rowland C, Cabanela ME. Primary uncemented total hip arthroplasty in patients $<40$ years old: 10 to 14-year results using first-generation proximally porous-coated implants. J 
Arthroplasty 2001: 16:140-144

74. Effenberger H, Heiland A, Ramsauer T, Plitz W, Dorn U. A model for assessing the rotational stability of uncemented femoral implants. Arch Orthop Trauma Surg 2001; 121:60-64

75. Endler M. Grundslagen und erste FünfJahresergebnisse mit der PolyäthylenSchraubpfanne. In: Zweymüller K. (ed.), Das Zementfreie Hüftendoprothesen System Zweymüller - Endler. Wien: Facultas. 1986: 110-122

76. Engh CA, Claus AM, Hopper RH, Engh CA. Long-term results using the Anatomic Medullary Locking hip prosthesis. Clin Orthop 2001: 393:137-146

77. Engh CA, Culpepper WJ, Engh CA. Long-term results of use of the Anatomic Medullary Locking prosthesis in total hip arthroplasty. J Bone Joint Surg 1997; 79-A: 177-184

78. Engh CA, Griffin WL, Marx CL. Cementless Acetabular components. I Bone Joint Surg 1990; 72-B:53-59

79. Engh CA, Hooten JP, Zettl-Schaffer KF, Ghaffarpour M, McGovern TF, Macalino GE, Zicat BA. Porous-coated total hip replacement. Clin Orthop 1994: 298:89-96

80. Engh CA. Hopper RH, Engh CA, McAuley JP. Wear-Through of a modular polyethylene liner. four case reports. Clin Orthop 2001: 383:175-182

81. Engh CA, Massin P. Cementless total hip arthroplasty using the Anatomic Medullary Locking stem. Clin Orthop 1989; 249:141. 158

82. Engh CA. Massin P. Suthers KE. Roentgenographic assessment of the biologic fixation of porous-surfaced femoral components. Clin Orthop 1990; 257:107. 128

83. Engh CA, McGovern TF, Bobyn JD, Harris WH. Quantitative evaluation of periprosthetic bone-remodeling after cementless total hip arthroplasty. J Bone
Joint Surg 1992; 74-A:1009-1020

84. Engh CA, McGovern TF, Schmidt LM. Roentgenographic densitometry of bone adjacent to a femoral prosthesis: Clin Orthop 1993; 292:177-190

85. Engh CA, Sychterz C, Engh C. Factors affecting femoral bone remodeling after cementless total hip arthroplasty. I Arthroplasty 1999; 14:637-644

86. Eyres KS, Bell MJ. Kanis JA. New bone formation during leg lengthening: evaluated by dual energy $x$-ray absorptiometry. I Bone Joint Surg 1993; 75-B:96-106

87. Fitzpatrick R, Morris R, Hajat S, Reeves B, Murray D, Hannen D, Rigge M. Williams O, Gregg P. The value of short and simple measures to assess outcomes for patients of total hip replacement surgery. Quality in Health Care 2000; 9:146-150

88. Fox GM, McBeath AA, Heiner JP. Hip replacement with a threaded acetabular cup: a follow-up study. J Bone Joint Surg 1994: 76-A:195-201

89. Gade HG. A contribution to the surgical treatment of osteoarthritis of the hip-joint: a clinical study. Acta Chirurgica Scandinavica 1947; 95 (Suppl 120):39-43

90. Galante $\mathrm{G}$. The need for a standardized system for evaluating results of total hip surgery. editorial. I Bone Joint Surg 1985; 67-A:511-512

91. Garcia-Cimbrelo E, Cruz-Pardos A, Cordero J, Sanchez-Sotelo I. Low-friction arthroplasty in patients younger than 40 years old: 20 - to 25 -year results. I Arthroplasty 2000: 15:825-832

92. Garcia-Cimbrelo E, Cruz-Pardos A, Madero R, Ortega-Andreu M. Total hip arthroplasty with use of the cementless Zweymüller Alloclassic system: a ten to thirteen-year follow-up study. J Bone Joint Surg 2003: 85-A:296-303

93. Garcia-Cimbrelo E, Martinez-Sayanes JM. Minuesa A. Munuera L. Mittelmeier ceramic-ceramic prosthesis after 10 year. 1 
Arthroplasty 1996; 11:773-781

94. Gardeniers JWM. Treatment of osteonecrosis by joint replacement. Hip International 1998; 8 (3):159-166

95. Garellick G, Herberts P, Malchau H. The value of clinical data scoring systems: are traditional hip scoring systems adequate to use in evaluation after total hip surgery? I

Arthroplasty 1999; 14:1024-1029

96. Garellick G, Malchau H, Herberts P. Specific or general health outcome measures in the evaluation of total hip replacement: a comparison between the Harris Hip Score and the Nottingham health profile. J Bone Joint Surg 1998; 80 B:600-606

97. Gartland JJ. Orthopaedic clinical research: deficiencies in experimental design and determinations of outcome. J Bone Joint Surg 1988; 70-A:1357-1364

98. Geesink RGT, de Groot K, Klein CPAT. Chemical implant fixation using hydroxylapatite coatings: the development of a human total hip prosthesis for chemical fixation to bone using hydroxyl-apatite coatings on titanium substrates. Clin Orthop 1987; 225:147-170

99. Geesink RGT. Osteoconductive coatings for total joint arthroplasty. Clin Orthop 2002; 395:53-65

100. Geesink RGT, Hoefnagels N. Eight years results of ha-coated primary total hip replacement. Acta Orthop Belg 1997; 63 (suppl 1):72-75

101. Geesink RGT, Hoefnagels NHM. Six-year results of hydroxyapatite-coated total hip replacement. J Bone Joint Surg 1995; 77-B: 534-547

102. Gekeler J. Bemerkungen zur Form und Grösse des Zweymüller-hüftendoprothesen schaftes. Aktuelle Probl Chir Orthop 1985; 29:33-38

103. Gillespie WJ, Pekarsky B, O'Connell DL. Evaluation of new technologies for total hip replacement: economic modelling and clinical trials. J Bone Joint Surg 1995; 77-B:

528.533

104. Gross Portney L, Watkins MP.

Foundations of clinical research; applications to practice, New Jersey. Prentice Hall Health. 2000

105. Grübl A, Chiari C, Gruber M, Kaider A, Gottsauner-Wolf F. Cementless total hip arthroplasty with a tapered, rectangular titanium stem and a threaded cup: a minimum ten-year follow-up. J Bone Joint Surg 2002; 84-A:425-431

106. Grübl A, Csepan R, Delaunay C, Gördes W, Kaider A, Parzer R, Zenz P, GottsaunerWolf F. 6-10-Jahres-Ergibnisse des zementfreien Alloclassic Hüftsystems: eine multizentrische Survival Studie. Z Orthop 2003; 141:303-308

107. Gruen T, McNeice GM, Amstutz HC. «Mode of failures of cemented stem-type femoral components: a radiographic analysis of loosening. Clin Orthop 1979: 141:17-27

108. Guillemin F, Bombardier C, Beaton D. Cross-cultural adaptation of health-related quality of life measures: literature review and proposed guidelines. J Clin Epidemiol 1993; 46 (12):1417-1432

109. Gut M, Hilfiker B, Schreiber A. 5- bis 7-jahresergebnisse der zementfreien hüftgelenkspfanne nach Endler. Z Orthop 1990; 128:598.605

110. Hall ML, Heavens J, Ell PJ. Variation between femurs as measured by dual energy $x$-ray absorptiometry (dexa). Eur J Nucl Med 1991: 18:38-40

111. Harkess JW. Arthroplasty of hip. In: Crenshaw AH (ed.), Cambell's operative orthopaedics. Missouri: Mosby-Year book. 1992: $441-626$

112. Harris WH. Traumatic arthritis of the hip after dislocation and acetabular fractures: treatment by mold arthroplasty: an endresult study using a new method of result evaluation. J Bone Joint Surg 1969; 51-A: 


\section{7-755}

113. Harris WH. The case for cementing all femoral components in total hip replacement. CJS 1995; 38 (suppl 1):s55. s60

114. Harris WH. The osteolysis phenomena in total hip and total knee replacement surgery. In: Rieker C, Oberholzer S, Wyss U. (eds.). World tribology forum in arthroplasty. Bern, Göttingen, Toronto, Seattle: Hans Huber. 2001: 17-23

115. Harris WH, Schiller AL, Scholler JM, Freiberg RA, Scott R. Extensive localized bone resorption in the femur following total hip replacement. J Bone Joint Surg 1976; 58-A:612-618

116. Harris WJ. Wear and periprosthetic osteolysis: the problem. Clin Orthop 2001; 393:66-70

117. Havelin LI, Engesaeter LB, Espehaug B, Furnes O, Lie SA, Vollset SE. The Norwegian Arthroplasty Register. 11 years and 73,000 arthroplasties. Acta Orthop Scand 2000; 71:337-353

118. Havelin LI, Espehaug B, Vollset SE, Engesæter LB. Early failures among 14,009 cemented and 1,326 uncemented prostheses for primary coxarthrosis: the Norwegian Arthroplasty Register, 1987. 1992. Acta Orthop Scand 1994; 65:1-6

119. Havelin LI, Espehaug B, Vollset SE, Engesæter LB. Early aseptic loosening of uncemented femoral components in primary total hip replacement: a review based on the norwegian arthroplasty register. J Bone Joint Surg 1995; 77-B:11-17

120. Havelin LI, Espehaug B, Vollset SE, Engesaeter LB, Langeland N. The Norwegian arthroplasty register. a survey of 17,444 hip replacements 1987-1990. Acta Orthop Scand 1993; 64:245-251

121. Heekin RD, Callaghan JJ, Hopkinson WJ, Savory CG, Xenos JS. The porous-coated anatomic total hip prosthesis, inserted without cement: results after five to seven years in a prospective study. J Bone Joint Surg 1993: 75-A:77-91

122. Herberts $P$, Malchau $H$. Long-term registration has improved the quality of hip replacement: a review of the Swedish THR Register comparing 160,000 cases. Acta Orthop Scand 2000; 71:111-121

123. Hoefnagels NHM, Dhert WJA, Gosens T, Bulstra SK, de Vet HCW, van Langelaan EJ, Okhuysen-Vonk S, Geesing RGT. De Oxford Heupscore. Een Nederlandstalige patièntenvragenlijst ter evaluatie van het resultaat van een totale heupprothese. Ned Tijdschr Orthop 2002; 9 (4):5-16

124. Hofmann AA, Feign ME, Klauser W, VanGorp CC, Camargo MP. Cementless primary total hip arthroplasty with a tapered, proximally porous-coated titanium prosthesis: a 4- to 8-year retrospective review. J Arthroplasty 2000; 15:833-839

125. Hozack WJ, Rothman RH, Booth RE, Balderston RA. Cemented versus cementless total hip arthroplasty. a comparative study of equivalent patient populations. Clin Orthop 1993: 289:161. 165

126. Hughes SS, Furia JP, Smith P, Pelligrini VD. Atrophy of the proximal part of the femur after total hip arthroplasty without cement: a quantitative comparison of cobalt-chromium and titanium femoral stems with use of dual X-ray absorptiometry. J Bone Joint Surg 1995; 77-A:231-239

127. Huiskes R. Oorzaken van falen van heupen kniearthroplastieken. Ned Tijdschr Geneeskd 1998; 142:2035-2040

128. Huiskes R. Failed innovation in total hip replacement: diagnosis and proposals for a cure. Acta Orthop Scand 1993; 64:699-716

129. Huiskes R. Stress shielding and bone resorption in THA: clinical versus computer-simulation studies. Acta Orthop Belg 1993; 59 (supp 1):118-129

130. Huiskes R. Finite element analysis of 
acetabular reconstruction: noncemented threaded cups. Acta Orthop Scand 1987: 58:620-625

131. Huiskes $R$, Weinans $H$, van $R B$. The relationship between stress shielding and bone resorption around total hip stems and the effects of flexible materials. Clin Orthop 1992: 274:124-134

132. Huo MH, Martin RP, Zatorski LE, Keggi KJ. Total hip arthroplasty using the Zweymüller stem implanted without cement: a prospective study of consecutive patients with minimum 3-year follow-up period. J Arthroplasty 1995: 10:793-799

133. Huo MH, Martin RP, Zatorski LE, Keggi KJ. Total hip replacements using the ceramic Mittelmeier prosthesis. Clin Orthop 1996: 332:143-150

134. Hwang SK. Park JS. Cementless total hip arthroplasty with AML, PCA and HGP prostheses. Int Orthop 1995; 19:77-83

135. Ilchmann T, Franzên H, Mjöberg B, Wingstrand $\mathrm{H}$. Measurement accuracy in acetabular cup migration: a comparison of four radiologic methods versus roentgen stereophotogrammetric analysis. I

Arthroplasty 1992: 7:121-127

136. Ilchmann T, Mjöberg B, Wingstrand

H. Measurement accuracy in acetabular cup wear: three retrospective methods compared with roentgen stereophotogrammetry. J Arthroplasty 1995: 10:636-642

137. Ilstrup DM, Nolan DR, Beckenbaugh RD, Coventry MB. Factors influencing the results in 2,012 total hip arthroplasties. Clin Orthop 1973: 95:250-262

138. Jacobs JI, Roebuck KA, Archibeck M. Hallab NJ, Glant TT, Osteolysis: Basic science. Clin Orthop 2001; 393:71-77

139. Jacobs IJ. Skipor AK, Doorn PF, Campbell P, Schmalzried TP, Black J, Amstutz HC. Cocalt and chromium concentrations in patients with metal on metal total hip replacements. Clin Orthop 1996: 329S:

\section{s256-s263}

140. Jantsch S, Leixnering M. Schwägerl, Hackl $\mathrm{H}$. Shaft fissures due to implantation of cementiess total endoprostheses of the hip joint: an experimental study. Arch Orthop Trauma Surg 1988; 107:236-241

141. Johanson NA, Charlson ME, Szatrowski TP. Ranawat CS. A self-administred hiprating questionnaire for the assessment of outcome after total hip replacement. J Bone Joint Surg 1992; 74-A:587-597

142. Johnston RC, Fitzgerald RH, Harris WH, Poss R, Müller ME, Sledge CB. Clinical and radiographic evaluation of total hip replacement: a standard system of terminology for reporting results. J Bone Joint Surg 1990; 72-A:161-168

143. Jones LC, Hungerford DS. Cement disease. Clin Orthop 1987; 225:192-206

144. Judet $\mathrm{R}$, Judet $\mathrm{J}$. Technique and results with the acrylic femoral head prosthesis. I Bone Joint Surg 1952; 34-A:173-180

145. Justice AC, Covinsky KE, Berlin JA. Assessing the generalizability of prognostic information. Ann Int Med 1999; 130 (6): 515.524

146. Kabo JM, Gebhard IS, Loren G. Amstutz HC. In vivo wear of polyethylene acetabular components. I Bone Joint Surg 1993; 75-B:254-258

147. Kalender WA. Effective dose values in bone mineral measurements by photon absorptiometry and computer tomography. Osteoporosis Int 1992: 2:82-87

148. Kaplan EL, Meier P. Nonparametric estimation from incomplete observations. J Am Stat Assoc 1958: June:457-481

149. Katz JN, Phillips CB, Poss R, Harrast IJ. Fossel AH, Liang MH. Sledge CB. The validity and reliability of a total hip arthroplasty outcome evaluation questionnaire. J Bone Joint Surg 1995; 77 . A:1528-1534

150. Kavanagh BF, Fitzgerald RH. Clinical and roentgenographic assessment of total hip 
arthroplasty. a new hip score. Clin Orthop 1985; $193: 133 \cdot 140$

151. Kawamura H, Bourne RB, Dunbar MJ. Rorabeck $\mathrm{CH}$. Polyethylene wear of the porous-coated anatomic total hip arthroplasty with an average 11-year follow. up. | Arthroplasty 2001; 16 (8-suppl 1): 116-121

152. Kawamura H, Dunbar MJ, Murray P. Bourne RB, Rorabeck $\mathrm{CH}$. The porous coated anatomic total hip replacement: a ten to fourteen-year follow-up study of a cementless total hip arthroplasty. I Bone Joint Surg 2001: 83-A:1333-1338

153. Kearns McCarthy C, Steinberg GG, Agren M, Leahey D, Wyman E, Baran DT. Quantifying bone loss from the proximal femur after total hip arthroplasty. I Bone Joint Surg 1991; 73-B:774-778

154. Kerr R, Resnick D, Sartoris DJ, Kursunoglu S, Pineda C, Haghighi P, Greenway G, Guerra J. Computerized tomography of proximal femoral trabecular patterns. I Orthop Res 1986: 4:45-56

155. Kilgus DJ, Shimaoka EE, Tipton JS, Eberle RW. Dual-energy $x$-ray absorptiometry measurement of bone mineral density around porous-coated cementless femoral implants: methods and preliminary results. J Bone Joint Surg 1993: 75-B:279-287

156. Kim YH, Kim JS, Cho SH. Primary total hip arthroplasty with a cementless porouscoated anatomic total hip prosthesis: 10- to 12-year results of prospective and consecutive series. I Arthroplasty 1999; 14: 538.548

157. Kim YH, Kim JS, Cho SH. Strain distribution in the proximal human femur. an in vitro comparison in the intact femur and after insertion of reference and experimental femoral stems. I Bone Joint Surg 2001; 83-B:295-301

158. Kim YH, Kook H, Kim JS. Total hip replacement with a cementless acetabular component and a cemented femoral component in patients younger than fifty years of age. J Bone Joint Surg 2002; 84-A: 770-774

159. Kiratli BJ. Heiner JP, McBeath AA, Wilson MA. Determination of bone mineral density by dual $\mathrm{x}$-ray absorptiometry in patients with uncemented total hip arthroplasty. J Orthop Res 1992; 10:836-844

160. Knelles D, Barthel T, Karrer A, Kraus U, Eulert J, Kölbl O. Prevention of heterotopic ossification after total hip replacement: a prospective, randomized study using acetylsalicylic acid, indomethacin and fractional or single-dose irradiation. J Bone Joint Surg 1997; 79-B:596-602

161. Kobayashi S, Eftekhar NS, Terayama K, Joshi RP. Comparative study of total hip arthroplasty between younger and older patients. Clin Orthop 1997; 339:140-151

162. Korovessis P. Piperos G. Michael A. Periprosthetic bone mineral density after Mueller and Zweymueller total hip arthroplasties. Clin Orthop 1994; 309:214 221

163. Korovessis P, Piperos G. Michael A. Baikousis A, Stamatakis M. Bone mineral density changes around stable uncemented Zweymueller total hip arthroplasty. Int Orthop 1997: 5 (6): $389-396$

164. Kosinski M, Keller SD. Hatoum HT, Kong SX, Ware JE. The SF-36 health survey as a generic outcome measure in clinical trials of patients with osteoarthritis and rheumatoid arthritis: tests of data quality, scaling assumptions and score reliability. Medical Care 1999; 37 (5):10-22

165. Kröger H, Miettinen H, Arnala I, Koski E, Rushton N, Suomalainen O. Evaluation of periprosthetic bone using dual-energy $x$-ray absorptiometry, precision of the method and effect of operation on bone mineral density. I Bone Min Res 1996; 11 (10):1526-1530

166. Krugluger J. Eyb R. Bone reaction to uncemented threaded polyethylene acetabular components. Int Orthop 1993; 


\section{$17: 259.265$}

167. Kutschera HP, Eyb R, Schartelmüller T, Toma C, Zweymüller K. Das zementfreie Zweymüller Hüft-system: Ergibnisse einer 5-Jahres-Nachuntersuchung. Z Orthop 1993: 131:513-517

168. Lai KA, Shen W], Chen CH, Yang CH, Hu WP, Chang GL Failure of hydroxyapatitecoated acetabular cups: ten-year follow-up of 85 Landos Atoll arthroplasties. J Bone Joint Surg 2002; 84-B:641-646

169. Laskey MA, Crisp AJ. Cole J, Compston JE. Comparison of the effect of different reference data on Lunar DPX and Hologic QDR-1000 dual-energy X-ray absorptiometers. Br J Radiol 1992; 65:1124 1129

170. Laupacis A, Bourne R, Rorabeck C, Feeny D, Wong C. Tugwell P, Leslie K, Bullas R. The effect of elective total hip replacement on health-related quality of life. J Bone Joint Surg 1993; 75-A:1619-1626

171. Lester DK, Campbell P, Ehya A, Rude RK. Assessment of press-fit hip femoral components retrieved at autopsy.

Orthopedics 1998; 21:27-33

172. Lewis G. Design issues in clinical studies of the in vivo volumetric wear rate of polyethylene bearing components. J Bone Joint Surg 2000; 82-A:281-287

173. Lieberman JR, Hawker G, Wright JG. Hip function in patients $>55$ years old: population reference values. J Arthroplasty 2001; 16:901-904

174. Lintner F, Böhm G, Bösch P, Brand G, Endler M. Zweymüller K. Ist hochdichtes Polyäthylen als Implantatmaterial zur zementfreien Verankerung von Hüftendoprothesen geeignet?: eine histomorphologische Untersuchung an explantierten Polyäthylenschraubpfannen. Z Orthop 1988; 126:688-692

175. Lintner F, Böhm G, Brand G, Obenaus C, Klimann S. Gewebliche Reactionsformen des Titaniumschaftes. In: Zweymüller
K. (ed.), 10 Jahre Zweymüller-

Hüftendoprothese: II Wiener Symposium. Bern, Stuttgart, Toronto: Verlag Hans Huber. 1990: 47-60

176. Lintner F, Zweymüller K, Böhm G, Brand G. Reactions of surrounding tissue to the cementless hip implant Ti-6Al-4V after an implantation period of several years: autopsy studies in three cases. Arch Orthop Trauma Surg 1988: 107:357-363

177. Lintner F, Zweymüller K, Brand G. Tissue reactions to titanium endoprostheses: autopsy studies in four cases. J Arthroplasty 1986; 1:183-195

178. Lord G, Bancel P. The madreporic cementless total hip arthroplasty. new experimental data and a seven-year clinical follow-up study. Clin Orthop 1983; 176:6776

179. Loupasis G, Hyde ID, Morris EW. The Furlong hydroxyapatite coated femoral prosthesis: a 4 to 7-year follow-up study. Arch Orthop Trauma Surg 1998; 117:132. 135

180. Loupasis G. Hyde ID, Morris EW. The furlong hydroxyapatite-coated total hip replacement in patients under age 51: a 6 year follow-up study. Acta Orthop Belg 1998; 64 (1):17-24

181. Mahomed NN. Arndt DC. McGrory BJ. Harris WH. The Harris hip score: comparison of patient self-report with surgeon assessment. J.Arthroplasty 2001; $16: 575.580$

182. Malchau H. Herberts P, Ahnfelt L. Prognosis of total hip replacement in Sweden: follow-up of 92,675 operations performed 1978-1990. Acta Orthop Scand 1993: 64:497-506

183. Malchau H, Herberts P, Eisler T, Garellick G. Söderman P. The Swedish total hip replacement register. J Bone Joint Surg 2002: 84-A (suppl 2):2-20

184. Malchau H. Kärrholm J. Wang YX. Herberts P. Accuracy of migration 
analysis in hip arthroplasty: digitized and conventional radiography, compared to radiostereometry in 51 patients. Acta Orthop Scand 1995; 66:418-424

185. Malchau H, Wang YX, Kărrholm J. Herberts P. Scandinavian multicenter porous coated anatomic total hip arthroplasty study: clinical and radiographic results with the 7- to 10-year follow-up evaluation. J Arthroplasty 1997; 12:133-148

186. Mallory TH, Lombardi AV, Leith IR, Fujita H, Hartman JF, Capps SG, Kefauver CA, Adams JB, Vorys GC. Why a taper? J Bone foint Surg 2002; 84-A (suppl 2):81-89

187. Maloney WJ. National joint replacement registries:has the time come? J Bone Joint Surg 2001; 83-A:1582-1585

188. Maloney WJ, Harris WH. Comparison of a hybrid with an uncemented total hip replacement: a retrospective matched-pair study. J Bone Joint Surg 1990; 72-A:1349. 1352

189. Maloney WJ, Sychterz C, Bragdon C, McGovern T, Jasty M, Engh CA, Harris WH. Skeletal response to well fixed femoral components inserted with and without cement. Clin Orthop 1996; 333 : $15-26$

190. Mancuso CA. Salvati EA. Johanson NA. Peterson MGE, Charlson ME. Patients' expectations and satisfaction with total hiip arthroplasty. I Arthroplasty 1997: 12:387. 396

191. Mankin HJ, Mow VC, Buckwalter JA, Iannotti JP, Ratcliffe A. Form and function of articular cartilage. In: Simon SR. (ed.). Orthopaedic Basic Science. AAOS, 1994: 1.44

192. Martini F, Lebherz C, Mayer F, Leichtle U. Kremling E, Sell S. Precision of the measurements of periprosthetic bone mineral density in hips with a custommade femoral stem. J Bone Joint Surg 2000; 82-B:1065-1071

193. Martini F, Schmidt B. Sell S.
Wertigkeit und Reproduzierbarkeit osteodensitometrischer DEXA-messungen nach hüfttotalendoprothesenimplantation. Z Orthop 1997; 135:35.39

194. Martini F, Sell S, Kremling E, Küsswetter W. Determination of periprosthetic bone density with the dexa method after implantation of custom-made uncemented femoral stems. Intern Orthop 1996; 20:218. 221

195. Mauerhan DR, Mesa J, Gregory AM, Mokris JG. Integral porous femoral stem: 5- to 8-year follow-up study. I Arthroplasty 1997: 12:250-255

196. Mazess R, Collick B. Trempe J, Barden H. Hanson J. Performance evaluation of a dual-energy X-ray bone densitometer. Calcif Tissue Int 1989; 44:228-232

197. McGee MA, Howie DW, Ryan P, Moss IR, Holubowycz OT. Comparison of patient and doctor responses to a total hip arthroplasty clinical evaluation questionnaire. J Bone Joint Surg 2002; 84 A:1745-1752

198. McGovern TF, Engh CA, Zett-Schaffer K, Hooten IP. Cortical bone density of the proximal femur following cementless total hip arthroplasty. Clin Orthop 1994; 306 : 145.154

199. McGrory BJ, Shinar AA, Freiberg AA, Harris WH. Enhancement of the value of hip questionnaires by telephone follow-up evaluation. J Arthroplasty 1997; 12:340-343

200. McLaughlin JR, Lee KR. Total hip arthroplasty with an uncemented femoral component: excellent results at ten-year follow-up. J Bone Joint Surg 1997; 79-B:900. 907

201. McMurray R, Heaton I, Sloper P, Nettleton S. Measurement of patient perceptions of pain and disability in relation to total hip replacement: the place of the Oxford hip score in mixed methods. Quality in Health Care 1999; 8:228-233

202. McNally SA, Shepperd JAN, Mann CV. 
Walczak JP. The results at nine to twelve years of the use of a hydroxyapatite-coated femoral stem. J Bone Joint Surg 2000; 83-B: 378-382

203. Menon DK, McCreath SW. 5- to 8-year results of the freeman press-fit hip arthroplasty without HA coating: a clinicoradiologic study. J Arthroplasty 1999; 14:581-588

204. Merle d'Aubigné R, Postel M. Functional results of hip arthroplasty with acrylic prosthesis. J Bone Joint Surg 1954; 36-A: 451-475

205. Mirsky EC, Einhorn TA. Bone densitometry in orthopaedic practice. J Bone Joint Surg 1998; 80-A:1687-1698

206. Mont MA, Hungerford DS. Proximally coated ingrowth prostheses: a review. Clin Orthop 1997: 344:139-149

207. Mont MA, Maar DC, Krackow KA, Jacobs MA, Jones LC, Hungerford DS. Total hip replacements without cement for noninflammatory osteoartrosis in patients who are less than forty-five years old. J Bone Joint Surg 1993; 75-A:740-751

208. Mont MA, Yoon TR, Krrackow KA, Hungerford DS. Clinical experience with a proximally porous-coated second-generation cementless total hip prothesis: minimum 5-year follow-up. J Arthroplasty 1999; 14: 930-939

209. Morscher E. Noncemented acetabular fixation in primary total hip replacement. In: Morscher E.W. (ed.), Endoprosthetics. Berlin Heidelberg New York: SpringerVerlag. 1995: 143-179

210. Morscher EW, Hefti A, Aebi U. Severe osteolysis after third-body wear due to hydroxyapatite particles from acetabular cup coating. J Bone Joint Surg 1998; 80-B:267272

211. Müller U, Gautier E, Roeder C, Busato A. The relationship between cup design and the radiological signs of aseptic loosening in total hip arthroplasty. J Bone Joint Surg

\section{3; 85-B:31-36}

212. Murray D. The Hip. In: Pijnsent $P$, Fairbank J. Carr A (eds.), Outcome measures in orthopaedics. Oxford: Butterworth/ Heinemann. 1993: 198-222

213. Murray DW, Carr AJ, Bulstrode CJK. Survival analysis of joint replacements. I Bone Joint Surg 1993; 75-B:697-704

214. Murray DW, Carr AJ, Bulstrode CJK. Which primary total hip replacement? I Bone Joint Surg 1995; 77-B:520-527

215. Naumann T, Buchner F, Eckardt V. Der Oberschekelschmerz nach Zweymüller-TEP: computertomografische Untersuchungen über das morphologische Verhalten des metadiaphysären Femur. Z Orthop 1987: 125:664-668

216. Nies de F, Fidler MW. The Harris-Galante cementless femoral component. Acta Orthop Scand 1996; 67:122-124

217. Noble PC, Alexander JW, Lindahl LJ, Jew DT, Granberry WM, Tullos HS. The anatomic basis of femoral component design. Clin Orthop 1988; 235:148-165

218. Noble PC, Box GG, Kamaric E, Fink MJ, Alexander JW, Tullos HS. The effect of aging on the shape of the proximal femur. Clin Orthop 1995; 316:31-44

219. Norton MR, Yarlagadda R, Anderson GH. Catastrophic failure of the Elite Plus total hip replacement, with a Hylamer acetabulum and zirconia ceramic femoral head. J Bone Joint Surg 2002; 84-B:631-635

220. Nunn D, Freeman MAR, Evans SJW. The measurment of migration of the acetabular component of hip prosthesis. J Bone Joint Surg 1989; 71-B:629-631

221. Offringa M, Assendelft WJJ, Scholten RJPM. Inleiding in evidence-based medicine: klinisch handelen gebaseerd op bewijsmateriaal, Houten/Diegem: Bohn Stafleu Van Loghum. 2000

222. Olefsky JM. Obesity. In: Wilson JD, Braunwald E, Isselbacher, et al. (eds.). Harrison's Principles of internal medicine. 
New York: McGraw-Hill, Inc. 1991: 411-417

223. Ostendorf $M$, Johnell $O$, Malchau $H$, Dhert WJA, Schrijvers AJP, Verbout A]. The epidemiology of total hip replacement in the Netherlands and Sweden: present status and future needs. Acta Orthop Scand 2002; 73:282-286

224. Owen TD, Moran CG, Smith SR, Pinder IM. Results of uncemented porous-coated anatomic total hip replacement. J Bone Joint Surg 1994; 76-B:258-262

225. Perka C, Fisher U, Taylor W, Matziolis G. Developmental hip dysplasia treated with total hip arthroplasty with a straight stem and a threaded cup. J Bone Joint Surg 2004; 86-A:312-319

226. Petersilge WJ, D'Lima DD, Walker RH, Colwell CW. Prospective study of 100 consecutive Harris-Galante porous total hip arthroplasties: 4- to 8-year follow-up study. J Arthroplasty 1997; 12:185-193

227. Philips FM, Pottenger LA, Finn HA, Vandermolen J. Cementless total hip arthroplasty in patients with steroidinduced avascular necrosis of the hip: a 62-month follow-up study. Clin Orthop 1994: 303:147-154

228. Pieringer $\mathrm{H}$, Auersperg V, Griessler W, Böhler N. Long-term results with the cementless alloclassic brand hip arthroplasty system. J Arthroplasty 2003; 18:321-328

229. Plenk H, Salzer M, Locke H, Stärk N, Punzet G, Zweymüller K. Extracortical attachment of bioceramic endoprostheses to long bones without bone cement. Clin Orthop 1978; 132:252-265

230. Poss R, Clark CR, Heckman JD. A concise format for reporting the longer-term follow-up status of patients managed with total hip arthroplasty. J Bone Joint Surg 2001; 83-A:1779-1780

231. Poss R, Walker P, Spector M, Reilly DT, Robertson DD, Sledge CB. Strategies for improving fixation of femoral components in total hip arthroplasty. Clin Orthop 1988; 235:181-194

232. Puolakka TJS, Laine H-J, Moilanen TPS, Koivisto A-M, Pajamäki KJJ. Alarming wear of the first-generation polyethylene liner of the cementless porous-coated Biomet Universal cup: 107 hips followed for mean 6 years. Acta Orthop Scand 2001; 72:1-7

233. Purtill J], Rothman RH, Hozack WJ, Sharkey PF. Total hip arthroplasty using two different cementless tapered stems. Clin Orthop 2001; 393:121-127

234. Reigstad A, Røkkum M, Bye K, Brandt M. Femoral remodeling after arthroplasty of the hip: prospective randomized 5-year comparison of 120 cemented/uncemented cases of arthrosis. Acta Orthop Scand 1993; 64:411-416

235. Reikerås O, Gunderson RB. Excellent results of $\mathrm{HA}$ coating on the grit-blasted stem: 245 patients followed for 8-12 years. Acta Orthop Scand 2003; 74:140-145

236. Reikeràs $\mathrm{O}$, Gunderson RB. Failure of HA coating on a gritblasted acetabular cup: 155 patients followed for 7-10 years. Acta Orthop Scand 2002; 73:104-108

237. Ricci WM, Westrich GH, Lorei $M$, Cazzarelli JF, Pellicici PM, Sculco TP, Wilson PD. Primary total hip replacement with a noncemented acetabular component: minimum 5-year clinical follow-up. J Arthroplasty 2000; 15:146-152

238. Sabatier JP, Guardier-Souquieres G. Noninvasive methods of bone-mass measurement. Clin Rheum 1989; 8 (s2): 41-45

239. Sabo D, Reiter A, Simank HG, Thomsen M, Lukoschek M, Ewerbeck V. Periprosthetic mineralization around cementless total hip endoprosthesis: longitudinal study and cross-sectional study on titanium threaded acetabular cup and cementless Spotorno stem with DEXA. Calcif Tissue Int 1998; 62:177-182

240. Salzer M, Zweymüller K, Locke H, Zeibig 
A, Stārk N, Plenk jH, Punzet G. Further experimental und clinical experience with aluminum oxide endoprostheses. J Biomed Mater Res 1976; 10:847-856

241. Sarmiento A. Reflections on a 25-year experience with total hip replacement. In: Finerman GAM, Dorey F, Grigoris P. McKellop HA. (eds.). Total hip arthroplasty outcomes. New York: Churchill Livingstone. 1998: xiii- xv

242. Sartorius DJ, Resnick D. Current and innovative methods for noninvasive bone densitometry. Radiol Clin N America 1990; $28(2): 257.278$

243. Sartorius DJ, Resnick D. Dual-energy radiographic absorptiometry for bone densitometry, current status and perspective. Am J Roentgenol 1989; 152: 241-246

244. Savilahti S, Myllyneva I, Lindholm TS, Jorma K, Pajamäki J, Nevalainen J. Laippala P. Clinical outcome and survival of link RS total hip prosthesis. J Bone Joint Surg 1995: 77-B:369-373

245. Schmalzried TP. Patient activity and wear. In: Rieker C, Oberholzer S, Wyss U. (eds.). World tribology forum in arthroplasty. Bern, Göttingen, Toronto, Seattle: Hans Huber. 2001: 31-34

246. Schmalzried TP, Callaghan JJ. Wear in total hip and knee replacements. J Bone Joint Surg 1999; 81-A:115-136

247. Schmalzried TP, Shephard EF, Dorey FI. Jackson WO, dela Rosa M., Fa'vae F, McKellop HA, McClung CD, Martell JM, Moreland J.R., Amstutz HC. Wear is a function of use, not time. Clin Orthop 2000: $381: 36-46$

248. Schmalzried TP, Wessinger SJ, Hill GE, Harris WH. The Harris-Galante porous acetabular component press-fitt without screw fixation: five-year radiographic analysis of primary cases. I Arthroplasty 1994; 9:235-242

249. Schmidt M, Weber H, Schön R.
Cobalt chromium molybdenum metal combination for modular hip prostheses. Clin Orthop 1996; 329S:s35-s47

250. Semlitsch M. Stand der Werkstofftechnik des Zweymüller-Hüftprothesensystems nach 10 Jahren klinischer Praxis. In: Zweymüller K. (ed.), 10 Jahre ZweymüllerHufftendoprothese: II Wiener Symposium. Bern, Stuttgart, Toronto: Verlag Hans Huber, 1990: 14-22

251. Semlitsch M. Panic B. Ten years of experience with test criteria for fractureproof anchorage stems of artificial hip joints. Eng Med 1983; 12 (4):185-198

252. Seral F, Villar JM, Esteller A, Gonzalo VF, Abad 1, Martinez GM, Jorda E, Espinar E. Five-year follow-up evaluation of the noncemented press-fit titanium hip-joint endoprosthesis. Clin Orthop 1992; 283: 49.56

253. Shepherd MM. Assessment of function after arthroplasty of the hip. I Bone Joint Surg 1954; 36-B:354-363

254. Smith SE, Estok DM, Harris WH. 20-Year experience with cemented primary and conversion total hip arthroplasty using so-called second-generation cementing techniques in patients aged 50 years and younger. J Arthroplasty 2000; 15:263-273

255. Söderman P, Malchau H. Validy and reliability of swedish WOMAC osteoarthritis index: a self-administered disease-specific questionnaire (WOMAC) versus generic instruments (SF-36 and NHP). Acta Orthop Scand 2000; 71:39-46

256. Söderman P, Malchau H. Is the Harris hip score system useful to study the outcome of total hip replacement? Clin Orthop 2001; 384:189-197

257. Söderman P, Malchau H. Herberts P. Outcome after total hip arthroplasty: Part 1. General health evaluation in relation to definition of failure in the swedish National Total Hip Arthroplasty register. Acta Orthop Scand 2000: 71:354-359 
258. Soto MO, Rodriquez |A, Ranawat CS. Clinical and radiographic evaluation of the Harris-Galante cup: incidence of wear and osteolysis at 7 to 9 years follow-up. I Arthroplasty 2000; 15:139-145

259. Spittlehouse AJ, Smith TWD, Eastell R. Bone loss around 2 different types of hip prostheses. J Arthroplasty 1998; 13:422-427

260. Stellinga D. Drei-Jahres-Ergibnisse von 100 Zweymüller-Hüfttotalprothesen. Spezifische Röntgencharakteristika. In: Zweymüller K. (ed.), 10 Jahre ZweymüllerHüftendoprothese: II Wiener Symposium. Bern, Stuttgart, Toronto: Verlag Hans Huber. 1990: 132-135

261. Sullivan PM, MacKenzie JR, Callaghan JJ. Johnston RC. Total hip arthroplasty with cement in patients who are less than fifty years old: a sixteen to twenty-two-year follow-up study. J Bone Joint Surg 1994; 76-A:863-869

262. Sumner DR, Galante JO. Determinants of stress shielding: design versus materials versus interface. Clin Orthop 1992; 274: 202-212

263. Sutherland CJ. Wilde AH, Borden LS, Marks KE. A ten-year follow-up of one hundred consecutive Müller curved-stem total hip-replacement arthroplasties. J Bone Joint Surg 1982; 64-A:971-982

264. Tompkins GS, Jacobs II. Kull LR, Rosenberg AG, Galante JO. Primary total hip arthroplasty with a porous-coated acetabular component: seven-to-ten nyear results. J Bone Joint Surg 1997; 79-A:169176

265. Tonino AJ, Oosterbos C, Rahmy A, Thèrin $\mathrm{M}$, Doyle $\mathrm{C}$. Hydroxyapatite-coated acetabular components: histological and histomorphometric analysis of six cups retrieved at autopsy between three and seven years after successful implantation. I Bone Joint Surg 2001; 83-A:817-825

266. Tooms RE, Harkess JW. Arthroplasty: introduction and overview. In: Crenshaw
AH (ed.), Cambell's operative orthopaedics. Missouri: Mosby-Year book. 1992: 371-387

267. Visuri T, Pukkala E, Paavolainen P, Pulkkinen P. Riska EB. Cancer risk after metal on metal and polyethylene on metal total hip arthroplasty. Clin Orthop 1996; $329 \mathrm{~S}: \mathrm{s} 280-\mathrm{s} 289$

268. Wahner HW. Use of densitometry in management of osteoporosis. In: Marcus R, Feldman D, Kelsey J (eds.). Osteoporosis. San Diego: Academic Press. 1996: $1055-1074$

269. Walker PS, Robertson DD. Design and fabrication of cementless hip stems. Clin Orthop 1988; 235:25-34

270. Walker PS, Gold BL. The tribology (friction, lubrication and wear) of all-metal artificial hip joints. Wear 1971: 17:285-299

271. Wanivenhaus A, Zweymüller K. 5-10jahresergebnisse mit einer füsschenpfanne aus keramik zur knochenzementfreien implantation. Z Orthop 1988: 126:508-512

272. Weissinger M, Helmreich C. Langfristige resultate mit dem zementfreien Alloclassic-schaft nach Zweymüller. Z Orthop 2001; 139:200-205

273. Weller S, Braun A, Gellrich JC, Gross U. Importance of prosthesis design and surface structure for the primary and secondary stability of uncemented hip joint prostheses. In: Learmonth ID (ed.). Interfaces in total hip arthroplasty. London Berlin Heidelberg: Springer-Verlag. 1999: 81-101

274. Wiklund I, Romanus B. A comparison of quality of life before and after arthroplasty in patients who had arthrosis of the hip joint. J Bone Joint Surg 1991; 73-A:765-769

275. Wilkinson JM, Peel NFA, Elson RA, Stockley 1, Eastell R. Measuring bone mineral density of the pelvis and proximal femur after total hip arthroplasty. J Bone Joint Surg 2001: 83-B:283-288

276. Willert HG, Buchhorn GHH, Göbel D. Köster G, Schaffner S, Schenk 
R. Semlitsch M. Wear behavior and histopathology of classic cemented metal on metal hip endoprostheses. Clin Orthop 1996; 329S:s160-s186

277. Willert H.G. Trautmann M. Verlaufskontrollen bei klinischen Problemfallen. In: Zweymüller K (ed.), 10 Jahre Zweymüller-Hüftendoprothese: II. Wiener.Symposium. Bern, Stuttgart, Toronto: Verlag Hans Huber. 1990: 108-113

278. Wolff J. Das Gesetz der Transformation der Knochen, Berlin: Kirchenwald. 1892

279. World Health Organization Study Group. Assesment of fracture risk and its application to screening for postmenopausal osteoporosis, Report.no 843.Geneva. World Health Organization. 1994;

280. Wright JG, Young NL, Waddell JP. The reliability and validity of the self-reported patient-specific index for total hip arthroplasty. J Bone Joint Surg 2000; 82-A: 829-837

281. Wroblewski BM, Siney PD. Charnley lowfriction arthroplasty of the hip: long-term results. Clin Orthop 1993; 292:191-201

282. Wurnig C, Auersperg V, Boehler N, Steindl M, Kiss H, Zweymüller K, Kotz R. Short term prophylaxis against heterotopic bone after cementless hip replacement. Clin Orthop 1997; 334:175-183

283. Xenos IS, Callaghan JI. Heekin D, Hopkinson WJ, Savory CG, Moor MS. The porous-coated anatomic total hip prosthesis, inserted without cement: a prospective study with a minimum of ten years of follow-up. J Bone Joint Surg. 1999; 81-A:74-82

284. Yahiro MA, Gantenberg JB, Nelson R, Lu HTC, Mishra NK. Comparison of the results of cemented, porous-ingrowth, and threaded acetabular cup fixation: a metaanalysis of the orthopaedic literature. J Arthroplasty 1995; 10-3:339-350

285. Zahiri CA, Schmalzried TP, Szuszczewicz
ES, Amstutz HC. Assessing activity in joint replacement patients. J Arthroplasty 1998; 13-8:890-895

286. Zweymüller K, Lintner FK, Semlitsch MF. Biologic fixation of a press-fit titanium hip joint endoprosthesis. Clin Orthop 1988; 235:195-206

287. Zweymüller K., Semlitsch M. Concept and material properties of a cementless hip prosthesis system with $\mathrm{Al}_{2} \mathrm{O}$, ceramic ball heads and wrought Ti-6Al-4V stem. Arch Orthop Trauma Surg 1982; 100:229-236

288. Zweymüller K. 20 Years of cementless hip prostheses. In: Zweymüller KA (ed.), 20 Years of Zweymuller hip endoprostheses. Bern, Göttingen, Toronto, Seattle: Verlag Hans Huber. 2002: 11-23

289. Zweymüller K, Lintner F, Böhm G. The development of the cementless hip endoprosthesis: 1979-1994. In: Morscher E.W. (ed.), Endoprosthetics. Berlin Heidelberg: Springer-Verlag. 1995: 309-325

290. Zweymüller K, Samek V. Radiologische Erkenntnisse der Titaniumpfanne. In: Zweymüller K (ed.), 10 Jahre.ZweymüllerHüftendoprothese., II.Wiener.Symposium. Bern, Stuttgart, Toronto: Verlag Hans Huber. 1990: $35-46$ 


\section{Appendix 1.}

\section{Fixation and Stability Score [82]}

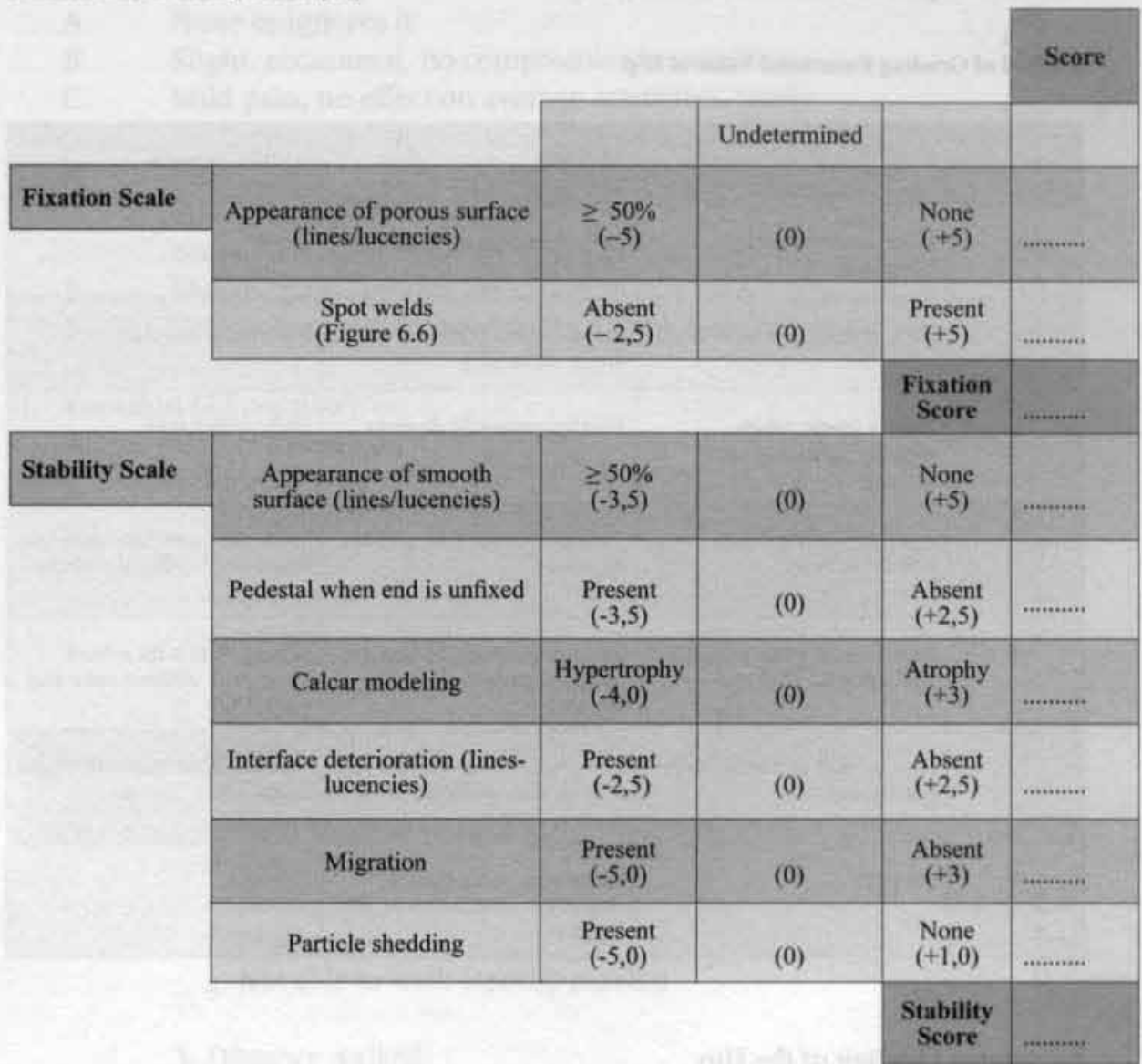

Fixation Score + Stability Score $=$ Total Score

\section{CATEGORY}

\begin{tabular}{|l|c|c|c|}
\hline & Fixation Score & Stability Score & Total Score \\
\hline Unstable & $<-5$ & $<-5$ & $<-10$ \\
\hline Suboptimum, but stable & $-5 \leftrightarrow 0$ & $-5 \leftrightarrow 0$ & $-10 \leftrightarrow 0$ \\
\hline Ingrowth suspected & $0 \leftrightarrow+5$ & $0 \leftrightarrow+5$ & $0 \leftrightarrow+10$ \\
\hline Bone ingrown & $>+5$ & $>+5$ & $>+10$ \\
\hline
\end{tabular}




\section{ApPENDix 2.}

Merle D'Aubigné Pain-Walk-Mobility score [204].

\section{Method of Grading Functional Value of Hip}

\begin{tabular}{|c|l|l|l|}
\hline Grade & Pain & Mobility & Abitity to walk \\
\hline 0 & $\begin{array}{l}\text { Pain is intense and } \\
\text { permanent }\end{array}$ & $\begin{array}{l}\text { ankylosis with bad position } \\
\text { of the hip. }\end{array}$ & None \\
\hline 1 & Pain is severe even at night & $\begin{array}{l}\text { No movement: pain or } \\
\text { slight deformity }\end{array}$ & Only with crutches \\
\hline 2 & $\begin{array}{l}\text { Pain is severe when } \\
\text { walking; prevents any } \\
\text { activity }\end{array}$ & Flexion under 40 degrees & Only with canes \\
\hline 3 & $\begin{array}{l}\text { Pain is tolerable with } \\
\text { limited activity }\end{array}$ & $\begin{array}{l}\text { Flexion between } 40 \text { and } 60 \\
\text { degrees }\end{array}$ & $\begin{array}{l}\text { With one cane, less than one } \\
\text { hour: very difficult without } \\
\text { a cane }\end{array}$ \\
\hline 4 & $\begin{array}{l}\text { Pain is mild when walking } \\
\text { it disappears with rest }\end{array}$ & $\begin{array}{l}\text { Flexion between } 60 \text { and } 80 \\
\text { degrees: patient can reach } \\
\text { his foot }\end{array}$ & $\begin{array}{l}\text { A long time with a cane: } \\
\text { short time without cane and } \\
\text { with limp }\end{array}$ \\
\hline 5 & $\begin{array}{l}\text { Pain is mild and inconstant; } \\
\text { normal activity }\end{array}$ & $\begin{array}{l}\text { Flexion between } 80 \text { and } \\
90 \text { degrees; abduction of at } \\
\text { least 15 degrees }\end{array}$ & $\begin{array}{l}\text { Without cane but with slight } \\
\text { limp }\end{array}$ \\
\hline 6 & No pain & $\begin{array}{l}\text { Flexion of more than } 90 \\
\text { degrees; abduction to } 30 \\
\text { degrees }\end{array}$ & Normal \\
\hline
\end{tabular}

\section{Functional Grading of the Hip}

\begin{tabular}{|c|c|}
\hline \multicolumn{2}{|c|}{ Mobility Normal or Nearly Normal } \\
\hline P+W score & Functional grading of the hip \\
\hline 11 or 12 & very good \\
\hline 10 & good \\
\hline 9 & medium \\
\hline 8 & fair \\
\hline 7 or less & poor \\
\hline
\end{tabular}

If the mobility is reduced to 4 , the result is classed one grade lower.

If the mobility is reduced to 3 or less, the result is classed two grades lower. 
I. Pain (44 possible)

A. None or ignores it 44

B. Slight, occasional, no compromise in activities $\quad 40$

C. Mild pain, no effect on average actrivities, rarely

D. Moderate pain, tolerable but makes concessions to pain.

Some limitation of ordinary activity work. May require occasional pain medicine stronger than aspirin 20

E. Marked pain, serious limitation of activities 10

F. Totally disabled, crippled, pain in bed, bedridden 0

II. Function ( 47 possible)

A. Gait (33 possible)

1. Limp
a. None
b. Slight
c. Moderate
d. Severe

2. Support
a. None
b. Cane for long walks
c. Cane most of the time
d. One crutch
e. Two canes
f. Two cruthes
g. Not able to walk (specify reason)

3. Distance walked
a. Unlimited
b. Six blocks
c. Two or three blocks
d. Indoors only
e. Bed and chair 
B. Activities (14 possible)

1. Stairs
a. Normally without using a railing
b. Normally using a railing
c. In any manner
d. Unable to do stairs

2. Shoes and Socks
a. With ease
4
b. With difficulty
c. Unable

\section{Sitting}
a. Comfortably in ordinary chair one hour
b. On a high chair for one-half hour $\quad 3$
c. Unable to sit comfortably in any chair 0

4. Enter public transportation

III. Absence of deformity points (4) are give if the patient demonstrates:
A. Less than $30^{\circ}$ fixed flexion contracture
B. Less than $10^{\circ}$ fixed adduction 1
C. Less than $10^{\circ}$ fixed internal rotation in extension 1
D. Limb-length discrepancy less than 3.2 centimeters

IV. Range of motion (index values are determined by multiplying the degrees of motion possible in each arc by the appropriate index)
A. Flexion

$\begin{array}{lll}0-45 \text { degrees } & X & 1.0 \\ 45-90^{\circ} & X & 0.6 \\ 90-110^{\circ} & X & 0.3\end{array}$
B. Abduction

$\begin{array}{llr}0-15^{\circ} & \text { X } & 0.8 \\ 15-20^{\circ} & \text { X } & 0.3 \\ \text { over } 20^{\circ} & \text { X } & 0\end{array}$
C. External rotation in ext.

$\begin{array}{llr}0-15 & X & 0.4 \\ \text { over } 15^{\circ} & X & 0\end{array}$
D. Internal rotation in extension
any
$\mathrm{X}$
0
E. Adduction
$0-15^{\circ}$
$\mathrm{X}$
0.2 
To determine the over-all rating for range of motion, multiply the sum of the index values $\mathrm{X} 0.05$.

Record Trendelenburg test as positive, level, or neutral. 
I. Pijn (44 punten)
A.
geen
B. licht en incidenteel, geen aktiviteitsbeperking
C. mild, soms erger bij ongebruikelijke activiteiten, geen invloed op ADL
D. matig, enige beperking van ADL of werk
E. ernstig, forse beperking van $\mathrm{ADL}$
F. invalide, continue pijn, pijn in bed

II. Functie (47 punten)

A. looppatroon (33 mogelijk)

1. manken
a. niet
b. licht
c. matig
d. ernstig

2. hulpmiddel
a. geen
b. stok bij lange wandeling
c. stok bijna altijd
d. een kruk
e. 2 stokken
f. 2 krukken
g. niet in staat te lopen

3. loopafstand
a. onbeperkt
b. ongeveer $1 \mathrm{~km}$
c. ongeveer 100-200 m
d. alleen binnenshuis
e. niet in staat te lopen

B. Activiteiten (14 punten)

1. traplopen
a. Normaal
b. Normaal met leuning
c. met bijtrekken van de voet
d. onmogelijk 
2. aantrekken schoenen en sokken
a. makkelijk
b. moeilijk
c. onmogelijk

3. zitten
a. Comfortabel in lage stoel
b. Comfortabel in hoge stoel
c. op geen enkel stoel comfortabel

4. openbaar vervoer
a. mogelijk
1
b. onmogelijk
0

III. Afwezigheid van contracturen/beenlengteverschil levert 4 punten op indien:
A. minder dan $30^{\circ}$ flexiecontractuur
B. minder dan $10^{\circ}$ adductiecontractuur
C. minder dan $10^{\circ}$ endorotatiecontractuur in extensie
D. minder dan $3.2 \mathrm{~cm}$ beenlengteverschil

IV. Beweeglijkheid van de heup (5 punten)
A. Flexie
$0-45^{\circ}$
X
1.0
$45-90^{\circ}$
$\begin{array}{ll}\mathrm{X} & 0.6\end{array}$
$90-110^{\circ}$
$\begin{array}{ll}\mathrm{X} & 0.3\end{array}$
B. Abductie
$0-15^{\circ}$
$15-20^{\circ}$
$>20^{\circ}$
$\begin{array}{ll}\mathrm{X} & 0.8\end{array}$
$\mathrm{X} \quad 0.3$
$\mathrm{X} \quad 0$
C. Exorotatie in extensie
$0-15$
$>15^{\circ}$
$\begin{array}{lr}X & 0.4 \\ X & 0\end{array}$
D. Endorotatie in extensie
X
0
E. Adductie

$$
\begin{array}{r}
0-15^{\circ} \\
>15^{\circ}
\end{array}
$$
$\begin{array}{lr}\mathrm{X} & 0.2 \\ \mathrm{X} & 0\end{array}$

(score voor beweeglijkheid wordt bepaald door optellen van bovengenoemde waarden en dit met 0.05 te vermenigvuldigen) 


\section{2-Item Hip Questionnaire on the Perceptions of Patients about Total Hip Replacement [53]}

Item

During the past four weeks

1) How would you describe the pain you usually had from your hip?

\section{Scoring categories}

\author{
1 None \\ 2 Very mild \\ 3 Mild \\ 4 Moderate \\ 5 Severe
}

2) Have you had any trouble with washing and drying yourself (all over) because of your hip?

3) Have you had any trouble getting in and out of a car or using public transport because of your hip? (whichever you tend to use)

1 No trouble at all 2 Very little trouble 3 Moderate trouble 4 Extreme difficulty 5 Impossible to do

1 No trouble at all 2 Very little trouble 3 Moderate trouble 4 Extreme difficulty 5 Impossible to do

4) Have you been able to put on a pair of socks stockings or tights?

1 Yes, easily

2 With little difficulty

3 With moderate difficulty 4 With extreme difficulty 5 No, impossible

5) Could you do the household shopping on your own? I Yes, easily

2 With little difficulty

3 With moderate difficulty 4 With extreme difficulty 5 No, impossible

6) For how long have you been able to walk before

1 No pain $/>30$ minutes the pain from your hip became severe? 216 to 30 minutes (with or without a stick)

35 to 15 minutes

4 Around the house only

5 Not at all 
7) Have you been able to climb a flight of stairs?

8) After a meal (sat at a table), how painful has it been for you to stand up from a chair because of your hip?

9) Have you been limping when walking, because of your hip?

10) Have you had any sudden, severe pain "shooting", "stabbing or "spasms"- from the affected hip?

11) How much has pain from your hip interfered with your usual work (including housework)?

12) Have you been troubled by pain from your hip in bed at night?
1 Yes, easily

2 With little difficulty

3 With moderate difficulty

4 With extreme difficulty

5 No, impossible

1 Not at all painful

2 Slightly painful

3 Moderalty painful

4 Very painful

5 Unbearable

1 Rarely/never

2 Sometimes or just at first

3 Often, not just at first

4 Most of the time

5 All of the time

1 No days

2 Only 1 or 2 days

3 Some days

4 Most days

5 Every day

1 Not at all

2 A little bit

3 Moderately

4 Greatly

5 Totally

1 No nights

2 Only 1 or 2 nights

3 Some nights

4 Most nights

5 Every nights 


\section{Dutch Oxford Heup SCore (DUTCh translation)}

The Dutch translation of the Dawson 12-item hip questionnaire with two questions, VAS painscore and four satisfaction questions added [123]

1) Hoe zou u de pijn omschrijven die u normaal in/rond uw heup heeft?

2) Heeft u, door uw heup, moeite met het wassen en afdrogen van uw hele lichaam?
1 geen pijn

2 heel licht

3 licht

4 matig

5 ernstig

1 helemaal geen moeite

2 beetje moeite

3 nogal wat moeite

4 veel moeite

5 onmogelijk om te doen

1 helemaal geen moeite

2 beetje moeite

3 nogal wat moeite

4 veel moeite

5 onmogelijk om te doen

$1 \mathrm{ja}$, gemakkelijk

2 met een beetje moeite

3 met nogal wat moeite

4 met veel moeite

5 nee, onmogelijk

$1 \mathrm{ja}$, gemakkelijk

2 met een beetje moeite

3 met nogal wat moeite

4 met veel moeite

5 onmogelijk

6) Hoe lang kunt $\mathrm{u}$ lopen (met of zonder stok) voordat 1 langer dan 30 minuten de pijn in/rond uw heup ernstig wordt?

216 tot 30 minuten

35 tot 15 minuten

4 alleen in en om het huis

5 helemaal niet 
7) Kunt u trappen lopen?

1 ja, gemakkelijk

2 met een beetje moeite

3 met nogal wat moeite

4 met veel moeite

5 nee, onmogelijk

8) Hoe pijnlijk is uw heup, als u na het eten aan tafel, 1 helemaal niet pijnlijk uit uw stoel opstaat?

2 beetje pijnlijk

3 nogal pijnlijk

4 erg pijnlijk

5 ondraaglijk

9) Trekt $u$, vanwege uw heup, met uw been tijdens het lopen (afgelopen 4 weken)?

1 zelden / nooit

2 soms (bv. de eerste passen)

3 vaak (bv. niet alleen de eerste paar stappen)

4 meestal

5 altijd

10) Heeft $u$ wel eens dagen waarop $u$ plotselinge,

1 nee, nooit

ernstige pijn (scheuten, steken en/of krampen) in/rond uw heup heeft?

2 1-2 dagen

3 een aantal dagen

4 meeste dagen

5 elke dag

11) In hoeverre beïnvloedt de pijn in uw heup

1 helemaal niet

uw dagelijkse werk (inclusief huishoudelijk werk) 2 een beetje

3 nogal

4 veel

5 totaal

12) Heeft $u$ wel eens nachten waarop $u$ in bed

1 nooit last heeft van pijn in/rond uw heup?

21-2 nachten

3 een aantal nachten

4 meeste nachten

5 elke nacht

13) Gebruikt u hulpmiddelen (stok(ken), $\operatorname{kruk}(k e n), \quad 1$ nooit looprek) bij het lopen?

2 soms

3 vaak

4 meestal

5 altijd 
14) Wordt u bij uw seksuele activiteiten belemmerd I nooit/niet van toepassing door uw heup?

$$
\begin{aligned}
& 2 \text { soms } \\
& 3 \text { vaak } \\
& 4 \text { meestal } \\
& 5 \text { altijd }
\end{aligned}
$$

15) Hieronder ziet $U$ een lijn getekend met links de woorden "helemaal geen pijn" en rechts de woorden "ondragelijke pijn". De bedoeling is dat U op deze lijn één kruisje zet om aan te geven hoeveel pijn U de afgelopen 4 weken in/rond Uw heup heeft gehad.

Voorbeeld:

helemaal geen pijn | X ondragelijke pijn

Uw situatie:

helemaal geen pijn | ondragelijke pijn

16) Geef aan welke van de volgende drie situaties het beste bij $U$ past (één antwoord aankruisen):

- ik heb aan één zijde (links of rechts) een heupprothese en géén andere gezondheidsproblemen die van invloed zijn op mijn dagelijks functioneren.

- ik heb aan beide zijden (links én rechts) een heupprothese en géén andere gezondheidsproblemen die van invloed zijn op mijn dagelijks functioneren.

- Aan één of beide zijde(n) problemen met de heup én andere gezondheidsproblemen (bv rugproblemen, reuma, nierziekte, hartaandoening, neurologische aandoening etc.) die van invloed zijn op mijn dagelijks functioneren, zijnde:

17) Is door de operatie de beweeglijkheid of functie van uw heup beter geworden?

$0 \mathrm{Ja} \quad 0 \mathrm{Nee}$

18) Is door de operatie de pijn in/rond uw heup minder geworden?
$0 \mathrm{Ja}$
0 Nee

19)Bent u tevreden met het resultaat van de operatie?

$0 \mathrm{Ja} \quad 0$ Nee

20) Hoe is Uw heup nu vergeleken met de vorige keer dat $U$ de vragenlijst heeft ingevuld?
0 beter
0 hetzelfde
0 slechter 


\section{Hip Society Work/Activity LeVel [142]}

(check one)
A. (- Heavy Manual Labor - frequently lifts $23-45 \mathrm{~kg}$ vigorous sports (e.g. singles tennis or recquetball)
B. Moderate Manual Labor - lifts $\leq 23 \mathrm{~kg}$, moderate sports (e.g. walking or bicycling $>5 \mathrm{~km}$ )
C. $\quad$ Light Labor - heavy house cleaning, yard work, assembly line, light sports (e.g. walking $\leq 5 \mathrm{~km}$ )
D. Semi-Sedentary - white collar, bench worker, light housekeeping
E. S Sedentary - minimum capacity for walking or other activity
F. Bedridden or confined to wheelchair

Werk/Activiteitenniveau volgens Hip Society (Dutch translation)
A. Z Zwaar werk - kan 23-45 kg optillen, intensieve sporten (bv, tennis)
B. Gemiddeld zwaar werk - kan $\leq 23 \mathrm{~kg}$ optillen, lichte sporten (wandelen/fietsen $>5 \mathrm{~km}$ )
C. Licht werk - zwaar huishoudelijk werk - lichte sporten (bv wandelen $\leq 5 \mathrm{~km}$ )
D. Half zittend - licht huishoudelijk werk
E. Z Zittend - weinig aktief - weinig wandelen
F. $\mathrm{Bed}$ - stoel 


\section{University of California at Los ANgeles 10-Point RATING SYSTEM [7]}

\begin{tabular}{|c|l|}
\hline Level & Activity \\
\hline 1 & Wholly inactive: dependent on others; cannot leave residence \\
\hline 2 & Mostly inactive: very restricted to minimum activities of daily living \\
\hline 3 & $\begin{array}{l}\text { Sometimes participates in mild activities such as walking, limited housework, } \\
\text { and limited shopping }\end{array}$ \\
\hline 4 & Regularly participates in mild activities \\
\hline 5 & $\begin{array}{l}\text { Sometimes participates in moderate activities such as swimming and can do } \\
\text { unlimited housework or shopping }\end{array}$ \\
\hline 6 & Regularly participates in moderate activities \\
\hline 7 & Regularly participates in active events such as bicycling \\
\hline 8 & Regularly participates in very active events such as bowling or golf \\
\hline 9 & $\begin{array}{l}\text { Sometimes participates in impact sports such as jogging, tennis, skiing, } \\
\text { acrobatics, ballet, heavy labor, or backpacking }\end{array}$ \\
\hline 10 & Regularly participates in impact sports \\
\hline
\end{tabular}

least active $\quad$ average most active

$\leftarrow \quad 10 \mathrm{~cm} \rightarrow$




\section{U.C.L.A. Activiterten NiveAu (Dutch translation)}

\begin{tabular}{|l|l|}
\hline Niveau & Activiteit \\
\hline 1 & Ik ben afhankelijk van anderen en kom mijn huis niet uit. \\
\hline 2 & $\begin{array}{l}\text { Ik kan maar weinig dingen doen, ik ben voomamelijk afhankelijk van } \\
\text { anderen. }\end{array}$ \\
\hline 3 & $\begin{array}{l}\text { Soms kan ik licht belaste activiteiten doen, zoals wandelen, licht } \\
\text { huishoudelijk werk, beperkt boodschappen doen. }\end{array}$ \\
\hline 4 & Ik kan deze activiteiten regelmatig doen. \\
\hline 5 & $\begin{array}{l}\text { Ik kan soms activiteiten doen zoals zwemmen, normaal uitvoeren van } \\
\text { huishoudelijk werk, boodschappen doen. }\end{array}$ \\
\hline 6 & Ik kan deze activiteiten vaak doen. \\
\hline 7 & Ik kan regelmatig meedoen aan activiteiten zoals fietsen. \\
\hline 8 & Ik kan regelmatig meedoen aan evenementen zoals bowlen en golfen. \\
\hline 9 & $\begin{array}{l}\text { Ik kan soms meedoen aan sporten zoals trimmen, tennis, skiën, en ook aan } \\
\text { zware arbeid en rugzak-vakanties. }\end{array}$ \\
\hline 10 & Ik kan regeimatig aan deze sporten meedoen. \\
\hline
\end{tabular}

4 Wilt $\mathrm{U}$ op de onderstaande balk aangeven in welke mate $\mathrm{U}$ de activiteit kunt verrichten

\begin{tabular}{lcc} 
minst actief & gemiddeld actief & meest actief \\
\hdashline$\leftarrow$ & $10 \mathrm{~cm}$ & $\rightarrow$
\end{tabular}




\section{APPENDIX 3}

Cases of aseptic loosening of the acetabular component which had been revised.

CASE 1: 9 age at surgery 66.8 years; aseptic loosening 140.8 months postsurgery; cemented device

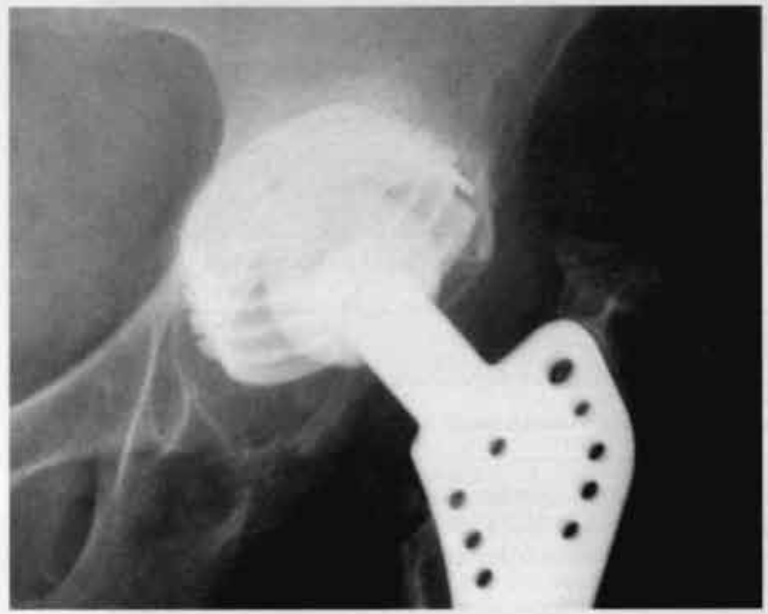

CASE 2: $\$$ age at surgery 49.2 years; after 72.2 months aseptic loosening acetabular component; cemented device

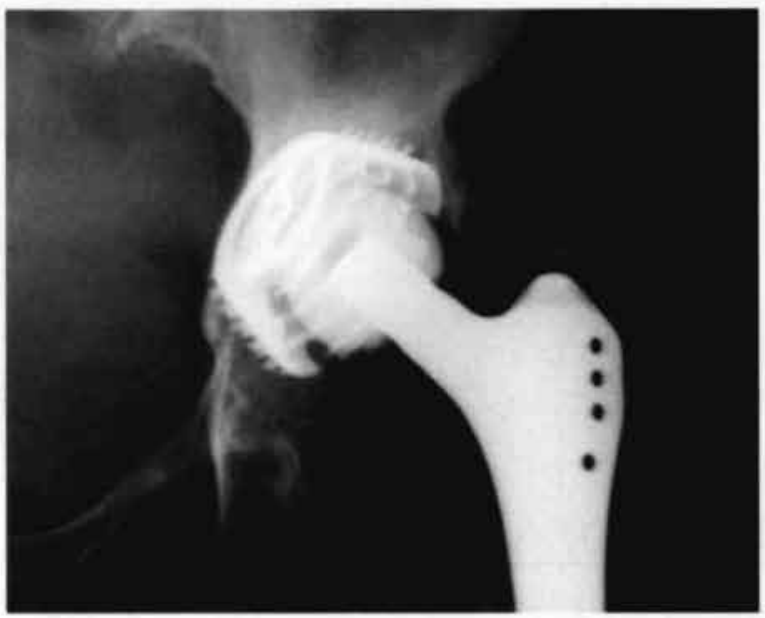


CASE 3: $\sigma^{\text {}}$ age at surgery 54.8 years; aseptic loosening 140.2 months postsurgery; impaction bone grafting, reinforcemnt ring, cemented cup; revision 3 months after follow-up study two

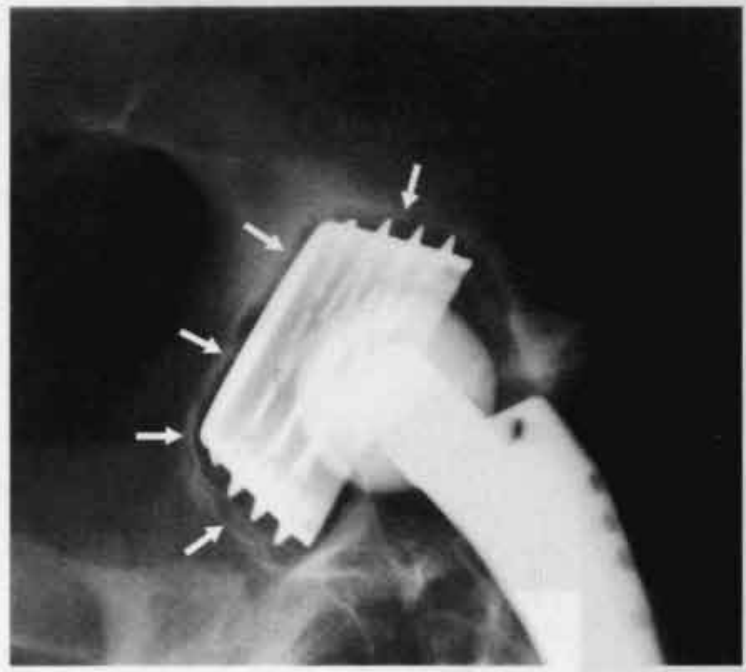

CASE 4: $Q$ age at surgery 54.3 years; aseptic loosening 64.3 months postsurgery; cemented device

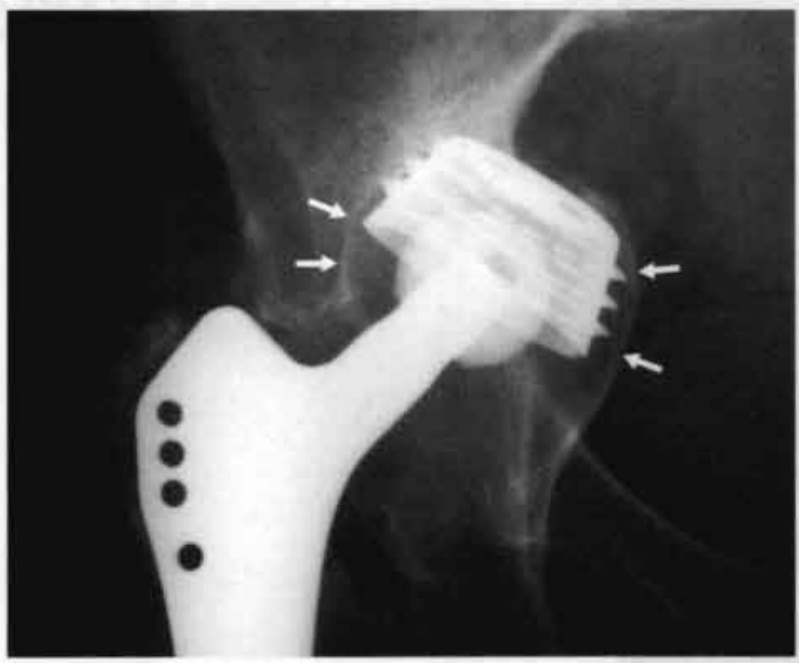


CASE 5: $O$ age at surgery 43.4 years; aseptic loosening 85.5 months postsurgery; cemented device

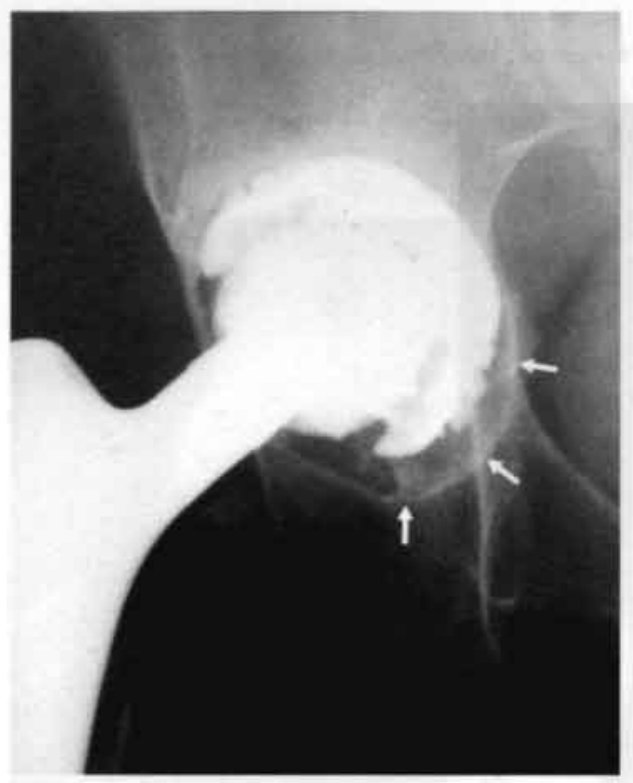

CASE 6: $ᄋ$ age at surgery 57.4 years; aseptic loosening 138.9 months postsurgery; larger Zweymüller threaded cup

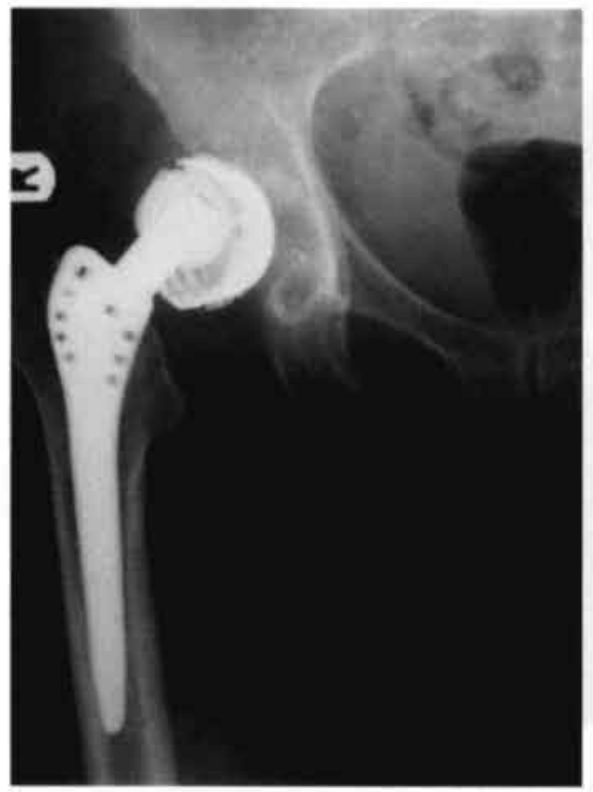


CASE 7: $\sigma^{7}$ age at surgery 61.9 years; aseptic loosening 63.9 months postsurgery; cemented device

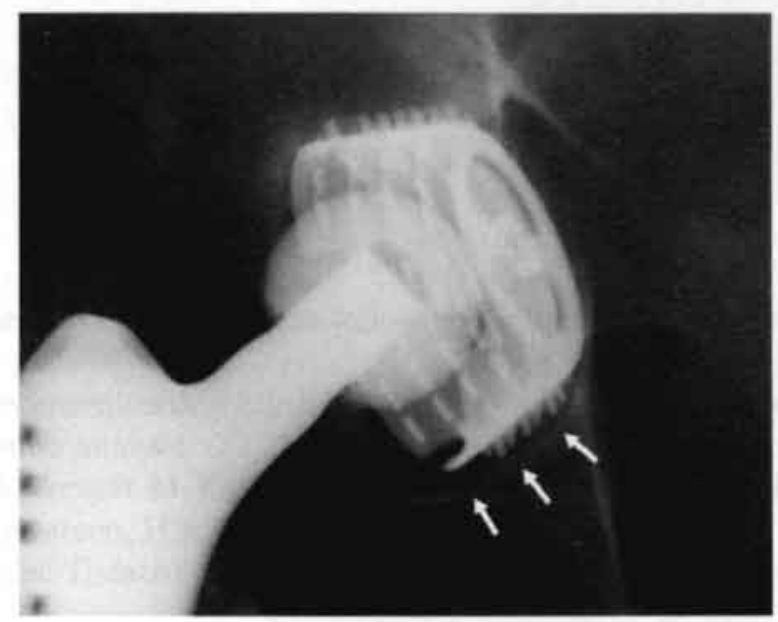

CASE 8: $ᄋ$ age at surgery 61.1 years; aseptic loosening 58.6 months postsurgery; cemented device (no radiographs available).

CASE 9: $ᄋ$ age at surgery 78.1 years; aseptic loosening 37.4 months postsurgery; cemented device (no radiographs available); deceased 58.3 months after primary surgery. 



\section{PUBLICATIONS}

This thesis is based upon the following publications and poster:

De ongecementeerde totale heupprothese volgens Zweymüller, een retrospectieve multicenter analyse

A.M.J.S. Vervest, M. Kenters, A.I. Klomp, G.J.T.M. Boog, W.H.J.C. van Heeswijk, O.S. Ingwersen, H.A.G.M. Sala, J.Vegter

In: Ned Tijdschr Orthop 2000; 2:5-11

A historical cohort study of 754 Zweymüller cementless stems of two designs and the threaded titanium cup

A.M.J.S. Vervest, M. Kenters, A.I. Klomp

In: Zweymüller KA (ed). 20 Years of Zweymüller Total Hip Endoprosthesis. Bern, Göttingen, Toronto, Seattle: Verlag Hans Huber 2002: 49-62

Bone mineral density 10 years after a Zweymüller uncemented stem prosthesis T.M.J.S. Vervest, W.H.J.C. van Heeswijk, P.G. Anderson, J. van Limbeek In: Hip International 2003; 13 (4):205-214

De Oxford heup score: de Nederlandstalige vragenlijst toegepast op een cohort patiënten met een Zweymüller ongecementeerde totaleheupprothese A.M.J.S. Vervest, P.G. Anderson

In: Ned Tijdschr Orthop 2004; 11:18-24

The Zweymüller cementless total hip prosthesis in patients aged 50 years and younger

Ton M.J.S. Vervest, Patricia G. Anderson

In: Hip International, accepted 
Decreased bone mineral density at the calcar region 10 years after a Zweymüller cementless stem prosthesis

Ton M.J.S. Vervest, Wim H.J.C. van Heeswijk, Patricia G. Anderson, Jacques van Limbeek

In: Santore RF, Friederich NF (eds.), 25 Years of biologic fixation prof.dr. K. Zweymüller, the compendium of non-cemented total hip replacement. Urban \& Fischer 2005: in press

Long-term survival of the Zweymüller cementless total hip arthroplasty Ton M.J.S. Vervest, Patricia G. Anderson

Poster A.A.O.S. 72 ${ }^{\text {nd }}$ Annual Meeting February 23-27, 2005 Washington, DC U.S.A.

Ten to twelve year results with the Zweymüller cementless total hip prosthesis Ton M.J.S. Vervest, Patricia G. Anderson, Freek van Hout, Frit-Hein Wapstra, Robert T. Louwerse, Juriaan W.A. Koetsier

In: J Arthroplasty, accepted. 
Het verrichten van wetenschappelijk onderzoek en het schrijven van een proefschrift is een inspanning die door vele personen wordt geleverd. Al diegene die hebben bijgedragen aan mijn proefschrift wil ik hartelijk danken voor hun inzet. In het bijzonder wil ik noemen:

Prof.dr. R.G.T. Geesink, hooggeleerde promotor, beste Ruud. Tijdens mijn opleidingsjaar in Maastricht kreeg het onderzoek naar de resultaten van de Zweymüller prothese concrete vormen. In meerdere gesprekken is de grote lijn van het onderzoek vastgelegd en is het onderzoek uitgegroeid tot dit proefschrift. Je bent een zeer drukbezette hoogleraar waardoor mijn verzelfstandiging in het verrichten van wetenschappelijk onderzoek is gestimuleerd. Ik dank je dat ik heb mogen leren van jou uitgebreide en internationaal befaamde kennis van heupprothesen.

Prof.dr. J.M.A. van Engelshoven en Prof. dr. H. van Mameren wil ik hartelijk danken voor hun bereidheid om zitting te nemen in de beoordelingscommissie. Prof.dr. S.K. Bulstra, hooggeleerde heer, beste Sjoerd. Dank voor je enthousiasme voor het wetenschappelijk onderzoek, wat zich tevens vertaald heeft in een stelling die ik heden zal verdedigen.

Prof.dr. R.G. Pöll, hooggeleerde heer, beste Ruud. Dank voor je interesse in mijn onderzoek en onze samenwerking in het Slotervaart ziekenhuis.

Prof.dr. K. Zweymüller, very learned, dear Karl. It is a very great honour that I could study the prosthesis you have developed. During several dialogues you have given me inspiration for this study.

Dr. A.B. Wymenga, weledelzeergeleerde heer, beste Ate. Dank voor de vaak onverwachte ontmoetingen op orthopedisch en nautisch gebied. Dat je mij in contact hebt gebracht met Patsy, heeft veel voor mij en het onderzoek betekend. Dr. A.G.J. Nollen, weledelzeergeleerde heer, beste Ad. Van jou en de overige stafleden van de vakgroep orthopaedie van het Sint Joseph Ziekenhuis Veldhoven heb ik de orthopaedie mogen leren. Ik weet dat je het waardeert dat een perifeer opgeleide orthopeed uiteindelijk een promotiestudie succesvol beëindigt. 
Wim van Heeswijk en Patsy Anderson, mijn paranymfen.

Beste Wim, vanaf het begin heb je je ingezet voor dit onderzoek en het is me een bijzonder genoegen dat je mij tijdens de verdediging wilt steunen.

Beste Patsy, zonder jouw hulp en je uitgebreide kennis van de statistiek was het niet gelukt. Bijna alle artikelen heb ik samen met jou geschreven. Tot de laatste print, voordat het verzonden werd naar een tijdschrift, bleef je mij corrigeren in grote en kleine (engelse) taalfouten. Ik vind dat fantastisch.

Ron Slagter, medisch illustrator. Dank voor je grandioze illustraties waarmee je de uitgave van mijn proefschrift hebt verfraaid.

Frank Derksen, Hillart Wagenmakers, Arnoud Vervest. Dank voor jullie altijd beschikbare hulp bij het repareren van de computer en het uitvoeren van diverse computer programma's.

Nicolette Hoefnagels en Rieny van den Munckhof (Trialbureau orthopaedie AZM). Dank voor de Oxford Heup Score en jullie analyse van het eerste onderzoek.

Familie, vrienden, trimclub "de Rhijnauwen Runners", mede-auteurs, collega's en mijn maatschapsleden Gooi-Noord, Blaricum. Dank voor jullie belangstelling. Vaak werd me gevraagd wanneer het nu gebeuren zou gaan en vele kennen mij alleen als bezig met het onderzoek. Dank voor het geduld.

Lieve ouders, ze zijn niet meer. Vaak denk ik aan hen. Zij waren altijd trots op hun kinderen en zullen dat altijd zijn.

Lieve Annemarie, vele zeildagen (ook die met regen en wind) zijn aan ons voorbijgegaan omdat ik bezig was met de voorbereiding van dit proefschrift. Jij vermaakte de kinderen in Artis en op de kinderboerderij. Maar, stormen hebben we overwonnen, verbouwingen hebben we overleefd en ook dit proefschrift. Ik dank jou bijzonder voor je geduld en uithoudingsvermogen. Ik waardeer jouw juridische kennis en kunde, waardoor ik mijn laatste stelling durf te poneren.

Lieve Anna en Eline, nog te klein om papa echt gemist te hebben. Ik wil jullie vragen met mama in te schepen, want samen hebben we nog vele mijlen voor de boeg. 


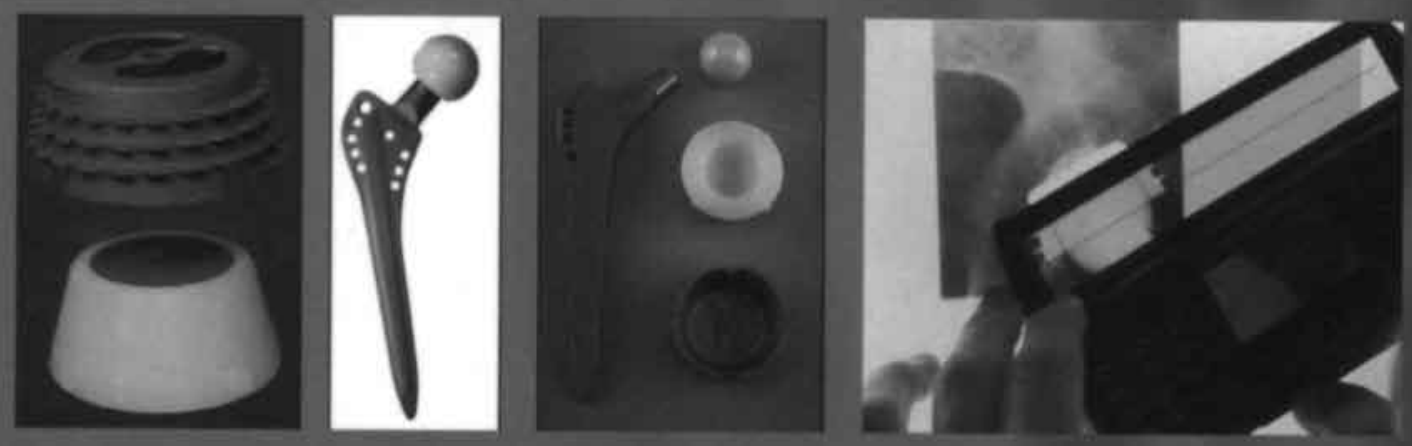